\title{
CONVENIENT FICTIONS:
}

THE SCRIPT OF LESBIAN DESIRE IN THE POST-ELLEN ERA.

\section{A NEW ZEALAND PERSPECTIVE}

By

\author{
Alison Julie Hopkins
}

A thesis submitted to Victoria University of Wellington in fulfilment of the requirements for the degree of Doctor of Philosophy

Victoria University of Wellington 



\section{Acknowledgements}

I would like to acknowledge those people who have supported me in my endeavour to complete this thesis. In particular, I would like to thank Dr Alison Laurie and Dr Lesley Hall, for their guidance and expertise, and Dr Tony Schirato for his insights, all of which were instrumental in the completion of my study.

I would also like to express my gratitude to all of those people who participated in the research, in particular Mark Pope, facilitator of the 'School's Out' programme, the staff at LAGANZ, and the staff at the photographic archive of The Alexander Turnbull Library. I would also like to acknowledge the support of The Chief Censor, Bill Hastings, and The Office of Film and Literature Classification, throughout this study. Finally, I would like to thank my most ardent supporters, Virginia, Darcy, and Mo. 


\begin{abstract}
Little has been published about the ascending trajectory of lesbian characters in prime-time television texts. Rarer still are analyses of lesbian fictions on New Zealand television. This study offers a robust and critical interrogation of Sapphic expression found in the New Zealand television landscape. More specifically, this thesis analyses fictional lesbian representation found in New Zealand's prime-time, free-to-air television environment. It argues that television's script of lesbian desire is more about illusion than inclusion, and that lesbian representation is a misnomer, both qualitatively and quantitively. In order to assess the authenticity of television's lesbian fictions, I sampled the opinions of New Zealand's television audience through focus group and survey methodology, and analysed two primary sources of lesbian representation available between 2004-2006.
\end{abstract}

Television and other media provide the social and cultural background - the milieu against or within which their fictions, dramas and comedies are set. Even when media texts are clearly non- or anti realistic (fantasy films, for instance), they usually attempt to produce their narratives as consistent, familiar and in keeping with the cultural characteristics, values and proclivities of mainstream contemporary society. This is not realism so much as a set of arbitrary conventions that are read as, or stand for, reality and the real. In short, the media is a teller of stories and fairy tales; and since mainstream Western culture has naturalised homonormativity, television's fairy tales are almost exclusively tales of heterosexuality. Television, from this perspective, reinscribes and reinforces what Pierre Bourdieu refers to as the 'masculine order'.

Television uses reality to frame messages of compulsory heterosexuality, and it rarely presents homonormative messages. Lesbian representation is, therefore, difficult for a heteronormative medium to render without effort. Homonormativity is, for lesbian audiences, a central part of the cultural background - the components of realism, if you like, within which representations of lesbians would 'play out' their stories in media texts. Television stories which ignore this imperative deny both the audience's ability to interpret for themselves the integrity of the representation, and their ability to acquire new knowledge of lesbians. 


\section{TABLE OF CONTENTS}

Page

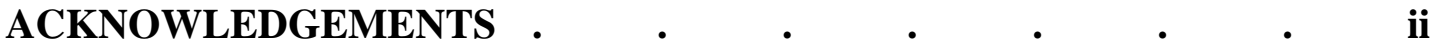

ABSTRACT . $\quad . \quad$. $\quad . \quad$. $\quad . \quad$. . . .

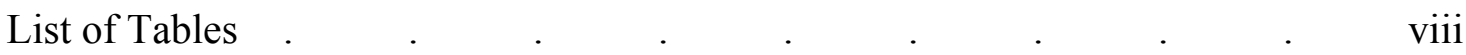

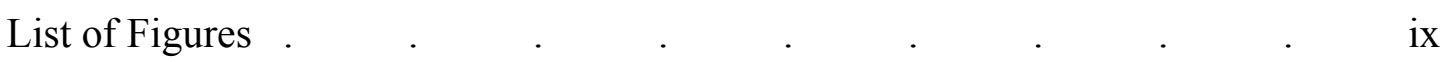

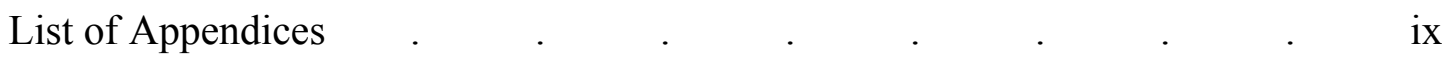

1. CHAPTER ONE: Introduction $\quad$ - $\quad$ •

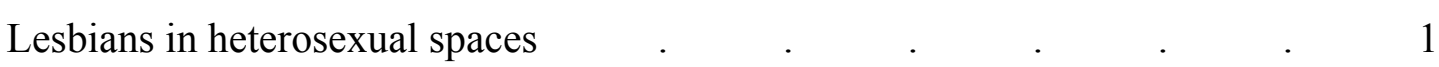

$\begin{array}{llllllllllll}\text { Media Representations and Heteronormativity. } & \text {. } & \text {. } & \text {. } & & & 4\end{array}$

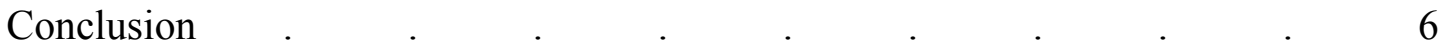

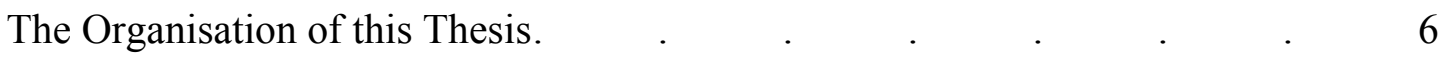

2. CHAPTER TWO: Theoretical Perspectives and Contexts $\quad$ r $\quad$ • 9

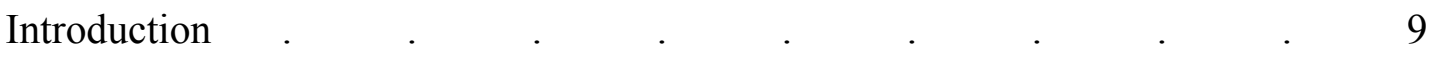

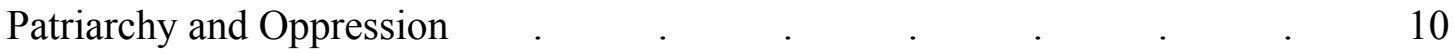

$\begin{array}{llllllllllll}\text { Defining and Classifying Lesbians } & \text {. } & \text {. } & \text {. } & \text {. } & \text {. } & & 12\end{array}$

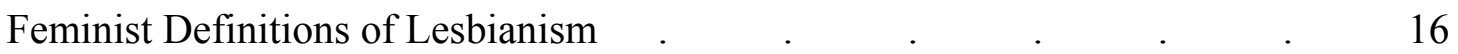

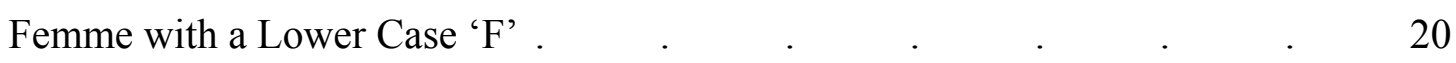

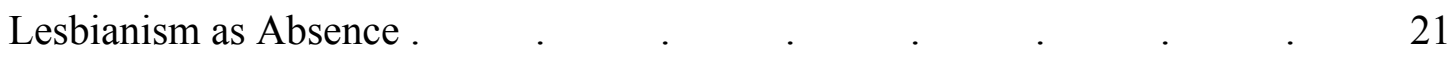

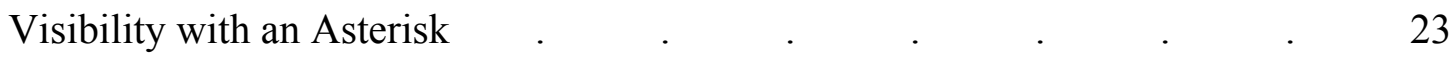

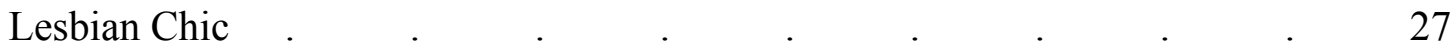

Pre-Ellen Representations of Homosexuality on Television . . . . $\quad 29$

The New Protocols of Same-Sex Desire $\quad . \quad$. $\quad$. $\quad$. $\quad$. 35 


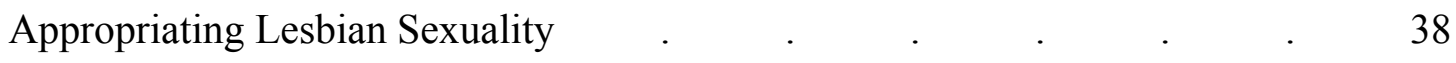

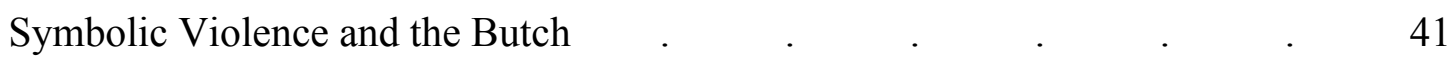

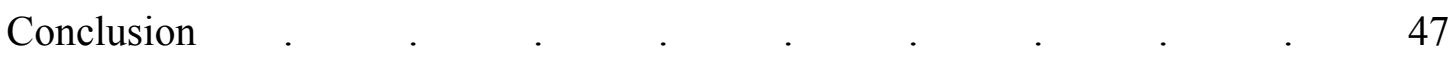

CHAPTER THREE: Representations of Lesbianism in Television $\quad$ • $\quad 48$

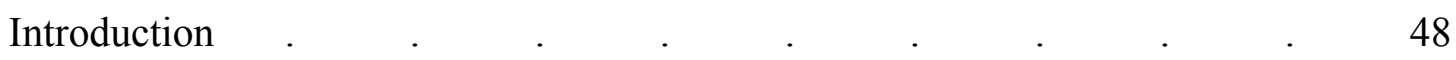

Studies of Gay and Lesbian Visibility in the Media $\quad . \quad$. $\quad . \quad$. $\quad 49$

Lesbian Representation and Self-Validation $\quad . \quad$. $\quad . \quad$. $\quad . \quad 58$

Significances and Pleasures of Identification $\quad . \quad \ldots \quad$. $\quad . \quad$. $\quad 61$

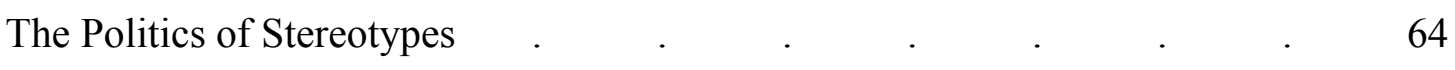

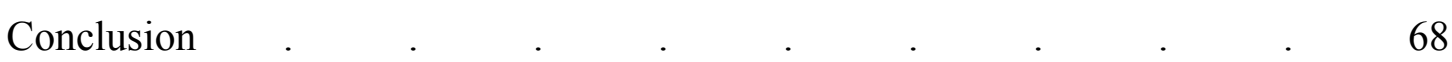

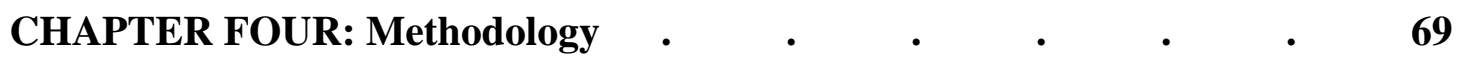

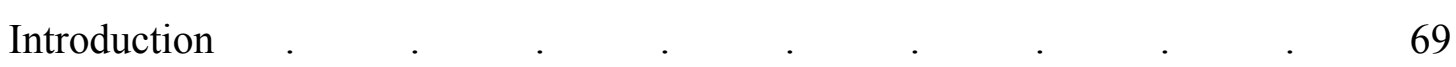

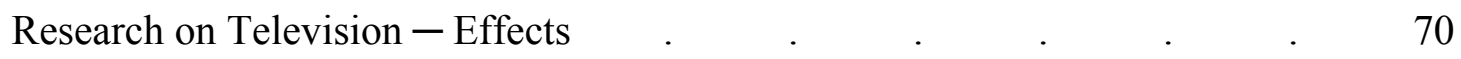

Techniques for Analysing Lesbian Representation on Television . 71

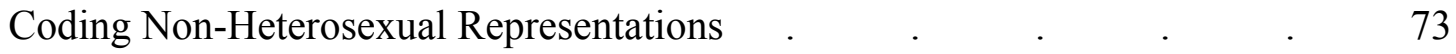

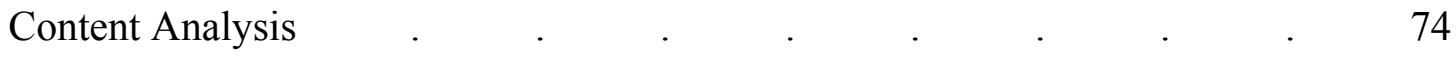

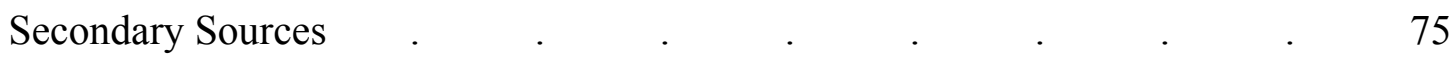

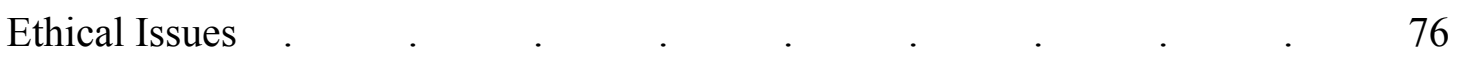

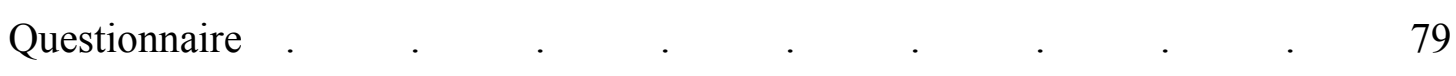

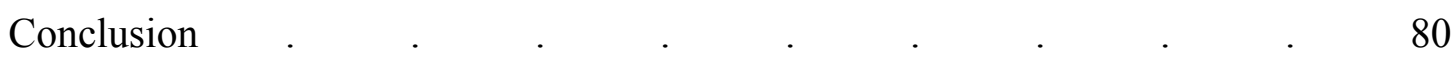


CHAPTER FIVE: Results of Television Landscape Analysis and Focus

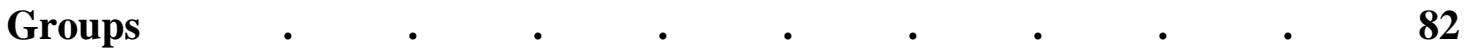

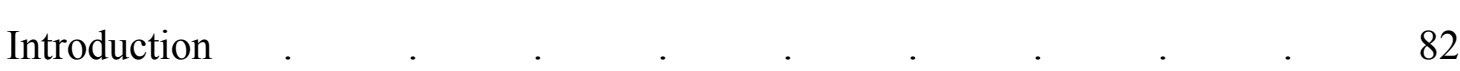

Media Policy and the Representation of Minorities $\quad . \quad$. $\quad . \quad$. $\quad$. $\quad 82$

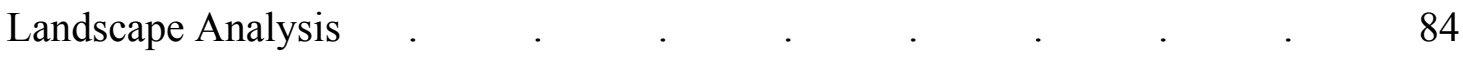

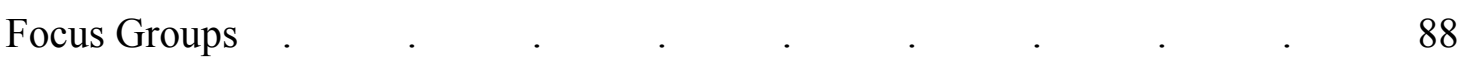

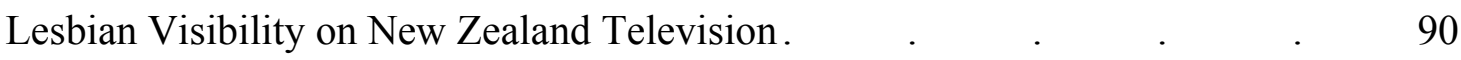

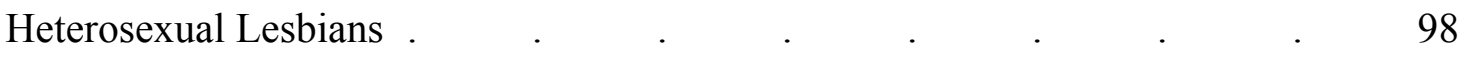

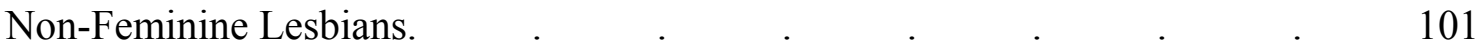

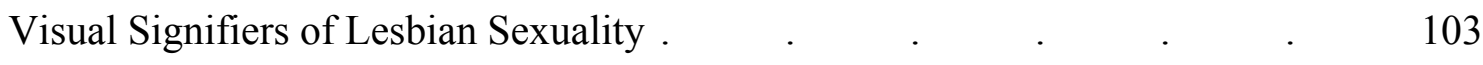

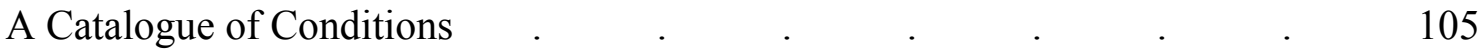

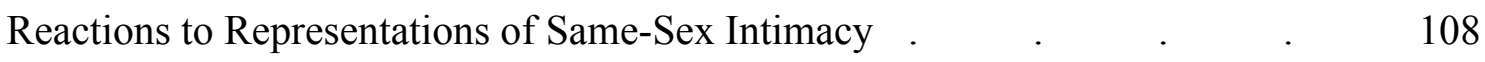

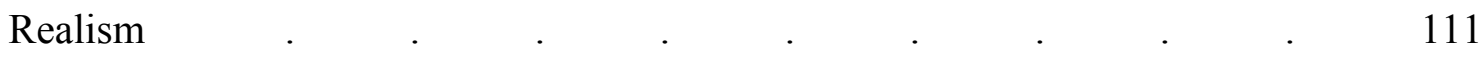

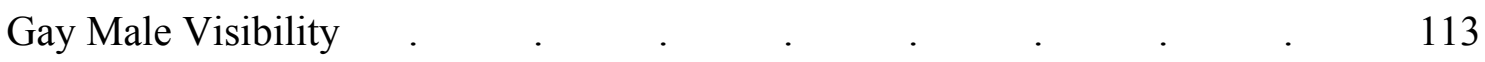

Tensions of Compromise: Testimonies of Lesbian Viewers . $\quad 116$

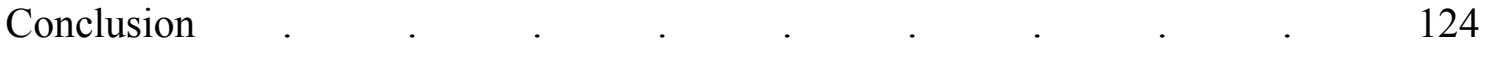

CHAPTER SIX: Critical Communication Theories and the Politics of

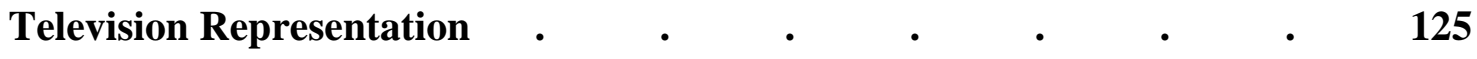

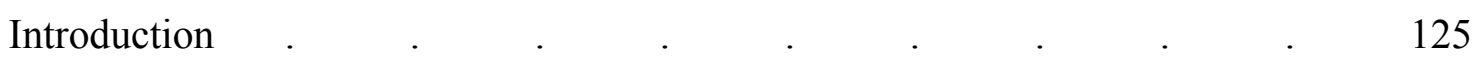

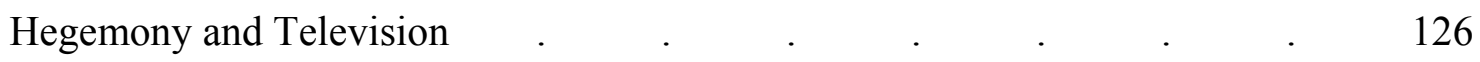

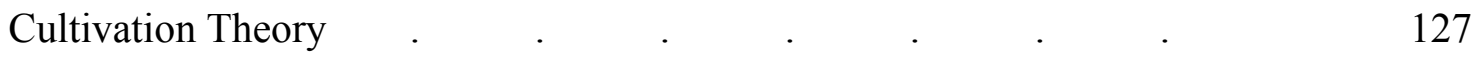

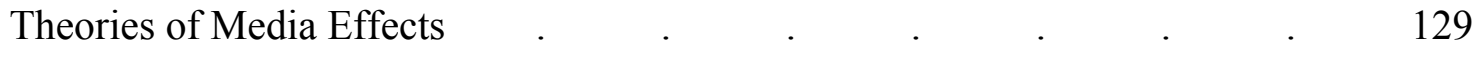

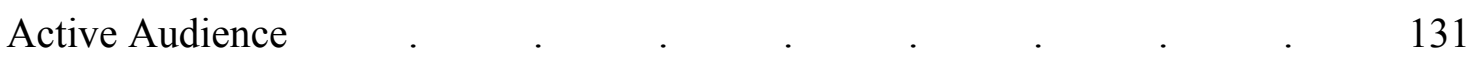

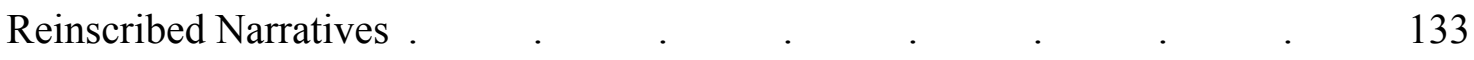


CHAPTER SEVEN: Television, Soaps and Lesbian Representation $\quad$ • 136

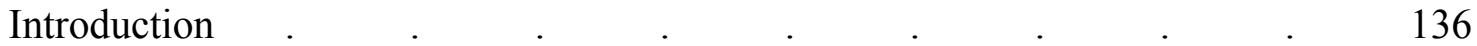

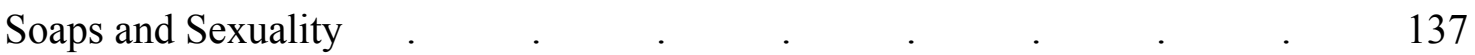

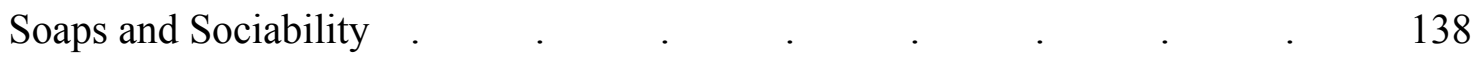

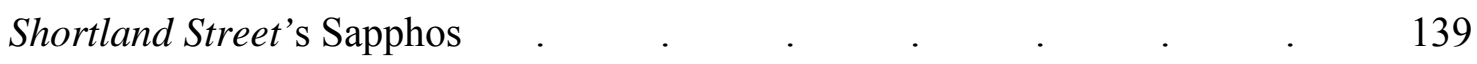

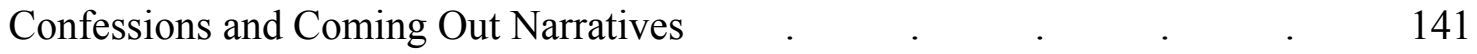

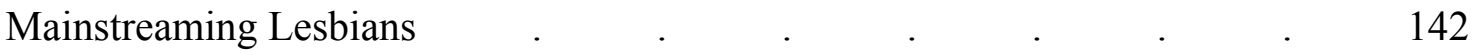

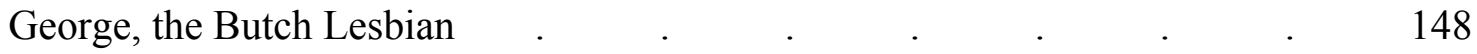

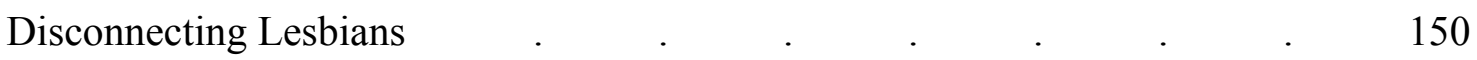

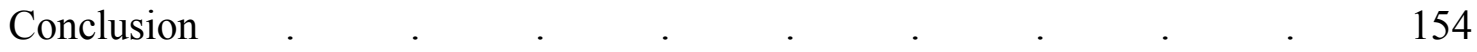

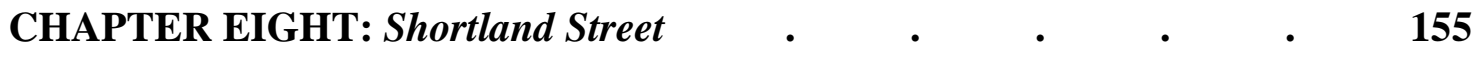

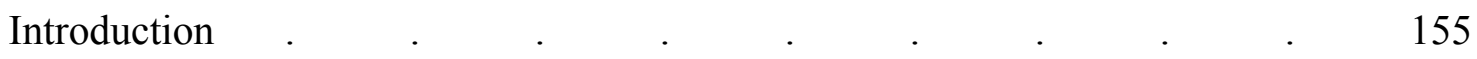

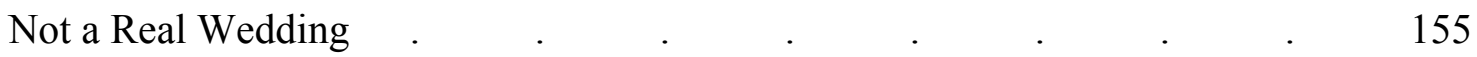

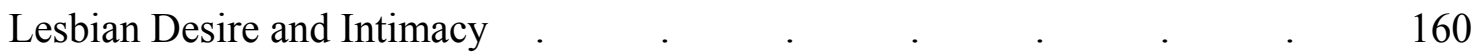

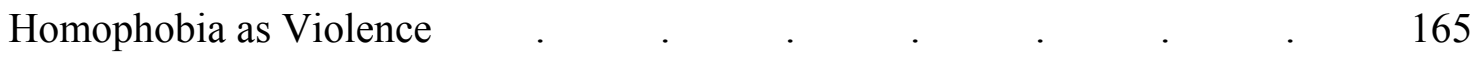

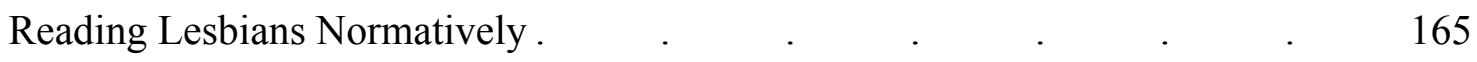

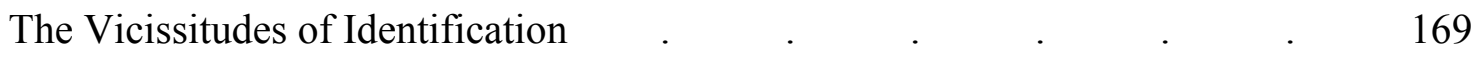

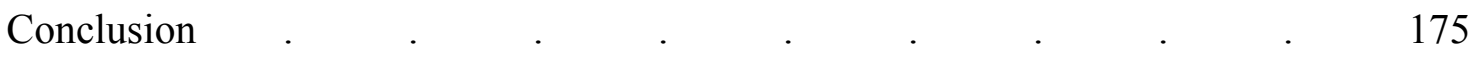

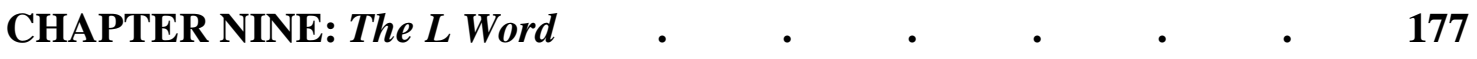

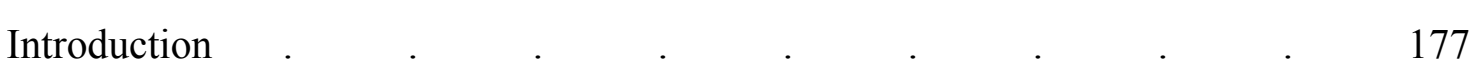

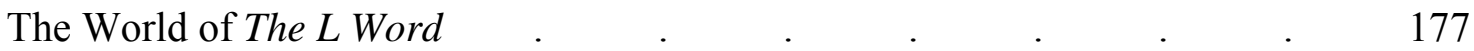


Sexual Expression in The L Word

The Reality of Homophobia

A Privileged World

Bisexuality

The Good/Bad Gay Dichotomy.

The Myth of the Affluent Gay .

Conclusion

CHAPTER TEN: Discussion .

Introduction

Focus Groups: Comparisons and Contrasts

Reading Shortland Street and The L Word

Looking at Identification

Limitations

Future Directions

Conclusion

A Final Word

REFERENCES.

\section{LIST OF TABLES}

Table 1 .

Table 2 .

Table 3 . 


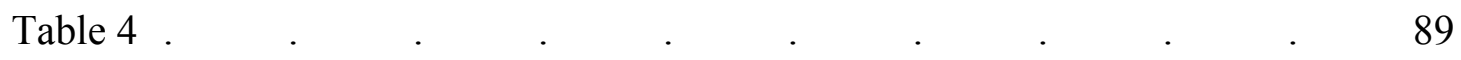

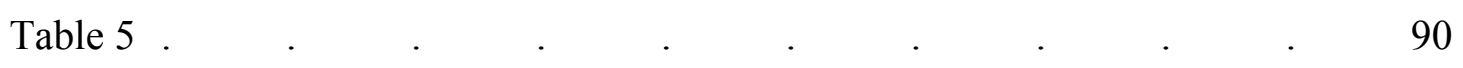

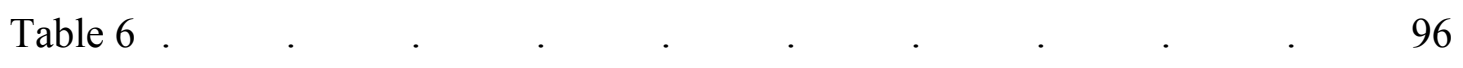

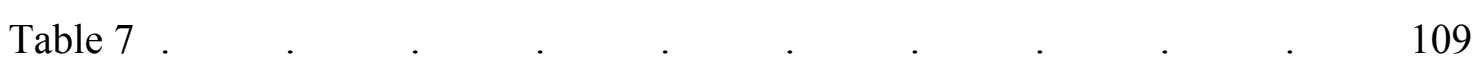

\section{LIST OF FIGURES}

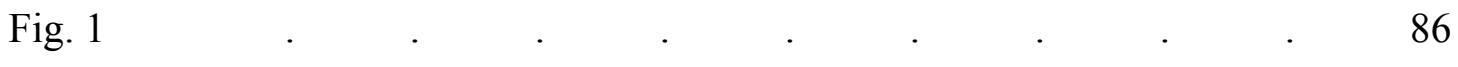

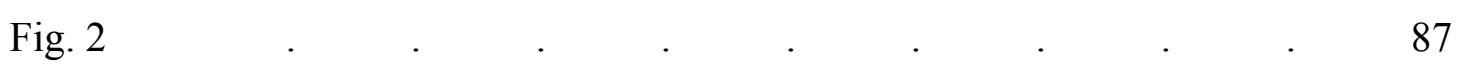

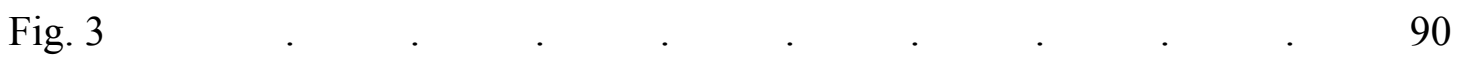

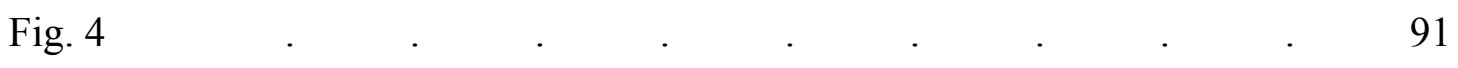

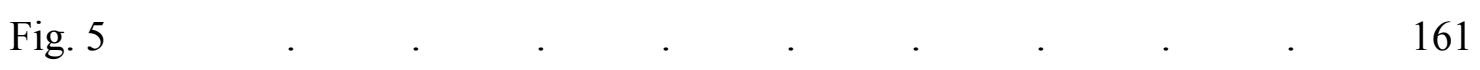

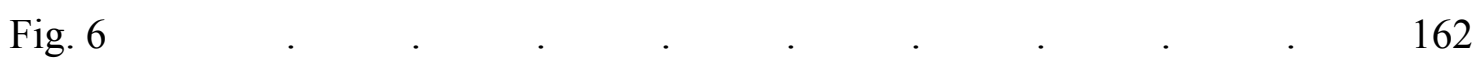

\section{LIST OF APPENDICES}

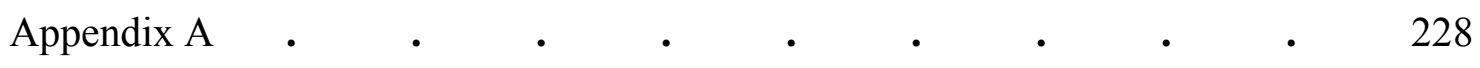

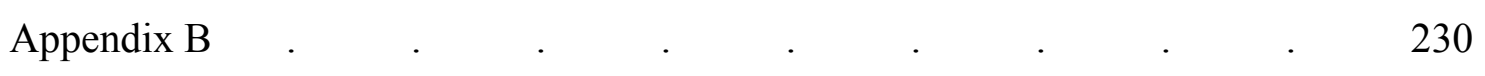

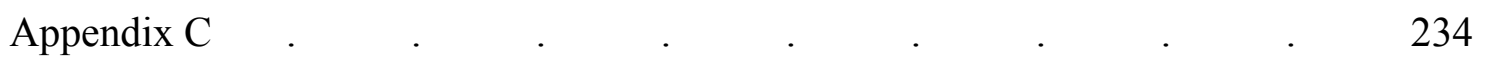

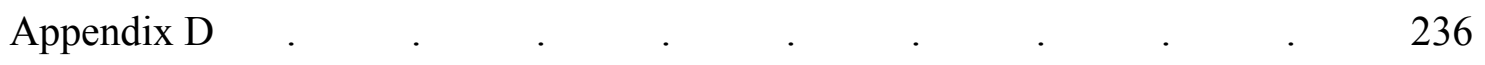

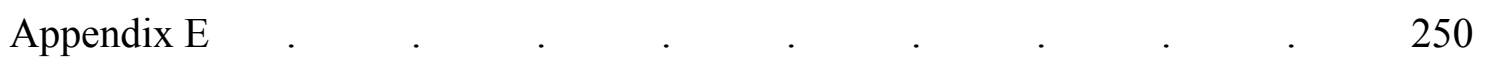

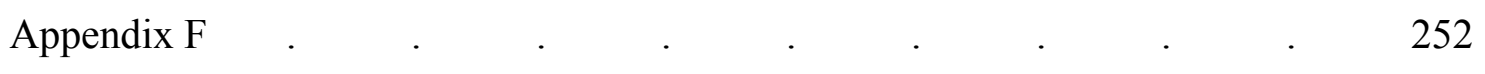

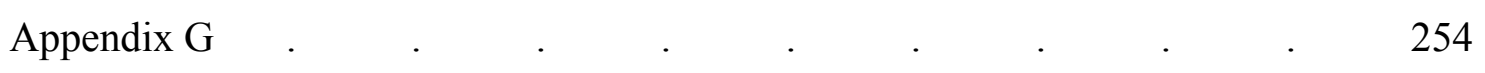

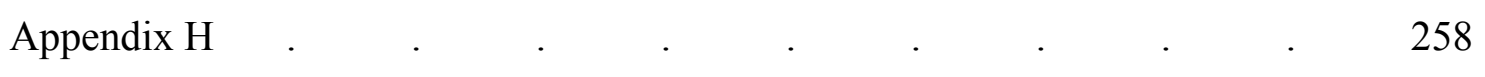

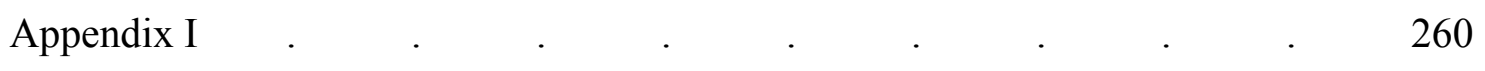

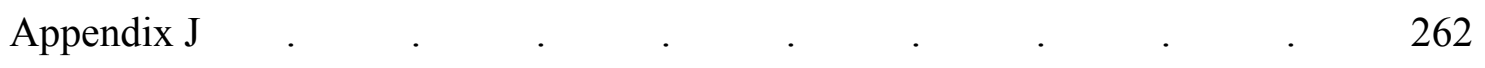




\section{Chapter 1}

\section{Introduction}

This thesis considers, analyses, and evaluates the representation of lesbian characters in prime-time television texts, a phenomenon about which media scholar Kelly Kessler finds little has been published (Kessler 2006, p.131). Communication theorist George Gerbner and colleagues argue television tells "most of the stories to most of the people most of the time" (Gerbner et al. 1986, p.18). So influential is television as a medium, media critic Roger Horrocks argues, any person or news item to appear in the prime-time slot translates to "nationwide exposure and the possibility of becoming a topic of dinner-table or morning-tea discussion in every corner of the country" (Horrocks 2004a, p.22). ${ }^{1}$ Academic Ann Ciasullo insists one of the best ways to understand what the lesbian figure signifies in popular culture is to "examine the tales it tells about her" (Ciasullo 2002, p.7). What tales are told about lesbians is the primary concern of this thesis. This study offers a robust kōrerorero, a critical and informed interrogation, of Sapphic expression in the New Zealand television landscape. ${ }^{2}$ I will describe and analyse fictional lesbian representation available in this country's prime-time free-to-air television texts.

In a foundational lesbian feminist text written over 30 years ago, lesbian activists Sydney Abbott and Barbara Love wrote: "Lesbians are [told] by society as a whole, by the media - especially on television - that women love men" (Abbott and Love 1972, p.37). This thesis will consider to what, if any, extent this situation has changed. No longer isolated oddities, the panoply of sexual minority characters now found in many Western mainstream television texts has been noted by many cultural critics, including Suzanna Walters (Walters 2001, p.5), Stephen Capsuto (Capsuto 2000, p.xiii), Gail Hawkes and John Scott (Hawkes and Scott 2005, p.80) and David Gauntlett (Gauntlett 2002, p.13).

\section{Lesbians in Heterosexual Spaces}

To what extent are television's Sapphic fictions ideologically neutral? Drawing directly on the art-reflects-reality paradigm, communication theorist Larry Gross maintains media visibility reflects real social power (Gross 1994, p.143). Fellow communications theorist

\footnotetext{
${ }^{1}$ The prime-time period in New Zealand is from 6.00 p.m. to 10.30 p.m. and it is during this time that the largest number of viewers will to be watching (Horrocks and Perry 2004, p.326).

${ }^{2}$ Māori are the indigenous people of Aotearoa (New Zealand). The Māori word 'kōrerorero' is translated into English as the word for 'discussion' (P.M. Ryan 1995, p.400).
} 
Stephen Littlejohn extends this by arguing: "The irony of the media, especially for television, is they present the illusion of diversity and objectivity, when in fact they are clear instruments of the dominant order" (Littlejohn 1999, p.236). Many feminist media scholars such as Lisbet van Zoonen and feminist writers like Kath Davies, Julienne Dickey, and Teresa Stratford charge the dominant group - privileged economically, legally and socially - is comprised of white, middle-class, males (Davies, et al. 1987, p.12; van Zoonen 2004, p.50); and that this group is overwhelmingly heterosexual (Gross 2001, p.4). ${ }^{3}$ Cultural theorist Linda Holtzman, and communications scholars Michael Morgan and James Shanahan argue that, as owners and controllers of the media, television reflects the biases and interests of this group (Holtzman 2000, p.301; Morgan and Shanahan 1997, p.9; see also Gross 2001). More generally, sociologist Pierre Bourdieu argues that:

The particular form of symbolic domination suffered by homosexuals ... is imposed through collective acts of categorisation which set up significantly negatively marked differences, and so create ... stigmatized social categories. As in some kinds of racism, this symbolic domination takes the form of denial of public, visible existence (Bourdieu 2001, pp.118-119).

A core concept in many feminist approaches to analysing the media is the notion of distortion. Types of distortion identified by feminist scholars include women's underrepresentation in the media and the prescriptive way in which femininity is represented (van Zoonen 2004, p.30). Feminists call for more realistic images of women in the media. But how do we define distortion in the context of a heterogeneous and culturally fragmented population? There is no unifying lesbian culture, or reality; no way in which one lesbian character can embody the diversity of ethnicity. To define a prototypical lesbian character, I accept the position of lesbian theorist Alix Dobkin, who argues that despite the plurality that characterizes the multifarious population of self-identified lesbians (Dobkin 1990, p.4), they are unified by the orientation of their sexual desire for

\footnotetext{
${ }^{3}$ In New Zealand, Rick Ellis was appointed the chief executive of TVNZ (TV One and 2) in May 2006, while Jeff Latch was appointed as Head of TVNZ in 2007. At the time of writing this thesis, Brent Impey is the New Zealand CEO of CanWest, owners of 3 and C4, while the President and CEO of CanWest internationally is Peter Viner. Chief Executive of Māori television is Jim Mather. Among the major international networks, CBS network president is Leslie Moonves; President and CEO of The Walt Disney Company is Robert Iger; Barry M. Meyer is the chairman of Warner Bros. Entertainment Inc.; the acting chairman of the BBC is Anthony Salz; and ITV's chairman is Michael Grade.
} 
their own sex. This is the most recognisable element of any lesbian characterisation or representation.

It follows, then, that accounts of lesbians as representative of, belonging to, or part of, a specific identity formation (based on the idea of shared cultural mores, desires, and practices) need to work within and make sense of the frame of homonormativity. Homonormativity is the antithesis of heteronormativity. Author and cultural theorist Michael Warner defines heteronormativity as the omnipresent and institutionalised norm that heterosexuality is normal and natural (Warner 1993, p.xxi); a sexual preference that “needs no explanation" (Hawkes and Scott 2005, p.6). As post-structuralist philosopher Judith Butler writes: "The category of human ... is crafted in time, and ... it works through excluding a wide range of minorities" (Butler 2004, p.13). More specifically, heteronormative narratives and forms of representation work to ensure certain forms of activity are marked not just as unnatural, but as being outside what can be understood as human. By contrast, sexuality expert Didi Herman advises, homonormativity refers to the construction of the norm that homosexuality is a natural and normal state, equal to heterosexuality (Herman 2003, p.144).

As academics Gavin Brown, Kath Browne and Jason Lim emphasise, "the concept of 'homonormativity' has a range of meanings and is used to understand how homosexuality is constructed within class, racial and ethnic norms" (Brown, Browne and Lim 2007, p.12). While a homonormative perspective is seen by some as desirable and inclusive referring to the apparent acceptance of sexual difference in social and political spheres others argue that this progress privileges some and marginalises others. For example, Lisa Duggan identifies the emergence of a 'new' homonormativity, one that privileges gays and lesbians who have aligned themselves and their organisations with dominant capitalist systems. Instead of promoting the human rights of lesbians and gays, Duggan argues that the neoliberal politics of this new homonormativity "does not contest dominant heteronormative assumptions and institutions but upholds and sustains them" (Duggan 2002, p.175). Similarly, Jin Binnie argues that alignment with capitalist and heteronormative systems privileges white middle class gay men while excluding others "on the basis of race, class, gender and disability" (Binnie 2007, p.34). This thesis has adopted Herman's (2003) explanation of a homonormative perspective that lesbian sexuality is normal and natural, as depicting lesbian characters and lesbian sexuality as equal to, but different from, heterosexual characters and heterosexuality is crucial to positive lesbian representation. 


\section{Media Representations and Heteronormativity}

Communication and media theorists employ various metaphors to describe the process whereby the media represents the world. Communications theorist Denis McQuail suggests the "media are windows that enable us to see ... interpreters that help us make sense of experience ... filters that screen out part of the experience ... and barriers that block the truth" (McQuail cited in Littlejohn 1999, p.328). Sociologist Todd Gitlin uses a fun house mirror metaphor to explain how the media image stands in relation to, and refracts rather than reflects, social reality. Gitlin's work focuses on the news media, highlighting how news reporting can slant and obscure the reality of a situation or issue and the profound impact deliberate media manipulation can have. He argues television offers distorted reflections:

The facts reported were out there in the real world, true: out there among others. The media reflection was more the active, patterned remaking performed by mirrors in a fun house (Gitlin 1980, p.29).

This analogy highlights the way television cognitively warps fiction into fact; lengthening and widening some parts of reality while minimising and ignoring others. Such warping is reminiscent of the distortion many feminists argue is perpetrated against women and their sexuality by male-dominated media (van Zoonen 2004, p.30). Gitlin's carnival of mirrors is evident in fictional texts. This study considers to what extent, and in what manner, the lesbian image has been distorted.

According McQuail, media hegemony positions media as the tool of the dominant ideology (McQuail 1994, p.256), and cultivation theory focuses on how television shapes viewer's perceptions (Gerbner et al. 1986, p.18). Symbolic annihilation, a parallel perspective also implicates television in shaping the social value ascribed homosexuals. Gerbner and Gross have coined the term 'symbolic annihilation' to account for the imbalances and inequities of sexual minorities in mediated representation (Gross 1994, p.143; Gerbner and Gross 1976, p.182). Symbolic annihilation describes the relationship between those who control the media, who is seen in the media, and how they are treated. In the Western world the group with the most social and economic power is predominantly comprised of white, middle-class, heterosexual males, and media representations reflect their interests (Davies et al. 1987, p.12; Gross 2001, p.4; van Zoonen 2004, p.50). The result is an immensely powerful and ubiquitous medium full of white heterosexuals promulgating white heterosexual values. Further, any group that does 
not or is thought not to reflect these values, is either made to comply (by promoting warped constructions of their authentic characteristics), or is simply omitted in favour of groups who do support white heterosexuality. Either strategy preserves the status quo, serving the dominant group while symbolically annihilating the minority.

Symbolic annihilation is only one form of what Bourdieu refers to as symbolic violence. The other side of these politics of representation that is carried out in the media is to convince dominated groups of their own lack of worth. Bourdieu writes:

To speak of domination or symbolic violence is to say that ... the dominated tend to adopt the dominant point of view on themselves. Especially through the destiny effect produced by stigmatizing and categorizing and in particular through real or potential insults, that can thus be led to apply to themselves and to accept ... 'straight' categories of perception, and feel ashamed of sexual experience which, from the point of view of the dominant categories, defines them (Bourdieu 2001, p.119).

Feminist author Gayle Tuchman (1978) applied the concept of symbolic annihilation to the way in which women are trivialised, marginalised, and excluded by the media. Julienne Dickey finds that symbolic annihilation is "doubly profound" for women who are lesbians (Dickey 1987a, p.82). Lesbian author Terry Castle argues that lesbians are, by their very existence, considered a threat to heterosexuality (Castle 1993, pp.4-5) and are, therefore, "inherently problematic and controversial to the mass media" that promotes heterosexuality (Gross 1991, p.20). Consequently, the mainstream media environment (particularly prime-time) utilises symbolic annihilation strategies that ignore meaningful difference between lesbians and heterosexual individuals, or burden lesbian characters with conditions to maintain the primacy of heterosexuality. As researcher Michael Hurley notes, one such strategy is to omit representations of homophobia and discrimination (Hurley 2005, p.51).

Whatever forms of feminism one encounters, psychologist Hilary Lips finds that the fundamental assumption of the feminist movement is that power differences between men and women are socially constructed and actively maintained (Lips 1991, p.6), and maintained for men's benefit (Julienne Dickey 1987b, p.74). As political theorist Valerie Bryson suggests, these power imbalances operate in both the private and public spheres (Bryson 1999, p.185). They also operate in the mass media (Littlejohn 1999, p.231), as the 
works of Susan Faludi (1992), and Naomi Wolf (1991) attest. Recent work on the contradictory character of contemporary gender representation by psychologists Janna Kim et al. (2007), and Sharon Lamb and Lyn Mikel Brown (2006), found that the social norms relating to women's (hetero)sexuality that Wolf (1991) and Faludi (1992) described are transmitted through fictional television texts as cautionary tales. The American Psychological Association has conducted research that shows the proliferation of sexualised images of girls and young women in advertising and the media harms girls' self-image and healthy development (American Psychological Association 2007). This is in keeping with Wolf's (1991) seminal exposition regarding the media's effect on adult women decades earlier.

\section{Conclusion}

According to feminist theorists Darlene Hantzis and Valerie Lehr, a phallocentric society is considerably more comfortable ignoring or containing female sexuality than investigating it (Hantzis and Lehr 1994, p.107); in other words, acknowledging the desire that exists between women, forces patriarchy and its participants to consider the unpleasant prospect of women who do not need men. As Castle explains, lesbian sexuality challenges heterosexuality as the natural/preferred state because it excludes men and makes male desire redundant, provoking "anxiety and hatred" (Castle 1993, pp.4-5).

This study is underpinned by a series of research questions designed to gauge the frequency and forms of the representation of lesbian characters on prime-time television in New Zealand. The major objectives of this study are to investigate:

- The frequency of lesbian representation in fictional texts on New Zealand television between 2004-2006.

- The forms these representations take.

- The extent to which these representations of lesbianism, and the narratives within which they are located or lodged, constitute a form of symbolic violence.

\section{The Organisation of This Thesis}

Chapter 2 provides the contextual background to this thesis. Here, I trace the historical definitions of 'a lesbian', and how those scientific and political definitions are reflected in media representations of lesbian characters, from early film's celluloid Sapphos to television's first mainstream lead lesbian character, Ellen, and subsequent television 
characters. I then examine the representational protocols that have been employed when representing sexual minorities in the pre- and post-Ellen era.

Chapter 3 presents a review of the sparse international and domestic literature available about lesbian representation on television. Next, the importance of visibility to minority populations is discussed, particularly the injury caused by stereotypes, the power of fiction to influence our attitudes, and the psycho-social relationships viewers often form with fictional characters.

Chapter 4 details the methodology and methods by which I analyse lesbian representation on prime-time New Zealand television. The methods - content analyses, survey questionnaires, and focus groups - reflect the feminist research principles described by feminist researchers Patti Lather (1991, pp.70-76), Mary Maynard and June Purvis (1994, pp.3-4), and sociologist Shulamit Reinharz (1992, p.2).

The results of the landscape analyses, focus group discussions, and questionnaires are presented in Chapter 5. The results of my snapshot of lesbian representation within primetime fictional programming on the four most popular free-to-air channels are presented first, followed by the results of the focus group discussions and accompanying questionnaire to reveal the perceptions of the integrity of lesbian representation on New Zealand television.

Chapter 6 considers the hegemonic effect of Western society's most ubiquitous medium, and outlines the media theories I use to illustrate how mainstream free-to-air television transmits mainstream gender and sexuality norms. Theories and concepts explored are cultivation analysis, media hegemony, and symbolic annihilation, all of which provide explanations of the omnipresent caveats that plague lesbian visibility on television.

Chapters 7, 8, and 9 present the content analyses of the two most significant sources of lesbian representation that appeared on New Zealand television during 2004 to 2006. The primary focus of each stand-alone analysis is to determine the homonormativity of their respective lesbian characters through documenting the conditions and caveats on their visibility. The programmes are locally produced prime-time soap Shortland Street, and American-produced drama The L Word. 
Chapter 10 draws together the study's findings and evaluates them against the literature and relevant media theories to describe the complexities of conditional lesbian representation in New Zealand television programming. Future research directions are suggested and my conclusions presented. 


\section{Chapter 2}

\section{Theoretical Perspectives and Contexts}

The primary aims of this chapter are to locate the theoretical perspective of this thesis; chart the history of the definition of a lesbian; and to chart the history of lesbian representation in television.

\section{Introduction}

An integral part of any lesbian identity is the need for, and articulation of, a lesbian perspective; a perspective that feminist researcher and lesbian activist Julia Penelope finds challenges and sits outside patriarchal accounts and perspectives (Penelope 1990, pp.106107). Consequently, lesbian author Sarah Hoagland asserts, while mainstream society oppresses lesbians and lesbian lives by erasing our presence and our value (Hoagland 1990, p.275), articulating and affirming lesbian identity/ies challenges heterosexuality and heterosexism. Feminist theorist Bette Tallen argues feminist theory challenges "the basic patriarchal institutions of church and family" (Tallen 1990, p.241), and, as lesbian philosopher Marilyn Frye asserts, it does so by exposing them as systems of women's oppression (Frye 1983, p.1). The concept of patriarchy is therefore central to much feminist thought. Patriarchy is a cultural ideology that legitimises male dominance over women and over family structures (Lips 1991, p.149). Although originally referring to patriarchy's power over the family, Kate Millett's thesis is that:

in all known societies the relationship between the sexes has been based on power ... This power takes the form of male domination over women in all areas of life; sexual domination is so universal, so ubiquitous and so complete that it appears 'natural' and hence becomes invisible (Millett 1970, cited in Bryson 1999, p.185).

Further, Frye argues:

Whatever features an individual male person has which tend to his social and economic disadvantage (his age, race, class, height, etc.), one feature which never tends to his disadvantage in the society at large is his maleness. The case for females is the mirror image of this. Whatever features an individual female person has which tend to her social and 
economic advantage (her age, race, etc.), one feature which always tends to her disadvantage is her femaleness (Frye 1983, p.31).

For feminist theorist Monique Wittig, even the category 'woman' itself has been imposed on human females in order to enforce their continued exploitation and oppression (Wittig 1992, p.11).

\section{Patriarchy and Oppression}

Feminists argue that patriarchy manages to oppress women by relating them to the two primary functions for heterosexual men: motherhood and sex, the Madonna and the Whore (Frye 1983, p.1; also discussed by feminist film critic Laura Mulvey 1975, p.6). Madonnas are revered but infantilised and desexualised, while Whores are wholly sexualised, to the detriment of any other quality or characteristic they may have. Oppression depends upon clear definitions of roles (Frye 1983, p.33), so 'women' roles relate to men-loving and men-serving activities and expressions, and 'men' roles relate to women-loving and men-serving activities and expressions. It is worth noting there are other types of oppression (class/socio-economic status and ethnicity are amongst the primary oppressions discussed by feminists and humanists), but it is almost unthinkable that men should be oppressed for being men (Frye 1983, p.16).

Patriarchy maintains and perpetuates this power dynamic through all forms of cultural activity, including televised narratives. An example of this phenomenon is to be seen in the dissemination of pornographic texts and narratives. As feminist author Catharine MacKinnon writes:

Pornography does not simply express or interpret experience; it substitutes for it. Beyond bringing a message from reality, it stands in for reality ... pornography makes the world a pornographic place ... establishing what women are said to exist as, as seen as, are treated as, constructing the social reality of what a woman is and can be (MacKinnon 1993, p.25).

One of the main functions of feminist thought is to reveal this power dynamic, and in the process advance social, political, and ethical knowledge by countering the primacy of patriarchal thought or what Bourdieu refers to as the concomitant naturalisation and normalisation of masculine domination, which functions to constitute women "as 
symbolic objects whose being ... is a being-perceived" (Bourdieu 2001, p.66). This has the effect of:

keeping them in a permanent state of bodily insecurity, or more precisely of symbolic dependence. They exist first through and for the gaze of others, that is, as welcoming, attractive and available objects. They are expected to be 'feminine', that is to say, smiling, friendly, attentive, submissive, demure, restrained, self-effacing. And what is called 'femininity' is often nothing more than a form of indulgence towards real or supposed male expectations ... As a consequence, dependence on others ... tends to be constitutive of their being (Bourdieu 2001, p.66).

Some women's identity categories are more commensurate with and accepted by patriarchal culture, thereby reducing the level of oppression they experience and increasing the opportunities available to them. As media theorist Angharad Valdivia emphasises, the closer these components of identity situate women to the dominant culture, the closer to the "avenues of power" they become (Valdivia 1995, p.16). Identity categories that are less congruent with the dominant group, on the other hand, are more likely to be subject to oppression (Bryson 1999, p.66). As a subcategory of the class of women, lesbians cannot perform the activities typically ascribed to women, and so are left almost role-less (Frye 1983, p.167).

This situation is even more accentuated for lesbians of colour. The social value ascribed to skin colour "has a profound effect on the lives of individuals and on the workings of society as a whole" (Bryson 1999, p.51). Media theorists Shuchi Kothari, Sarina Pearson and Nabeel Zuberi insist society tends to frame all identities through the lens of white culture (Kothari et al. 2004, p.135; see also Bryson 1999, p.51, Gross 2001, p.4), much as it does with heterosexuality. Lesbian author Susan Hawthorne notes that initially, the feminist movement was dominated by a western bias (Hawthorne 2002, p.36) which largely ignored the experiences of women who were not white. Work by Black lesbian feminist Audre Lorde (1984), Black lesbian sisters Barbara and Beverly Smith (1983), and Vietnamese-born filmmaker and cultural theorist Trinh T. Minh-Ha (1991), and other likeminded theorists have attempted to redress this omission by exploring the oppression of minority cultures and how this oppression intersects with sex, gender roles, and sexuality. In other words, they consider how, in MacKinnon's terms, "group defamation is the verbal form inequality takes" (MacKinnon 1993, p.99). 
The tensions related to multiple minority identities have been discussed by Lorde, who steadfastly resists the pressure to make lesbianism her dominant identity because she finds "this is a destructive and fragmenting way to live" (Lorde 1984, p.120). Echoing Lorde's sentiments, Māori lesbian feminist Ngahuia Te Awekotuku refers to the "colliding urgencies" of her life as wahine takataapui, a Māori lesbian, as she moves "within many worlds", and negotiates her membership in both Māori and middle-class Pākehā society (Te Awekotuku 1991a, p.20). She interrogates her multiple identities from a feminist perspective:

It is often said that being Maori and feminist must be a contradiction; that feminism is some imported pakeha idea about being female and being put down for being female, that it has no place in the Maori world ... I disagree, because feminism is what we make it; it's a matter of how we define it for ourselves, in terms of our own oppression as women. And no one can deny that in the last two centuries Maori women have lost, or been deprived of, economic, social, political and spiritual power... and this loss, ... invites a feminist analysis, or feminist view, of what has happened (Te Awekotuku 1991b, p.10).

It is important to recognise the necessity of incorporating the perspectives of lesbians of colour into this thesis, particularly as three of the lesbian characters I analyse in later chapters are women of colour.

\section{Defining and Classifying Lesbians}

As this thesis is about lesbian representation on television, it is supported by a framework of identity politics. The issues inherent in defining and classifying 'a lesbian' and an explanation of the position I have adopted when identifying a lesbian television character are discussed.

The definition of 'a lesbian' has a long and complicated history. Lesbian scholar Barbara Baird notes the terms 'sapphism' and 'lesbianism' are the legacy of the Greek poet Sappho, who wrote about her lust, love, and adoration for other women. Despite this history, the idea that a woman "might be a lesbian" and that a person's identity is based on their sexuality or sexual practice is relatively new (Baird 2005, p.63). Sexual practices among European peoples were used to organise family kinship, and were governed by 
religious institutions and discourse. As sociologist David F. Greenberg demonstrates, religious thought often set the ground rules for early law, and as women were not thought to penetrate each other with their bodies, sex between women escaped legal punishment (Greenberg 1997, p.310). Still, for all the benefits an absence of biblical and criminal sanctions brought, the disadvantages of a relative lack of social recognition were powerful. By the time female homosexuality had gained a level of attention, advances in medical knowledge began to reclassify religious categories of non-procreative sexual behaviour (Greenberg 1988, p.403). It is by and through this classificatory paradigm that lesbians have come to be defined. As historian Angus McLaren argues, by classifying and defining sexual pathologies, key contributors to sexological discourse, such as Richard Von Krafft-Ebing, Havelock Ellis and Magnus Hirschfield, sought to catalogue the many aspects of sexuality; tracing its etiology, exploring fantasies, fetishes, and pleasures of the body to set out a taxonomy of 'perverts' - including homosexuals, sadists and masochists, and frigid women (McLaren 1999, p.92). What was once viewed exclusively under the lens of religion was now viewed by science and, once pathologised, came to define sexuality as an essential component of an individual's identity (Hawkes and Scott 2005, p.9).

Early sexologists advanced many theories about homosexuality (see lesbian theorist Sheila Jeffreys' 1997 critique in The Spinster and Her Enemies). Lesbianism was first considered a sign of moral degeneracy (Greenberg 1988, p.403; Hawkes and Scott 2005, p.305), then as a hereditary condition (McLaren 1999, p.92). Post-structuralist philosopher Judith Halberstam has found that at the beginning of the nineteenth century, the mannish woman 'might have been called a 'hermaphrodite', a 'tribade', or a 'female husband' rather than a lesbian, and none of these labels quite adds up to, or feeds directly into, what we now understand as a lesbian sexual orientation" (Halberstam 1998, p.50).

In a history of sex and pleasure in Western culture, Gail Hawkes notes that homosexual sexologists Karl Ulrichs and Edward Carpenter were keen to avoid the classification of 'sodomite' or 'pederast', and spoke instead of "the third sex", individuals that would be classified as "urnings" (Hawkes 2004, p.129). Reviewing the documents of early sexologists, academics Laura Doan and Chris Waters point out that Carpenter insisted that these men and women belonged to one sex biologically, but belonged "mentally and emotionally" to the other (Doan and Waters 1998, p.43). The cross-pollination of gender and sexuality became clearly entrenched in sexology. 
While it was von Krafft-Ebing who first promoted gender inversion as an important symptom of lesbianism (McLaren 1999, p.103), Havelock Ellis extended von KrafftEbing's argument by concluding that the passions of the "'abnormal' were not as bizarre as they might appear" (ibid., p.95). According to Ellis's model, homosexuals fell into two categories: true inverts and pseudo-inverts. "“[T]rue' inverts were born that way, and nothing could make them normal", while 'pseudo-inverts' were people who were involved in "inverted behaviour through circumstances rather than natural inclination, and were really natural heterosexuals" (The Lesbian History Group 1989, p.10). These 'pseudo' lesbians were seen as vulnerable to the sexual and corrupting advances of the latter, a belief that would culminate in the myth of the predatory lesbian" (Doan and Waters 1998, p.43). While he sometimes challenged the "equation of effeminacy with male homosexuality", Ellis remained committed to von Krafft-Ebing's belief that lesbianism "was accompanied by a recognizable mannishness" (Doan and Waters 1998, p.43), which was in keeping with the sartorial expression of Carpenter's urnings. Similarly, Freud considered that masculinity was something "normal women should not have; that a lesbian certainly would have; and that a male homosexual, despite expectations, might have" (McLaren 1999, p.118).

Early sexological investigations concluded lesbian desire was a phenomenon that existed in the lower and working classes, and it was upon these women the 'sexual invert' was based. Much of this can be attributed to the fact that the liaisons of middle-class lesbians were usually more private, while working class lesbians were recognisable. As lesbian historian Lillian Faderman observes, when sexologists realised that the "romantic friendships of middle-class women went beyond the platonic", they also realised that lesbian desire was not confined to the classes "beneath" them (Faderman 1992, p.39).

By the 1920s Freud challenged the inversion hypothesis and the naturalness of heterosexuality, hypothesising that all humans are born with "polymorphously perverse potentials", but are forced to become "normal" (Hawkes 2004, p.150). ${ }^{4}$ Addressing lesbianism specifically, Freud posited that girls must give up their mothers as love objects and transfer that love to men "in search of the penis that has been denied them"; failure to

\footnotetext{
${ }^{4}$ Freud also theorised about homophobia. Stanford C. Read advises Freud held that the repulsion many individuals feel about homosexuality:

is due, in great part to the existence in the ordinary mind of a homosexual component of the sexual instinct, which finds indirect expression in the condemnation of homosexuality in others, in the same way as the repression of the sexual instinct in the prude expresses itself in the condemnation of normal sexual activity (Read 1998, p.59).
} 
negotiate this route successfully may lead to lesbianism (The Lesbian History Group 1989, p.11). ${ }^{5}$

Despite the classification of lesbian sexuality, what lesbians actually did sexually was never addressed, presumably because it did not involve the penis. In comparison to the focus on male homosexuality, von Krafft-Ebing, Ellis, Brown, and Freud's few references to female homosexuality appear "little more than a footnote" (Hawkes 2004, p.166). The silence about lesbian sexual activity was not simply due to its perceived irrelevance. The eroticization of male power and women's passivity by sexologists confirmed existing gender norms (McLaren 1999, p.103), and this strengthened the assumption that lesbian sexuality was confounded with gender roles. Even so, lesbian appearance, behaviour, and self-identity initially proved less threatening to male-defined norms than "its erotic expression" (Hawkes 2004, pp.127-128). All same sex desire undermines the naturalness of heterosexuality, but lesbian desire in particular "challenged the both female sexual passivity and the sexual supremacy of men" (Hawkes 2004, p.127), and was acceptable only under two conditions: "that lesbians signalled their 'condition' by emulating men, and that details of their sexuality was kept from the public eye" (ibid., p.169). It was not until the inter-war years, when women began to challenge the traditional roles of men, that lesbian sexuality received more scrutiny, "especially for sexual activity that excluded men altogether" (Hawkes 2004, p.169). By the 1950s lesbianism was considered as much of a threat to patriarchy as male homosexuality. Thus, the “'diagnosis' of lesbianism was a way to limit women's freedoms, while re-establishing male dominance both in and outside of the bedroom" (ibid., p.170). Lesbian historian Alison Laurie argues that many governments refused to criminalise lesbian sexuality, fearing criminal sanctions would give official recognition to lesbianism and encourage it (Laurie 1987, p.63). The lack of acknowledgement of lesbianism by governments can be seen as a form of symbolic annihilation of lesbian sexuality on a cultural level.

Sexology was both a product and a project of modernity (Hawkes and Scott 2004, pp.2223 ), and its chief outcome was a new definition of what constituted natural sexual expression; it fixed sexual desire with a type of person. For example sociologist Alfred Kinsey devised the Kinsey Scale by which sexuality could be measured. At one end were

\footnotetext{
${ }^{5}$ Fuss finds that Freud himself could not escape the "taint" of a feminine identification. In his therapeutic sessions, the role Freud found himself playing was not that of a paternal instructor, "but more often the less comfortable role of maternal educator: a substitute mother figure imparting sexual knowledge to adolescent girls: for it is mother whose 'proper' role is to educate her daughter on matters of sexual and social conduct" (Fuss 1993, p.61).
} 
those individuals who identified as exclusively heterosexual, at the other those who identified as exclusively homosexual. Kinsey theorised that most individuals were positioned on one of the many gradations along the scale; thus, few individuals could be considered truly hetero- or homosexual, most appearing instead to be somewhat bisexual, although one sex is usually preferred (Hawkes and Scott 2005, p.308). This relationship illustrates the inherent issue in constructing a definition of a lesbian: it takes place within the dominant discourse of heterosexuality, against which all other sexualities are measured.

\section{Feminist Definitions of Lesbianism}

While sexology improved tolerance of same-sex desire, lesbian feminists were dissatisfied with the theories offered by white male sexologists, and sought other answers for what constitutes lesbian desire (The Lesbian History Group 1989). As Claudette Kulkarni (2001) emphasises, the debate of identity politics is intertwined with discussions of gender as well. She lists the four positions of the debate as: essentialists, who argue that sexuality/gender are innate, social constructionists who argue sexual orientation and/or gender is socially and historically constructed; the interactionist/synthesizers who argue for a concept of identity that bridges essentialism and social constructionism, and postmodernists/poststructuralists who argue against the concept of identity altogether (Kulkarni 1997, p.68).

Emerging from the most radical sectors of the women's movement in early 1970s, the argument that sexuality was socially constructed had a profound resonance with many lesbian feminists. A quality of this movement was to consider sexuality as a set of socially constructed or prescribed behaviours, mores, and acts (Jeffreys 1989, p.13). ${ }^{6}$ As lesbian theorist Celia Kitzinger emphasises in her pivotal work The Social Construction of Lesbianism, "neither heterosexuality nor lesbianism are "natural': both are political constructions" (Kitzinger 1987, p.64). This view related well to Freud's argument that heterosexuality was not necessarily natural (Hawkes 2004, p.150). An influential text by the group known as Radicalesbians, argued that lesbianism was neither a medical nor an innate condition and argued that lesbianism could be elected, and was a choice available to all women. Thus the category of 'woman-identified-woman' came into being (Kramarae and Treichler, 1985, p.494). Following on from this, lesbian theorists such as

\footnotetext{
${ }^{6}$ The pressure to be heterosexual and the punishment for those who reject it suggests that it may be less of an innate response and more social conditioning, and Freud's theory confirms this hypothesis (Read 1998, p.59). However, the value ascribed heterosexuality (as normal and therefore correct), deftly precludes debate amongst the heterosexual public about the naturalness of their sexuality.
} 
lesbian philosopher Adrienne Rich extended the lesbian sexual identity to a political identity that did not require sexual activity as proof. In a powerful challenge to heterosexism, she argued the existence of a lesbian continuum, regardless of whether individuals identify as lesbian or not (see Rich 1993, p.239). Such a definition offered lesbianism as a political choice for heterosexual feminists who sought to engage politically and emotionally with other women (Bryson 1992, p.214).

Identity politics assumes, or is often predicated upon, a sense of unification. While elective lesbianism subverted the medicalised definition of lesbianism, it also blurred the distinction between lesbian and heterosexual women and propelled lesbianism "into a wider social consciousness" (Hawkes 2004, p.171); there was dissent about this newly labelled group. Jeffrey's comment is typical of this response:

Lesbianism cannot be subsumed beneath the good feelings of handholding sisterhood. This leaves no space to talk about specifically lesbian oppression and gives us little chance to build up the history and culture of lesbianism which we need for our pride and our survival ...Women who simply have 'best friends' who are women share neither lesbian oppression nor lesbian experience (Jeffreys 1989, p.22).

Cultural anthropologist Gayle Rubin writes that the radical feminist agenda of 'womanidentification' was challenged particularly because it ignored many of the differences that existed between primary lesbians (women who desire women exclusively and whose desire is congruent with their identity) and elective lesbians (see Rubin 1993, p.28). Extending a lesbian identity to all women denies the specific sexual and erotic aspect of being a lesbian (Jeffreys 1989, p.22). ${ }^{7}$ The notion of a lesbian continuum also sits uneasily with lesbians of colour (see Smith and Smith 1983, p.121 for more discussion). Faced with such a loose definition of identity, sociologist and media theorist Arlene Stein observes that primary lesbians became concerned with "fixing boundaries, making membership more exclusive, and hardening the notion of lesbian 'difference"' (Stein 1997, p.384).

Lesbian sex radicals, as they became known, argued:

\footnotetext{
${ }^{7}$ And presumably relays to heterosexual women that their sexuality is false.
} 
there neither is, nor should be, any automatic correspondence between lesbian-feminist political beliefs and lesbian sexual practices and it was time that lesbians freed themselves to enjoy sexuality without the restraints inculcated in them as women or imposed on them by the movement (Faderman 1992, p.253).

In other words; the sexual component of a lesbian identity precludes non-lesbians from claiming it. As Kitzinger insists, lesbians are different from heterosexual women because they are subjected to oppressions which "shape and mould lesbian consciousness ... so that lesbians may have greater insights into the functioning of male power" (Kitzinger 1987, p.64). ${ }^{8}$ Despite this distinction, separate forms of oppressions can be related to one common source: the femaleness of the individual.

In her pragmatic definition, Penelope argues that a lesbian is a woman who relates "sexually and emotionally with other lesbians" (Penelope 1990, p.97), but at her most political she argues overtly that the label 'woman' is a concept and label of patriarchy that:

shifts our focus, directing our attention away form [sic] lesbian community. As soon as we name ourselves Lesbians, we step outside the category of 'woman' ... [however] when we change categories from 'woman' to 'lesbian', we're still oppressed as 'female' and oppressed for daring to be 'non-woman' (ibid., pp.103-104).

One way individuals can assist the creation of an identity is to publicly claim it for themselves. To retain a focus on lesbian identity and issues, Penelope argues, “'Lesbian' is preferable to 'gay woman' or other terms, to ensure Lesbians retain our visibility and claim credit for ourselves and our achievements as Lesbians" (Penelope 1990, p.104). While accepting Penelope's assertion that claiming a lesbian identity mitigates against its social denial, it is necessary to take issue with her argument that all lesbians should out themselves in order to challenge patriarchy and be true to themselves and others (Penelope 1990, p.94). This abstracts what is, for many women, a very practical question, with potentially adverse or even harmful consequences.

\footnotetext{
${ }^{8}$ An excellent appraisal of Kitzinger's (1987) work is offered in a special edition of the journal Lesbian and Gay Psychology Review (2005).
} 
A postmodern perspective rejects the concept of identity as it has long been defined. Queer thinkers theorised in a new, but controversial, vernacular. As author and critic Sophia Phoca notes, notions about gender and sexuality were radically challenged with the emergence of queer studies in the 1990s. The emergence of queer theory "put to question all reigning schemes of gendered/sexual normativity (Phoca 2001, p.61). The 'queer umbrella' offered shelter to individuals who were, or considered themselves to be, nonnormative in their sexual practices and/or sex and gender identities. According to cultural theorist Mark McLelland, this cloak of belongingness was the primary benefit, and also the chief difference, with regard to the previous goal of finding a common basis for a shared (or consensual) identity (McLelland 2005, p.146).

Queer theory appears to offer a shared identity, proponents argue, because it does not invoke the commonly used and prized binary labels related to sex, gender, and sexuality that heterosexism relies upon (see the works by French postmodernist Michel Foucault 1978, Butler 1990, Halberstam 1998, and by fellow post-structuralist philosopher Diana Fuss 1991, for examples). In order to subvert the conventional cultural codes related to these labels, the substitute label 'Queer' offers a lexical side-step around narrow identity categories to include the minorities that do not fit within them (Hawkes and Scott 2005, p.70). As an epistemological stance, feminist theorists Caroline Ramazanoglu and Janet Holland argue queer offers a method to dissolve the primacy of the binaries which the project of heterosexuality depends upon (Ramazanoglu and Holland 2002, p.89).

Queer theory continues to evolve, but there are fissures in the alliance between queerists and some feminists. Queer theory's premise that homophobia is the central form of oppression is criticised by some feminists as they argue it privileges sexuality over gender, and reduces the gender-bound experiences of women (Jeffreys 1994, p.469). Researcher John Fenaughty also points out that queer theory fails to recognise the patriarchal privilege of men (Fenaughty 2004, p.73), thus rendering it incompatible with feminist inquiry (Ramazanoglu and Holland 2002, p.97).

While gender essentialists rely on biology as the basis of differences (Kulkarni 1997, p.69), postmodernist theorists such as Butler, argue that gender is a performance (Butler 1990, p.137). Rather than being open to the myriad possibilities available to people under the rubric of being 'queer', Butler charges that feminists, with their insistence on the binary view of gender, stultify options of expression (Butler 1990, p.4). Still, as philosopher Rosi Braidotti (cited in Ramazanoglu and Holland 2002, p.91) argues, "In 
order to announce the death of the subject one must first have gained the right to speak as one". Similarly, Rich characterizes the "lesbian experience ... as being a profoundly female experience, with particular oppressions, meanings and potentialities we cannot comprehend as long as we simply bracket it with other sexually stigmatized existences" (Rich 1993, p.239). The essence connecting all lesbians is their sexual desire for their own sex (Dobkin 1990, p.4), and this is the position from which I evaluate lesbian television characters. While the politics of 'a lesbian identity' continue to be rigorously contested in other settings, the characters the producers have created are depicted as 'lesbian' and the character's perspectives and actions flow from this identity and are evaluated accordingly.

\section{Femme with a Lower Case ' $F$ '}

While exploring the epistemological efforts to define a lesbian, the binary descriptors of Butch and Femme inevitably arise and require addressing. It is outside the scope of this thesis to discuss the extent to which erotic Butch/Femme role-play exists within lesbian cultures: rather, I am concerned with how lesbian masculinity and femininity is depicted in television. According to lesbian author Joan Nestle, the Butch/Femme erotic role-play configuration has its own perspectives, behaviours, aesthetics, and politics (Nestle 1992, p.138). Without intending to signal nascent heterosexuality, feminine lesbians adopt many of the elements of the male-defined model of femininity. As author Jane Ussher points out, the Femme lesbian, the woman who engages in erotic conversations with Butch lesbians, is very different from the feminine lesbian (Ussher 1997, p.466). According to Jeffreys, the femininity of the Femme has an "acquired powerlessness" in her chosen role and is engaged in a kind of "romantic masochism", preferring to be subordinate to her Butch (Jeffreys 2003, p127). Since the 1970s many women have rejected traditional standards of femininity, rejecting what they see as "the passivity and subservience associated with archetypal femininity"; many women now "wear make-up and sexy clothes to show they can be both feminine and strong" (Ussher 1997, pp.72-73). Lesbians who adopt this same aesthetic are often called Lipstick Lesbians (Stein 1992, p.436). However, unlike the Femme and the Butch/Femme configurations, the feminine lesbian is attracted to women regardless of their femininity or masculinity.

Butch is the "lesbian vernacular term for women who are more comfortable with masculine gender codes, styles, or identities than with feminine ones" (Rubin 1992, p.467). An oversimplification sees the word butch used to describe any woman who does not comply with the dominant schema prescribed by heterosexism. As Rubin notes "Butches vary widely in how masculine they feel ... in how they present themselves ... 
and how they relate to their female bodies. Some butches are only faintly masculine, some are partly masculine, some butches are very manly, and some 'drag kings' pass as men" (Rubin 1992, pp.469-470). Butch is also a deliberate rejection of male-defined femininity, and a transgression of traditional binary structures. Butchness is not bound by sexuality; while just as many lesbians do not possess masculine attributes many heterosexual women do (Hawkes and Scott 2005, p.71). However, any woman who does not conform to the male-defined model of femininity is sometimes considered to be a lesbian. While masculinity can be performed by either sex (Butler 1990, p.137; Halberstam 1998, p.144), female masculinity seems to become most threatening to men when it is coupled with lesbian desire (Halberstam 1998, p.28).

When discussing feminine and masculine lesbians and lesbian characters I do not intend to invoke or impose the Butch/Femme binary where it may not be applicable, so I have adopted the following textual code. To avoid confusion, lesbian characters that do not participate in Butch/Femme dyads but who are lesbians who conform to male-defined codes of femininity are categorised as femmes with a lower case ' $f$ '. Femme lesbians and lesbian characters that enjoy erotic role-playing with Butch lesbians and Butch lesbian characters are referred to as Femmes with an upper case 'F'. The terms 'femme' and 'feminine lesbian' are used interchangeably to refer to feminine lesbians and feminine lesbian characters. Similarly, masculine lesbians who enjoy erotic role-playing with Femme lesbians will be referred to as Butch with an upper case ' $B$ '. When discussing lesbians and lesbian characters who conform to male-defined codes of masculinity but are not necessarily involved in Butch/Femme roles, the terms 'masculine', 'non-feminine', or 'butch' with a lower case 'b' will be used.

\section{Lesbianism as Absence}

The political and scientific struggle(s) to understand and define the lesbian identity and lesbianism have been reflected in popular culture via the media. A brief history of the lesbian image in film is presented here, followed by a discussion of the emergence of sexual minorities on television.

When discussing the lesbian characters in early Western literature and fantasy texts, Castle finds a "ghosting" effect of the lesbian figure in texts: "insert the lesbian and watch her disappear" (Castle 1993, p.6). The "ghosting", or symbolic annihilation, of the lesbian can be traced in all forms of literature and entertainment, from the pages of early eighteenth century texts, the destruction of lesbian-themed art works, through to sanitised 
biographies of significant historical women such as Eleanor Roosevelt (Castle 1993, pp.45). In 1928, Radclyffe Hall wrote the novel The Well of Loneliness. Although devoid of sex scenes and with heterosexuality restored in the end, the book was banned in Britain after a censorship trial, for fears the novel would encourage or legitimise lesbianism. As lesbian historians Julie Glamuzina and Alison Laurie note, in New Zealand the book was banned from importation until "at least" 1936, but could be borrowed from some New Zealand libraries by 1950 (Glamuzina and Laurie 1995, p.53). According to author Jonathan Dollimore, thirteen years before Hall's novel, Sapphic expression within the pages of D.H. Lawrence's book The Rainbow was singled out by the then editor of the Sunday Express James Douglas as, "an especially disgusting and subversive aspect of the novel" (Dollimore 2001, p.101). While Lawrence protested that he and writers like him merely told the truth about a reality that was repressed, Douglas argued work like Lawrence's "leads us in the direction of forbidden knowledge, 'it opens all the doors that the wisdom of man has shut, bolted and double-locked"” (Dollimore 2001, p.101). When radio broadcasting began in America in the 1920s, homosexuality was considered so offensive that "even antigay speeches were banned from the airwaves" (Capsuto 2000, p.3). However, when television began to erode radio's audience in the 1950s, the tight censorship of radio in the U.S. relaxed slightly, allowing audiences to hear the first explicitly lesbian radio character featured in the British radio crime anthology Black Mountain, in 1952. The appearance of "Jeannette" lasted a mere 90 seconds, just time enough for the character to be strangled to death by a spurned male soldier (Capsuto 2000, p.20).

Under the rubric of "sex perversion", depictions of explicit heterosexual sex were forbidden at the cinema, but pulp novels that dealt with lesbian sexuality flourished. However, as Faderman observes, these narratives were generally "cautionary tales... that encouraged the idea in women that lesbianism was sick or evil and that if a woman dared love another woman she would end up lonely or suicidal" (Faderman 1992, p.146). The representation of homosexuals in film and their early treatment by the film industry generally has been the subject of exhaustive research, most notably by the late film historian Vito Russo. According to Russo, while explicitly lesbian characters were prohibited throughout the Hays Code years, lesbianism was often implied (Russo 1981, p.102). ${ }^{9}$ As media scholar Patricia White points out, the censorship of all homoerotic imagery only encouraged lesbian and gays to read queerly, against the patterns of

\footnotetext{
${ }^{9}$ For an authoritative account about lesbian images in film, theory and spectatorship in classic Hollywood cinema, see uninvited by White (1999).
} 
heterosexuality (White 1999, p.2); for sexual minorities representation was something that had to be created within their own minds (Walters 2001, p.132). ${ }^{10}$ This is where lesbian audiences learnt to read queerly; there was no legitimate representation, only possibility created by ambiguity. Actresses who displayed sexual ambiguity by engaging in lesbianlike behaviours, while not explicitly claiming a lesbian identity provided lesbian audiences with plenty of opportunity to do just that. As Walters observes:

'Tough women' like Joan Crawford and Mercedes McCambridge who dressed as cowboys in the film Johnny Guitar, regal women without men (Queen Christina) and schoolmarms and their adoring charges (Maedchen in Uniform) all became icons for lesbian viewers (Walters 2001, p.133).

Although lesbian implications were associated with feisty heterosexual characters, other representations were anything but positive. Characters imbued with "sinister lesbian overtones" appeared in plots that involved prisons and mental hospitals (for example, Caged 1950, The Snake Pit 1948), and such characters were often predatory and unscrupulous (for example, Young Man with A Horn 1950, All About Eve 1950) (Gross 2001, p.59). Two lesbian films that "bookended" the Hays Code period were Queen Christina (Rouben Mamoulian 1933) and The Killing of Sister George (Robert Aldridge 1968). Films of this kind depicted gender inversion as a marker of homosexuality "and thus as a visible difference" (White 1999, p.9). From the murderous mannish Evelyn Harper (Hope Emmerson) in Caged to the butch cowgirls in Johnny Guitar, the connative coding of lesbianism was present in all genres over the next 30 years, becoming especially prevalent in horror films where film scholars Harry Benshoff and Sean Griffin find the most common representational protocol for lesbians at this time was the lesbian vampire (Benshoff and Griffin 2004, p.305).

\section{Visibility with an Asterisk}

The 1960s saw a more liberal outlook on sexuality in all its forms, in particular female sexuality (Ciasullo 2002, p.131). With the threat posed by the new, uncensored medium of television the Motion Picture Association of America was forced to temper its stand on

\footnotetext{
${ }^{10}$ During this time, Hollywood legend has it that mogul Sam Goldwyn, who was instrumental in the formation of the two largest Hollywood studios, Paramount Pictures and Metro-Goldwyn-Mayer, was told that Radclyffe Hall's The Well of Loneliness would not be acceptable for a movie because it was the story of a lesbian. Goldwyn supposedly replied: "So what? We'll make her an American" (Gross 2001, p.59). As Russo observes, Goldwyn's suggestion "captured the spirit of the truth. It was not as American as apple pie to be queer, and the closeted version of countless gay screenwriters, directors, actors and technicians were submerged into the heterosexual, all-American fantasies of the majority" (Russo 1981, pp.62-63).
} 
same-sex desire. Rather than being banned, a policy document issued on 3 October 1961 stated:

In keeping with the culture, the mores and values of our time, homosexuality and other sexual aberrations may now be treated with care, discretion and restraint (Gross 2001, p.59).

Ciasullo notes while the liberal discourse of the 1960s helped to "put lesbianism on the mainstream map, it also to some extent complicated cultural stereotypes of the lesbian as a mannish aggressive dyke whose feminine partner isn't 'really' a lesbian" (Ciasullo 2002, p.132). Breaking away from the distinction, Ciasullo continues: "newly visible lesbians might be masculine or feminine; might hang out in a bar or a classroom, might be a prostitute or a married woman. The types, and possibilities, had thus multiplied" (Ciasullo 2002, pp.132-133).

Although lesbianism no longer suffered symbolic oblivion, communication scholars Fred Fejes and Kevin Petrich find displays of Sapphic desire were largely used as titillation for heterosexual male audiences (Fejes and Petrich 1993, p.398). Most representations continued to underscore the supposed perversity of lesbianism, showing characters as murderous villains (Capsuto 2000, p.110; Walters 2001, p.166), prisoners, mentally ill (Gross 2001, p.59), or facing tragic ends (Benshoff and Griffin 2004, p.312). Lesbianism "was still being portrayed as a state of arrested development or as a pathetic lifestyle on which straight audiences were meant to take pity" (Ciasullo 2002, p.158).

Romance for the celluloid lesbian was equally bleak. Tension in the romantic genre is usually generated by the struggle of a couple overcoming various obstacles before they achieve their romantic union. Sociologist Tamsin Wilton finds that the impediments to lesbian romance are rather more sinister as "heterosexual men, suicide, murder, neurosis, isolation, depression, homophobia and the fear of discovery" are the favoured hurdles that thwart lesbian desire (Wilton 1995, p.97). Tragic or violent death stalked many lesbian characters. Depicted as being troubled by their sexuality, many lesbian characters were doomed to fates such as insanity, depression, murder, or suicide (Benshoff and Griffin 2004, p.312; Gross 2001, p.59; Wilton 1995, p.97). Often overcome by homicidal tendencies (Amy North in Man With A Horn, Matron Harper in Caged, Eve Harington in All About Eve), lesbian characters usually had an abbreviated life, either killing themselves (Martha in The Children's Hour, aka The Loudest Whisper in Britain, 1962), 
or being killed (Rosa Klebb in From Russia With Love, 1963). Hollywood's articulation of lesbianism was clear: lesbianism led to either spiritual or physical death. While some celluloid Sapphos killed themselves because of their sexuality, others such as Jo (Barbara Stanwyck in Walk on the Wild Side 1962), Lakey (Candice Bergen in The Group 1966), and Madam Irma (Shelley Winters in The Balcony 1963) accepted theirs, giving lesbians a more sexually strident, if not more lecherous and predatory, voice (Russo 1981, pp.143144).

In 1964, nearly seven decades after the advent of commercial cinema, the first film to depict male homosexuality, The View from the Bridge, was shown in New Zealand. The then Chief Censor of New Zealand, Mr D.C. McIntosh, freely admitted in an interview with Thursday magazine that he had personal repugnance with regard to homosexual themes, something the reporter decrees is "a fairly average Kiwi male reaction" (Thursday, 11 June 1970, p.25). However, he thought it important that films on social problems, such as drug taking and homosexuality, be shown to the public and that one of the great dangers in society was the "suppression of knowledge of problems" (The Taranaki Herald, October 14, 1965, np). Thus The View from the Bridge escaped the censor's knife.

Researcher Paul Christoffel finds that by the mid 1970s heterosexual sex scenes were not uncommon on New Zealand's cinema screens (Christoffel 1989, p.31); but whether sassy, sissy, or suicidal, expressions of homosexuality throughout the 1960s were always scornful. It seems lesbians and gays could be either "pathological, predatory, and dangerous; villains and fools, but never heroes" (Russo 1981, p.122). Social opprobrium, validated by these representations, has helped encourage the notion of lesbianism "as the negative other of heterosexual culture" (Wilton 1995, pp.97-98). A second controversial film to come to New Zealand in this period was one of the first Hollywood films to explicitly represent lesbianism, The Killing of Sister George. ${ }^{11}$ Robert Aldridge's controversial film was progressive in that, for the first time, audiences saw lesbians dancing and flirting in a safe environment. However, the film concentrated on the physical and spiritual destruction of the curmudgeonly and aging actress June Buckridge (Sister George), reinforcing the message that a woman who gave in to same-sex passions was doomed to an unhappy existence (McLaren 1999, p.185). While the lesbian characters offered were not positive, Sapphic expression was at least being featured. With the

\footnotetext{
${ }^{11}$ According to Keith Howes, in Britain, the 1965 stage version of The Killing of Sister George received the 'blessing' of Lord Chamberlain's office because the word 'lesbian' was not used (Howes 1993, p.455).
} 
protagonist being a character actress, the film also suggests that lesbians may have always been present in the dominant culture, "accepted and loved by audiences in genres that never admitted the existence of homosexuality" (White 1999, p.136).

Stimulated by the changes in the Motion Picture Code, the 1960s and 1970s forced some degree of lesbian and gay representation out of "a reluctant Hollywood" (Walters 2001, p.134). It was in this time that feminism's engagement with women's roles in film and in the film industry, began. As feminist filmmaker Jeni Thornley attests, "the resurgence of Australian filmmaking in the early 1970s coincided with the second wave of feminism" (Thornley 1987, p.62). Also amongst this coterie of women filmmakers, was New Zealand filmmaker Jane Campion, whose films such as Peel (1982), and A Girl's Own Story (1983), explored the power imbalances within in society, "especially the unequal position of women and children" (Freiberg 1987, p.328). However, as Walters notes, given the "heady combination" of sexism and homophobia, it comes as no surprise that the weight of gayness in film has been represented by gay men (Walters 2001, p.162). Faderman observes that while gay men were seeking partners in newspaper ads, and heterosexual men and women were avidly devouring expositions on sexuality such as The Joy of Sex: A Gourmet Guide to Love Making, "such 'sexualisation' passed most lesbians by" (Faderman 1992, p.247). Stein suggests that the broadening of the category of lesbianism to include heterosexual women "transformed lesbianism into a normative identity that over time came to have as much — and sometimes more — to do with life-style preferences (such as the choice of dress or leisure pursuits) and ideological proclivities (anticonsumerist, countercultural identifications), as with sexual desires or practices" (Stein 1997, p.382). Further, lesbianism was depicted by pornographers as a "sexual phenomenon" in the 1970s and this rendered lesbianism even less visible (Faderman 1992, p.247).

The 1980s was the decade in which the world became aware of the Acquired Immune Deficiency Syndrome (AIDS) epidemic. As Gross notes, because the disease emerged in groups that were "largely despised and rejected, AIDS proved once again the truism that the importance of an event may be determined less by what happened than to whom it happened" (Gross 2001, p.97). While it is outside the scope of this thesis to consider the history of all non-heterosexual representation on television, e.g. representation relating to the AIDS crisis, or the inclusion of lesbians and gays in reality programmes, I note Emile Netzhammer and Scott Shamp's findings that the media coverage of AIDS increased significantly after the AIDS-related death of gay actor Rock Hudson in 1985 
(Netzhammer and Shamp 1994, p.91). However, with the early media accounts linking the disease to gay men's sexuality, IV drug users or Haitians (Gross 2001, p.97), it was soon determined that lesbians were a low risk group and therefore rarely, if ever, mentioned in this context.

A favoured representational strategy during the 1980s was to depict lesbianism as "a temporary interruption in the flow of heterosexual life", as lesbian characters often forsook their lesbian lovers for a man, (i.e. Personal Best [1982], Gross 2001, p.74), or appeared in films such as A Different Story (1978) where it was implied that lesbians were really heterosexual (Russo 1981, p.231). Lesbian audiences were profoundly underwhelmed when the lesbian relationship between Shug and Celie in Alice Walker's Pulitzer Prize-winning The Color Purple (1985) was reduced to a "chaste kiss" (Benshoff and Griffin 2004, p.89). However, in only a few more years, things took a different turn.

\section{Lesbian Chic}

One socially stereotyped image that plagued lesbian film characters, when seen at all, is the "flannel-shirted, overweight, hairy-legged, "man-haters"” persona (Walters 2001, p.161). In a remarkable turnaround, lesbians became "chic" in the 1990s (Capsuto 2000, p.340) as long as they were aesthetically feminised. Under this palliative spin, the "fashionable lesbian" was no longer an oxymoron. New words were used to describe lesbians who appropriated the markers of heterosexual femininity, such as the 'Designer Dyke' or 'Lipstick Lesbian'. ${ }^{12}$ 'Lesbian chic', the etiology of which was coined from bisexual experimentation in the 1920s (Faderman 1992, p.63), had different connotations for different people. Some thought lesbian chic referred to the media's exploitation of lesbians as "something kinky, exotic and titillating" (Capsuto 2000, p.341); or that it referred to the greater visibility of lesbians stars like k.d. lang, and to news items that revealed the sexuality of such stars; that lesbian chic referred to celebrities who were feigning lesbianism as a fashion statement; or that it referred to an increased interest in playing lesbian roles from women like Whoopi Goldberg, Glenn Close and Emma Thompson (Capsuto 2000, p.341). Whatever the reason, the 1990s iteration of lesbianism meant that desire between women had become fashionable. The lesbian history of rejecting the heterosexual codes of femininity was suddenly forgotten as lesbians were being envisioned as "the ultimate 1990s party girl" (Walters 2001, p.162). The packaging was so titillating that celebrities like Madonna feigned lesbianism in order to be

${ }^{12}$ Ussher (1997) emphasises that the Lipstick Lesbian is different from some feminine lesbians who seek to hide their sexuality in order to 'pass' as a heterosexuals. 
fashionably exotic. Out had become 'in'. Picking up on the marketability of this social trend, lesbianism held an increasing fascination for Hollywood executives, who began to produce films with lesbian themes. Similar to White's (1999) observations about films like The Killing of Sister George, communications scholar Tom Reichert, gay, lesbian and transgender activist Kevin R. Maly and fellow communications theorist Susan C. Zavoina point out that one consequence of the lesbian chic phenomenon was that lesbian mainstream invisibility became less extreme, and that homoerotic images of women in film, television, and other media became increasingly prevalent, despite existing primarily for the sexual pleasure of heterosexual men (Reichert, Maly and Zavoina 1999, p.132). ${ }^{13}$

Despite more Hollywood visibility, the lesbian audience would find more to be annoyed about than to celebrate, as many of the old stereotypes were still invoked. For example, while films with best friend/lesbian connotations such as Fried Green Tomatoes at the Whistlestop Café (1991), Beaches (1988), and Outrageous Fortune (1987) could be seen as a cinematic adaptation of Rich's lesbian continuum (discussed in Chapter 2, p.19); ${ }^{14}$ they all still involved the death of one of the female characters, while other lesbian characters continued to disown their sexuality and their lover simultaneously such as in Three of Hearts (1993), (Walters 2001, p.166).

Lesbian film critic B. Ruby Rich argues that this period was characterized by the invocation of the murderous lesbian stereotype (Rich 1995, p.i). ${ }^{15}$ While the conflation of lesbian sexuality and violence is not new, New Zealand made a significant contribution to this association with the release of Heavenly Creatures (1994), a fictional depiction of the intense relationship between Christchurch schoolgirls Pauline Parker and Juliet Hulme who murdered Pauline's mother Honora in 1954. The film suggests the reason for the murder was so they could continue their relationship. The relationship between the schoolgirls became the subject of much debate; the idea that the two girls were in a lesbian relationship has been widely accepted. Avoiding the death penalty for murder because of their age, the girls were pronounced 'bad' rather than 'mad', and jailed, a finding that helped link lesbianism with "violent death, criminality and insanity" in the

\footnotetext{
${ }^{13}$ Supporting Reichert et al.'s (1999) analysis is work by Gill (2007) who also finds that 'lesbianism' seen in mainstream advertising has little to do with lesbians and more to do with titillating heterosexual males and sexism (Gill 2007, p.103).

${ }^{14}$ Rich posited that lesbianism exists on a continuum that comprises the homosocial bonding of women from the breastfeeding mother through to the dying woman of ninety who is being cared for by women. Women can move in and out of this continuum whether they identify as lesbian or not (Rich 1993, p.240).

${ }^{15}$ A more recent examination of the killer lesbian stereotype is examined by Wendy Minkoff (2003).
} 
public's mind, and helped to initiate new forms of anti-lesbian sentiment in New Zealand (Glamuzina and Laurie 1995, p.165).

The murderous lesbian cliché is not altogether negative. As Rich insists, "a figure that's equal parts heroine or villain, promise or threat, depending on viewer identification" means that for some lesbian viewers, killer dykes become icons (Rich 1995, p.i). An example of this phenomenon was the bisexual cult classic Faster Pussycat, Kill! Kill!, which drew large lesbian audiences, as did films depicting true events involving lesbian killer couples such as Fun and Sister My Sister (ibid., p.i). ${ }^{16}$ Any feelings of empowerment lesbian viewers may have taken from these icons was more incidental than by design, however, as Russo argues there is sufficient evidence Hollywood is not interested in depicting the reality of lesbianism and lesbian desire (Russo 1981, p.246). Walters agrees, noting the roles reserved for feminine lesbian characters who must be vicious killers, or worse, "misguided souls ready to be rescued from a life of Sapphic sorrow by rough and ready men" (Walters 2001, p.162). ${ }^{17}$

\section{Pre-Ellen Representations of Homosexuality on Television}

Journalist and communications scholar Marguerite Moritz finds the television industry has employed many of the cinematic strategies used to contain subversive women and Sapphic expression (Moritz 1994, p.140).

In the early years television mirrored the animus that surrounded same-sex desire by maintaining a silence about lesbianism (Moritz 2003, p.198). Just as early television was complicit in upholding myths about race, gender, class, and religion, it also maintained a "cherished myth about lesbians too: the myth that they don't exist" (Capsuto 2000, p.24). By the mid 1960s gay male characters cropped up occasionally, defined by their 'problem' (Gross 2001, p.83), as murderers (Capsuto 2000, p.57) or molesters (Fejes and Petrich 1993, Hantzis and Lehr 1994). The prohibition on lesbianism, however, remained in force. As Capsuto notes, "The gay male had become socially 'visible', but the lesbian is [still] the invisible woman" (Capsuto 2000, p.43, brackets added). It seemed that the word

\footnotetext{
${ }^{16}$ Glamuzina and Laurie recorded a range of emotions many New Zealand lesbians reported in response to the Parker/Hulme case. While some lesbians were traumatised at the conflation of lesbian sexuality with crime or insanity (Glamuzina and Laurie 1995, pp.170-171), many identified with the girls' feelings toward their parents (ibid., p.174), and some were just thrilled to realise they weren't the only ones who desired their own sex (ibid., p.168).

17 The latest iteration of Hollywood's killer dyke films, Monster (2003), centres on the life of Eileen Wuornos, one of America's few female serial killers.
} 
"lesbian" could hardly be spoken "without some qualification or distortion to heighten its scurrilous, shady appeal” (Howes 1993, p.456). Lesbian humourist Yvonne Zipter jokes:

[T] here were simply no lesbians on TV. Therefore, we had to make them up: Betty and Wilma, Lucy and Ethel, Miss Hathaway, Alice from The Brady Bunch. Obviously, judging from the above cast of characters, we were a desperate people (Zipter 1995, cited in Capsuto 2000, p.xiii).

Due to the paucity of explicitly lesbian fictions, lesbian viewers imagined the most unlikely cartoon characters (Betty and Wilma appeared in the cartoon The Flintstones and were both married to men), or the characters that did not conform to female stereotypes (the androgynous Miss Hathaway from The Beverly Hillbillies), were lesbians.

A new development that became popular in television texts of the early 1970 s was to split lesbian representation into two distinct categories: the radical, menacing lesbian feminist (the 'bad' lesbian), and the harmless, agreeable lesbian (the 'good' lesbian) (Ciasullo 2002, p.129) who also conformed to traditional feminine stereotypes (Capsuto 2000, p.70). Conventionally attractive, this new moderated lesbian image was stripped of the stereotypical characteristics that many heterosexual viewers found so unpalatable. By segregating the 'good' lesbian from the 'bad' extremist lesbian, the lesbian image was made more acceptable to heterosexual sensibilities. Safe and sanitised, this new iteration of lesbian identity became highly visible and "available for mainstream consumption" (Ciasullo 2002, pp.128-129). This fissure, this heterosexually determined demarcation between the 'good' lesbian and the 'bad' lesbian, would be exploited more thoroughly in later decades. While the 'good' lesbian identity allowed the subject of desire between women to emerge from shadowy invisibility, it did not contest heterosexual space. The emergence of the feminine lesbian character at this time merely provided scriptwriters with the opportunity to pen cautionary tales about the fate that awaits such women, as these demure, depoliticised, and pretty lesbian characters were shown as "unhappy and angst-ridden" individuals, fated to lead wretchedly miserable lives (Capsuto 2000, pp.69$70)$.

In the post-Stonewall era, an increasingly politicised gay and lesbian community began to demand changes in American networks' representations of homosexuals (Capsuto 2000, p.59). Networks appeared to respond to this pressure and began to include sympathetic representations of lesbians and gays. By the early 1970s, American television was 
presenting gays in "a more vibrant" and complex way than had been seen throughout the “entire history of U.S. film” (Russo 1981, p.223). Particularly noteworthy was All in the Family with its unorthodox hero Archie Bunker. The show not only discussed homosexuality, but it also challenged common stereotypes of the time (Russo 1981, p.223). The success of these comedies showed that stereotyping and prejudice could be exposed and criticized with humour. As Russo recounts, putting the pejoratives like

fag or lezzie into the mouth of Archie Bunker and other bigots, categorised those terms in the public mind as unacceptable and made homophobia a concrete threat that involved the slander of increasingly real people (Russo 1981, p.223).

Still, gay television characters were frequently cast as "violent sociopaths" (Capsuto 2000, p.7) including Police Woman (1974), where three lesbians kill and rob an old woman; Marcus Welby (1974), where a teenager is molested by his male teacher; and Upstairs Downstairs (1971) where the family's footman murders his male ex-lover with an axe (Capsuto 2000, pp.106-107). As film critic Richard Dyer points out: the "amount of hatred, fear, ridicule and disgust packed into those images is unmistakeable" (Dyer 1999, p.297).

In 1985, a British organisation, known as the Lesbian and Gay Broadcasting Project (LGBP), monitored one week's output of radio and television in order to see whether these media were informing and educating the public about alternate sexuality in an impartial way. The results, author and gay rights campaigner Terry Sanderson reports, were "damning", and in response to the findings, lesbian and gay activists put pressure on British broadcasting companies to improve the representation and visibility of sexual minorities in the media (Sanderson 1995, pp.18-19). Author and film critic Stephen Tropiano (2002) notes the pressure had some effect as prime-time scripts began to reflect the lesbian and gay communities' concerns. Gay rights, employment discrimination, and anti-gay violence became familiar issues tackled by many British programmes such as Angels, Brookside, EastEnders, The Bill, Casualty, and Emmerdale (Sanderson 1995, p.21), and in American shows such as Barney Miller, All in the Family, Maude (Tropiano 2002, p.185), The Streets of San Francisco and Hill Street Blues (Capsuto 2000, p.7). The tenor however, was more often pity than condemnation, as characters were presented as "saintly victims of prejudice" (Capsuto 2000, p.7). Gay characters were shown tolerance over total acceptance (Tropiano 2002, p.12), and the focus of these slightly more 
agreeable representations were gay men, while lesbians remained in the shadows (Gross 2001, p.82).

Although homosexuals were appearing with greater frequency in American-made content, representation still remained rare (Holtzman 2000, p.303). It was, "a false spring" (Gross 2001, p.84). The representation of lesbians and gays was restricted to certain formulas which included one-off appearances of gay or lesbian characters, disconnecting gay characters from other gay people, and storylines that preached tolerance of gays not acceptance. Capsuto argues that these representations were employed to pique "the interest of jaded viewers and appeased gay libbers, but avoided the outcry that an ongoing positive role might have attracted," all strategies that maintained the status quo that "gay people were a 'them' not part of an 'us"' (Capsuto 2000, p.72). In addition, homosexuality was positioned as a 'problem' to be solved (Gross 2001, p.83) and, according to communications scholar Bonnie Dow, only ever depicted in terms of the effect it had on heterosexuals (Dow 2001, p.129). The 'good' gay/‘bad' gay protocol, originating in the 1970 s, had now become a common representational strategy in television narratives.

Not until the 1980s did sexual minorities achieve "quantifiably meaningful" representation on television (Walters 2001, p.61). For lesbian characters the 1980s was the decade in which they began their "fictional coming out" (Moritz 1994, p.126). Capsuto observes the "'bad' gays were the ones with a sex drive", while the "good" gays were asexual. Under this protocol, it was no surprise then that the first passionate same-sex kisses in prime-time were between murderers (Capsuto 2000, p.7). While imitating the depictions of lesbians in film, lesbian characters remained a rare sight and when they were seen were often violent (Capsuto 2000, p.227), or manipulated to conform to men's interests and assuage their egos, and their sexuality (Dickey 1987b, p.74).

One popular 1980s American sitcom noted for its lesbian subtext was Kate and Allie. Unfortunately, any positives lesbian viewers may have taken from the ambiguity of the women's relationship was dashed in one episode. Facing eviction, Kate and Allie pose as lesbians to keep their apartment. When their landlady (Janet) and her partner (Miriam) hold a dance to honour Kate and Allie as members of the sisterhood, Kate and Allie revealed the truth. Despite the ruse, the women were able to keep their apartment and reassert their heterosexuality. Resolving the issue with no hard feelings, Kate and Allie and Janet and Miriam go to the dance together, firm friends. The plot neatly dismissed the possibility for hopeful lesbian viewers that "two women living together with kids could 
ever be lovers" (Walters 2001, p.62), but did allow the idea that lesbians could be suitable friends for heterosexuals. Janet and Miriam had the potential to become regulars on the show, but they did not appear again (Capsuto 2000, p.201). When a lesbian was finally included as a recurring character, sexual expression was the one thing missing. Marilyn McGrath, the nurse in the BBC's medical drama Heartbeat, was an explicitly lesbian character. The narrative surrounding the lesbian character of Marilyn was progressive insofar as her lesbianism was a non-issue (Tropiano 2002, p.45). However, her sexuality was completely hidden as Marilyn neither talked, nor was asked, about her relationship with her partner, Patti (Hantzis and Lehr 1994, p.112), and while the series depicted heterosexual couples making love, Marilyn and Patti were not even permitted to touch (Tropiano 2002, p.46).

Following the fashion of lesbian chic in movies, the 1990s was a decade of landmarks for sexual minorities on American television, a decade that saw increased visibility toward the identity and lifestyle of sexual minorities (Capsuto 2000, p.248). It was the decade when "the love that dare not speak its name became the love that would not shut up!" (Walters 2001, p.29). Most notable for lesbian audiences in the early part of the decade was the kiss between two female attorneys on LA Law in 1991. Other lesbian regulars on New Zealand television screens were found in sitcoms Roseanne (Roseanne's friend played by lesbian comic Sandra Bernhardt), Mad About You (character Paul Buckman's sister Debbie played by Robin Bartlett), and Friends (Carole and Susan), where they were even mothers (Capsuto 2000, p.346). ${ }^{18}$ The late 1990s also saw the creation of the New Zealand-based mythological cult hit Xena: Warrior Princess with its strong lesbian subtext. Cultural theorist Becca Cragin argues the rise in the number of lesbian characters was an effect of producers marketing television to professional women in the post-feminist era (Cragin 2006, p.194). These characters were limited to isolated episodes in long-running series about groups of women (she cites The Golden Girls, Cagney and Lacey, and Kate and Allie), and were secondary rather than core cast.

This has not changed significantly over the last ten years. Ellen Morgan's (Ellen) coming out narrative was groundbreaking but politically empty (see Capsuto 2000; Dow 2001; Tropiano 2002; and Walters 2001). Dr Kerry Weaver (ER), an emotionally damaged character, become more shrill by the episode as she grieved for her dead partner and the baby taken from her by her partner's parents. The promising love story between Tara and

\footnotetext{
${ }^{18}$ Kessler (2006) and Walters (2001) both provide excellent discussions about the homonormative shortcomings of Friends.
} 
her girlfriend Willow (Buffy the Vampire Slayer), culminated in death, addiction, and evil after one season. Carole and Susan (Friends) seemed only to exist as comedic leverage for Chandler and Joey's amusement or titillation. Tina (Smallville) had the distinction of being dead and evil. Zoë Tate of Britain's Emmerdale murdered her half-brother and had an affair with her brother's fiancée, before enduring a bout of schizophrenia. In Australia's Home and Away nurse Eve Jacobsen/Zoë MacCallister was a psychotic stalker, intent on exacting a murderous revenge on the good heterosexual folk of Summer Bay because of the beachside community's treatment of her girlfriend, Sarah Lewis.

The figure of the lesbian seems to be made more safe and agreeable for the heterosexual audience by ascribing it anarchic qualities (Moritz 1994). Gross summarises the situation:

Hardly ever shown in the media are just plain gay folk, used in roles that do not centre on their difference as an anomaly that must be explained, a disappointment that might be tolerated, or a threat to the moral order that must be countered through ridicule or physical violence (Gross 2001, p.16).

One of the critical moments of any lesbian's life is her coming out process, something, political theorist Samuel A. Chambers points out she would not have to do if society were not so comprehensively heteronormative (Chambers 2006, p.97). Amongst the suite of conditions that make lesbian and gay sexuality safe for television audiences is the coming out script (Capsuto 2000, pp.4-5), or the discourse of confession. While the coming out narrative can have an educative value for heterosexual characters (and audience members), it is also conservative in the sense that heterosexual presumption requires same-sex desire "remains something to be 'explained' and 'accepted"' (Walters 2001, p.200), while heterosexual maturation requires little explanation. As Hurley argues, heteronormative media often presents the coming out narrative as the way gays and lesbians find self-acceptance, and in doing so frames same-sex sexual activity with guilt (Hurley 2005, p.54).

Case studies of contemporary lesbian television representation illustrate that although lesbian television characters may present differently to their celluloid predecessors, the way they are represented is similar. Television imitates all things Hollywood (Capsuto 2000, p.184). An aesthetic imperative to include lesbian and gay characters also ensured television productions had a contemporary "chic" look (ibid., p.2). 
While television was undergoing a "minor lesbian revolution" with the growing number of gay or bisexual women characters appearing in the mainstream environment (Capsuto 2000, p.346), their inclusion often generated controversy (Holtzman 2000, p.303). Television employs multiple tactics to deal with lesbian representation. The most common tactic has been to ignore lesbians and lesbian sexuality completely; and the next best option has been to resort to negative representation.

\section{The New Protocols of Same-Sex Desire}

New protocols have emerged to contain same-sex desire, ones that bring "higher levels of subordination and repression" (Fejes and Petrich 1992, p.412). As lesbian authors Julia Penelope and Susan Wolf asseverate: "Much of what is touted as lesbian 'visibility' erases us" (Penelope and Wolf 1993, p.6). This is perhaps best demonstrated by the control maintained on lesbian visibility by the conditions placed on contemporary television representation. The script lesbian characters must now follow is assimilation to heterosexuality. This is especially so regarding their physical appearance, and also their advocacy of heterosexual values, but less so for their use in plotlines. These "more subtle images of heterosexually-defined homosexuality, are just as damaging to affirmative gay and lesbian identity and politics" (Fejes and Petrich 1993, p.412). The first of the mainstreaming strategies involves naturalising the monogamous relationship.

After observing the way alternate sexualities are represented in mainstream media texts, Academics Kathleen Battles and Wendy Hilton-Morrow argue that there is a relatively new tool in the suite of representational strategies employed to contain the threat posed by same-sex desire: depicting lesbians and gays as inherently similar to heterosexuals (Battles and Hilton-Morrow 2002, p.101). Where once sexual minorities were depicted as "deviants, as aliens from sexual outer space set to wreak havoc on straight ('normal') society", gays and lesbians can now be represented as no different to heterosexuals (Walters 2001, p.16). The "trend of representing lesbians and gay men as "just like everybody else," allowed for same-sex couples to more easily enter into television narratives (Capsuto 2000, p.352). While such a strategy may be thought of as moving away from the pathological model that saw homosexuality as an illness, representing lesbians and gay men as no different to heterosexuals, this trend can also be seen as homophobic and as promoting a homogenising response (Cragin 2006, p.197; Fejes and Petrich 1992, p.412). As Kitzinger points out, the "gay affirmative" notion is just as socially constructed as the pathological perspective (Kitzinger 1987, p.vii). For example, 
while gay weddings may be thought of as normalising lesbian characters, their inclusion can just as easily be seen as a cultural instruction to same-sex couples to conform to the heterosexual model of monogamy and stability before they can be considered acceptable (Kessler 2006, p.138); a heteronormative patriarchal requirement begrudged by Merri Lisa Johnson (2006, p.116), when appraising The L Word.

The discourse of assimilation "eradicates the difference difference makes" (Walters 2001, p.19), and the assimilationist model successfully forecloses on any aspect of gay and lesbian identity, sexuality or community that "too directly challenge the heterosexual regime" (Fejes and Petrich 1993, p.412). By minimising the differences between heterosexual, lesbians (or gay men), Kitzinger points out: "our behaviours and differences are reduced to those forms congruent with the dominant order" (Kitzinger 1987, p.48). Under this regime, lesbian television characters are often desexualised (Kessler 2006, p.131) and depoliticised (Cragin 2006, p.197; Dow 2001, pp.132-136); or at best, they are confined within a heteronormative space of tolerance (Herman 2003, p.144). Dow's analysis of the series Ellen shows that bleaching lesbian or gay identities of their difference, to the extent that the homosexual element is effectively lost, mutes the existence and material effects of a homophobic culture, and masks the contradictions that while media representatives claim there is progress for homosexuals, the straight world ignores the issues affecting gays and lesbians as a group (Dow 2001, pp.135-136).

Similarly, Wilton criticises the British television production Portrait of a Marriage (1990) for showing the desire between women, but ignoring the realities of heterosexism and patriarchal control that affected even wealthy socialites like Violet Trefusis and Vita Sackville-West (Wilton 1995, pp.118-119). ${ }^{19}$

This differing treatment of lesbian and heterosexual television characters stems from the sex roles heterosexuals insist upon in order to distinguish between men and women, a requirement that supports the project of heterosexuality (Herman 2003, p.144). The problem that mainstream media has with crafting characteristic lesbian representation is that with only two models with which to understand classes of individuals, the project of

\footnotetext{
${ }^{19}$ According to biographer Diana Souhami, Vita's original manuscript (or confession), that was published after her death by her son Nigel Nicholson, was originally entitled 'Portrait of a Lesbian Relationship'. However, Nicholson added 50,000 words to Vita's original 120,000-word manuscript, and set his mother's relationship with Violet into the context of his parents' marriage, with his father as the hero (Souhami 1996, p.xi).
} 
heterosexuality therefore (mis)understands lesbianism as a biological woman taking on the heterosexual male's role of desiring women.

The demarcation between 'good' and 'bad' lesbian, a fracture that began in the 1970s, now includes new factors that have widened the gap further. The new protocol appears to be: 'good' gays are those individuals who are "born with it, those who are in a committed couple, those who go to Church, those who have kids, those who have weddings, those who want acceptance", as opposed to the 'bad' gays, "those who celebrate their preference as a choice, those who prefer multiple partners, those who criticise the nuclear family, those who are atheists, those who want radical social change" (Walters 2001, p.76).

Normalising sexual minorities in the media by assimilating them has also caused a fracture line within the homosexual community (Walters 2001, p.53). While assimilationists seek to minimise differences between same-sex desire and heterosexuality, authors James Keller and Leslie Stratyner point out that disciples of the queer movement are not apologetic about their queerness, but celebrate it (Keller and Stratyner 2006, p.3).

Lesbians and gays are like heterosexuals in many aspects of our lives, and many gay people want to assimilate. However, for those who do, self-respect is defined by the toleration of heterosexual society and not to be depicted as "freaks and others, as sideshows to the main stage of heterosexual family life" (Walters 2001, p.19). One reason for this is that these individuals have internalised mainstream values "without realizing it", and as a consequence are "profoundly heterosexist in their thinking and outward behaviour" (ibid., p.17). With regard to television representation, the normalising strategy might be "successful in humanising gays for straight audiences, [but] has a tough trade-off that can push other gays further into the margins" (Walters 2001, p.77). Thus, the assimilated lesbian characters are palatable for the heterosexual audience, while those who do not conform to male-defined model of femininity, like the butch, are rendered unacceptable.

While the increasingly available chic lesbian image has helped to dissolve the traditional stereotypes that have plagued lesbian representation, is it correct? Studies and treatises like Naomi Wolf's (1991) thesis, The Beauty Myth, have exposed the constraints on women's media image and related its proscriptive effect on our self-esteem and aspirations to its inherent relationship with capitalism. Similarly, other contemporary studies by Richard 
Conway (2006); Kim et al. (2007), and Noelle St Germain (2003) reveal the gendered and heteronormative scripts of television, and the other effects of media stereotypes on young girls (Lamb and Brown 2006; American Psychological Association 2007). With the dominance of the notion of the feminine lesbian in mainstream television texts, some form of the Beauty Myth has been extended to lesbians. The representation of the heterosexually constructed lesbian not only precludes other types of lesbians from being shown, and advises lesbians and heterosexuals alike that this is what a lesbian looks and acts like; it also co-opts her image into the sexual service of heterosexual men.

Capsuto (2000) regards the sitcom Friends as evidence of the emergence of friendlier attitude toward lesbian images on television, and argues the depiction of Ross's lesbian ex-wife Carole and her partner Susan provides viewers with lesbian representation that avoids most of the clichés reserved for lesbians (Capsuto 2000, p.349). ${ }^{20}$ However Carole and Susan, and other characters like Chandler's gay cross-dressing father, who present as happy outside heterosexuality, are treated as subjects of amusement for a heterosexual audience (including the show's main characters). For example, the fact that Ross's wife Carole left him for a woman is treated as a source of hilarity for Chandler and Joey, and used to imply that Ross was, first, such a bad lover he caused her lesbianism, and second, an unobservant husband not to realise his wife was unresponsive to him.

\section{Appropriating Lesbian Sexuality}

The most reliable source of lesbian visibility has been in pornography. Sex-acts between women have been employed as an aid "in the service of male sexuality" (Russo 1981, p.6) since many heterosexual men are aroused by the thought of lesbian sexuality (Kinsey et al. 1965, p.486). Writer Patricia Duncker observes these sexually explicit, lesbian-themed opuses have usually been made for men, by men (Duncker 1995, p.6). The Chief Censor of New Zealand, Bill Hastings, also confirms this trend, commenting the majority of the adult material involving explicit sex acts between women is not for lesbian audiences but is, instead, aimed at a heterosexual male audience (W. Hastings personal communication, 26 September 2006). This trend has followed into mainstream television, where the idea that heterosexual men are supposedly titillated by depictions of lesbian sexuality "has enough basis in reality to have become a running joke" on sitcoms (Capsuto 2000, p.332). In fact, Kim et al. (2007, pp.153-154) found a significant proportion of all sexual content

${ }^{20}$ Friends preceded Ellen in this country by a few months. Re-runs of the show still continue in New Zealand in 2007, on 2. 
in the programming they studied involved female characters appropriating lesbian sexuality to titillate male characters.

This has several effects. In the first instance, lesbian sex acts are appropriated by heterosexual female characters for heterosexual male characters' enjoyment (Capsuto 2000, p.332; Kim et al. 2007, pp.153-154). As a consequence, communications scholar Julie Andsager notes, lesbian sexuality may also act as a source of instruction for young women seeking to attract men (Andsager 2006, p.43). Second, by appropriating aesthetics, accessories, and behaviours, the feminine lesbian is "less distinguishable from heterosexual women" than her other lesbian sisters, many of whom still cultivate a deliberate androgyny as a powerful political statement (Faderman 1992, p.273). Third, because she most resembles a heterosexual woman, the feminine lesbian's true sexuality is called into question (Ciasullo 2002, p.206; Ussher 1997, p.58). This relates to the pseudoinvert hypothesis of Havelock Ellis who declared that, unlike their mannish sisters, pseudo lesbians became involved in her inverted behaviour "through circumstances rather than natural inclination and were really normal heterosexuals" (Jeffreys 1989, p.10).

Ciasullo (2002) argues the feminine lesbian is at once sexualised and desexualised: on the one hand, the lesbian is made into an object of desire for straight audiences, looking "just like" conventionally attractive heterosexual women; on the other hand, because the representation of desire is usually suppressed in these images or contained in plots that serve male audiences, she is "dehomosexualised" (ibid., p.182). Similarly, author Diane Hamer argues the cultural script reserved for the feminine lesbian is that she needs to be:

essentially feminine and heterosexual; her lesbianism at most a passing phase, resulting from seduction by a predatory butch or a temporary retreat from men after some damaging experience (Hamer 1994, p.71).

Imbued with so many heterosexist sensibilities, the sexuality of the lesbian character is able to be "wished or imagined away" by the fevered heterosexual mind (Ciasullo 2002, p.223; Nestle 1992, pp.143-144). One extension of this condition for television's femme is that she is required to display a large amount of sexual capriciousness and/or confusion 
about her sexuality (Walters 2001, p.162; Wilton 1995, p.97). ${ }^{21}$ The script of lesbian desire, according to this strategy, sees the confused female character experiment with same sex attraction, but then recommit to heterosexuality in the end (Hamer 1994, p.71). This argument is certainly supported by many pornographic texts where females are shown having sex with each other but immediately stop when a male enters the scene and engage in heterosexual intercourse with him. The popularity of such pornographic sequences and the regular inclusion of such lesbian scenes, suggests that this is a prevalent fantasy for many male heterosexually-identified viewers (W. Hastings personal communication, 26 September 2006). It may also indicate their desire to regard lesbians as bisexual, and therefore, available to them. The articulation of the feminine lesbian's sexuality as confused or merely capricious locates lesbian desire within the category of deviancy, making her sexuality a choice and an informed one at that: it appears as if she has actively chosen lesbianism because it offers her better sexual experiences. Certain kinds of deviancy are socially acceptable, and 'socially acceptable' appears to be a code for 'attractive to heterosexual men'. A femme character's (supposedly) sexual schizophrenia, a myth rooted in early sexological discourse, is attractive to men and therefore has the potential to titillate heterosexual audience members, as well as offer the opportunity for her to become heterosexual, accounting for its popularity as a plot device. When she does eventually respond to a male character's advances (because of her sexual instability), heterosexuality is restored to the plot. ${ }^{22}$

Some might argue that the presence of bisexual female characters destabilises heteronormativity enough to allow a narrative space for lesbian characters. This may be true. However, this thesis argues that bisexuality does little for lesbian representation when characters introduced as lesbians are transformed into bisexual characters. This is the strategy deployed in the storylines of many lesbian characters described in the literature and in this thesis. As Penelope and Wolf insist, increased inclusion of bisexual characters is another way lesbian sexuality is appropriated in order to promote the notion there "aren't any 'real' lesbians - women who are not sexually available to men - only bisexual women" (Penelope and Wolf 1993, p.6). Further, as Hantzis and Lehr argue,

\footnotetext{
${ }^{21}$ Examples of this strategy in film include Lilith (1964), Pussy Galore in Goldfinger (1964), Personal Best (1982); Another Way (1982), Three of Hearts (1993), and Kissing Jessica Stein (2001). On television during my broader research period alone (2004-2006), I have noted four recurring lesbian characters, Jay Copeland and Maia Jeffreys (Shortland Street), Gail (Shortland Street), and Marissa (The OC), being shown as confused about their sexuality, or being seduced by a man.

${ }^{22}$ An example of a heterosexual man successfully seducing a lesbian, and the subsequent distress this relationship caused many lesbian viewers, is discussed at length in my analysis of Shortland Street (see Chapter 8, pp.169-170).
} 
representation of lesbian sexuality is the most important way to combat heterosexism (Hanztis and Lehr 1994, p.108).

Representing the feminine lesbian also has an arguably unintended effect. Some lesbian feminists may view those lesbians who appropriate feminine attributes as regressive, "assimilating into the straight world, shedding their anger and forgetting their roots" (Stein 1992, p.432), so they may pass in a heterosexual society more easily than less feminine women. However, as Nestle (1992, p.141) argues, the feminine lesbian unsettles heterosexuality in a very different way. For example, Capsuto notes Ellen DeGeneres' femininity disconcerted one conservative American organisation, enough for a spokesperson to claim an attractive and openly lesbian lead on television would "cause children to experiment with gay sex" (Capsuto 2000, p.386). The worry here seems to be that, when stripped of its pejorative connotations, lesbianism becomes a temptation.

Illuminating the temper of contemporary lesbian representation in mainstream American cultural texts, Ciasullo (2002) suggests that the feminine lesbian is the most represented lesbian. Another effect of appropriating lesbian desire within mainstream television texts is that the privileging of the feminine lesbian over other lesbians creates a beauty myth for all lesbians to receive, internalise, and adhere to.

\section{Symbolic Violence and the Butch}

Until the popularity of Lipstick Lesbians, the social stereotype of the intractable dowdiness associated with lesbians was another prejudice that had stood uncorrected. However, the media's uptake of the feminine lesbian pivots solely on her heterosexual appeal (Ciasullo 2002, p.218). However, the only recognisable trait in television's articulation of the feminine lesbian is her femininity; the conditions of her representation demand she be available for the male gaze (as well an ever-present possibility of her being seduced by a man) in order to make her more palatable to heterosexual audiences. To be desirable but unattainable places the feminine lesbian in a powerful position, as the lesbian who is conventionally pretty and unavailable for men would surely constitute a position of considerable power. The feminine lesbian employs conventional (heterosexual) codes of femininity to attract and signal her desire for women, while removing herself from men's grasp. The mannish woman, however, has the potential to subvert the whole category of masculinity as defined in heteronormative terms, and the social response to her is, film and cultural theorist Judith Roof finds, an "anger and anxiety about a decentering of phallic privilege" (Roof 1991, p.249). 
Translating this to the area of media representation, the consequence of transgressing gender roles is narrow, negative, trivialised, or worse, not depicted at all. These consequences fall under the rubric of 'symbolic annihilation' (Gerbner and Gross 1976, p.182). Non-feminine lesbians are the most likely to suffer such symbolic oblivion because, unlike the femme, the butch is not a consumable image. She cannot be "'delesbianised', because her body is already and always marked as a lesbian. She is more visible than the femme - and thus, if represented, more 'lesbian' than the femme" (Ciasullo 2002, p.211). In contrast to the 'good' femme, the butch is the 'bad' lesbian; her sexuality indistinguishable from her feminism" (Ciasullo 2002, p.129) and, therefore, incongruent with the desires of the heteropatriarchy. And, when she is visible, she is represented "as an anomaly, an aberration whose sexual/gender indeterminacy evokes a curiosity, confusion and even derisive laughter (ibid., p.217).

Another contributor to the butch's invisibility in the media is that, within (mainstream) television, her masculinity makes her "ugly", in opposition to the stereotype of "beauty", and as such is "an affront to an image-based culture" (Ciasullo 2002, p.208). Paradoxically, this is the same quality that heightens her visibility in the real world; her media invisibility gives rise to her real visibility (ibid., p.217). Further, mannish lesbians have a history of being associated with a working class status (Faderman 1992, p.42), despite the existence of lesbians in 'higher society' (ibid, p.39), and fictional television texts most often favour a heteronormative attractiveness the butch does not have, nor seeks to cultivate.

Some contemporary series do reflect a 'kitchen sink' reality within which butch characters are welcome; the BBC's Bad Girls is an example. This series is unusual in its homonormative perspective (Herman 2003). The lesbian characters span a realistic continuum of femme/butch identities, ranging from conventionally femme (Nikki and Helen), to 'soft butch' or androgynous (Denny and Shaz) and butch (Al McKenzie). When displays of sexuality and intimacy are analysed, the butch and soft butch lesbian characters are accorded very little intimacy compared with conventionally 'pretty' lesbians. Instead, Al, Denny, and Shaz are called upon to do the menacing and fighting. It seems the butch is kept around to rough things up, thus associating masculine lesbians with a capacity for violence; directly reflecting filmic strategies. 
The soft butch is an interesting phenomenon. Her representation can be considered as an effect of loosening the constraints on feminine lesbian depictions or as tokenism towards the butch on behalf of patriarchy. Halberstam notes an emerging trend of feminising or softening butch characters in mainstream film texts. In Fried Green Tomatoes Mary Stuart Masterson's tomboy dyke character Idgie Threadgoode, who is coded as butch in the novel, is instead feminised in the film (Halberstam 1998, p.217). Television has also utilised this strategy. For example, Nan and Kit from the Victorian drama Tipping the Velvet were, in the novel, supposedly mannish enough to pose as male impersonators and to live as rent boys. Similarly, the androgyny of The L Word's Shane is supposedly so profound that she was able to turn tricks as a toy boy for Hollywood homosexuals.

Despite the incredulity associated with mainstream versions of the butch (arising most likely from the tension to produce titillating enough lesbians to appeal to large, mainstream audiences), under the right conditions her presence can have the effect of challenging heteronormativity. The butch lesbian is perhaps better able to challenge mainstream cultural fantasies about sexuality than the feminine lesbian because, in the "culture of the straight mind", the only "real" lesbian is the butch" (Ciasullo 2002, p.218). The feminine lesbian in contrast can be considered to participate in what Ciasullo (ibid., p.218) describes as "desirable deviance" in regard to her sexuality. However, this arrangement places the practice of lesbianism in high visibility, but it also effectively divorces lesbians from their own sexuality.

This tension between sexuality and sexual identity is illustrated in one of the most famous (to date) television programmes featuring a lesbian character: Ellen. The sitcom Ellen was groundbreaking largely because it disrupted the usual patterns of lesbian representation by going beyond the 'one shot' or 'one episode' approach. The bold steps taken by both Ellens, fictionally and personally, were critical for minority visibility despite censure from gay and heterosexual critics. DeGeneres finally gave lesbians a positive role model, one of their own who they could see every week, and a world in which they could identify with and vicariously participate.

DeGeneres had naively hoped she could stay apolitical, a 'good' lesbian, while taking such a political step (Capsuto 2000, p.386). Actually being a lesbian did make a difference to what was deemed permissible (Walters 2001, p.85) and the character's epiphany had placed her right in the vortex of media hype about sexuality. Anti-gay activists feared the show had the potential to normalise homosexuality (Capsuto 2000, p.386) and others 
criticised it for doing little to challenge the normative structures of heterosexist society (Dow 2001, pp.135-136). Still others considered the programme was becoming too political. For example, Stuart Bloomberg, chairman of ABC Entertainment said, in an Entertainment Weekly interview, that as "the show became more politicized and more issue-oriented, it became less-funny, and audiences noticed" (Tropiano 2002, p.248). The very thing that had made Ellen famous had become a liability for the network.

That the show was criticised for focussing too much on same-sex relationships caused consternation for some critics. Tropiano finds the criticism "extremely troubling when one considers that no show has even been accused of being too straight for obsessing on opposite-sex relationships (which describes 99 percent of everything on television)" (Tropiano 2002, p.249). How could Ellen have been less gay, he implores, "be gay every other week? Every fourth episode?" (ibid., p.249). Was she neither chic enough, nor bad enough either? By homonormative standards, Ellen had to be politically weak to keep her palatable for heterosexual audiences (Dow 2001, p.134).

The period immediately after Ellen screened was noted for its paucity of lesbian representation (Capsuto 2000, p.409). This “did not stop prime-time's female regulars from kissing each other on the lips ... for either plausible or exploitative reasons" (ibid., p.409). It appeared sexually nebulous female characters achieved this right more readily than Ellen did. Heading this faux-lesbian trend was the immensely popular post-Ellen hit, Ally McBeal, which was shown in New Zealand in 1998/99. The character of Ally McBeal seemed to like kissing women, but her heterosexuality was quickly reasserted; the women involved would discuss on the next day, the "missing ingredient you need for the tingle" that is, the penis (Walters 2001, p.120). As Walters comments, "no series has delved into the straight heart of the heterosexual at once disgusted by and desirous of gay sexuality as Ally McBeal" (ibid., p.119). It made lesbian sexuality (or, more correctly, bisexuality) visible by suggesting women were attracted to other women. The show was located within the prevailing context of heteronormativity, however, and all of the women resumed their interest in men, specifically citing the absence of the penis as the reason for ending their dalliance with lesbian sexuality (ibid., p.120). It reiterated for the audience that lesbian sex acts (no matter how fleeting) were deviations that are not as pleasurable as heterosexual sex acts, and there must, by extension, be something wrong with active lesbians. Nothing in these representations suggested lesbians were an "ongoing part of society" (Capsuto 2000, p.409). More recently, the American cult hit Sex in the City reprised this version of lesbian desire. Of the series, gender theorist Rosalind Gill (2007) comments that despite 
showing a female world of homosociality, including its " 'frank' and 'liberated' talk", a central character enjoying a kiss with another woman, and another central character having a sexual relationship with a woman, normative heterosexuality is always restored (Gill 2007, pp.244-245).

With the exception of Ellen DeGeneres, lesbian characters, as well as being constructed by heterosexuals, are also usually played by heterosexuals; a point revealed through television's secondary texts, which media critic John Fiske lists as specialist fan magazines, journalistic criticism, and printed gossip (Fiske 1987, p.85). ${ }^{23}$ These accompanying texts are another source of conditions on lesbian visibility, if only an indirect one. Actors who play gay characters are invariably asked to confirm their heterosexuality by being interviewed about how difficult it must be to play gay, and how their heterosexual partners must feel seeing them do so (Gross 1991, p.28). In an interview with Anna Julienne who plays Shortland Street's lesbian nurse Maia Jeffreys, Rebecca Barry, reporting for e.g. Magazine, the weekly home entertainment lift-out published by The New Zealand Herald, immediately established the actor's (hetero) sexuality. Apparently at a loss to even say the word "lesbian", Barry fumbled, "So, first things first um, are you..." to which Julienne replied, "I'm not a lesbian, no" (Barry 2004, p.4). While Julienne had no concerns about playing a lesbian, she indicates other actresses did:

The thing with Shortland Street is the public start to think you are your character. Maybe some people are worried about that - they wouldn't want other people to think they're a lesbian. I know of some other women who went for it and their male partners were a bit, kind of, funny about it (Barry 2004, p.4).

In contrast, the actress Jennifer Beals, who plays Bette Porter in The L Word feels a heavy responsibility about playing a lesbian, and wants to lend credibility to her character. In an interview with Oliver Hall in Express magazine, Beals states: "We are aware of our responsibility and the historic importance of the show, which is exciting and makes us very vigilant about our characters" (Hall 2005, p.10.). Beals continues about her experience playing Bette Porter:

Mostly I have people who come up to me to say 'thank you, for representing us' ... To be changing the face of television, and one day

${ }^{23}$ A recent exception to this rule is Leisha Hailey (Alice) in The L Word. 
hopefully, humanity. Even though I think that's a really tall order at the moment (Hall 2005, p.10).

When Hall asked if her experience on The L Word tempted her to experiment with her sexuality, Ms Beals was clear, "Not at all” (Hall 2005, p.11).

Another way interviews are skewed for the heterosexual audience is by making the assumption the heterosexual actors who play gay characters found same-sex intimacy difficult. For example, while the intimate scenes with her onscreen lover Jay presented no problems, Julienne asserts her own and her fellow actress Jaime Passier Armstrong's (who plays Jay Copeland) heterosexuality saying "I think it's so far away from reality for both of us .... We have a giggle about it and don't take it too seriously" (Barry 2004, p.5). Similarly, actress Rachael Stirling, who played Nan King in Tipping the Velvet, was repeatedly asked by interviewers how she coped with the lesbian sex scenes. Stirling was reported as saying that tabloids reporters were "obsessed" with the lesbian scenes in the drama. "If anything I had underestimated people's homophobia. The tabloids have been like piranhas around a rotting corpse." (It's not just two birds snogging. Telegraph.co.uk, para 3. http://www.telegraph.co.uk/arts/main.jhtml?xml=/arts/2002/10/08/bfstir08.xml. [accessed 19 August 2007]).

Television, communication scholars as Alfred Kielwasser and Michelle Wolf observe, "conspires with other media - and with other social structures such as family, school, and church - in discounting homosexuality" (Kielwasser and Wolf 1992, p.363). Secondary texts, such as magazines, also serve the interests of, and reinforce, heterosexual culture. When actors who play lesbian characters are interviewed they are required to reiterate their heterosexuality by discussing their (male) partner, their wedding plans, or their baby plans. In restoring heterosexuality, these texts juxtapose the real with the fictional. Exactly what effect this reaffirmation of actors' heterosexuality has on the homosexual viewer and the relational processes that can develop between the viewer and the viewed is not known. The comments by homosexual or heterosexual actors made in interviews lead on to other questions: should lesbian actors/entertainers be expected to be political? If so what does this mean in terms of equality of representation? What consequence would neglecting to reassert their heterosexuality have on their careers? When heterosexual actors reinforce their heterosexuality, do their revelations minimise the effects of bigotry and homophobia? These questions are part of a wider discourse regarding the cultural effect of lesbian television representation. 


\section{Conclusion}

The lesbian perspective is an insider's perspective which encompasses the phenomena of patriarchal oppression and considers the multiple worlds in which lesbians exist. The legacy of historical movements where attempts have been made to define the 'lesbian' individual is present in popular media, particularly in film and television representations of lesbian characters. This chapter has discussed the history of the presence and the treatment of the lesbian image within the media, illustrating the way identity politics are involved in television representation. The following chapter explores the effect of television representation of lesbians and lesbianism. 


\section{Chapter 3}

\section{Representations of Lesbianism in Television}

This chapter reviews the sparse literature on the presence of fictional lesbians within television and locates this within the mode of stereotyping to limit lesbian expression. Leading on from this I present the psycho-social theories of homophily, identification, and para-social interaction (PSI) that explain why viewers watch and the attraction that minority characters like lesbians have for underrepresented populations.

\section{Introduction}

Lesbians are currently enjoying a period of acknowledgement in mainstream television. Accompanying this visibility is a small but burgeoning body of research that explores lesbian representation in mainstream media texts. A search of the literature on lesbian representation and lesbian audiences' estimation of that representation yields several trends:

- the media investigated is typically film (Minkoff 2003; Clare Whatling 1997; White 1999; Wilton 1995), or literature and other texts (Castle 1993; Ciasullo 2002), rather than television;

- studies typically group lesbians and gay men together on film (Battles and HiltonMorrow 2002; Benshoff and Griffin 2004; Capsuto 2000; Dyer 1980; Fejes and Petrich 1993; Gross 2001; Howes 1993; Russo 1981; Sanderson 1995; Tropiano 2002; Walters 2001), and also on television (Battles and Hilton-Morrow 2002; Capsuto 2000; Meta Carstarphen and Susan Zavoina 1999; Fejes and Petrich 1993; Gross 2001; Howes 1993; Keller and Stratyner 2006; Tropiano 2002; Walters 2001);

- once arbitrarily grouped as a sexual minority along with gay males, lesbian characters and audiences are now equated with ethnic minorities on the assumption that the oppressions and effects of social opprobrium they experience is the same, or similar enough;

- the majority of the studies are authored by American academics, use American subjects, and examine American-produced programming; and

- the academic attention that examines the opinions of audiences about Sapphic fictions can be divided into three categories of research: histories, content 
analyses, and studies that employ some form of respondent feedback such as a survey or questionnaire.

This research addresses a gap in the international literature. Studies dedicated to how the fictional lesbian appears in contemporary television texts are rare (see Dow 2001; Herman 2003; St Germain 2003). Remaining unaddressed is the influx of lesbian character into prime-time television texts (Kessler 2006, p.131). Rarer still are analyses of lesbians on New Zealand television; a literature search on New Zealand studies of lesbians on New Zealand television yielded no results. ${ }^{24}$

A sample of the literature that does exist on lesbian characters is discussed below. Even these examples, chosen for their relevance to my research, do not address the need for analyses of the prime-time television landscape and lesbian audiences' opinions of it, particularly from a non-American perspective.

\section{Studies of Gay and Lesbian Visibility in the Media}

In this authoritative guide to the history of gay and lesbian visibility in America, Walters' book All the Rage, the Story of Gay Visibility in America (Walters 2001) investigates the myths that surround the new queer aesthetic. Walters' observations provide a history of gay and lesbian visibility in the media, and the social and political progress of sexual minorities in America. She shows that the visibility of sexual minorities usually results in concessions that render them safe. Whether these representations are emptied of political significance, or effectively work to reinscribe heteronormativity, Walters (2001), Castle (1993), and Dow (2001), argue that, for sexual minorities, being seen is not the same as being known.

One study that explored how lesbians in the U.S. use visibility to learn about themselves, and how others perceive them, is Noelle St Germain's study (St Germain 2003) that examines the relationship between television and lesbians' self-esteem and development. St Germain's work revealed how lesbians use the media to gain "a basic understanding of the experiences of an under-represented social minority in the context of a media-focussed culture that provides limited and mostly negative depictions of their experience" (St Germain 2003, p.2). The study's most salient findings were that participants actively sought out media representation that reflected their sexuality, and did so for validation, a sense of connectedness, and to develop a sense of self (ibid., p.168). This need for

${ }^{24}$ Recently, it has come to my attention that New Zealand researcher Anita Brady has submitted her doctoral study that examines representations of queerness in mediated commodity cultures. 
connection is explicable in terms of the relational theories of homophily, identification, and para-social interaction. According to communications theorists Keren Eyal and Alan Rubin, these concepts help to explain how viewers can develop strong emotional attachments to media personae, especially if they perceive the character to be similar to them (Eyal and Rubin 2003, p.80); can relate to characters' experiences or perspectives and vicariously participates in the characters' experiences. According to communications scholar Cynthia Hoffner, this process is known as identification (Hoffner 1996, pp.389390); and through the disclosures the characters make about themselves over time, viewers can develop a pseudo-friendship or a para-social relationship (Rubin et al. 1985, pp.156-157), all of which can reduce feelings of social isolation.

Although St Germain did not specifically utilise these theories, her results support them. Participants invested heavily in the characters, plots, and themes (St Germain 2003, p.177). Even so, they routinely reported the quality of representation to be lacking, because the lesbian characters shown often involved a high quotient of negativity (storylines that revolved around hardship or outcomes that were violent). St Germain's participants expressed their anger at the inadequacy and the many stubborn stereotypes that plague lesbian characters on television but, at the same time, were extremely appreciative of those images that were available as "any representation was preferable to invisibility" (St Germain 2003, p.178). Highlighting a similar willingness to tolerate any visibility as long as it's lesbian visibility, Walters observed lesbians watched the "awful jock-drama" Personal Best, even though the overt narrative was that "lesbian finds true love with a sexist man" (Walters 2001, p.134). Despite her findings, St Germain's study lacked a large subject pool $(n=19)$, and only focussed on self-identified fans of two television programmes, Buffy the Vampire Slayer and Xena: Warrior Princess.

The aim of Herman's (2003) study was to investigate representations of sexuality on Seasons $1-3$ of the successful British series Bad Girls, part of the women-in-prisongenre, which feminist cultural critic Judith Mayne observes is one of the few established genres "where lesbianism is not an afterthought or anomaly" (Mayne 2000, p.118). Herman found Bad Girls to be premised on a homonormative construct (Herman 2003 p.155). Contributing to the homonormativity of the series is that lesbian relationships are represented as an ordinary feature of the characters' social life, and all the heterosexual relationships, except one, are depicted as problematic and unappealing. More subversive is that many heterosexual characters are shown as being more flawed than the homosexual 
characters, with the dominant effect being that heterosexuality is often "depicted as a site for out of control, dangerous, excessive behaviour" (Herman 2003, p.154).

Herman's analysis of online forums and message boards about the Bad Girls series revealed the profound effect the programme had on many lesbian viewers. The consequence of the show for one lesbian viewer is exemplified in the title of Herman's study: "Bad Girls changed my life". The young woman quoted in the title credits the series with allowing her to become "the real me", and for bringing her "new amazing friends", while other viewers praised the show for encouraging in them a sense of community and making them feel safer and less isolated (Herman 2003, p.156). Herman's study focuses on a single source of lesbian visibility, a non-American drama, and also non-American audiences. Importantly, Herman's own, very positive analysis of the series is echoed by lesbian viewers' feedback, and is evidence of the broader significance of the series to lesbian viewers. However, it did not address a number of important issues and questions, such as, whether Bad Girls was the only source of lesbian representation during this time period? Was it the most significant source? Could it be compared to non-prime-time sources? What did lesbian audiences think of these other sources?

A different angle was taken by Dow (2001) who analysed the narrative produced by the American media's discourse about the coming out of American television's first lead lesbian character, Ellen Morgan, and the disclosure of Ellen DeGeneres' own sexuality. After her analyses of both media personas, Dow concludes, "If acceptance is merely a matter of being heard, or being recognised, or having one's own confession acknowledged, so to speak, Ellen is progress" (Dow 2001, p.136). While Dow acknowledges that the DeGeneres/Morgan double-dip provided two pivotal moments in the history of lesbian cultural visibility, she also emphasises that "it is not the sexuality that has been repressed in television, but, rather, the politics of sexuality" (ibid., p.135).

Dow finds further support for the ideological manipulation that occurs in mediated discourses about lesbian sexuality. After identifying the lack of homonormativity in the character and storylines of Ellen Morgan, she challenges the popular interpretation of a character's coming out as an escape from the repressive regime of heterosexuality, and instead argues the "positive visibility given to the lesbian identity of Ellen is not the same as political progress - or even political awareness - and it is a mistake to confuse them" (Dow 2001, p.136). Dow argues that the opportunity to highlight real consequences for lesbians and gays living in a heterosexual culture could have been addressed in Ellen 
Morgan's coming out, but were not. While the character of Ellen Morgan defiantly claimed her homosexuality, the realities and politics of her sexuality were hidden, as all of the usual protocols reserved for dealing with peripheral groups like lesbians were implemented into the plotlines. There was no sexual interaction, and Ellen's sexual identity revelations were treated as a problem. Dow argues that this weakens the subversive potential of her character, while the actual coming out episodes "repeatedly emphasize the personal issues over the political ones, that is, it presents acceptance by family and friends as most crucial" (Dow 2001, p.132). Dow's analysis of the media discourse surrounding the coming out of both actor and character, and the show's handling of Ellen Morgan's new sexual identity, explores how some social authorities (media critics and publications, and television itself) understand and value lesbian representation, but the study did not illuminate how the wider community positioned the representation and surrounding discourse.

Although his study focussed on gay male characters, author Guy Mark Foster's content analysis of the representation of ethnicity and sexuality offered conclusions similar to those of Dow and Walters. Foster analyses the ethnic assimilation of Keith, the gay African American character on HBO's series Six Feet Under, arguing that Keith's ethnic differences are only presented visually, not politically. In doing so, Six Feet Under maintains the focus (almost) squarely on the status quo: white Americans (Foster 2006, p.102).

An earlier study by Kielwasser and Wolf (1992), applied several communications theories to the televised discourses marketed to American adolescents in the early 1990s. This study explored how the theories' components are evidenced in mainstream television programming, arguing that the lack of visibility contributes to feelings of isolation among gay and lesbian youth. In particular, the authors challenge the idea that gay and lesbian youth could break the silence by reading queerly (Kielwasser and Wolf 1992, p.364). While a gay or lesbian teenager "can certainly recast" the boy-meets-girl configuration into a same-sex dyad, this interpretation does not alleviate the perception that they are alone, nor does it validate their sexuality (Kielwasser and Wolf 1992, p.364).

Merri Lisa Johnson, one of the contributors to Reading The L Word: Outing Contemporary Television (2006), the first anthology of work that examines television's first ever lesbi-centric drama, The L Word, criticises the programme and the lesbian characters as "not feminist enough or not radical or not queer enough" (Johnson 2006, 
p.132). Moreover, Johnson finds the programme to be characterized by a limited rather than progressive narrative, because the series delivers "a version of love as limited to heterosexual patriarchal monogamous reproductive models" (ibid., p.116). Johnson argues monogamy is upheld in a number of ways; for example, the "disembodied intercourse" Bette and Candace have in jail "prioritises sexual exclusivity", while the character of Shane pays homage to Bette and Tina's relationship despite her resistance to sexual commitment (ibid., p.124).

Similarly, Chambers assesses the series as largely heteronormative in its construction (Chambers 2006, p.82). Chambers argues the series fails to challenge heteronormativity, and instead provides familiar and 'safe' protocols that heterosexual viewers can relate to, such as the ultra-sound scene with Bette and Tina in Season 1, Episode 4 (Lies, Lies, Lies) or Dana and Tonya's marriage announcement in Season 1, Episode 13 (Limb From Limb) (ibid., p.95). The basis for this criticism, Chambers argues, is that to ignore the hegemony of heteronormativity altogether allows it to go unchallenged, a charge Dow directs at Ellen (Dow 2001, pp.135-136). Citing Dana's coming out plot and how Dana and Lara's first sexual experience together was represented, Chambers points out that opportunities to explore lesbian sexuality in full were not taken (Chambers 2006, pp.96-97).

According to Susan J. Wolfe and Lee Ann Roripaugh, the mainstream appeal of the series has "not surprisingly ... elicited highly ambivalent and hotly debated responses among its lesbian viewers, revealing intense anxieties regarding lesbian identity and representation" (Wolfe and Roripaugh 2006, p.43). After two seasons of the series, responses ranged from complaints about the assimilated appearance and behaviours of the lesbian characters, through to accolades about how the show dispels negative stereotypes (ibid., p.44). Given the relative invisibility of lesbians in mainstream television, Wolfe and Roripaugh find that The $L$ Word "bears inordinate responsibilities and impossible representational burdens" (Wolfe and Roripaugh 2006 p.54). They conclude that the programme's attempts at soothing representational angst among some of its lesbian viewers is both "savvy and subversive" (ibid., p.54).

A content analysis study by Kessler focuses on American-produced programmes with lesbian characters that screened in prime-time slots during the 1990s, and launches a similar attack to that of Chambers. She argues that "programs such as Friends, Mad About You, Roseanne, Spin City, and Will and Grace ... set the bar for gay and lesbian primetime comic representation" (Kessler 2006, p.130), noting the normative conditions 
shackling the characters. She focuses her analysis on the lesbian characters found in Friends and Mad about You, and discusses the appearance of lesbian characters in these programmes as comedic devices. Here, the devices are the 'fault' of the genre: the sitcom, which is predicated on the resolution of a confusing situation (Kessler 2006, p.132) that relies on the social norms the audience holds as truths (ibid., p.133). For example, Friends' lesbians Carole and Susan are secondary characters, linked to the core characters by the marriage and child Carole had with Ross. Carole and Susan's relationship is treated as a source of anxiety for Ross, as much is made of how his ex-wife's sexuality (supposedly) weakens his masculinity (Kessler 2006, p.134). To make the lesbians more palatable for heterosexual viewers, Kessler argues, Carole and Susan appear as hyperfeminine women: both are traditionally feminine-looking, and both are almost totally focussed on being mothers to Ross and Carole's child, Ben (Kessler 2006, p.134). Aside from their sexually sanitised same-sex relationship, Carole and Susan are as heterosexual in looks and behaviour as the core cast; they even marry each other (ibid., p.135). Their assimilated behaviour and aesthetic certainly do not challenge the audience's capacity for acceptance of homonormativity. Similarly, the lesbian sister of the male lead in Mad About You fulfils the heterosexual norm of having a long-term and monogamous relationship (Kessler 2006, p.134). The condition of her visibility is palpable: she must follow heterosexual norms to be accepted (ibid., p.137) by both her audience and her fellow characters. This assimilated lesbian is considered the 'good' lesbian, as she conforms to heterosexist norms rather than challenges them.

Kim et al.'s study found that references to compulsory heterosexuality in the sexual content of sitcom and drama scripts comprised $45 \%$ of all activity measured (Kim et al. 2007, p.150). Sexual activity is used to establish, claim, and maintain male heterosexual characters' masculinity and female characters' femininity (ibid., p.148). The study found nearly half of all sexual content fell into various 'Sex as Masculinity' codes (ibid., 2007, pp.147-148), illustrating television's fixation with male heterosexuality. The sexuality of male characters was "prominent, regardless of age, race, or family role" (ibid., p.151). While compulsory heterosexuality was the primary message for all characters, the specific form was:

accumulating sexual experience with women is an important, desirable, and even necessary component of masculinity, and boys/men should obtain sexual experience by any means possible ... [and] ... attracting 
boys/men's attention is the primary way by which girls/women attain and assert (a form of) power (ibid., p.154).

Sitcoms showed significantly more references to compulsory heterosexuality per hour than dramas (Kim et al. 2007, pp.149-150), largely because male leads are more prevalent in sitcoms, and much comedy derives from them having to claim their heterosexuality (ibid., p.153). Just $1.5 \%$ of sexual content fell into the 'Appropriation of Female Homosexuality' code, where activity depicted male heterosexual characters becoming aroused by faux-lesbian sexual activity (ibid., pp.153-154). No actual lesbian characters were noted.

The coding system Kim et al. (2007) developed is interesting and appears to concur with feminist principles of analysis, but the study falls short on two crucial points. First it fails to take into account the inevitably formalised heterosexual relationships of the characters coded (the marital status, for example). Due to the arrangement of characters solely in formal heterosexual dyads and their progeny, this position is rendered as natural and universal. Second, the system could be improved further by exploring the complementarity between the various 'Sex as Masculinity' codes and the 'Male Oriented Homophobia' and 'Appropriating Female Homosexuality' codes. These scripts could be re-categorised as part of the Sex as Masculinity suite, as they all aid the male characters to assert their heterosexual masculinity. A code, or series of codes, which explores nonheterosexual masculinity and femininity would be a valuable extension of this study.

The action in Friends described by Kessler (2006) appears to conform to Kim et al.'s (2007) model. For example, while at Carole and Susan's apartment Ross looks at a photograph of their friend Tanya and mistakes her for a man, 1980s singer Huey Lewis (Kessler 2006, pp.139-140). Canned laughter is heard. The implication is that the audience is presumed to be a heterosexual audience and, in case the audience is unclear as to how they should react, they are given instructions via the canned laughter. The skit illustrates the duality inherent in the assimilation model: the sexuality of the femme lesbian is acceptable while that of the apparent butch is rejected.

Commensurate with Dow's discussion of the political quietism of Ellen (Dow 2001, p.134), the representation of the lesbian characters in these programmes (The L Word, Friends, Will \& Grace and Mad About You), strips them of their membership to an unprivileged community (lesbians), while modifying their characteristics and storylines to 
resemble the privileged community (heterosexuals). These conditions of isolation and assimilation serve to endear the characters to the mainstream audience, so much so that it suggests they are breaking stereotypes. Commenting on the American television landscape, journalist Benjamin Svetkey writes:

[T]oday, in 2000 A.D. (After DeGeneres) gay characters are so common on television, so un-exotic, that their sexual orientation has become all but invisible to most viewers. It is, in a sense, the ultimate sign of acceptance . .. (Svetkey 2000, p.26).

Echoing the same sentiments, The Dominion Post suggests that:

Not since the bachelor, Batman, and his long-time companion, Robin, conquered the rugged ground of homosexual desire, wearing only $\mathrm{Y}$ fronts, has there been a TV age so notably queer (The Dominion Post, TV Week, 6 January 2004, p.10).

Such conditional visibility is a concern not only because it creates the impression that lesbianism is widely accepted, and that lesbians wholeheartedly subscribe to marriage/monogamy and motherhood; but also because it denies visibility to lesbians who do not assimilate with mainstream (heterosexual) norms.

Contrary to Kessler's (2006, p.138) argument that secondary characters are closest to the audience's ethical sensibilities, Cragin argues that marginalisation of lesbians (and gays) occurs when sexual minority characters appear in secondary roles, because they are unlikely to be able to advance the plot and have limited authenticity (Cragin 2006, p.194). Significant harm and marginalisation also occurs when lesbian sexuality is treated as a problem within a television script (ibid., p.194). The problematising of lesbianism is not reserved for secondary characters; the storylines led by core characters often support patriarchy by treating lesbianism as an issue that heterosexual characters must deal with, or grieve over. Cragin's analysis of Ellen's demise also addresses the situation where the sitcom employs a lesbian secondary character to that of a lesbian lead. Cragin notes that after the coming out episode Ellen faltered, apparently trying to present an exclusively 'good' gay persona (Cragin 2006, p.198). In addition, Ellen Morgan became a lesbian in a sea of heterosexuals, and was therefore left without a mechanism for romantic tension (ibid., p.198). 
Cragin's (2006) primary focus is the difficulty of combining the sitcom genre with sexual politics and a lesbian lead; the rules of the genre, she argues, stops such a situation from occurring. As Conway observes, the action of the sitcom must be resolved by the episode end, and return the characters to the positions they held at the start (Conway 2006, p.81). There is little room for advancing sexual politics in this format (Cragin 2006, p.200). As the genre works at the level of normalized heterosexist binaries and the complementarity of the binaries, sitcom rules render homosexuality as "a burlesque" (Conway 2006, p.79). In addition, Cragin attributes Ellen's lack of homonormative politics to DeGeneres' internalised homophobia. DeGeneres clearly intended to assimilate herself and her onscreen persona to the 'good' gay model, in reaction to the 'bad' gay model. This is, of course, DeGeneres' choice, but as a publicly accessible icon of lesbianism with executive control of a primary source of visibility for all lesbians, it is regrettable that she did not choose to support (or showcase) a more progressive fictional persona. Cragin's examination of Ellen drew on observations of and about the programme, but also on tertiary texts such as interviews with DeGeneres, the show's executives, and from media critics' reviews to supplement her own analysis.

The last international study I will discuss is by Hantzis and Lehr, who examined the first lesbian character to appear regularly on prime-time television in America (Capsuto 2000, p.240), Marilyn McGrath from the British series Heartbeat. While the inclusion of a central lesbian character was supposed to be "positive", Hantzis and Lehr criticized the programme's anti-feminist messages and the many weaknesses in Marilyn. The show affirms the patriarchal reality that confines the expression of women's desire (Hantzis and Lehr 1994, p.108); the heterosexual women are afforded sexual expression (albeit defined and contained by men), but Marilyn's sexual expression is notably absent. Lesbianism "is rendered as a "non-sexuality": heterosexual characters constantly discuss their relationships, while Marilyn neither talks about nor is asked about her relationship with Patti (ibid., p.112). She is present but her sexuality is hidden. Hantzis and Lehr argue that Marilyn's primary role is mothering (ibid., p.116), thus promoting the idea that lesbianism and maternalism are synonymous because of gender. ${ }^{25}$ Marilyn cares for many of the core characters at different and significant times in their lives. While Hantzis and Lehr attribute this to the maternal lesbian stereotype, and explore the idea that this 'carer' role reflects lesbians "who feel vulnerable to charges of sexual seduction" (ibid., pp.116-117), there is another possibility here. A rule of the serialised drama is that single heterosexual

${ }^{25}$ Ironically, this strategy positions a lesbian as one half of the Madonna-Whore dichotomy that Frye (1983, p.1), argues is reserved for heterosexual women. 
characters must typically form a couple. This is manufactured through an event characters endure together, or through the intervention of another character. That other character can easily be the lesbian: she is not competition for the female character to endure, she is not available to the male character to pursue, and typically has her own relationship status explained away by a vague partner who is extraneous to the action. Thus, the lesbian brokers heterosexism.

Searching the New Zealand literature for studies relevant to this thesis yielded one result by market research company Labett Research and Marketing (2006), headed by Tess Labett. The research was commissioned by New Zealand On Air to "Help NZ On Air to identify the most appropriate means to cater for the viewing interests of the gay and lesbian community" (Labett 2006, p.2). Similar to St Germain's (2003) research, Labett's study reported gays and lesbians' primary motivations for seeking gay content on television to be acceptance and validation, normalisation and visibility, not just entertainment (Labett 2006, p.iv). While Labett's research provides one of the few insights into the satisfaction levels of the New Zealand non-heterosexual television audience, all of the six qualitative focus groups were restricted to the New Zealand's North Island, and only four South Island participants were interviewed by telephone. A greater criticism is that Labett's work is ostensibly market research, and not published in a peer-reviewed publication. However, due to the paucity of New Zealand research examining the opinions of sexual minorities about how they are shown on television, it is relevant to this study.

An earlier study by Christine Atmore explored lesbian representation in New Zealand print media. In her 1992 thesis Atmore discusses the media accounts of an assault on a New Zealand playwright and lecturer, Mervyn Thompson. The reporting of the event positioned lesbians (considered to be the perpetrators of the attack) as fascist, as exotic 'others', or as man-haters (Atmore 1992, p.209). Atmore connects this positioning with heterosexism.

\section{Lesbian Representation and Self-Validation}

Researchers and advocacy groups have commented upon the unique relationship lesbians and gay men have with media content (see Gross 2001; Kielwasser and Wolf 1992; St Germain 2003). Underlying the interest in the way media represent sexual minorities is the belief that visibility affords those minorities a sense of positive self-worth. As theorist film critic Richard Dyer explains: 
Because, as gays, we grew up isolated not only from our heterosexual peers but also from each other, we turned to the mass media for information and ideas about ourselves (Dyer 1980, p.1).

Connections have been established between healthy human development and the need to see oneself represented in the larger culture (St Germain 2003, p.168; Kielwasser and Wolf 1992, p.353). As Capsuto notes:

Most people do not notice this need in themselves: If they belong to a majority race, majority religion, majority sexual orientation, and are not physically disabled, they have seen people much like themselves on screen as far back as they can remember. For other people, though, any sort of media visibility, however fleeting, can have a visceral importance (Capsuto 2000, p.413).

Because lesbians (and gay men) tend to be socially and culturally isolated (Dyer 1980, p.1), they are particularly susceptible to the power of the mass media (Gross 1991, p.26), largely because they take their "cues about their sexual identities and the prevailing social attitudes about [lesbian] sexuality based on what they see in the media" (St Germain 2003, p.4). The notion of the media 'mirroring' oneself is vital to developing a healthy lesbian identity because there are so few mirrors available to sexual minorities, and especially because lesbians do not see themselves shown within their familial structures. Even if a lesbian does have another lesbian in the family, this fact is often kept secret, especially from younger children (Gair 1985, cited in St Germain 2003, p.27). Consequently, lesbians are frequently isolated from society and from each other. Television and film may be the primary, or indeed the only, source where many lesbians can see their lives reflected without risk of personal exposure. The profound effect any exposure can have on a hidden population like lesbians is highlighted in Glamuzina and Laurie's (1995) research into the trial of Christchurch schoolgirls Pauline Parker and Juliet Hulme. While the trial took place six years before television transmission had begun in New Zealand, Glamuzina and Laurie record the significant effect the intense coverage of the case, in both newspaper and radio, had on many lesbians in this country (Glamuzina and Laurie 1995, pp.165-181). Responses recorded by Glamuzina and Laurie ranged from traumatisation to excited identification. When discussing the merits of the sitcom Ellen, Dow writes that "The fiction of personal authenticity and control provides psychological comfort in a deeply homophobic culture" 
(Dow 2001, p.135). However, when lesbians look to be represented on television, their reflection in the cathode ray, they most often see lesbian realities overcoded by overwhelming patterns of heterosexuality.

St Germain's (2003) study of fans of the television cult hits Xena: Warrior Princess and Buffy The Vampire Slayer, revealed that lesbian participants sought lesbian characters to "normalize and affirm" their sexuality, and to reduce their "fear, anxiety, confusion and isolation" (ibid., p.iv). When asked to identify the emotions they experienced when searching for lesbian images in the media, participants reported feelings of "fear/anxiety, confusion/self-questioning, isolation/loneliness, sadness/depression, guilt/self-loathing, excitement and curiosity ... [and] relief" (St Germain 2003, pp.169-170). The ages of the participants in St Germain's study ranged from the 13 to 50 years of age with the largest number in the 19-24 year group ( $\mathrm{n}=9$ ). While the American cult teen hit Buffy the Vampire Slayer has a significant following amongst lesbians and feminists, the series still conveys heteronormative values (Herman 2003, p.144). For example, lesbian sex acts are veiled in the metaphor of magic. By avoiding explicit depictions of the characters' physical intimacy, the mystery surrounding lesbian sexuality is upheld. It is clear lesbian audience members have to struggle through their own internalised shame when they seek out their reflections in the media. Similar to St Germain's study, New Zealand lesbian and gay participants of Labett's research reported their primary motivations for seeking gay content on television were acceptance and validation, normalisation and visibility, rather than entertainment (Labett 2006, p.iv). While many participants of St Germain's (2003) and Labett's (2006) studies expressed anger at the way sexual minorities were represented, they were extremely appreciative of that representation.

Given the authority of the media to transmit cultural norms (Conway 2006, p.76; Gerbner et al. 1986, p.18; Holtzman 2000, pp.300-301), and the efficacy of stereotypes in shaping the cultural consciousness (Gross 1991), the role the media have in the formation of gay identity (St Germain 2003, pp.168-169), is significant. As Sherrie Inness writes:

Due to the low visibility of lesbians for much of this century, even up to the present, they are particularly susceptible to being 'created' by popular representation. These representations help cultivate the 'reality' of lesbianism for many people, especially for individuals with minimal or no direct contact with lesbians (Inness 1997, cited in St Germain 2003, p.26). 


\section{Significances and Pleasures of Identification}

Just as they develop negative and positive feelings about real people, television viewers develop similar impressions of television characters, often becoming intensely involved and invested in media personae as if they were real (Hoffner and Cantor 1991, p.90). To understand the attraction viewers can develop for fictional characters, we must examine three significant relational processes that occur in mass mediated relationships.

The first in this process is homophily. Homophily is the degree of similarity between an audience and the television characters they watch. The similarity can be subjective (the audience identifies with the character's personality, values, or actions) or objective (the audience and the character have the same occupation) (Eyal and Rubin 2003, p.80). Homophily is like a magnet: attractive characters capture audiences' attention. Mulvey (1975) discusses the homophily-like meta-quality of the media as a system in which audiences are encouraged to take pleasure from watching.

The second process, referred to as identification, describes the relationship that occurs when a viewer shares the same or similar perspective with a fictional character, and vicariously participates in the characters' experiences when viewing (Hoffner 1996, pp.389-390). Identification relies on actors and directors to "entice" viewers to identify with characters. According to communications theorist Jonathan Cohen, identification is "partly achieved by offering an illusion of reality, a semblance of how people behave and react in real life, and a consistency of character that resonates with audience members" (Cohen 2006, p.185). As fellow communications scholar David Morley comments, "[o]ne can hardly imagine any television text having any effect whatever without that identification" (Morley 1992, p.209). Identification helps secure a loyal audience.

Para-social interaction (PSI), the last of the relational theories, was developed by communication theorists Donald Horton and R. Richard Wohl (1956). Fellow communications scholars Rebecca Rubin and Michael McHugh advise PSI focuses most on the social aspect of learning from television representation, as it is thought that favourable para-social relationships (PSR) develop into and refer to "one-sided interpersonal relationships that television viewers establish with media characters" (Rubin and McHugh 1987, p.280). In this way, fellow communications theorists Alan Rubin, Elizabeth M. Perse and Robert A. Powell, find PSI is experienced as "seeking guidance from a media persona, seeing media personalities as friends, [and] imagining being part of a favourite programme's social world" (Rubin, Perse and Powell 1985, pp.156-157). Para- 
social relationships (PSR) are similar to an individual's interpersonal relationships in that they are formed on the basis of attraction (through homophily and identification), and maintained (through PSI) over time (Cohen 1997, p.518). The strength of these one-sided relationships varies from individual to individual, and also between individuals and television characters, as viewers must develop homophily or identify with a character before a para-social relationship can develop. The benefits of para-social relationships are exclusively social. Research has found para-social relationships are related to a need for a friendship and intimacy, although it does not necessarily alleviate feelings of loneliness in viewers (Cohen 1997, p.519). ${ }^{26}$ Most importantly for television producers, though, is that these psycho-social relationships account for increased viewing (ibid., p.518). Increased viewing is associated with perceived disclosure by the character, which leads to a greater feeling of intimacy and reliance on that character (Horton and Wohl 1956). The more the character divulges, the more the audience likes or identifies with them.

The explanations offered by homophily, identification, and para-social interaction shed some light on how mass-mediated relationships can help alleviate feelings of social isolation among minority groups, such as lesbians and gays. Often preferring the "stifling agony" of the closet rather than risking social and familial rejection (Gross 2001, p.219), the profound significance fictional characters can have for sexual minorities is demonstrated by this New Zealand viewer who, after watching the coming out storyline of Coronation Street's character Todd Grimshaw, wrote:

I have followed the story closely because Todd's experience is the same as mine ... I was married with children when I realised I was gay. Like Todd, I was burying my feelings ...Even though there was no-body else I couldn't cope with living the way I was. I cried through every episode of Coro Street. I have now found the courage to end my marriage and have come out to my family ... So to the anti-gay storyline viewers, I could have easily become another suicide statistic, so Coro Street literally saved my life (Linda, Tauranga, The TV Guide, 12-18 February 2005, p.116).

Homophily and identification, the connection felt from identifying with a character, cross the gender divide. That this correspondent benefited so profoundly from the coming out story of a gay man is evidence of how intense para-social relationships can be. While it is

\footnotetext{
${ }^{26}$ It could be argued that the opportunity to develop para-social relationships with lesbian characters could assist lesbians to come out. This is an area worthy of future study.
} 
a safe assumption that lesbians watch and derive some pleasure from heterosexual narratives, to share in that pleasure lesbians are required to put on another hat/code/identity, such as 'woman' or, 'human being', forcing them to neglect their primary hat of 'lesbian'. The opportunity for lesbians to identify or develop para-social relationships with lesbian characters is extremely limited, firstly because there are so few characters available, and secondly because the ways in which they are shown, are so circumscribed by the heterosexual patterns television typically transmits. It is a reasonable assumption that the more homonormative the depiction, the more likely lesbian audience members will develop PSR with lesbian characters. But to what extent does this process require that such representations are characterized by a high degree of cultural specificity?

According to anthropologist Clifford Geertz, cultural specificity relies on the assumption that there are both significant and insignificant differences between cultural groups that affect the way those within a culture and those external to it make meaning (Geertz 1983, p.57). According to this theory, cultural specificity would naturally affect the homophily an audience can develop with a television character; for a television character to hold the greatest cultural resonance with this country's lesbian audience, specific cultural signifiers must be present. This implies that international programmes cannot engage New Zealand lesbian viewers, and that lesbians are an homogeneous group bound by geographic and associated socio-cultural boundaries. There will always be myriad differences within lesbian populations (Baird 2005, p.78).

The heterogeneity of various lesbian communities within them (sporty, lipstick, aged, activist) necessarily means there can be no unifying lesbian narrative, at least in cultural terms. What is most likely to resonate with lesbian audiences is not the accent of the actors or some other cultural signifier, but the recognisable element that the characters are lesbian. Lesbian philosopher Ann Ferguson identifies features of lesbian networking practise, such as bars and magazines, that provide opportunities for "any women regardless of class, racial or ethnic background to find a common identification as lesbian" (Ferguson 1990, p.80). Although Ferguson is referring to women typically operating within their own geographical communities, it is likely the same unifying experience could be achieved were the medium for shared common experience a televised one in the shape of a sitcom or drama.

As Ruth Simkin (cited in Penelope and Wolf 1993, p.6) and Dobkin (1990 p.4) argue, there are specific experiences all lesbians share regardless of their country of origin or 
their specific subtypes. None of the intimacy with, or attachment to, television characters is exclusively dependent on, or restricted by, boundaries of cultural specificity. It is therefore not necessary to have locally produced lesbian representation screened solely to local audiences; lesbian audiences can read against the cultural grain and enjoy product from any country. The relational processes of homophily, identification, and para-social interaction enable very intimate and intense relationships to occur despite the lack of cultural identifiers.

\section{The Politics of Stereotypes}

One of the chief vehicles for presenting televised lesbian characters to the world is through the use of stereotypes. Stereotypes easily communicate identifiable and familiar ideas, scenarios, and scripts to the viewer because the viewer knows what to expect. According to cultural theorists Jack Nachbar and Kevin Lause, stereotypes express a general agreement about the characteristics of a social group made by the dominant group (Nachbar and Lause 1992, p.240). In this way, stereotypes are part of the cultural fabric of a society; the ideas and rules a stereotype expresses are known to each member regardless of their social status. As journalist and political commentator Walter Lippmann emphasises, stereotypes impart socially sanctioned 'knowledge' about groups, even if no member of a society has had contact with the group targeted by the stereotype (Lippmann 1961, p.25). Media ethics specialist Deni Elliott argues our knowledge of certain groups originates from stereotypes (Elliott 2003, p.12; see also Dyer 1993, p.14).

Countertypes are positive stereotypes. Nachbar and Lause (1992, p.239) argue that they are no more acceptable than the negative stereotypes they seek to change because, when scrutinised, the old stereotype can be seen underneath. For example, the independent, career-focussed woman is often really searching for marriage, as manifest by characters Ally McBeal (Ally McBeal) and Carrie Bradshaw (Sex in the City). Countertypes can be given strength when coupled with a homonormative view which, as Herman reminds us, represents lesbianism as "normal, natural, good, and unremarkable in and of itself" (Herman 2003, p.144). However, because television is implicated in the "political project" of sustaining heteronormativity by disseminating the norm that all people "ought to be heterosexual" (Herman 2003, p.144), countertypes of alternate sexualities are important. ${ }^{27}$ Gross sums up the situation:

\footnotetext{
${ }^{27}$ This suggests that heterosexuality may be less of an innate response and more a derivation of social conditioning, returning to Freud's assertion.
} 
The stereotypic depiction of lesbians and gays as abnormal, and the suppression of positive or even 'unexceptional' portrayals serve to maintain and police the boundaries of moral order. It encourages the majority to stay on their gender-defined reservation, and tries to keep the minority quietly hidden out of sight. For the visible presence of healthy, unapologetic lesbians and gay men does pose a serious threat: it undermines the unquestioned normalcy of the status quo, and it opens up the possibility of making choices that people might never have otherwise considered could be made (Gross 2001, p.16).

The predominately male ownership of the media, specifically television, allows white, upper-class men to reinforce the views that suit their interests (Elliott 2003, p.12; Gross 2001, p.11; Morgan and Shanahan 1997, p.9). The ways in which television depictions of women are constructed and valued also reflect the biases of the predominately male media owners (Dickey 1987b, p.76; Frye 1983, p.13). Consequently, television perpetuates cultural myths and stereotypes about gender roles and the value of men and women (Capsuto 2000, p.1; van Zoonen 2004, p.17). If the perennial aim of heterosexuality is to limit gender and sexuality to narrow roles, stereotypes are the perfect vehicle, and dualism an effective mechanism. Stereotypes typically highlight the biological basis for differences between women and men, yet the difference is "negligible compared to their similarities" (Dyer 1993, p.16). As queer theorist Eve Kosofsky Sedgwick emphasises, the homo/heterosexual binary marks not only sexuality but other significant categories including masculine/feminine and majority/minority (Sedgwick 1990, p.11). Likewise, the categories of homosexual and heterosexual are stereotyped as opposites, even when the responses and behaviour of people of both categories are very similar. The most important function of dualism and stereotypes is to maintain sharp boundary definitions, "to define clearly where the pale ends and thus who is clearly within and who is clearly beyond it" (Dyer 1993, p.16). Stereotypes do more than impose boundaries of what is acceptable and legitimate behaviour, however; "they also insist on the boundaries exactly at those points where in reality there are none" (ibid., p.16).

Frye contends that sex stereotypes are created by men for men (Frye 1983, p.13). Examining this argument further, Dickey finds "the relationship of male image-makers to the female body has a long and inglorious tradition" creating stereotypes for women's bodies and women's behaviour (Dickey 1987b, p.74). Kim et al. argue that images of women are consistently funnelled into archetypes that are aligned with heterosexual men's 
requirements: wife, lover, mother, daughter, sister, and that all are defined in relation to the male (Kim et al. 2007, p.151). Māori lesbian researcher Michelle Erai points out these definitions are affected by other social influences: "tribal mores, Christianity, law, immigration, technology, and misogyny" (Erai 2004, p.40). Women who transgress these definitions are likely to attract negative reactions from men (and women), particularly if the transgression is perceived as severe (Butler 1990, p.140). Television is very quick to illustrate the consequences of transgression with frightening monotony (see Kim et al. 2007). The Women's Monitoring Network argue the pervading message transmitted to audience members is "that [women] do not, must not, exist in ways which do not fit these stereotypes, for that is beyond male fantasy, beyond male control and therefore threatening" (Women's Monitoring Network 1987, p.70).

Stereotyped depictions of women not only must present women and women's experience, they shape the audience's expectations regarding women and, by doing so, deny alternative expectations. The Women's Monitoring Network regards one of the most destructive distortions delivered by the male-controlled media is with regards to women's sexuality (Women's Monitoring Network 1987, p.70), because stereotyped patterns in televised texts restrict how women's desire is defined and expressed (Chambers 2006, pp.96-97; Hantzis and Lehr 1994, p.108; Morgan and Shanahan 1997, p.9). Television endlessly recycles storylines depicting women loving and desiring men (Abbott and Love 1972, p.37; Johnson 2006, p.116; Kim et al. 2007, p.150), and because television producers and script writers are "unwilling to threaten heterosexuality and the heterosexist male role of definer and centre of female relationships" (Hantzis and Lehr 1994, p.119), andro-centric scripts have become the status quo. Even when lesbian characters are added to a cast, the script often allows male characters to possess them and rehabilitate their sexuality to a heteronormative one.

While extreme stereotypes of super-feminine and submissive women now seem anachronistic to most viewers, stereotypical depictions of lesbians still flourish. It can be argued that when lesbian sexuality is shown, stereotypes work to deride lesbians and to deny that lesbian sexuality constitutes a viable and valid choice. Similar to Gitlin's (1980) fun-house mirror analogy, the stereotypical images of lesbians appear to magnify some parts of lesbianism while ignoring others. Generally, the part that is amplified is her sex life, her mental stability, or her style of dress. Several theorists argue the stereotypes most often used to discredit lesbian characters operate as a plot device, such as: lesbians are sexually unstable (Gross 2001, p.74; Walters 2001, p.162; Wilton 1995, p.97); lesbians 
are really heterosexual (Nestle 1992, pp.143-144; Ussher 1997, p.58); lesbians are murderous killers (Rich 1995, p.i); lesbians are ugly and dress badly (Walters 2001, p.161); or lesbians-are-just-like-everyone-else (rendering them depoliticised through assimilation) (Cragin 2006, p.196; Dow 2001, pp.135-136).

Lorde (1984), Butler (1990), Te Awekotuku (1991a, 1991b), Minh-Ha (1991), and Valdivia (1995) all argue identities are complex constructions, comprised of different codes. While some codes are immutable, others can be taught, adopted, exploited; all are ascribed a value. The primacy of each code changes in relation to the situation encountered (Lorde 1984; Minh-Ha 1991). As feminist theorist Jacquelyn Zita notes (1990, p.239), one motivation for this fluidity is self-preservation, and, as I argue, is related to patriarchal hegemony. Discussing lesbian and gay stereotypes, Dyer counsels:

what we should be attacking in stereotypes is the attempt of heterosexual society to define us for ourselves, in terms that fall inevitably short of the 'ideal' of heterosexual society (that is, taken to be the norm of being human) and to pass this definition off as necessary and natural (Dyer 1999, p.300).

Similarly, media scholars Paul Lester and Susan Ross insist "to stereotype is both in a real and in a metaphorical sense, to lose sight of the individual" (Lester and Ross 2003, p.2).

While stereotypes appear immutable, some forms of active audience theory (see Chapter 6 , p.131) suggest the meanings of stereotypes, like any text, are negotiable, with nondominant readings potentially available, depending on who is watching. For example, media researcher and author Sue Abel writes that stereotypes are used ironically, and that audiences are literate in decoding manipulative images (Abel 2004, p.123). Abel argues that commensurate with Foucauldian notions of power and its fluidity, stereotyping is a two-way street (ibid., p.123). A significant body of research confirms, however, that we are all influenced by the images and words we consume (Bourdieu 1998; Claudia Bell 1996; Elliott 2003; Gerbner et al. 1986; Gross 1991; Holtzman 2000; Kielwasser and Wolf 1992; see also Lippmann 1961, p.25; and communications theorist Barry Sapolsky 2003, p.296) despite our awareness of the fictitious nature of the media. As Gross asserts, "even the most sophisticated of us" can attribute areas of our 'knowledge' of reality to what we have learnt from fictional television characters and how those representations 
have influenced our attitudes and opinions (Gross 1991, p.22). ${ }^{28}$ Our learning happens because of our innate ability to experience events and social situations vicariously. However, our knowledge, the product of that learning process, is open to criticism because its source (most often) produces misrepresentation and bias (Elliott 2003, p.12). What viewers often learn from television is how to be white heterosexuals to the exclusion or detriment of all other identities. Fictional programming, more than news or public affairs, reinforces these values, patterns, and norms (see Gerbner et al. 1979, 1986).

\section{Conclusion}

This chapter has reviewed the national and international literature related to fictional lesbian representation in television and outlined the theories explaining audiences' parasocial relationship with media personae. The stereotypes television uses to promote the project of heterosexuality go to the heart of the representation available affecting, in particular, viewers' ability to forge para-social relationships with lesbian characters.

\footnotetext{
${ }^{28}$ For example, participants in a poll conducted by Mintel, Britain's largest market research group that assessed attitudes toward gay lifestyles, reported that the media was "an important source of information about minorities" (Gauntlett 2002, p.13).
} 


\section{Chapter 4}

\section{Methodology}

In feminist research, the methods of gathering and analysing data are aligned with, but separate to, the methodology of the study. The methodology relates to the underlying assumptions of the methods used, and relays the researcher's political standpoint. The methods I use in this study to gather and analyse data relate to my political position as a lesbian, and as a feminist. In this chapter I present descriptions of the methodology and methods this study utilises, beginning with a discussion of feminist research principles, and ending with the study's multi-method approach.

\section{Introduction}

The political basis of feminist research has shifted from research exclusively on and with women to research that creates useful knowledge about women for the purpose of social change, note feminist researchers Liz Kelly, Sheila Burton and Linda Regan (Kelly, Burton and Regan 1994, p.28). While there are many feminist research methodologies, among them feminist empiricism, common components of feminist research focus on:

- the social construction of gender; finding truths relating to women's experience and their social realities;

- work to create and reclaim spaces for women's voices and truths;

- aiming to be consciousness-raising for the participants, the researcher, and the subsequent users of the knowledge the research generates;

- empowering women, particularly by capacity-building;

- acknowledging the opportunity research has for a reciprocal or co-constructive educative experience between the researcher and her participants; not purposely orchestrating or exploiting a power imbalance between researcher and her participants;

- the search for meaning is a more important goal than control of the study, acknowledging that any knowledge generated from research is impartial; and

- conducting research with difficult to reach populations (see work by feminist researchers Lather 1991, pp.70-76; Mary Maynard and June Purvis 1994, pp.3-4; Ann Oakley 2000; Ramazanoglu and Holland 2002, p.87; and Shulamit Reinharz 1992, p.2). 
Drawing on Māori and indigenous education specialist Linda Tuhiwai Smith's (1999) argument that research on indigenous peoples should be conducted by indigenous peoples, I too consider research on sexual minorities should be undertaken by members of those communities. The insider, or indigenous, perspective is crucial in developing the methodologies, conducting the research, and in distributing the analysis to the wider community; all elements that Tuhiwai Smith (1999 p.178) values. Similarly, reviewing leading feminist scholars' definitions of feminist research and feminist research methods, including the contentious issue of whether men can do feminist research, Reinharz (1992) concludes the sole prerequisite for feminist research is that it be conducted by a woman who calls herself a feminist (1992, p.4).

The connection between patriarchy and representation is intimate and omnipresent, argues feminist film theorist Teresa de Lauretis. The feminist critique of representation:

has conclusively demonstrated how any image in our culture - let alone any image of woman - is placed within, and read from, the encompassing context of patriarchal ideologies, whose values and effects are social and subjective, aesthetic and affective, and obviously permeate the entire social fabric and hence all social subjects, women as well as men (1984, pp.38-39).

The feminist perspective, therefore, affords the appropriate viewpoint from which to analyse representations of lesbians in the television landscape of New Zealand.

\section{Research on Television - Effects}

Germane to this study is the body of research about the effects that television has on its audience. In particular I draw on the work of communication scholars Gross and Gerbner. The overlapping themes in the corpus of their work on cultivation theory and symbolic annihilation offer valuable insights into the way television contributes to, and cultivates, the misrepresentation of lesbians. This culture of misrepresentation comes to constitute, effectively, a form of symbolic violence. Media hegemony associated with cultivation and symbolic annihilation theories can be understood in broad terms as the thesis that those in power use the media to represent their interests, and to undermine the interests of marginalised groups (McQuail 1994, p.256). These are macro-level theories that discuss the effects of mass media on a societal scale. The micro-level media effects theories illustrate the direct, individual, relationship an audience member develops with media 
personae. The micro-level theories I draw on, regarding homophily, identification, and para-social interaction (PSI), explain the psycho-social relationships audience members can form with television characters. I also argue the macro- and micro-level theories support each other thematically.

\section{Techniques for Analysing Lesbian Representation on Television}

In order to analyse and assess television's lesbian fictions, I have chosen a multi-faceted approach to this subject. The utility of using multiple research methods is not to produce a "single, unitary picture of truth", but to highlight any similarities, or patterns, in the data gathered with the effect of "maximising input to the research" (Maynard and Purvis 1994, pp.3-4). Methods should be selected that are appropriate to the research questions (Maynard and Purvis 1994, p.3). I use these methods:

- landscape analysis;

- content analysis;

- focus groups; and a

- questionnaire survey (combining both qualitative and quantitative items).

These methods afford the quantification and qualitative understanding of the fictional lesbian representation available to audiences, as well as the capacity to engage with television viewers in terms of their responses to such representation.

An examination of the televisual landscape was afforded by an analysis of the programmes in the prime-time slot (between 6.00 p.m. and 10:30 p.m. daily) of each day in a seven-day period (Monday 28 November 2005 to Sunday 4 December 2005). In this analysis I focussed on the four free-to-air channels (TV One, 2, 3 and Prime) that receive the largest audience share (TVNZ Annual Report 2007, p.8), and simultaneously recorded the programmes aired on each channel during prime-time. The week was selected at random. The resulting 126 hours of television captured 162 programmes that were then coded for channel, time slot, day of the week, and programme type: fiction (by the genres of sitcom, soap, and movie) or non-fiction (by the genres of news, documentary, game show, and reality). To support this sample, I used the programme listing found in The TV Guide, of the four channels, in four randomly selected weeks across 2005. The proportion in this sample indicated the week's programming analysed had a similar level of fictional programming as any other week of the year. 
The focus of the analysis is confined to the fictional programming within this sample, in order to better gauge the ways lesbianism was constructed within this country's television landscape; representation of lesbians and gays in non-fiction programming such as reality shows, is outside the scope of this thesis.

New Zealand's television landscape remains distinctive: there are close resemblances between the televised cultures of New Zealand, America, and Britain but, as New Zealand media critic and author Laurence Simmons insists, "the process of indigenisation made New Zealand television subtly and distinctly different" (Simmons 2004, p.70). New Zealanders are particularly aware of their cultural difference from the rest of the world; the flood of Anglo-American content has meant that local productions have always competed on an "uneven playing field" (Horrocks 2004b, p.273). Government grants are made to local producers to make programmes about New Zealanders or New Zealand to ensure cultural representation on New Zealand television screens; even if some of those programmes are copies of successful overseas models, they still feature our faces and our accents.

Because of its unique construction, it follows that the content of programmes on the New Zealand television landscape is also unique. Not only does the content depend upon network buying patterns, but the possible number of lesbian characters screened on New Zealand television is constrained because of the programming time available. Consequently, the landscape sports only a few programmes where lesbian characters frequently feature, as this thesis will show. This number is likely higher in countries with more television channels and larger television production industries. Susan Briggs notes that while American cable television offers more choice to subscribers, it also offers more socially-risqué and sexually explicit programming than network television (Briggs, 1998, p.120). New Zealand's free-to-air channels screen a mix of American cable and network programmes.

To measure lesbian representation in New Zealand prime-time fictional programming, I coded the content of the programmes using the criteria presented below. The method was based on an understanding of the principles of objectivity and manifest content (as evinced in Holtzman 2000, p.45; and Kim et al., 2007, p.147). The system of enumeration was the presence of a depiction, and the quantification of those instances. Specifically, I counted instances where non-heterosexual characters were represented. The classification 
of non-heterosexual characters included lesbian, gay male, bisexual female and male, and other sexual minority characters such as transgender people.

\section{Coding Non-Heterosexual Representations}

Author Emily Hamer's Occam's Razor view of lesbian sexuality is that "If a relationship looks like that of lovers, it is usually that of lovers. Lesbians are women who love women and this love of women is visible in how they have chosen to live their lives" (Hamer 1996, p.3). With a little modification, this paradigm applies to the coding system with which I identified the non-heterosexual characters on New Zealand television. Depictions were coded as a content unit of non-heterosexual representation if the character or narrative displayed one or more of the following criteria:

- character(s) described themselves as non-heterosexual or agreed to a label denoting their non-heterosexuality;

- character(s) has had or has a romantic attraction to, or relationship with, another non-heterosexual character;

- character(s) expresses a desire to have a romantic relationship with a nonheterosexual character or real person, regardless of that attraction being acted on;

- character(s) only presented with exclusively non-heterosexual signifiers and no dialogue of their own to suggest their heterosexuality;

- the narrative conveys to the audience by some other means the character is nonheterosexual.

In addition, I recorded references to non-heterosexuality where the:

- character(s) spoke about a non-heterosexual individual, group or community, or an act associated with non-heterosexuality;

- character(s) referred to another character or characters as a non-heterosexual or used a non-heterosexual label to describe them or their behaviour.

The characters could be core or supporting cast.

My original intention was to exclude characters who were infants or children, even if they were among the core cast, on the grounds that sexuality was unlikely to be marked or emphasised in characters so young. However, once I found heterosexuality was in fact marked in children (the youngest heterosexual pairings were between seven year old Kady 
and Franklin in My Wife and Kids, and Lisa Simpson and Milhouse in The Simpsons), as well as in non-human characters such as the goldfish and Rodger the dog in the cartoon series U.S. Dad, I modified this. Infants were omitted, but children were included in the count. $^{29}$

While the methodology of the content analysis required I count a content unit by the presence of non-heterosexual characters, it is useful to have an estimation of the heterosexual characters within the sampled programming. Reflecting the societal presumption of heterosexuality (Warner 1993, p.xxi), when a character was depicted who lacked non-heterosexual signifiers the character was recorded as heterosexual. However, to avoid artificially elevating the number of heterosexual characters in programmes with large casts such as The Simpsons, only the regular characters were counted. Similarly, for movies, which invariably include a high number of supporting actors, only the first 15 characters listed by the Internet Movie Database (www.imdb.com) were counted

\section{Content Analysis}

Narrative is quintessential to all human culture, and all narrative follows certain schemas, the components of which can be distilled, identified, and analysed (Fiske 1987, p.130). The message of a television narrative, whether fiction or non-fiction, can also be discovered or confirmed by breaking down its components (ibid., p.133). To analyse the components of lesbian-themed narratives within the New Zealand television landscape, I conducted a content analysis of two contemporary fiction series that contained recurring lesbian characters. One was a domestically-produced soap screening during prime-time, ensuring the widest television audience (Horrocks 2004a, p.22), the other was an American drama, screening for the first time in New Zealand but outside of prime-time. The New Zealand-made soap featuring lesbian characters as core cast members was an obvious candidate for inclusion in my research. Shortland Street enjoys a significant advertising profile, with advertisements running in magazines and on buses. It screens each week night on channel 2 at 7:00 p.m. for thirty minutes. I began my analysis of Shortland Street when the lesbian characters Maia and Jay were first introduced on 25 June 2004. Due to the characters' longevity and their involvement in major plot arcs, I extended my analysis originally planned for six months, to two and a quarter years, finishing on 31 August, 2006. Season One of The L Word, the first-ever lesbi-centric drama made for television, commenced screening in New Zealand on 5 September 2005

\footnotetext{
${ }^{29}$ An exception is the baby Stewie, a character on the animated series Family Guy, who is shown to be aroused by, and trying to date, his babysitter.
} 
after the New Zealand focus groups were conducted. It comprised 14 one-hour episodes. Initially The L Word screened on Mondays at 11.25 p.m. on 2 (The New Zealand Listener, 3-9 September 2005, 200(3408), p.78), outside the prime-time period I wanted to focus on. The series screened a year later on privately-owned channel Prime in a prime-time slot of 9.30 p.m. on Tuesdays (The New Zealand Listener, 28 October-3 November 2006, 206(3468), p.82). While it received no advertising on state-owned channel 2, Prime adopted a titillatory advertising strategy which is discussed in Chapter 9 (p.255). Prime's subsequent screening of the first series of The L Word also occurred after my focus groups had been conducted. I felt The L Word warranted analysis not just because it was the most significant source of lesbian characters on the New Zealand television landscape, but because it would provide a comparison with the way lesbian characters were treated on Shortland Street, an essentially heterosexual drama. Thus both Shortland Street and The L Word were selected for content analysis.

\section{Secondary Sources}

New Zealand viewers, like other audiences, often like to comment in secondary texts such as magazines or online forums about the quality, or lack of quality, in the content they consume. Just as Atmore (1992) used secondary texts to assist her analysis of lesbian representation in print media, I have drawn on correspondence and comment from popular New Zealand magazines such as The New Zealand Listener and The TV Guide, and the dedicated fan site for Shortland Street (www.streettalk.co.nz). Where applicable, I have included them in my stand alone analyses of Shortland Street and The L Word. To keep the integrity of the quotes and not to impose any unintended meaning, I have cited contributors' online remarks verbatim; grammatical errors and spelling mistakes remain uncorrected.

I used the same criteria established in the landscape analysis above to code and analyse the lesbian representation in these two series. In addition, I adapted the thematic model used by Fiske (1987, p.132; based on that of semiotician author Roland Barthes 1977) to analyse the themes of the content. The themes pertinent to this study are where same-sex attraction or relationships are shown as normal, natural, and even incidental; where characters voice political arguments that support their sexuality/sexual difference; where other characters supporting this; and where heterosexual characters who voice support for a same sex relationship or attraction. I also consider the community that lesbian characters belong to outside of their heterosexual contexts and relationships. 
One component of my research evolved in response to an entry in a secondary text. A Shortland Street viewer wrote a letter to The TV Guide (15-21 January 2005, p.114), one of the secondary texts I was observing as part of my content analysis of Shortland Street, complaining that the intimacy between the programmes' lesbian characters was of an extremely high level. I used this opportunity to add a quantitative analysis of the instances of intimacy between couples on Shortland Street, and sampled the nine episodes which screened immediately after the publication of the letter (weekdays between 17-27 January 2005). I used two content units - the presence of a kiss, and the presence of 'other' displays such as petting - noting their intensity, and noting within which couple type (homosexual and heterosexual) these occurred. For comparison, I selected at random a second nine episode period eight months later (weekdays from 8-18 August 2005). During the first measurement period, the storyline involved a lesbian love triangle between Maia, Jay, and Fee. The second period involved Maia and Jay's decision to start a family and to enter a Civil Union (see Chapter 8, p.155).

\section{Ethical Issues}

I utilised both questionnaire and focus groups in my investigation of participants' attitudes toward lesbian fictions on New Zealand television. Human Ethics approval for this component of my study was necessary because I would be researching the private thoughts and attitudes of human subjects. Approval was granted by the Victoria University of Wellington Human Ethics Committee on 24 May 2004. While the questionnaire and taped discussions were anonymous, participants were required to identify their sexuality in order to be assigned to the correct focus group, and meet other participants at the group.

All participants were provided with a consent form (Appendix A); were advised that their responses given in the discussion forum would be taped for the purposes of the study; and that their questionnaire responses were anonymous to the researcher and her supervisors. The attitudes and views of different groups are typically compared by the researcher (see work by researchers Richard Krueger and Mary-Anne Casey 2005, p.9), and I have noted similarities and differences between the groups, it was not my intention to assemble participants to enable group comparisons. Rather, the groupings allowed me to create an environment where participants felt more comfortable to disclose and discuss their thoughts about lesbian representation. 
I prepared open-ended questions to prompt the discussion forum and, to enable later comparisons between the groups as recommended by Krueger and Casey (2005, p.66), these were used in each group. When participants took charge of the conversation, I followed it. The lesbian and homosexual adolescent groups in particular were often discursive as they discussed experiences shared. The semi-structured interviewing technique used provided reciprocity, a "free interaction between the researcher and interviewee ... opportunities for clarification and discussion" (Reinharz 1992, p.18). In facilitating the focus groups, when I needed to advance the conversation I repeated participants' statements back to them, or linked statements from two or more participants, asking for confirmation of the intent of their statements. I often prefaced my own statements with an acknowledgement that what I was about to say was my own experience, or what I had read, and that I was seeking the participants' responses, experiences, or opinions of these instances. This also helped to promote discussion.

Researcher disclosure can influence focus group discussions (Krueger and Casey 2005, p.9). This point is highlighted in dramatic fashion by researcher Ann Phoenix who recalls the shock on the faces of some of the people involved in her research when they realised, upon meeting her for the first time, that she was Black (Phoenix 1994, p.55). Revealing my sexuality to focus group participants had the potential for alienating those who are homophobic and if I did not, homosexual participants might assume I was heterosexual and view me as an 'outsider' and hold back information. Because the participants were active participants (as discussed by Reinharz 1992, p.181), I decided to adopt a simple strategy: if I was asked I would tell. If I was not asked, I did not voluntarily disclose my sexuality unless I felt it necessary or that the discussion warranted it. As it transpired none of the focus group participants inquired.

Two difficulties are associated with researching sexual minorities: identifying such individuals, and then obtaining a representative sample of them. In her study, The Late Great Lesbian and Bisexual Women's Discrimination Survey, Jenny Rankine distributed 1000 questionnaires, but only 261 women responded. Of these women, 229 identified as lesbian, 27 as bisexual, and 5 chose not to label their sexuality. Rankine notes:

It is difficult to assess how representative this sample was of these populations as a whole, and the survey findings cannot be generalised to all lesbians and bisexual women since there is no consensus list of lesbians 
and bisexual people, no random sample of these people is possible in New Zealand (Rankine 1997, p.12).

It was not possible to locate a pool of self-identified lesbians and gays who were representative of all sexual minorities in New Zealand, and participation could not be assured. To locate members of the gay and lesbian community, I attended known local lesbian and gay events to increase the likelihood of obtaining sexual minority samples, and distributed 100 information sheets about my research and inviting potential participants to meet me at a designated place and time (Appendix B). I also sought the attitudes, opinions, and beliefs held by Australian lesbian viewers about television depictions of lesbian characters, to extend the pool of lesbians and to provide a comparison between lesbians in the two countries. Using the same approach, I canvassed a lesbian function. Fifty information sheets were distributed at a Sydney bar on a lesbianfriendly night (28 July 2004) (Appendix C). To locate members of the heterosexual majority, I employed a sample of convenience approach, distributing information sheets amongst my heterosexual colleagues, friends, and their acquaintances.

Given the importance of television as a source of information to lesbian and gay youth (see Kielwasser and Wolf 1992; St Germain 2003), I was eager to obtain the opinions of this demographic. I had anticipated that locating self-identified gay adolescents would be problematic as, despite the Youth 2000 study findings by Christel Le Brun, Elizabeth Robinson, Helen Warren and Peter Watson, that adolescents come out earlier than previously thought (Le Brun et al. 2004, p.40), adolescents are a relatively protected population. Fortunately, Wellington has a school-based diversity group called School's Out, and some of its members agreed to participate in my study. I was advised that gaining access to a group of heterosexual adolescents would be considerably more difficult (M. Pope, personal communication, 29 October 2004). I felt capturing the opinions of adolescents who identify as heterosexual were less important for this thesis than it was to capture the opinions of a more vulnerable population such as lesbian and gay youth, and did not pursue in my attempts to hold a focus group with heterosexual youth.

In total, I conducted five focus groups in New Zealand and one in Australia. The six groups comprised television viewers who were:

- New Zealand women who identified themselves as lesbians; 
- Australian women who identified themselves as lesbians;

- New Zealand women who identified themselves as heterosexual;

- New Zealand men who identified themselves as homosexual;

- New Zealand men who identified themselves as heterosexual; and

- New Zealand young people who identified themselves as lesbian or gay (16-21 years).

When three participants from the heterosexual men's group were unable to attend their focus group meeting, they agreed to complete the questionnaire (and view photographs) only, and were given postage paid and pre addressed envelopes in order to return the questionnaire to me.

\section{Questionnaire}

I constructed a questionnaire to be completed during a segment of the focus group (see Appendix D). The questionnaire was anonymous, and employed both qualitative and quantitative items designed to elicit participants' attitudes towards representation of fictional lesbians available on television. As recommended by Reinharz (1992, pp.200201), the questionnaire included open-ended questions that enabled participants to respond using their own lexicon and concepts, rather than those of the researcher.

One benefit of a questionnaire was that participants could confidentially provide material they perceived the other group members might find offensive. For example, a focus group member might feel embarrassed admitting verbally that they find lesbianism titillating. Questionnaires preclude this public disclosure. In addition, the first section of the questionnaire requested participants to record how they perceived society attributed qualities to women and to lesbians, rather than how they themselves did. This allowed participants to disclose perceptions about heterosexism and homophobic stereotypes, without fear of offending either me, as the researcher, or anyone in the group. Similarly, instead of being confined to the homosexual/heterosexual groupings initially used to recruit participants, participants were free to describe their sexuality in the questionnaire. I considered this a sensitive practice for two reasons: the individual's self-identity can change upon the individual's choosing (Minh-Ha 1991, p.113), and members of a stigmatised sexual minority may choose not to label their homosexuality. 
One principle of feminist research is that research should empower participants (Kelly, Burton and Regan 1994, pp.36-37). Anne Opie finds the gaze of the researcher empowers participants in a number of ways:

These can be through their contribution to making a social issue visible, the therapeutic effect of being able to reflect on and re-evaluate their experience as part of the process of being interviewed, and the generally subversive first outcome that their two consequences may generate (Opie 1992, cited in Maynard and Purvis 1994, p.17).

Accordingly I deemed it good practise to allow participants as much chance as possible to own the information they provide because, as Lather attests, it provides participants the opportunity to comment on their experience of participating in research (Lather 1991, p.77). Therefore, I included a feedback section in the questionnaire. In this space participants could comment about my research and their experience of it, as well as make any other comment they felt might be important.

The questionnaire included an item asking respondents to consider if the nine women in separate photographs appended to the questionnaire were lesbians, and why. The photographs were selected from the Neil Andersen Collection held by the Photographic Archive of The Alexander Turnbull Library. The images were selected on the basis that they depicted individual lesbians, and in a variety of clothing styles. In order to extend the diversity of lesbians and their aesthetics, I supplemented the photographs from the Neil Andersen Collection with pictures from my own personal collection. The photographs are included in Appendix E. Both the focus group discussion questions and the questionnaire were piloted for sense and conceptual feedback, as recommended by Krueger and Casey (2005, p.65). The pilot group comprised six of my colleagues, none of whom participated in the actual focus groups. One pilot participant noted two questions closely resembled each other and this was addressed by omitting one.

\section{Conclusion}

Alison Jones argues the researchers' experiences are essential to feminist research and that "our accounts can only be constructions, made up from language, meanings and ideas historically available to us, the 'I'" (Jones 1992, p.18). I acknowledge that I am a lesbian researching lesbian representation on television and cannot be separated from this research in the role of a mere objective observer. Accordingly, I use an 'insider's' perspective as 
discussed by Jones (1992) and Baird (2005) and poetically illustrated by Minh-Ha (1991). The methodology is therefore informed by my own experience as a lesbian growing up in a world where heterosexuality is assumed, privileged, rewarded, and required. I am qualified to write from such a perspective; however, because lesbians are a complex population (Baird 2005, p.78), I also acknowledge there are other 'insider' perspectives that differ from mine, and continued to acknowledge this throughout my focus groups.

In the following chapter I present the results of the landscape analyses and the focus groups. 


\section{Chapter 5}

\section{Results of Television Landscape Analysis and Focus Groups}

This chapter presents the results of the New Zealand prime-time television landscape analysis, including the content analysis of a prime-time programming sample. The results of the focus group discussions and accompanying questionnaire are also presented.

\section{Introduction}

Altogether, the New Zealand television landscape is comprised of six free-to-air channels, TV ONE, 2, 3, C4, Prime, and Māori Television. A paid subscription channel (SKY TV) is also available and provides several dozen channels, including some pay-per-view movies. The four free-to-air channels I sampled, TV ONE, 2, 3, and Prime, have the largest audience share (TVNZ Annual Report 2007, p.8). Their differing demographics are TV ONE (25-54 years), 2 (18-39 years), 3 (18-49 years) and Prime (25-54). TVNZ's channels TV ONE and 2 enjoy the largest audiences at all viewing times, followed closely by 3. Trailing the field at under $10 \%$ of the audience share is Prime (ibid., p.8). Mãori Television was launched in March 2004 and in 2007 attracted an average of 32\% of Māori viewers each month (www.maoritelevision.com), which translates to less than $4.3 \%$ of the New Zealand population each month.

\section{Media Policy and the Representation of Minorities}

The content of television and radio programmes remains subject to a mix of self regulation, codes of practice under The Broadcasting Act 1989, and guidelines implemented by The Broadcasting Standards Authority and the Advertising Standards Authority. The Act acknowledges minority interests in two ways - by "sponsoring specialist minority programmes and by mainstreaming (getting minorities represented in prime-time programmes for the general audience)" (Horrocks 2004a, p.24). However, "while New Zealand On Air (NZOA) has successfully championed diversity in the mainstream programmes it has funded ... support has been complicated by the reluctance of national networks to make time available" (ibid., p.24). With airtime a "precious, saleable commodity", networks believe that an "opportunity cost is at stake" preferring to relegate minority programmes, even when they are offered free, to Sunday mornings or late night slots (ibid., p.24). 
Although sexuality is not explicitly mentioned, section 4(1) of The Broadcasting Act 1989 obliges every broadcaster to be responsible for maintaining programmes which are consistent with:

1. The observance of good taste and decency;

2. The maintenance of law and order;

3. The privacy of the individual;

4. The principle that when controversial issues of public importance are discussed, reasonable efforts are made, or reasonable opportunities are given, to present significant points of view, either in the same programme or in other programmes within the period of current interest;

5. Any approved Code of Broadcasting Practice applied to programmes.

The Free-to-Air Television Code of Broadcasting Practice was a consequence of The Broadcasting Act 1989. The code allows viewers a system of complaint (http://www.bsa.govt.nz/pdfs/bsa-freetvcode.pdf). Formal complaints are made on the basis that the broadcaster has failed in its responsibility to maintain one or more of the following standards:

1. Good taste and decency

2. Law and order

3. Privacy

4. Balance

5. Accuracy

6. Fairness

7. Programme classification

8. Programme information

9. Children's interest

10. Violence

11. Liquor

Sexual minorities are officially afforded protection under $6(\mathrm{~g})$ of The Free-to-Air Television Code of Broadcasting Practice: 
Broadcasters should avoid portraying persons in programmes in a manner that encourages denigration of, or discrimination against, sections of the community on account of sex, sexual orientation, race, age, disability, or occupational status, or as a consequence of legitimate expression of religious, cultural or political beliefs.

Addressing sexual minorities more specifically, Kate Ward, the communications and research advisor at the Authority, advises that at a meeting of the Broadcasting Standards Authority on 15 and 16 October 1991, it was recorded that the Authority:

agreed that sexual orientation should be one of the criteria about which programmes should not encourage denigration or discrimination (Kate Ward, E-mail message to author, 15 June 2004) (see Appendix F for full reply).

Theoretically then, the policy is extremely supportive of sexual minorities.

\section{Landscape Analysis}

The landscape analysis constituted an investigation of the references to, and depiction of, lesbians and lesbianism in New Zealand's prime-time television landscape. I sampled the fiction programming available in the prime-time viewing window on New Zealand's four most popular free-to-air channels (TV One, 2, 3 and Prime) for seven consecutive days (Monday 28 November 2005 to Sunday 4 December 2005) by recording the programmes on VHS. The week was randomly selected.

As outlined in the Methodology chapter, I analysed the fiction/non-fiction ratio in the programme listings of The TV Guide to ensure the week of prime-time programmes I recorded were representative of all weeks in the year. The programmes were all scheduled to screen in prime-time on the four most popular free-to-air channels; one week randomly selected from each season. The weeks are presented in Table 1. 
Table 1. A sample of prime-time programming from each channel in each season.

\begin{tabular}{lll}
\hline Week Number & Date & Season \\
\hline Week One & 15-21 May 2004 & Autumn \\
Week Two & 31 July - 6 August 2004 & Winter \\
Week Three & $13-$ 19 November 2004 & Spring \\
Week Four & $15-$ 21 January 2005 & Summer \\
\hline
\end{tabular}

Programmes in both analyses were coded by the channel, the day of the week on which they appeared, time slot, whether they were fiction or non-fiction, and their genre.

Of the 604 prime-time programmes counted in the four week sample, the proportion of fiction programmes averaged $45 \%$; this closely resembled the ratio of the week selected for the prime-time programme analysis, suggesting the week was not anomalous in any way.

Of all prime-time programmes recorded in the targeted week $(n=162), 77$ were fiction (47.5\%) and 85 were non-fiction (52.5\%). There were clear differences between the four channels in the proportion of fiction and non-fiction programming (Table 2). Most primetime fiction is found on 2 on Wednesdays, while TV ONE has the lowest proportion of fiction programming over all the days.

Table 2. Number of fictional programmes by channel and by day (Monday 28 November 2005 - Sunday 4 December 2005).

\begin{tabular}{lcccccccc}
\hline & Monday & Tuesday & Wednesday & Thursday & Friday & Saturday & Sunday & Total \\
\hline TV ONE Fiction & 0 & 1 & 3 & 2 & 1 & 1 & 1 & $\mathbf{9}$ \\
2 Fiction & 5 & 4 & 7 & 4 & 6 & 3 & 4 & $\mathbf{3 3}$ \\
3 Fiction & 1 & 1 & 4 & 1 & 2 & 4 & 3 & $\mathbf{1 6}$ \\
Prime Fiction & 3 & 2 & 5 & 3 & 3 & 2 & 1 & $\mathbf{1 9}$ \\
& & & & & & & & \\
\hline Total & $\mathbf{9}$ & $\mathbf{8}$ & $\mathbf{1 9}$ & $\mathbf{1 0}$ & $\mathbf{1 2}$ & $\mathbf{1 0}$ & $\mathbf{9}$ & $\mathbf{7 7}$ \\
\hline
\end{tabular}


I then counted the characters presented within the fictional programming sampled. During the prime-time period analysed, 2 had the highest concentration of characters across the seven days (36\%), and TV ONE the lowest (18\%) (Fig. 1).

Fig. 1. Total characters by channel during prime-time (Monday 28 November 2005 Sunday 4 December 2005).

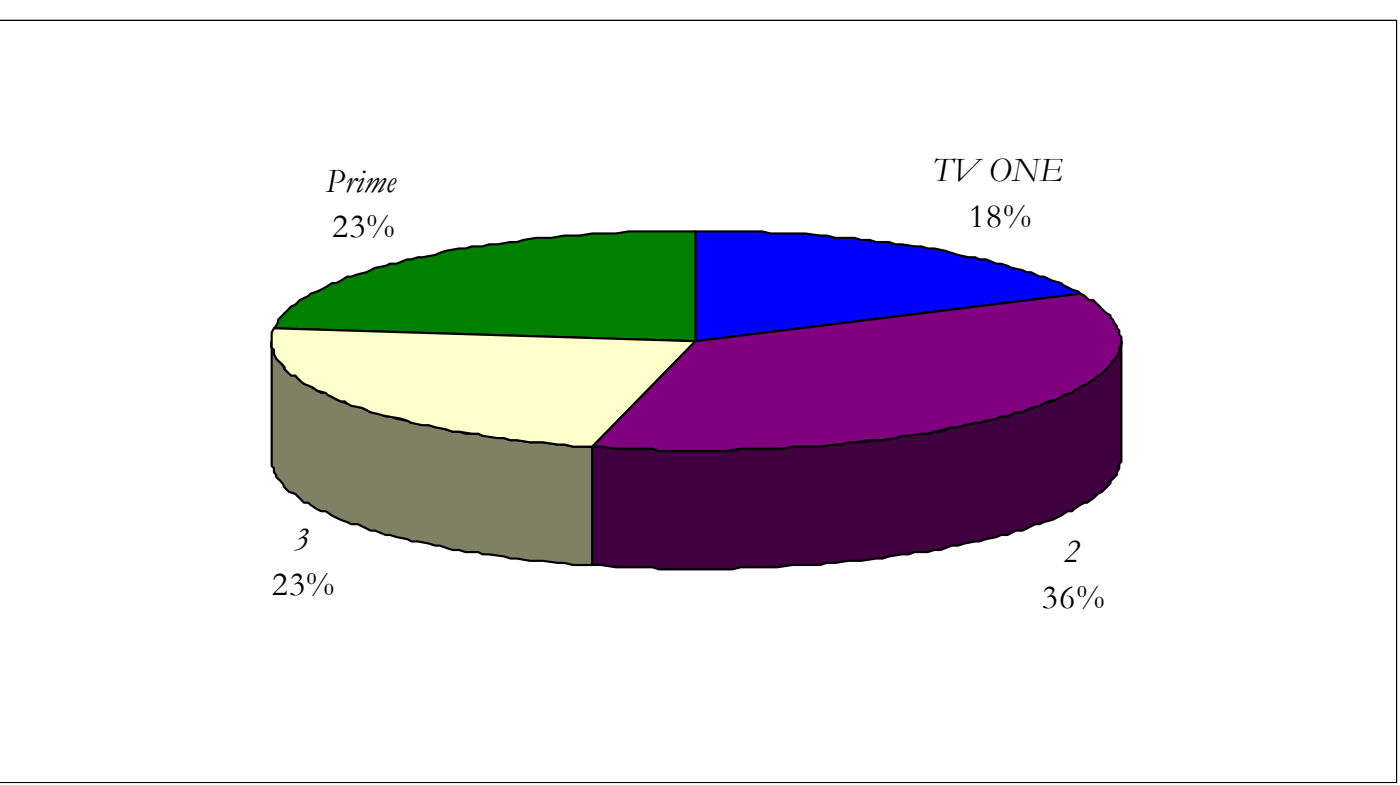

Of the 1192 characters counted in the measurement period, 96.8\% were heterosexual, $1.2 \%$ were lesbian, $0.8 \%$ were gay men, $0.4 \%$ were bisexual, and the remaining $0.8 \%$ were characters of other minority sexualities (Fig. 2). ${ }^{30}$ Of the lesbian characters, Shortland Street's Maia and Jay accounted for most lesbian visibility (10 of the 14 instances), as they both appeared each week night. This means there were actually only six separate lesbian characters: Maia, Jay, writer Cathy Zimmerman (also on Shortland Street), a butch gym teacher on the cartoon satire Family Guy, and two characters appearing in The Simpsons.

Gay male characters were more prevalent than lesbian characters. While gay male characters comprised just $0.8 \%$ of the 1192 characters recorded, they were all individual characters, suggesting a wider variety of representation than that for lesbian characters, most of which were recurring lesbian characters.

\footnotetext{
${ }^{30}$ Despite the author having prior knowledge that All Saints character Dr. Charlotte Beaumont was a lesbian character (if only for a short time), she was not included in the lesbian character count because no reference to her sexuality was captured during the sample.
} 
Fig. 2. Prime-time characters by sexuality (Monday 28 November 2005 - Sunday 4 December 2005).

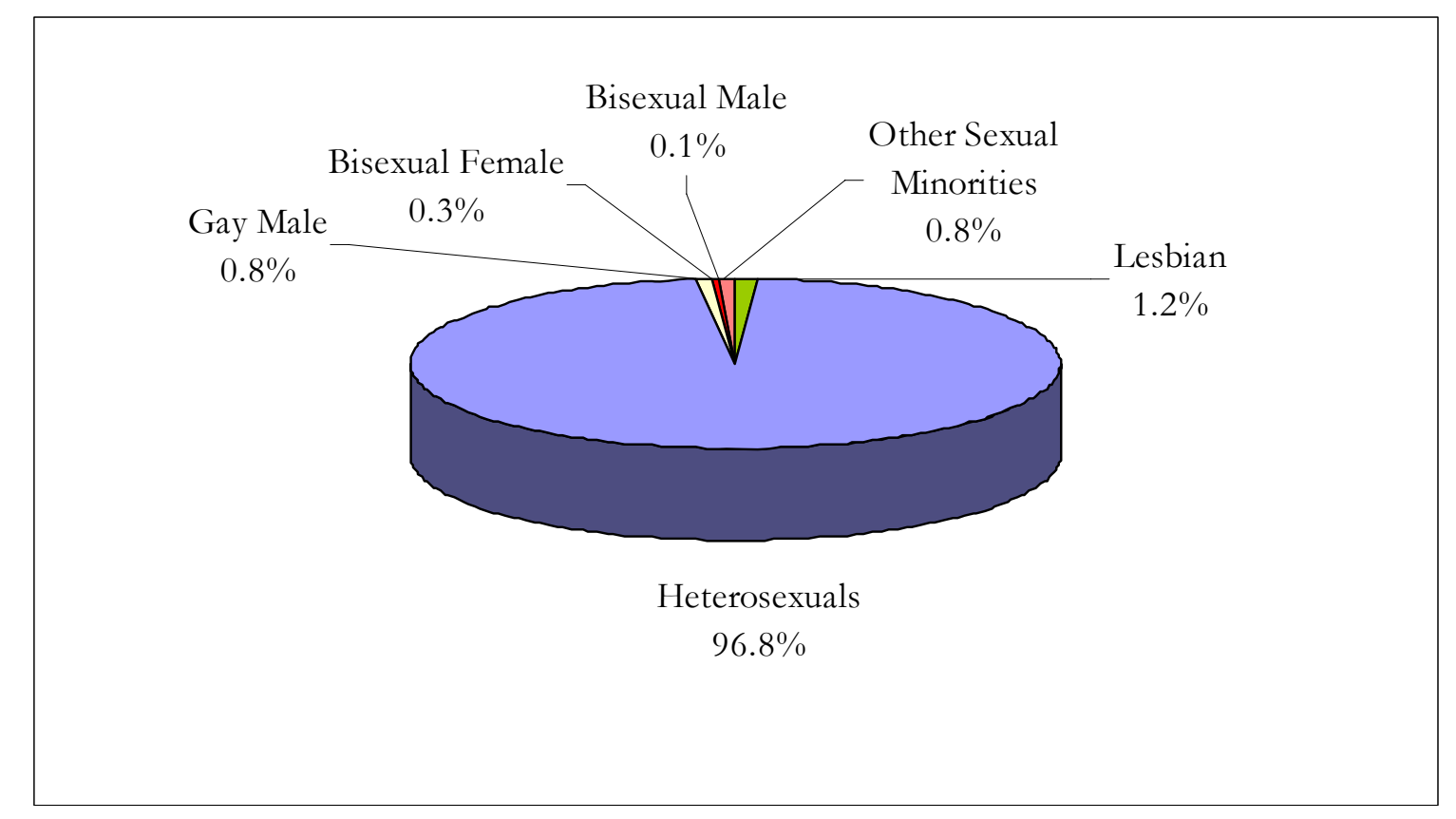

The distribution of each character type varied across the four channels. The majority of heterosexual characters appear on 2 (35.3\% of all heterosexual characters), then 3 (23.3\%), followed closely by Prime (23.2\%). 2 had the largest number of lesbian characters $(73.3 \%$ of all lesbian characters); followed by $3(20 \%)$. No lesbian characters were shown on $T V O N E$; this may be attributed to its lack of fictional programming during this particular week (only two days were dominated by fiction on TV One).

Very few characters screened during prime-time were non-heterosexual (Table 3). The highest proportion of lesbian characters was on 2, where lesbian characters made up $2.6 \%$ of all characters shown throughout the selected week (Table 3 ). This is solely due to its being the channel screening Shortland Street, where two lesbian characters both featured five times. 
Table 3. Percentage of the character types on each channel.

\begin{tabular}{lcccccc}
\hline & $\begin{array}{c}\text { Hetero- } \\
\text { sexuals }\end{array}$ & Lesbians & Gay Men & $\begin{array}{c}\text { Bisexual } \\
\text { Women }\end{array}$ & $\begin{array}{c}\text { Bisexual } \\
\text { Men }\end{array}$ & $\begin{array}{c}\text { Sexual } \\
\text { Minorities }\end{array}$ \\
\hline TV ONE & 97.2 & 0.0 & 0.9 & 0.0 & 0.5 & 1.4 \\
2 & 95.5 & 2.6 & 0.5 & 0.2 & 0.0 & 1.2 \\
3 & 97.8 & 1.1 & 1.1 & 0.0 & 0.0 & 0.0 \\
Prime & 97.1 & 0.4 & 1.1 & 0.7 & 0.0 & 0.7 \\
\hline
\end{tabular}

To summarise, the New Zealand television prime-time landscape comprises very little lesbian representation. The strongest, and most frequent, source of lesbian representation during the prime-time period was channel 2 due to it being the home of Shortland Street. While sexual minority representation did vary somewhat amongst the four channels, the overwhelming character type was heterosexual. The other channels were more likely to screen gay male and other sexual minority characters than lesbian characters.

\section{Focus Groups}

This section relates the findings from the six focus groups and the corresponding questionnaire returns. Focus groups and survey tools capture the opinions of an audience, which can then be compared to reveal patterns of similarity and difference (Krueger and Casey 2005, p.9). Participants' responses to the questions about lesbian representation were grouped into three main areas of concern: the visibility of lesbian characters on television; the trends or conditions participants noticed that are imposed on lesbian characters they recalled; and what effect these characters had on lesbian viewers in terms of the relational processes of homophily, identification, and PSI.

Participants were segregated into the following groups: self-identified lesbians (New Zealand lesbian focus group held 28 August 2004, in Wellington, New Zealand; the Australian lesbian focus group held 30 July 2004 in Sydney, Australia), homosexual men (focus group held 11 September 2004, in Wellington, New Zealand), heterosexual women (focus group held 16 October 2004, in Wellington, New Zealand), heterosexual men (focus group held 14 April 2005, in Wellington, New Zealand), and gay adolescents (focus group held 4 November 2004, in Wellington, New Zealand). The size of each focus group is shown in Table 4. 
Although participants nominated which focus groups they would attend, they were asked to confirm (and in some instances participants took the opportunity to further define) their sexual identity at the focus group. Participants were asked to tick the box that best described their sexuality; some participants chose more than one option. Consequently some tallies are higher than the actual group number.

Table 4. Focus group participants identify their sexuality.

\begin{tabular}{|c|c|c|c|c|c|c|c|c|}
\hline \multirow[b]{2}{*}{ Focus Group Category } & \multicolumn{8}{|c|}{ Participants' sexual identities } \\
\hline & Lesbian & $\begin{array}{c}\text { Hetero- } \\
\text { sexual }\end{array}$ & Bisexual & Queer & Gay & $\begin{array}{l}\text { Homo- } \\
\text { sexual }\end{array}$ & Other & Total \\
\hline Lesbians (New Zealand) & 8 & & 1 & & & & $1^{*}$ & 10 \\
\hline Lesbians (Australia) & 5 & & 1 & & & & & 6 \\
\hline Heterosexual women & & 7 & 1 & & & & $1 * *$ & 9 \\
\hline Homosexual men & & & & & 2 & 5 & & 7 \\
\hline Heterosexual men & & 8 & & & & & & 8 \\
\hline Homosexual adolescents & 4 & & 2 & 1 & 1 & & & 8 \\
\hline Total & 17 & 15 & 5 & 1 & 3 & 5 & 2 & 48 \\
\hline
\end{tabular}

There were more female participants than male (no participant identified themselves as transgender or intersex). Contributing to the gender imbalance is the fact that I have conducted two lesbian focus groups, one with participants from this country, the other in Australia.

Of the adult participants, New Zealand lesbians had the highest average age (44.0 years), considerably higher than the Australian lesbians (35.0 years), while the gay men had the lowest (23.6 years) (Table 5). Although the age differences might affect participants' personal television viewing histories, as older participants are likely to have viewed more television over their lives than younger participants, the average hours a day spent viewing television did not vary greatly between any of the groups (between 1.8 hours and 2.6 hours), (Fig. 3). 
Table 5. Focus group participants by age and television use.

\begin{tabular}{lcc}
\hline Focus Group & Mean Age (Years) & Mean \# of TVs in Home \\
\hline Lesbians (New Zealand) & 44.0 & 1.7 \\
Lesbians (Australia) & 35.0 & 2.3 \\
Heterosexual women & 36.7 & 1.2 \\
Homosexual men & 23.6 & 2.0 \\
Heterosexual men & 41.9 & 1.5 \\
Homosexual adolescents & 16.2 & 2.3 \\
\hline Overall Average & $\mathbf{3 2 . 9}$ & $\mathbf{1 . 8}$ \\
\hline
\end{tabular}

Gay adolescents and Australian lesbians had the highest average number of televisions in their homes (2.3 each); heterosexual women had the lowest (1.2). Overall, the participants $(n=48)$, had an average age of 32.9 years, nearly two televisions in their homes each (1.8), and spent a little over two hours a day watching television (2.05 hrs) (Table 5; Fig. $3)$.

Fig. 3. Average hours focus group participants reported watching television.

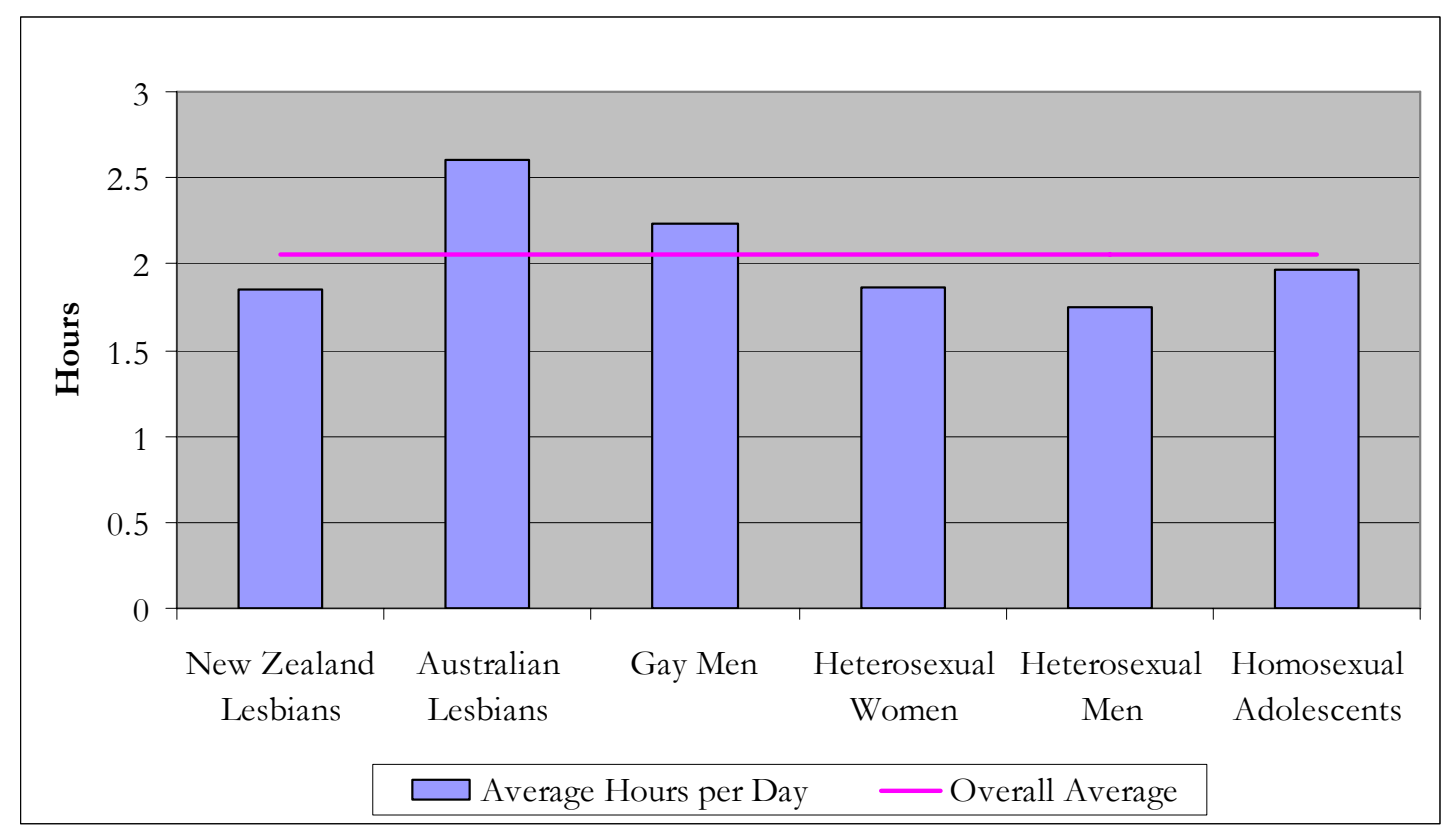

\section{Lesbian Visibility on New Zealand Television}

To gauge participants' experience of lesbian visibility on New Zealand television, I asked them to recall and list as many lesbian characters and the programmes in which they appeared as they were able. The frequency with which high profile prime-time characters were recalled was illuminating for two reasons: it confirmed both that prime-time 
programming is the most frequently watched by my participants, and, more importantly, the paucity of lesbian content within this environment.

Capsuto found that when underrepresented populations such as lesbians finally do recognise their lives on screen, "even for a moment, the reaction was strong" (Capsuto 2000, p.xiii). Nearly a decade after Ellen was screened it was still the second most frequently nominated source of lesbian characters out of all the programmes nominated, and Tipping the Velvet, a two-part mini-series, was the fourth (see Fig. 4).

Fig. 4. Programmes with lesbian characters as recalled by focus group participants.

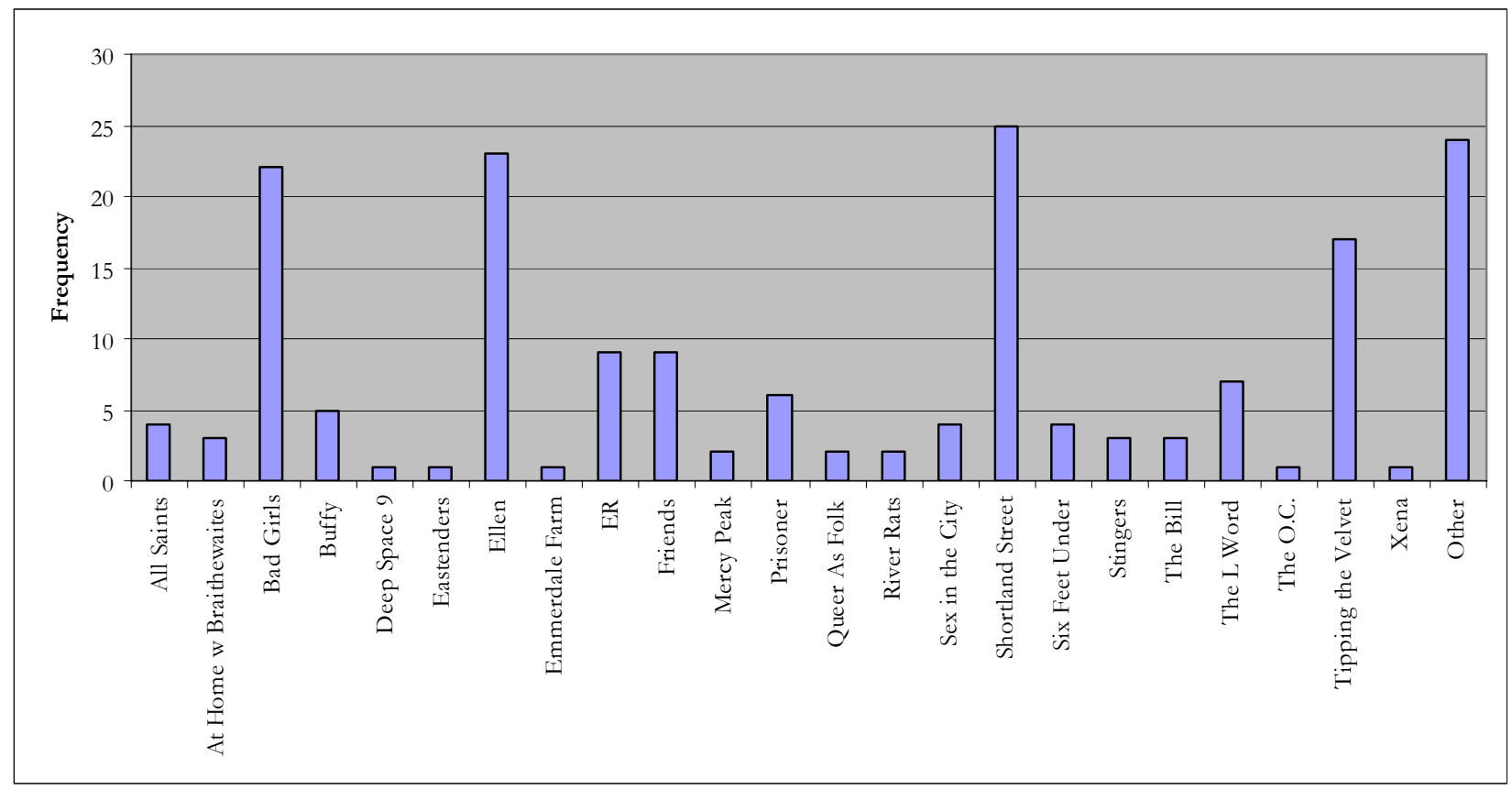

The characters recalled that were coded in the 'Other' category were titillatory texts such as Vampiros Lesbos; films such as Monster, Boys Don't Cry, and The Killing of Sister George; ancillary characters from programmes such as Ally McBeal; Miss Hathaway from The Beverly Hillbillies; or actual lesbian performers like this country's musical duo, the Topp Twins.

After controlling for the number of participants in each group, the Australian lesbian group recalled the most lesbian television characters (an average of 6.2 characters each). ${ }^{31}$ New Zealand lesbians were next (4.0 characters each), followed closely by heterosexual women (3.9 characters each). Heterosexual men recalled the next highest tally (3.1

${ }^{31}$ To control for differing group sizes, the characters participants recalled were tallied in each group and then divided by the number of participants in each group, establishing the same metric with which to compare the groups' scores. 
characters each), followed by gay men (3.0 characters each), and gay adolescents recalled the least (2.3 characters each).

As with New Zealand television, it is still rare for Australian television to feature significant lesbian characters, although there have been exceptions in recent years (Hawkes and Scott 2005, p.80). The L Word is one of those exceptions. Screening in Australia at the time of the focus group, the characters from The L Word contributed significantly to the tally for the Australian group $(n=6)$, and were nominated by all of the Australian participants. The $L$ Word had not screened on New Zealand television at the time the New Zealand focus groups were held. Prime-time lesbian characters Maia and Jay from Shortland Street were the most frequently nominated lesbian characters by New Zealand lesbian participants $(n=$ $6)$; the gay adolescent group $(n=4)$ and heterosexual women, $(n=9)$. Characters in the BBC's prison drama Bad Girls were most frequently recalled by heterosexual men $(n=6)$; and Ellen was the programme most recalled by the gay men $(n=4)$.

Zipter observed that an historical absence of an overt lesbian presence on television meant lesbian viewers had to "read" characters as lesbian to make space for themselves (Zipter 1995, cited in Capsuto 2000, p.xiii). Miss Hathaway from The Beverly HillBillies was one of the characters used to illustrate her point. Missing many of the attributes typically ascribed to female characters, Miss Hathaway's femininity was ambiguous enough to be read queerly. One of my lesbian focus group participants recalled bonding with the character when she was 13. That Miss Hathaway was among the small suite of lesbian characters this participant could recall, after forty years of television viewing, is indicative of the paucity of lesbian characters.

There is a considerable body of literature on the social norms to which Western women and men are expected to adhere (see Butler 1990; Halberstam 1998; Wolf 1991). The focus group participants confirmed New Zealand's social norms for women are similar, if not the same as, those of other Western countries. They are required to be feminine, slim, and attractive. Accompanying the physical requirements participants reported there is a societal expectation that women also be tolerant, nurturing, maternal, meek, and compassionate. Within those ideals participants noted paradoxes for example, women must be:

Assertive but acquiescent at the appropriate moments (heterosexual woman). 
Intelligent but not intellectual (New Zealand lesbian).

Clever but not more intelligent than a man, be stupid (New Zealand lesbian).

Reserved towards sex, but showing interest at the same time (gay adolescent).

Perhaps because they are acutely aware of these paradoxical impositions, participants from the heterosexual women's group astutely nominated some particularly negative societal stereotypes of women, such as:

Needy, incompetent, reliant on men, childish, naïve, trusting, gullible, facile, easily manipulated 'submissive', and 'compliant'. Dressed as a woman but not as a sex symbol

Several participants identified patriarchal power as the manipulating hand behind media images and that men are served by these stereotypes:

Keep men's egos and power base safe (New Zealand lesbian).

Seeing they (men) are the ones 'in charge' they can create women in any shape or form they like and it's very little to do with how women are in reality (New Zealand lesbian).

These are the qualities the patriarchy desires ... Ideally the patriarchy wants a woman to worship it (heterosexual woman).

Basic patriarchal assumptions - women are the main caregivers, primarily responsible for the domestic side etc. but also men wanting them to be sexually available, and/or a trophy (heterosexual man).

In direct contrast to the slim, feminine, compliant, and nurturing stereotypes of women, the descriptors nominated most frequently by participants regarding the attributes and behaviours reserved for lesbians were overwhelmingly negative. Focus group participants 
frequently nominated the film The Killing of Sister George as the quintessential image of the butch. When asked to list the prevailing characteristics they thought society ascribed specifically to lesbians, the majority of respondents across all groups described lesbians in terms that related to their butchness or masculine qualities: ${ }^{32}$

Dull, unable to get a man, sad, mad or bad, unattractive, badly dressed, shrill, political, fat, abnormal, unnatural, sinful are all common stereotypes or if you are younger, it's a phase, you'll get over it, butch, man-hating, bad taste in dressing and style generally (New Zealand lesbian).

Men-hating, angry, bitter, 'bra burning', unattractive, capable - not needy of men (Australian lesbian).

Butch, rough, big, short hair (heterosexual man).

Butch, stroppy, ambitious, selfish, man-hating, unfeminine, other (heterosexual woman).

Angry, butch, political, proactive, mannish, feminist (gay man).

Not very feminine, strong, rude, unattractive, arrogant (gay adolescent).

Again, participants theorised the genesis of stereotypes about lesbians stemmed from heterosexual men's power to control the social order:

For a 'proper' woman, who is soft and meek, to go against the 'norm', she must appear the exact opposite - unattractive and man-like (heterosexual woman).

We challenge the patriarchy and that threatens men's positions of power over women because they challenge the feminine ideal. There 'must' be a reason for it, society is threatened because we don't want/need men so a pile of negative attributes must be burdened on us i.e. if you change the status quo/culture you are vilified (Australian lesbian).

Because they [lesbians] fit into men's fear of what a woman might do or be if they don't need men and so they can again construct the lesbian as all

${ }^{32}$ When asked if they knew any lesbians, all participants replied that they did. 
that is bad. This is warning to heterosexual women that if they are too independent of a man, they will end up looking like a lesbian (New Zealand lesbian).

Again, the patriarchy! If lesbians were seen as pretty, etc., men would want, but couldn't have them. Must be subjugated, marginalised and put down by attributing qualities opposite to those the patriarchy finds attractive. Means men don't have to regard them as equals, i.e., men in women's bodies (heterosexual woman).

Lesbians are beyond male control or protection, lesbians escape from the requirements of the gender roles seen as suitable for women - dangerous, need to be labelled as 'other' (heterosexual woman).

As one young lesbian observed, masculine stereotypes hold such currency in society because lesbians:

Are girls that love girls. Society sees this as being a man's job (gay adolescent).

Participants discussed a further societal perception about lesbianism - that same-sex desire is inferior to heterosexuality. If heterosexuality is normal and natural (Rubin 1993, p.13), something must be wrong with those individuals who do not comply. A common strategy that encourages this myth sees lesbianism conflated with the notion that women who are sexually attracted to each other do so because of the result of a trauma, a mental disorder, or some other dysfunction. Lesbian participants were very aware of such misconceptions:

Unhappy, traumatised (New Zealand lesbian).

Dysfunctional and immoral (New Zealand lesbian).

Suffering some disorder, threatening....are probably that way because of some trauma (Australian lesbian).

Lesbianism is often conflated with masculinity (Creed 1995, cited in Baird 2005, p.63; Greenberg 1988, p.373), a point confirmed by my focus group participants. Despite 
confirmation that society views lesbians as unattractive and mannish, Sapphic characters in television texts are mostly white and nearly always feminine in orientation (Ciasullo 2002, p.201; Chambers 2006, p.82), while those lesbian images and stories that fall outside of heterosexual desire, such as mannish lesbians or homonormative lesbian texts, are ignored. Consistent with the literature, the increasing dominance of the feminine lesbian on this country's television screens was noted by participants from all groups. This information is recorded in the table below.

Table 6 . The femininity and masculinity of lesbian characters recalled by focus groups.

\begin{tabular}{lccccc}
\hline & \multicolumn{3}{c}{ Characters Recalled } & \multicolumn{3}{c}{ Pairings Recalled } \\
\hline & Masculine & Feminine & $\begin{array}{c}\text { Masculine/ } \\
\text { Masculine }\end{array}$ & $\begin{array}{c}\text { Feminine/ } \\
\text { Feminine }\end{array}$ & $\begin{array}{c}\text { Masculine/ } \\
\text { Feminine }\end{array}$ \\
\hline New Zealand lesbians & 6 & 9 & 0 & 9 & 6 \\
Australian lesbians & 4 & 6 & 1 & 5 & 3 \\
Homosexual adolescents & 3 & 4 & 1 & 3 & 2 \\
Heterosexual women & 4 & 8 & 1 & 6 & 4 \\
Homosexual men & 4 & 7 & 1 & 4 & 4 \\
Heterosexual men & 7 & 7 & 3 & 7 & 2 \\
\hline
\end{tabular}

Describing the lesbian characters they had recalled, participants wrote:

All white, middle-class, (New Zealand lesbian)

Yes - glam het identified. In all cases they were more feminine as they reflected society's concept of femininity (Australian lesbian).

They all tended to be portrayed as feminine except maybe Ellen (heterosexual woman).

The women were all very attractive (heterosexual man).

Pretty, sex symbols (gay adolescent).

Melodramatic, scheming, glamorous (gay man).

Impossibly glamorous very femme (New Zealand lesbian). 
Noting what I refer to as the symbolic annihilation of the butch lesbian, these participants wrote:

[Lesbian characters were] not masculine - not any of them

(New Zealand lesbian).

There is a real lack of butch masculine portrayals ... I don't see lesbians who are in the middle between butch and femme

(New Zealand lesbian).

I can't remember any masculine characters. I happen to know many masculine lesbians (gay man).

The reason the feminine lesbian schema has such currency in television texts is because she is a fantasy figure, incorporated into heterosexual men's desire (Capsuto 2000, p.332; Kinsey et al. 1965, p.486; Russo 1981, p.6). This was a point discussed by lesbian participants in Labett's (2006) study, and also understood by many of my own participants:

The girly lesbian is a construct of straight-male fantasy which they find erotic (homosexual man).

Tended to be more glamorous - appealing to men (Australian lesbian).

Adolescent participants were also aware of the titillatory value the lesbian femme holds for heterosexual men:

Guys just get turned on by girl on girl so they make up stuff to feed their thought (gay adolescent).

Shortland Street's lesbian characters Maia and Jay were the lesbian characters most frequently nominated by New Zealand participants. Participants described the characteristics of these characters, which reflected the assimilated 'good gay' attributes identified by Ciasullo (2002), Fejes and Petrich (1993), Kessler (2006), and Walters (2001). 
Maia and Jay - completely feminine, opposites to the stereotype of a lesbian (gay man).

Maia - Average pretty kiwi gal, really can't be distinguished from any other female character on the show (heterosexual woman).

Maia - pretty, a relatively inoffensive character despite her token sexuality (heterosexual woman).

Maia generally straight-acting (heterosexual woman).

Shortland Street characters - both 'femininely' beautiful and dressed like 'girly girls' (New Zealand lesbian).

\section{Heterosexual Lesbians}

In line with Ellis's legacy, part of the grammar in the script of lesbian desire that exists for the feminine lesbian character is that her sexuality is unstable, and she is capricious or confused about her sexuality (Hamer 1994, p.71; Walters 2001, p.162), experimenting (Gill 2007, pp.244-245), or going through a phase (Hamer 1994, p.71). These same stereotypes are perpetuated by New Zealand television, as these comments support:

Except in Bad Girls, the lesbians are portrayed as easily 'converted' by men (heterosexual man).

[Lesbian characters] went back to boys afterwards (heterosexual woman).

Doctor and Nurse on SS [Shortland Street] were portrayed as confused straight women (heterosexual woman).

Confused (Shortland Street) (gay adolescent).

I've been watching Shortland Street and I was quite pleased when they had the two lesbian characters come on.... But then after a couple of weeks, of course, their relationship broke up and it looked like they were steering the plot towards one of them getting together with a guy. It's really annoying (New Zealand lesbian) 
Discussing Shortland Street, a participant in the New Zealand lesbian group noted that Maia and Jay were "about the third" lesbian couple to appear in the 13 years of the soap's history. However, she also added those couples had broken up, exited the programme, or turned (back) to heterosexuality. Other observations noted by lesbian participants were "there were never happy endings" for the Street's lesbians, and the characters "don't do anything nice like have commitment ceremonies or babies or anything"; and they suggested that lesbian representation on Shortland Street really amounted to tokenism. Similarly, these participants commented:

They don't do things around the house or sit down to a meal together or you know ordinary stuff, there's always something around being sexual kind .... They're about to kiss, not kiss, been caught kissing (New Zealand lesbian).

They're focussed on the difficulty of them being together instead of just going 'these people are together' (New Zealand lesbian).

Lesbian relationships are subject to many of the same issues/pressures as heterosexual relationships. However, the script of same-sex desire written for Maia and Jay tended to focus on their problems and sexual activity rather than include happy, positive, loving, supportive moments in their relationship, as other heterosexual couples are allowed. Representing the characters in this way clearly positions them as 'others', limiting their ultimate assimilation to the 'good' gay model. Since the New Zealand lesbian focus group was held, storylines have included both a Civil Union and Maia's pregnancy. However, both events became ways in which same-sex desire was marginalised, problematised, and shown as capricious, while heterosexuality continued to be promoted.

A philosophical schism about the femme is evident among participants. For example, some participants laud the feminine lesbian as a welcome deviation from the dowdy stereotype of lesbianism; and even though lesbian characters conform to a schema preferred by heterosexual men, this was seen to be a preferable alternative to negative stereotypes: 
Personally I prefer glam rep. and the suggestion that lesbians don't have to be butch or that "you can always pick them". This helps my place in the world (Australian lesbian).

I've been watching Shortland Street and I was quite pleased when they had the two lesbian characters come on and they were gorgeous and they weren't butch and ugly and that was nice (New Zealand lesbian).

It was quite nice/encouraging to see nice pretty girls kissing (gay adolescent)

Other participants feared that an assimilated appearance, coupled with the lack of lesbian signifiers, provided the potential for the characters to be seduced by heterosexuality:

Lesbian characters are capable of swinging in the right circumstances (Australian lesbian).

There were two main reasons some participants distrusted the characterisation of glamorous lesbians. First they felt that their femininity implied they would 'return' to heterosexuality, presumably because they never looked like they 'left' it. Second, there was a feeling that they were there to play to the male heterosexual audience, and some lesbian viewers did not appreciate that they had to "share" these characters with that audience. From the discussions in the lesbian and adolescent focus groups, this understanding clearly affected their ability to develop a para-social relationship with the characters despite a level of homophily (in that both the characters and the audience were lesbian). It therefore diminished the amount of identification with the characters because they were not homonormative and, therefore, did not exclude non-lesbian audiences.

Considering the dominance of the feminine schema in television texts, another participant wondered if it is an effort, on the part of producers, to counter the butch lesbian stereotype that first appeared in the 1970s. The effect, she thought, was that previous extremely masculine lesbian characterisation has now been supplanted by extremely feminine ones, but she was unsure why this might be. Other participants suspected the increase in feminine lesbian characters was the result of one critical factor:

Men like to watch them (Australian lesbian). 
The Lipstick Lesbians are the acceptable version which is the object of male fantasy (heterosexual woman).

\section{Non-Feminine Lesbians}

The few non-feminine lesbian characters participants did recall were from prison dramas, BBC's Bad Girls and Australia's Prisoner, and their mannishness was conflated with a violent and aggressive disposition:

Al and Denny both wore masculine clothes had short hair and were physically strong and intimidated others (heterosexual man).

Den was aggressive and had a number of tattoos (heterosexual man).

Shaz and Denny because they seemed quite violent (heterosexual woman).

Bea of Prisoner - mean (Australian lesbian).

When non-feminine characters, of little titillatory interest to men, are included in mainstream fare, their personal relationships are often hidden. One lesbian participant put this into perspective in her comments about a character from the Australian series River Rats:

she was an average kind of woman/lesbian who was not designed to appeal to men. She was in a relationship although ... their relationship was never the subject of any storyline ....yet the personal lives of other characters were storyline. She didn't tantalise so we didn't really see anything of her relationship/s with women. If she was glam/attractive we would have done (Australian lesbian).

When discussing the prevalence of the prime-time feminine lesbian aesthetic, a New Zealand lesbian said she thought these characters were heterosexual constructions, because she had not met anyone who was like that in her social interactions. Contrasting the femme lesbians with the grittier and predominantly butch lesbian characters on Bad Girls, she said there did not appear to be "anything in-between". Because she had not met glamour dykes, she was apparently left believing the slammer dykes were true because 
they were the closest (aesthetically) to her friends; feminine lesbians were more like fictions.

Unlike her glamorous sister, the butch is not a popular image in mainstream texts in such an image-conscious age (Ciasullo 2002, p.129) because she is incongruent with the desires of patriarchy. The situation was summarised by this participant:

Butch lesbians have no 'value' or 'place' in our society and hence are very rarely seen on our television (Australian lesbian).

Halberstam has observed an emerging trend of feminised butch characters appearing in films (Halberstam 1998, p.217). Given that the way gays and lesbians are represented in films usually translates onto television (Fejes and Petrich 1993, p.399), it is no surprise that the narrative link that conflates lesbianism with masculinity is also manifest on television in the form of the feminised butch. With their embodiments becoming increasingly feminised, the Beauty Myth is extended to the butch, a phenomenon these comments support:

Bad Girls. Even the jailbird wears loads of make-up (Australian lesbian).

None of the characters I saw were masculine - Tipping the Velvet characters played at being male which was erotic but not truly masculine (New Zealand lesbian).

There was a fairly 'butch' character on Bad Girls (I think she was Denny's girlfriend) but I wouldn't use the term 'masculine' (Australian lesbian).

Often with a husky voice or behaviours considered masculine, but not visually fulfilling the butch stereotype (gay man).

Some participants offered the following suggestions:

I would like to see more butch/boyish dykes on TV (Australian lesbian)

I like seeing women being dominant/aggressive/butch (Australian lesbian) 
Get rid of stigma of butch lesbians, which does not need to be a bad thing (homosexual adolescent)

Let's have some confrontational characters that have shaved heads and don't like men very much! Push the limits (New Zealand lesbian).

Participants were asked about the sources of lesbian representation other than television they had accessed. Magazines were the most common source cited $(n=32)$, followed closely by film $(n=30)$. Art, theatre, and the Internet were the least cited sources of lesbian images by all groups. New Zealand lesbians nominated film (9), and magazines (6), while the Australian lesbians nominated newspapers (6), and magazines (6). For heterosexual men $(n=7)$, and women $(n=7)$, film was the main source of lesbian images other than television, whereas magazines were the medium most cited by gay adolescent participants (7), followed by the newspaper (3). All but one participant from the gay men's group had seen lesbian images in other media besides television.

\section{Visual Signifiers of Lesbian Sexuality}

Participants were shown nine photographs of different lesbians and asked to indicate which of the women they thought 'looked like a lesbian' (Appendix E). Many heterosexual participants demonstrated a high degree of literacy about lesbians. Comments included:

For me, all the images could be heterosexual or lesbian women. I know women of both sexualities who could fit all the images and I have no context to make a judgement (heterosexual man).

I don't believe you can determine someone's sexuality by looking at a single image. I could circle all of them or none of them (heterosexual woman).

None of the women is wearing a sign, so I can only look at them as people not as representations of any specific type of sexual identity. Any, none, or all of them might be lesbians, but to me they just look like strong individuals (heterosexual woman). 
Despite these responses, image $\mathrm{F}$ was the most frequently nominated, followed by $\mathrm{E}$ and C. The lesbians in images F and E had non-feminine attributes; F had a shaven head and a tattoo on her arm and while $\mathrm{E}$ has long hair she wore jeans and heavy boots. The lesbian in photograph $\mathrm{C}$ was feminine, wore makeup and was dressed in a leather $\mathrm{s} / \mathrm{m}$ dominatrix outfit. Participants commented about their choices:

'C': Overtly sexual dress, the stance of ' $E$ ': she looks like she would have a swagger! The shaved head and tattoo of 'F', 'I' hair (New Zealand lesbian).

'E': Masculine clothes, shirts boot and the way she's standing. 'F': short hair, tattoo - looks masculine. 'D': short hair, leather jacket (gay adolescent).

'E': No makeup, masculine clothes, masculine stance (heterosexual woman).

'B': Reminded me of the Topp Twins. 'C': just look at the outfit. 'D': masculine features. 'E': dress sense, particularly the shoes. F: rough, masculine look that fits the stereotype. 'G': 80's hair-do, pants (gay man).

'E': Her dress, with an untucked shirt and the style of her boots as well as they way she's standing. 'F': very short hair. 'I': again, very short 'boyish' hair very large earrings. This was interesting in that I could identify few actual characteristics (heterosexual man).

'B': Would not necessarily pick her as a lesbian. 'C': Yes. 'D': would not necessarily pick her as a lesbian. 'E': attitude is butch - yes could be a lesbian. 'F': yes - haircut. 'H': wouldn't have picked her. 'I': unsure out of context, not immediately identifiable as a lesbian (Australian lesbian).

As lesbian characters do not generally appear on television within a homonormative context, the signs of identity necessarily take on more significance. Perhaps this is why Maia and Jay were as hard to identify in the heteronormative environment of Shortland Street as the lesbians in the photographs. In a homonormative context like that of The L Word, a lack of 
obvious and stereotypical signs of lesbian identity does not affect the audience's ability to identify the lesbian characters.

Most participants agreed that lesbian characters were appearing more often on prime-time television:

There's more of it on mainstream TV, not just in porn (gay adolescent).

There are more characters playing lesbians, though still very few (New Zealand lesbian).

There are more lesbian characters on TV than there were 10 years ago (New Zealand lesbian).

Most also acknowledged the quality or verisimilitude of these characters had not improved significantly.

\section{A Catalogue of Conditions}

Gross argues the "suppression of positive or even 'unexceptional' representations serve to maintain and police the boundaries of moral order" (Gross 2001, p.16). Those participants unhappy with the gallery of fictional lesbians they had seen complained about the homogeneity of the characters:

In the main representation has been directed to either keep lesbians as nonthreatening e.g. pretty/glam or to tantalise men (Australian lesbian).

They all appear too glamorous and/or melodramatic (heterosexual man).

Because they always fit into some sort of stereotype ... they aren't just normal people (gay adolescent).

And the conditions that accompany them:

Lesbians on TV have much narrower lives than straight characters, who are represented as whole people (heterosexual woman). 
They always seem to be problem-plagued, breaking up, vulnerable and marginalised (New Zealand lesbian).

Relationships are always short-lived and full of drama (heterosexual woman).

Some were strong, but emphasis was on vulnerability, lack of acceptance, problems, emotional insecurity, partnership instability (New Zealand lesbian).

I notice in all the programmes I have seen the lesbian relationships I have seen are between young women and don't last. You don't see older women in stable long-term relationships and doing ordinary things and being sexual or intimate (New Zealand lesbian).

Or, that when lesbian characters were shown, their sexuality defined them:

In general, they are presented as plot devices, an 'issue' not as ordinary people who happen to be gay (heterosexual man).

There is nothing ordinary about it, it was introduced for one purpose, to explore a theme or otherwise the character was made something of (heterosexual man).

It is a paradox that while television's lesbians characters are defined by their sexuality, they are usually desexualised (Kessler 2006, p.131). A meaningful measure of contemporary lesbian representation is how intimacy between lesbian television characters is treated, particularly in comparison to heterosexual characters. While the literature supports the idea that the majority of heterosexual men find female coupling arousing (Capsuto 2000, p.332; Kinsey et al. 1965, p.486), sexual intimacies between women have usually been restricted to pornographic texts. Sex scenes of varying degrees involving heterosexual couples have been a staple part of mainstream television dramas for decades; they represent a reality of a couple's relationship. The same privilege is not extended to lesbians. The majority of participants (88\%) reported the lesbian characters they had seen were in romantic or sexual relationships, but the intimacy they remembered was weak, and sex was only implied: 
Kissing, covert making love, holding hands (New Zealand lesbian).

Rarely ... innuendo of a sexual relationship (heterosexual woman).

'Tame' kissing as compared to the more explicit kissing you see constantly with hetero characters (Australian lesbian).

Kissing, sex but not explicitly (gay man).

Kissing and cuddling, I don't think there was ever a shot of them in bed together (heterosexual man).

Or lesbian sexuality was explored as a dalliance:

Women were shown kissing but no sex scenes, but in an 'experimental way'...went back to boys afterwards (heterosexual woman).

Lesbian couples on Shortland Street were allowed fewer instances of intimacy observed during my analysis, and they were limited in their intensity. When Jay and Maia are paired with men, however, the intimacy was much more explicit. Even when lesbian intimacy was a central storyline, heterosexual intimacy still took primacy. In contrast with Shortland Street, the frissons between the women and their inamoratas in The L Word were explicit, while also being contextually comfortable. Further, The L Word's depiction of the issues involved when a lesbian couple want to start a family was eminently more realistic than Shortland Street's storylines (this issue will be explored in my analyses of the two series in Chapters 7 and 9).

When I asked participants if they could recall any happy, functioning lesbian couples on television, one participant from the heterosexual men's group responded:

No, I can't think of one. The fact that they are lesbians is the main thing about them and whatever happens is going to happen to them will be a result of that ... they are awaiting some sort of crisis, it's always a crisis around the fact that they are a lesbian not just that they have the same crises as everyone else (heterosexual man). 
Many heterosexual men find sex acts between women titillating (Capsuto 2000, p.332; Russo 1981, p.6). Many participants felt the lesbian characters they saw were paraded for the arousal of heterosexual men, as opposed to any desire to be inclusive:

The majority, especially U.S. shows, are tokenist, fit a stereotype conceived by non-lesbians, and/or are there for the little thrills their sexuality provides for heterosexuals (heterosexual woman).

Tends to focus on sexual aspects as a tool for male viewer arousal. (heterosexual woman).

Also tend to be all about lesbian 'sexuality' and sexual behaviours, and not all the other parts (economic, legal, domestic etc etc) of lesbian lives (heterosexual man).

Why focus on two girls kissing? I think it's only to turn on male viewers. Why are the women always young and pretty? That's what men want to see. Why not show more of the love and friendship part? (heterosexual woman).

\section{Reactions to Representations of Same-Sex Intimacy}

Participants' reactions to intimacy between lesbian characters in relationships are recorded in Table 7 below (participants were able to nominate more than one reaction from the choices available). The most frequent reaction $(n=26)$ was that participants were pleased lesbian sexuality was shown. Arousal was the second most frequent reaction $(n=14)$. Of the lesbian participants who reported that they were aroused by the intimacy, many also expressed their pleasure at seeing themselves and their sexuality represented. The reactions of the New Zealand and Australian lesbian samples were quite similar. The only participant who indicated she reacted with disgust was from the New Zealand lesbian group, and her disgust stemmed from the frustration she felt about the quality of lesbian fictions. She explained:

There have been good and bad portrayals. It is good to see portrayals of lesbians on TV but quite frustrating to see more negative images or a lack of long-term characterisation. 
Two New Zealand lesbian participants reported their embarrassment along with pleasure, their supporting comments reflected those from two homosexual adolescents who also reported embarrassment as a reaction. These participants found lesbian representation to be confronting when in the company of one's parents.

Table 7. Participants' reactions towards same-sex intimacy.

\begin{tabular}{|c|c|c|c|c|c|c|c|}
\hline & 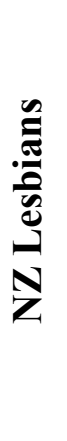 & 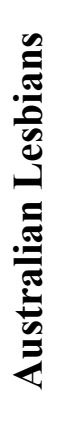 & 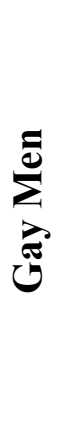 & 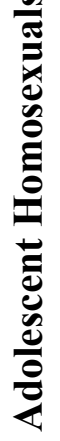 & 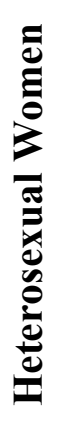 & 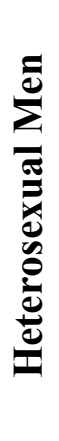 & $\stackrel{\vec{\sigma}}{\stackrel{\sigma}{\theta}}$ \\
\hline I was disgusted & 1 & 0 & 0 & 0 & 0 & 0 & 1 \\
\hline I had no significant reaction & 0 & 0 & 2 & 2 & 3 & 5 & 12 \\
\hline I was turned on & 5 & 5 & 0 & 1 & 0 & 3 & 14 \\
\hline I was offended & 0 & 0 & 0 & 0 & 0 & 0 & 0 \\
\hline I was pleased & 10 & 6 & 2 & 3 & 4 & 1 & 26 \\
\hline I was embarrassed & 2 & 0 & 0 & 2 & 0 & 0 & 4 \\
\hline I did not care & 0 & 0 & 2 & 0 & 0 & 1 & 3 \\
\hline Other & 2 & 1 & 3 & 0 & 3 & 0 & 9 \\
\hline
\end{tabular}

Combined, 15 participants reported they did not care about, or had no significant reaction to, representation of lesbian intimacy, suggesting they found the representation of samesex desire between women unremarkable. None of these were lesbian participants.

Eleven of the lesbian-identified focus group participants reported they had found some of the lesbian fictions they had seen arousing. The L Word and mini-series Tipping the Velvet were the two sources most mentioned by lesbian participants, where physical intimacy was most overt between its lesbian characters:

Full-on sex scenes in The L Word and Tipping the Velvet.

Performing oral sex, dildos. 
The L Word portrays all sorts of intimacy between the women.

Most explicit would be Tipping the Velvet and The L Word where characters were in bed together having sex.

Tipping the Velvet sexual contact.

Participants other than lesbians responded positively to lesbian desire represented on television:

It validated my own alternative sexuality. I was glad to see alternative sexualities presented because I felt it validated my own situation in the eyes of the audience (gay man).

Some recognised the importance being represented in mainstream media has on a marginalised minority such as lesbians:

I was pleased because I wanted my friends' relationships to be reflected in popular culture (heterosexual woman).

'Norming' homosexual relationships on screen I imagine may be

affirming for homosexual people, especially those who are young and 'confused' (heterosexual woman).

Others were pleased to see lesbian desire for their own edification:

Well, I don't really know many lesbians well and just wondered how their relationships would work (gay man).

I was interested to see how they would portray intimacy, I thought it was a bit forced, it didn't feel instinctive, maybe because it was a bit polite and ra-ra girls-schooly rather than what would actually happen (heterosexual woman).

However, intimacy between women, no matter how tepid, proved embarrassing for some of the adolescent participants: 
My parents were in the same room, so I left! (gay adolescent).

It's unusual to see so kinda kinky but weird if you see it with parents (gay adolescent).

After the more intimate nature of the discussion forums, I anticipated the anonymity of the questionnaire would result in participants replying in a more candid fashion, especially to the more sensitive questions included. While the topic was not brought up in discussions, three participants from the heterosexual men's group and one from the pilot were brave enough to say they were aroused by the intimacy, while one commented further that the femininity of the characters played a central role to his arousal:

The attraction was to the fact that both women in the scene looked very feminine. I guess it was the typical male reaction to the visual (heterosexual man).

\section{Realism}

When asked if the gallery of fictional lesbians they could recall were realistic, the majority of participants $(n=24)$ said no, 16 said yes, two said yes and no, and six were unsure. Not all participants gave reasons why they thought lesbian characters were unrealistic. Those who thought the characters they had recalled were unrealistic commented:

[Lesbian representation on television] does not represent the full spectrum of our community ... In the main representation has been directed to either keep lesbians as non-threatening e.g. pretty/glam or to tantalise men (Australian lesbian).

Because lesbians are all sorts of people, and the very limited appearances of lesbians does not portray our diversity (Australian lesbian).

Not at all realistic considering the range of lesbians I know (heterosexual woman).

Commenting on the heteronormative bias of lesbian characters on New Zealand television, these participants wrote: 
The Shortland Street lesbians seem totally unrealistic. They don't seem plausible in their interactions with each other, they sound like whiny schoolgirls. It just doesn't wash (heterosexual man).

They were all much more a part/concerned with heterosexual society than lesbians I know in real life (New Zealand lesbian).

Others thought realistic lesbian representation could not take place with so few lesbian characters:

You cannot have a realistic portrayal with such a small showing of lesbian characters (heterosexual woman).

While some of the characters recalled by participants were shown in low-status occupations that have long been the reserve for stereotypical lesbian characters (e.g., prisoners, prison officers, nurses, and factory workers), they noted many contemporary lesbian characters were placed in more professional roles (e.g., doctors, CEOs, art gallery museum manager, journalists, lawyers, entertainers, and a bookstore owner). The improved socio-economic status shown has been a welcome change for one lesbian participant:

Realistic portrayals of part of the community (professionals, 'feminine' appearance) (Australian lesbian).

However, the same participant continued:

- but unrealistic insofar as very limited portrayals of butch women (plus issues such as unemployment/lower economic status not really shown).

Many of the lesbian-identified participants, who felt the lesbian characters they had seen were realistic $(n=13)$, were still reserved in their assessments:

Portrayals of lesbians on tv has become more varied in the past few years and I enjoy seeing that. In life variety is huge, unfortunately tv does not come close to portraying such diversity (New Zealand lesbian).

Some portrayals are completely unrealistic (e.g., Lesbian Vampires), but that genre is not supposed to be realistic anyway. Others, (e.g., The $L$ 
Word), have quite a lot of observation about lesbian culture that rings true (Australian lesbian).

In line with Kitzinger's assertions that eroding the differences between sexual minorities, lesbians and gay men become aligned with the dominant order (Kitzinger 1987, p.48), some participants from the heterosexual women's group considered lesbian television representation was realistic specifically because of their assimilated characteristics and behaviour:

Portrayals are often very subtle and non-offensive.

They [the lesbian characters] have been portrayed as fairly normal-looking and acting women, no far out stereotypes.

Women on Shortland Street have been portrayed as 'normal' - not deliberately lesbian.

Some of the more recent examples on Shortland Street are just normal looking women.

\section{Gay Male Visibility}

When asked if gay men had a higher television profile than lesbians, the majority of participants thought they did (89.7\%), 6.2\% thought gay men were not more visible than lesbians, and $4.1 \%$ were unsure.

While seven individual lesbian characters were counted during the measurement period, there were 10 individual gay male characters. This supports the position that gay men occupy a more privileged place in the cultural consciousness than lesbians. Although the length of the sample period was modest, its reliability was affirmed by the large number of focus group participants $(98.5 \%)$ who reported the existence of this bias as a general occurrence. A number of female participants identified male privilege as one of the reasons why gay men have more visibility than lesbians:

Firstly because they are men and therefore have some degree of advantage - are likely to get their images out there, also gay male stereotypes have 
also been made 'safe' through programmes such as Queer Eye. They've become commodified (heterosexual woman).

Men generally still dominate most sectors of society - TV is no exception (New Zealand lesbian).

Because men in society in general are more visible and have more financial resources (New Zealand lesbian).

Blatant sexism...or should I say genderism! (heterosexual woman).

Because of the higher profile of gay men than lesbian women. Right back to the bible, lesbianism is not mentioned ... always low profile (gay adolescent).

A few participants thought gay men had achieved a higher profile because of negative attention by a heterosexist media:

Historically gay men have been portrayed in a negative way (e.g., gay German army personnel to indicate weakness) (heterosexual man).

They were stigmatised by law, linked with paedophilia, AIDS epidemic has pushed them into becoming more visible (heterosexual woman).

The majority of participants attributed the inequity between gay men and lesbians, especially within mainstream visibility, to the more positive social profile gay men had achieved:

They are not as disliked by society - and the whole good-looking, 'fabulous' gay boy thing seems to be entertaining for hets (Australian lesbian).

Their stereotypes are more attractive - good looks, witty talk, etc. (New Zealand lesbian). 
Traditionally gay men are perceived as having a 'fabulousness' factor that lesbians don't share in such media (gay man).

They're seen as good-looking, smart, cultured and entertaining (gay adolescent).

Some gay 'attributes' (dress sense, grooming, entertaining) are now seen as desirable characteristics in all men (heterosexual man).

Elaborating on the good gay/bad lesbian divide, these participants from the heterosexual men's group commented:

Participant A: You have shows like Queer Eye for the Straight Guy...there's no lesbian equivalent that I've heard of. It's around the myth that gay men dress better and have things to offer straight men about grooming. So I think that there are some stereotypes about gay men that are celebrated by TV and generally accepted by quite a wide audience.

Participant B: I think one factor is that gay men have had a role in being found funny by scriptwriters and now increasingly that's become quite a stock character in a lot of shows whereas I can't think of lesbians in the same way.

Participant C: I don't think people bat an eyelid about what sexuality an entertainer is ... but for some reason, mainstream shows have tended to conform to rigorous rules.

Theoretically, in the case of the Queer Eye programme, changing a heterosexual man's habits and dress to become more attractive to gay men is not frowned upon, because of the popular assumption that gay men have the same tastes as heterosexual women, the target of the Queer Eye client's own desires. As developing desire in women, or increasing the number of women that find the client attractive, is the goal of the programme, making him over, even in a gay image, is only a bi-product of the process.

The commodification of difference by the fashion industry has seen lesbian street fashion (e.g., trucker caps and singlets) "poached" and incorporated into heterosexual "high 
fashion" (Hawkes and Scott 2005 p.80). Despite the observation of media theorist Danae Clark that lesbians' sartorial identity is becoming fashionable (Clark 1993, p.189), my suggestion of a Lesbian Eye for the Straight Woman programme met with this response from participants in the New Zealand lesbian group:

Participant A: You wouldn't get the same kind of responses [as for Queer Eye for the Straight Guy], lesbian women tend to be more kind of negative: serious, not so fun, lacks style ... I know those aren't true, but...

Participant B: But are they not true? Haven't lesbians really been portrayed how lesbians are? Twenty-five years ago if you wore a dress to a club you got your throat cut and it's only recently, really, that lesbians have allowed women to wear a skirt, to wear dresses.

\section{Tensions of Compromise: Testimonies of Lesbian Viewers}

Commenting on how they reacted to seeing desire between lesbians characters depicted on television, these lesbian participants responded in the following ways:

Ecstatic that I wasn't the only one... As a child you don't get the opportunity to meet other kids with the same feelings, it's the first inkling I had that perhaps there was a community out there. Nice to see yourself represented in media (Australian lesbian).

I felt I was seeing something of my own desire being played out. I felt that these shows mirror me back which the het world doesn't (New Zealand lesbian).

Thrilled and affirmed! (New Zealand lesbian).

It is important to feel that my life is acknowledged, even indirectly in the media (New Zealand lesbian).

It was just so great to see intimacy between women instead of relentless heterosexual coupling (Australian lesbian). 
I could relate to the characters, either realistically or fantastically, because they act as mirrors to reinforce my legitimate place in the world (New Zealand lesbian).

While delighted to have their sexuality acknowledged (reflecting homophily and identification), the deeper vicarious pleasures (para-social bonding) lesbian participants took from the lesbian characters they found was often severely limited by the lack of homonormative values of the lesbian characters, as St Germain (2003) found in her study. Interestingly, the lack of explicitly lesbian characters did not spoil the vicarious viewing pleasures for one of my lesbian participants who said she enjoyed identifying with male characters in action movies. A scuba-diving character played by Lloyd Bridges had been one such role model, and the way that character (and others) interacted with female characters aided in the development of her own knowledge of her sexuality.

The majority $(n=33)$ of participants thought it was important for unambiguously lesbian characters to be seen on television, but for different reasons. Some heterosexual participants cited equality and education of society:

Because lesbian women exist! We can't fight prejudice if we don't provide wide-spread images of the whole spectrum of society. Lesbian women are doubly disadvantaged and therefore vulnerable to this prejudice - and must be realistically portrayed (heterosexual woman).

Reflecting the societal assumption that everyone, including television viewers, is heterosexual, this participant comments:

It gives the viewers exposure and therefore, hopefully some understanding about relationships other than theirs that exist in society. Knowledge hopefully leads to better understanding/empathy etc (heterosexual man).

It's important to depict all types of loving relationships frequently so they'll be accepted as 'normal'. People need to be exposed to the more mundane aspects of relationships involving lesbians not just the sex, to show lesbians are just like them or people they know (heterosexual woman). 
Similarly, many lesbian participants wanted to see more intimacy depicted between lesbian characters, but again, for different reasons, e.g. to see their own sexuality validated:

I was glad to see women together sexually I felt I was seeing something of my own desire being played out. I felt that these shows mirror me back which the het world doesn't (New Zealand lesbian).

Because being lesbian is to have sex and be attracted to women and seeing that on telly is a form of validation (New Zealand lesbian).

I would prefer to see more sensuous erotic lesbian relationships rather than the violent, heterosexual power sexual relationships and the continual degradation of women (New Zealand lesbian).

Some were sure that more frequent depiction of lesbian sexuality on television would educate heterosexuals:

Has a normalising effect and moves away from lesbian sexual intimacy being 'wrong', controversial or taboo (Australian lesbian).

It promotes our visibility and I think it has helped to increase public acceptance (New Zealand lesbian).

Others sought parity with heterosexuals:

Because there's loads of intimacy for straight couples, it's only fair (gay adolescent).

I don't see any reason to discriminate between levels of intimacy between heterosexual, gay, or lesbians - a level playing field (New Zealand lesbian).

Some demanded lesbian characters that were more sexually explicit purely for arousal:

Because I like to watch! (Australian lesbian). 
Other lesbian participants indicated they sought more finesse and more meaning from depictions of lesbian intimacy, other than just sex:

Too much importance is placed on fucking. The intimacy, not necessarily fucking, is to be encouraged (New Zealand lesbian).

Yes but only if there is a good balance of quality relationships and not just for the sex (New Zealand lesbian).

Intimacy, not sex - pandering to the patriarchy (New Zealand lesbian).

Confirming the lesbian participants' concerns about the exploitative aspect of lesbian intimacy, these participants observed:

Many representations of sex seem to be gratuitous to the story (heterosexual man).

Television, like other media, seems to mainly depict intimacy in pornographic terms, rather than terms of sensuality (heterosexual man).

On a more fundamental level, most lesbian and gay male participants wanted to see their lives reflected in meaningful ways:

Because I love to see my life validated and portrayed on TV (and books and movie screens too!). I like to see my story (Australian lesbian).

[Television] gives people who are coming out or otherwise something to identify with. We are part of the community just as much as any other group, why shouldn't we be portrayed? (Australian lesbian).

[Television] reflects my life back to me and gives openings for conversations with others and builds visibility (New Zealand lesbian). 
I could relate to the characters, either realistically or fantastically... they act as mirrors to reinforce my legitimate place in the world (New Zealand lesbian).

I think it important to feel that being lesbian is $\mathrm{OK}$, is not something to hide, not something so strange (New Zealand lesbian).

Because we are real people and we should be fairly represented (gay adolescent).

It is important to provide visible and fair representation to the gay community in order for the conservative right to see we are ordinary people (gay man).

The importance that television lesbian representation holds for many lesbian viewers was voiced by the majority of participants, lesbian and heterosexual, and the weaknesses in representation were also obvious to the majority of participants. Similar to St. Germain's participants, who expressed their anger at the stereotypes that characterize lesbian characters on television, but who were grateful for "any representation" (St Germain 2003, p.178), many of the lesbian participants in my study displayed a similar tension:

The heterosexual interpretation is always at the forefront of my mind, but I like it as it so rare to see lesbians on mainstream tv however misrepresented they are (New Zealand lesbian).

Showed stereotypes but watched it because that was all there was (New Zealand lesbian).

When you see so little lesbian representation on TV it is obviously enticing/exciting more so than if we viewed it regularly (Australian lesbian).

Because there are so few shows that portray lesbian sexuality so I am always pleased to see it (Australian lesbian).

There is a whole show about lesbians (Australian lesbian). 
Perhaps the comment most indicative of the lack of entitlement to more realistic lesbian representation was:

Although 'sanitised' portrayals in most instances it was at least the beginning of a level of acceptance - you have to start with small steps (New Zealand lesbian).

With the exception of some gay men, all participants agreed that lesbian representation was still inadequate. ${ }^{33}$ While more frequent representation of lesbian characters was a common change sought by participants, several sub-themes were evident concerning the quality of lesbian representation:

Not all lesbians are feminine - attractive, successful - perhaps a little more diversity which reflects lesbian community (New Zealand bisexual woman).

Have some successful relationships portrayed and lesbians who are just lesbian and not crazy or separating from their partner (New Zealand lesbian).

While others indicated a need for unexceptional lesbian representation, they did not nominate assimilation; they sought unremarkable representation:

They should have more depth than just their sexuality. Their sexuality should be incidental to their character rather than the defining characteristic. A wider range of women should be shown, even if they don't appeal to men (heterosexual man).

I'd like to see a variety of lesbians shown in long term relationships doing sport, working in ordinary jobs being butch as well as femme, being older, being mothers, daughters and lovers, not just as sexual partners but as life partners too (New Zealand lesbian).

\footnotetext{
${ }^{33}$ Those participants who did not support change offered no explanation. The opportunity to pursue this further in the focus groups was not available as the question was part of the questionnaire.
} 
Queers portrayed in a way where their sexuality is not the most important part of their characters (gay adolescent).

Other participants specifically requested more homonormative programming:

More programmes that reflect lesbian women's own opinions and ways of living (heterosexual woman).

What is not represented is the knowledge and contribution that lesbians make towards making this a better society in terms of commentary and discussion, film-making, documentary, and social commentary (New Zealand lesbian).

I think TV is a valuable tool for cultural change. If truthful representations of lesbians are shown on TV at least we are visible, at best society will start seeing lesbianism as normal and ok (New Zealand lesbian).

Another participant requested:

Make the characters more realistic. Don't undercut their sexuality by suggesting they could also be heterosexual at the same time (heterosexual woman).

I gave participants the opportunity to anonymously comment on their experience of the research process in the questionnaire. While not every participant completed this section (including the three heterosexual men who did not attend a focus group), those who did enjoyed some part of the process; nine participants indicated they enjoyed the whole process, and the majority $(n=23)$ found the discussion the most interesting component. Three participants reported they felt inhibited by the exposure/visibility of participating in the focus groups; two because they felt they did not watch enough television to contribute greatly to the group, while the group discussions brought up some unsettling memories for the third focus group participant. She commented:

Some of the ideas/memories had strong feelings attached to them that I would not necessarily have 'plugged into' in this kind of company. Maybe fewer people would have been a little easier (New Zealand lesbian). 
The strength of the feedback about the research experience as a whole was favourable:

I found the experience very interesting and personally thought-provoking. Would have liked more time to answer your questions (New Zealand lesbian).

Well structured and relaxed. I enjoyed it a lot (gay adolescent).

It was nice and relaxed and I was interested in the content (gay man).

Very good experience, good cross-section of ages and backgrounds (heterosexual woman).

Criticisms about the research process came from two participants who commented on the structure of the questionnaire and research process itself:

I found the questionnaire really difficult, it was so open. Great as oral questions (heterosexual man).

Perhaps some of the images would have been good to discuss at the start something more specific than a general chit chat about stereotypes...however maybe this would skew (potentially) the rest of the survey (gay man).

As facilitator of the focus groups and researcher, I found keeping the conversation relevant to my project, without stifling the spontaneity of the participants' interactions, a difficult balance to achieve. This was especially evident in the New Zealand lesbian focus group. As the schedule of focus groups progressed I became better able to keep participants energised, but focussed on the research questions. No participant commented about me or my role in the research. 


\section{Conclusion}

In summary, there are few lesbian television characters available on New Zealand television. The data captured in the focus groups and questionnaire revealed viewers' knowledge of stereotypes associated with lesbians was attributed to heterosexist forces reflected in media. Viewers' recall of lesbian television characters supported the paucity of characters from the content analysis of New Zealand's four, free-to-air television channels.

In this chapter, viewers have been given the opportunity to report their personal responses to the lesbian television representation available to them. Understanding the effect/s of this representation necessarily requires a theoretical framework with which to make meaning of its content and the manner in which the audience interprets it. This is the subject of the following chapter, and the framework will be used to support my analyses of Shortland Street and The L Word in subsequent chapters. 


\section{Chapter 6}

\section{Critical Communication Theories and the Politics of Television Representation}

To further my interrogation of lesbian representation on New Zealand television it is necessary to describe the interrelated media models of cultivation theory (Gerbner et al. 1986), symbolic annihilation (Gerbner and Gross 1976), and media hegemony (discussed by McQuail 1994), that explain television's use, and depictions of, sexual minorities. This chapter explores these theoretical perspectives and concludes with a discussion of the role internalised scripts have in how the audience interprets the messages the media promulgates. These theories are used to assess the homonormative quality of Shortland Street and The L Word, in later chapters.

\section{Introduction}

Critical communication theories are broadly concerned with the ideological domination of one group over another, and the ways in which dominant groups manipulate the media to further their own interests and "subvert the interest of certain groups and classes" Littlejohn 1999, p.225). Despite criticism that communication theory neglects the study of gender, gender difference, and sexuality (van Zoonen 2004, p.15). Whether they see class, culture, or gender as the basis of inequality in society, Denis McQuail writes that critical theorists postulate that the mass media promulgate the interests and ideology of the dominant societal group(s) (McQuail 1994, p.258). By reflecting the values, aspirations, expectations, and agendas of these groups, the media is an instrument by which dominant social groups perpetuate their dominance (Holtzman 2000, p.301; Morgan and Shanahan 1997, p.9; see also Gross 2001). This perspective has clear resonance with feminist theory and elects critical communication theory as a tool for feminist research. Essentially then, critical communication theory is concerned with:

- media content as a commodity controlled by the dominant social groups and used to promote their interests; and

- the media as a means of constructing a culture that benefits the interests of the dominant class (McQuail 1994, pp.255- 258). 


\section{Hegemony and Television}

The concept of hegemony, described by Italian Marxist Antonio Gramsci, has been adopted by communication scholars to explain the subtle influence media representation has on its audience. The media hegemony thesis positions media as the tool of the dominant ideology (Littlejohn 1999, p.334), and by representing the interests of those already in power, it subverts the interests of marginalised groups (McQuail 1994, p.256). It does this through pervasive and deliberate influence rather than through any forceful means (ibid., p.99).

Intense debate exists about the media's role in the maintenance of hegemony. Stuart Hall, and a group of cultural theorists known as the British Cultural Studies Group, posit that hegemony is "always a fluid process" and therefore ... "the struggle between contradictory ideologies of constantly changing" (Hall 1980, cited in Littlejohn 1999, p.235). Those who directly oppose the thesis of media hegemony argue that although "media portrays ideology explicitly ... opposing voices will always be part of the dialectical struggle between groups in society" (Littlejohn 1999, p.236). For example, communication scholar Kevin Carragee argues that while the news media emphasises the meanings of those in political or economic positions of power, oppositional groups can also advance dissenting political or social views via the same mode (Carragee 1993). However, Littlejohn points out, "the media are dominated by the prevailing ideology, and they therefore treat opposing views from within the frame of the dominant ideology which has the effect of defining opposing groups as "fringe"” (Littlejohn 1999, p.236). Dealing specifically with media bias about homosexuality, Linda Holtzman observes:

The dominant hegemonic belief has been that heterosexuality is natural and that homosexuality is therefore "unnatural". The scarcity of gay and lesbian characters and themes and the recurrence of negative images has been the popular media's contribution to this set of beliefs or ideology (Holtzman 2000, p.300).

Butler has pointed out that, "the racialization of the subject or its gendering or, indeed, it social abjection more generally is performatively induced from various and diffuse quarters that do not always operate as "official discourse"" (Butler 1997, p.157). More specifically, cultural theorists describe how common conceptions of reality amongst the viewing public are cultivated by accumulated exposure to the overall patterns of 
television. In this manner television insinuates its controllers' ideology in the viewer (Gerbner et al. 1986).

\section{Cultivation Theory}

Cultivation theory examines the relationship between accumulated exposure to television content and the viewer's perception of social reality:

Television is a centralized system of storytelling. It is part and parcel of our daily lives ... Television cultivates from infancy the very predispositions and preferences that used to be acquired from other primary sources ... television has become the primary common source of socialization and everyday information (mostly in the form of entertainment) of an otherwise heterogeneous population (Gerbner et al. 1986, p.18).

Television is the common symbolic environment believed to be an homogenising agent in culture (Gerbner et al. 1986). The images and relationships relayed into our homes every day by this ambient medium reflect the dominant societal norms, inform our world, and shape our beliefs. Viewers who spend significant time immersed in television viewing are more likely to perceive the world in a way that conforms to what they see on television, compared with those people who view television programmes discerningly (Gerbner et al. 1986, p.27). Moreover, heavy television viewers often subscribe to a reality consistent with that shown on television, even though television does not often reflect the actual world, and they come to adopt the reality they see on television as their own social reality (ibid., p.27). Gross and Gerbner call this phenomenon "mainstreaming" (Gross 2001, p.7, Gerbner et al. 1986), a term they developed to describe "a commonality of viewpoints and values that television tends to cultivate in its viewers" and which they have identified as the "embodiment of a dominant ideology" (Gross 1991, p.23). As Bourdieu writes, television representations and reports are produced:

Often without thinking and with no idea of the difficulty and seriousness of the subjects they are talking about or the responsibilities they assume by talking about them in front of thousands of people who watch ...without understanding what they see and without understanding what they don't understand. Because these words do things, they make things - they create 
phantasms, fears, and phobias, or simply false representations (Bourdieu 1998, p.20).

To demonstrate television's cultivation effect among heavy viewers, Gerbner and colleagues examined viewers' perceptions of older people. Older people are significantly under-represented in television drama. However, people over 65 are the fastest growing segment of the world population. Despite the reality, heavy viewers believed television's version of reality and regarded the elderly as a "vanishing breed" (Gerbner et al. 1986, p.27). Images of women on television provide another example of how the audiences' perceptions of gender differences can be influenced. Men appear on television in greater frequency than women. Interestingly, heavy viewers did not "ignore their daily experience", and believe that men radically outnumber women in society as they do on television, but heavy exposure to messages that position men as the heroes and women as the victims had a very real effect. Heavy viewers "absorb the implicit assumptions" embedded in the messages that men have greater abilities and more interests than women (Gerbner et al. 1986, p.28). Consequently Bourdieu argues:

The political dangers inherent in the ordinary use of television have to do with the fact that images have a peculiar capacity to produce what literary critics call a reality effect. They show things and make people believe in what they show... (representations) can be loaded with political or ethnic significance liable to unleash strong, often negative feelings, such as racism, chauvinism, hatred of the foreigner or, xenophobia (Bourdieu 1998, p.21).

Television promotes and naturalises heterosexuality to its audiences. The scripts of compulsory heterosexuality are so ubiquitous within prime-time television it is difficult for audiences to avoid it (Kim et al. 2007, p.156). This Moebius Strip of expectation becomes the unshakeable norm, a pattern so fundamental to the content of television that it affects every genre. Televisual representations of non-heterosexuality must always support heterosexuality (Conway 2006, p.79), as that is the mainstream message the mainstream audience expects to see. Consequently, television's fictional lesbians must serve the meta-narrative of heterosexuality: they cannot question it (resulting in the assimilated model), they suffer for rejecting it (the 'sad', 'bad', or 'mad' model), or they reinforce it (by turning to heterosexuality). At the same time, television viewers are a heterogeneous group, marked and disposed by differences in education, experience, ethnicity, age, sex, sexuality, socio-economic status, and relationships status. According to 
media scholars Frances Bonner, Lisbeth Goodman, Richard Allen, Linda Janes and Catherine King, these factors influence how they are likely to receive, interpret, and accept the prevailing mainstream patterns with which television is awash (Bonner, et al. 1992a, p.7; see also Minh-Ha 1991 p.5; and Fiske 1989, p.84).

\section{Theories of Media Effects}

Despite the findings in support of the hegemonic effect of the media, communication scholars are polarised about the extent of media effects on audiences, and the kinds of audiences that receive the messages the media intends. The major themes of contention relate to five broad areas: mass society vs. community; theories about limited vs. powerful effects; active vs. passive audience debates; theories of individual outcomes; and the body of work known as critical communication theories (Littlejohn 1999). At the heart of them all is the tension between the viewer and the viewed, and whether the power to make meaning from messages lies with the creators or the consumers of television programmes. $^{34}$

One of the earliest and best known communications theorists, Harold Lasswell, offered this simple model of communication to outline basic elements of communicating a message:

WHO

\section{SAYS WHAT}

IN WHICH CHANNEL

\section{TO WHOM}

\section{WITH WHAT EFFECT}

(Lasswell 1948, cited in Littlejohn 1999, p.338).

Although Lasswell identified three social roles performed by mass communication surveillance of the larger environment, achieving consensus among segments of society, and the transmission of culture - it is the last component in Lasswell's model that deals with how the medium affects the audience (Lasswell cited in Littlejohn 1999, p.338). Audience studies are typically aligned to this broad model and focus on reception (the ways people experience, interpret, and respond to media messages) and on functionality

\footnotetext{
34 This interest in causality is not a focus of Gerbner et al.'s (1986) cultivation theory, but it is a part of the cultivation model (Morgan and Shanahan 1997, p.9).
} 
(the way a medium functions in viewers' lives). Mulvey (1975) linked the audience with media's content in a different manner, proposing that the images were constructed for the purpose of voyeurism (she refers to Freud's conceptualisation of scopophilia), and that the audience was encouraged to watch for pleasure - a pleasure that Mulvey, and de Lauretis, argue is dependent on patriarchal ideology (Bonner et al., 1992b, p.191). Within the wider literature, the nature of the audience revolves around two related dialectics: whether the audience is a "mass public versus the idea that it is a small community" (Littlejohn 1999, p.335) and, most relevant to this study, whether the audience should be considered passive or active.

The theory of mass society considers viewers as an amorphous and malleable population that can be easily and heavily influenced by television (Gerbner et al. 1986, p.27; Lasswell 1948, cited in Littlejohn 1999, p.338). The concept of television audiences as an homogeneous mass arose largely from the idea that television was so powerful, so authoritative, that it replaced the church as the teacher of the populace (Lasswell 1948, cited in Littlejohn 1999, p.338). The most radical claims about television and its influence over the masses came from the pioneers of Critical Theory such as Theodor Adorno, Max Horkenheimer, and Herbert Marcuse from the Frankfurt School. ${ }^{35}$ These theorists argued that capitalism, empowered by technology that could reach whole populations, was in a position to restrict and control cultural life as never before. Further, they predicted mass cultural forms of communication like television would create, as media scholar Justin Lewis finds, a "mass culture that was uniform and banal, reducing cultural life to the lowest common denominator available in the marketplace" (Lewis 1991, p.6).

The majority of early effects studies on television focussed on the relationship between levels of television violence and various forms of social behaviours (Gauntlett 2002, p.28). Along with the international community, New Zealand has invested considerable research into this area. Recent research conducted by Rajen Prasad et al. (2004), at the Centre for Communication Research at the Auckland University of Technology, found violent television content to be one of multiple causes of violence in society. The study notes that, because violent actions are complex, it is not surprising that the link between exposure to fictional violence and committing real-world violence is weak to modest (Prasad et al. 2004, unpaginated document).

\footnotetext{
35 The members of the Frankfurt School were philosophers and academics all directly or indirectly associated with the Institute of Social Research (Institut für Sozialforschung) of the University of Frankfurt, in Germany.
} 
Communication theorists who consider viewers as an undifferentiated mass drew heavy criticism. In addition to being overly simplistic, the 'mass culture' theory was also criticised as being an expression of elitist values implying "popularity necessarily impoverished and degraded culture" (Lewis 1991, p.6). The contrasting view, discussed by communications theorist Thomas Lindlof, is that the audience consists of highly differentiated communities, each with its own values, ideas, and interests (Lindlof 1988, p.86; see also Fiske 1987, p.84). Discussing the debates amongst feminist researchers, Natalie Fenton (2001) points out that "feminist researchers also reacted against the simplistic conception of the process of mass communication as one of linear transmission from sender to receiver to claim that female audiences play a productive role in constructing textual meanings and pleasures" (Fenton 2001, p.112).

Despite agreement that the audience is comprised of a variety of groups, many contemporary researchers have returned to the effects tradition, noting the causality between television's effect and audiences' behaviours and attitudes (Littlejohn 1999, p.348). Central to the active/passive audience debate is the question of the source, or where the locus of control lies (ibid., p.337). Communications scholar Frank Biocca defines the locus of control as "the place or agent wherein resides the major determining or causal force of the content and orientation of the audience member's cognitions and behaviour" (Biocca 1988, p.67). For early mass theorists like Lasswell (1948) the locus of control lay with the mass media, while later cultural theorist Marshall McLuhan (1964) argued that control lay with the medium itself. In an active audience paradigm, however, the locus of control lies firmly with the audience.

\section{Active Audience}

Research that ascribes power to the audience has become known as active audience theory, and is in line postmodern theory's "emphasis on plurality and difference" (Fenton 2001, p.114). While early work by communications theorist Joseph Klapper (1960) advanced the idea that audiences are affected by other variables besides the messages of the mass media (resources, norms, and response cost), the interpretative authority of the individual was perhaps made most famous by Barthes (1977) in his argument regarding the 'death of the author'. Similarly, Hall et al (cited in Littlejohn 1999, p.239), in their encoding/decoding model, explored the interpretive possibilities of audiences using their own categories to decode media messages in a way that opposed the dominant or preferred meaning of a message. De Lauretis discusses the interaction between the 
"context, pertinence, and purposefulness" of codes that enable any readings of a text against the grain, or with it - by connecting with the individual's subjectivity (de Lauretis 1984, p.47), or what Bonner et al. refer to as 'positionality' (Bonner et al. 1992a, p.7). These accounts of media audiences conceptualises them, not as an amorphous mass of consumers but as individuals who "actively read television in order to produce meanings that connect with their own experience" (Fiske 1987, p.84; Fenton 2001, p.112; Minh-Ha 1991, p.5). Academic John Berger uses the term "ways of seeing" to place the onus of deciphering a message (regardless of its intent) with the audience and their own characteristics and experiences (Berger 1972 cited in Bonner et al. 1992a, p.5).

The specific strategy sexual minorities employ to create meaning for themselves within a sea of heterocentric content (Fejes and Petrich 1993, p.410; Gross 2001, p.18; Kielwasser and Wolf 1992, p.354; White 1999, p.2) is referred to as 'reading queerly'. A famous example of this is how gay men created their own meaning in The Wizard of $\mathrm{Oz}$ in the 1950s (Hurley 2005, p.48). Here, gay men interpreted a mainstream narrative in ways that reflected their current existence and their hope for a better future. Notably, this supposedly individual act found a place in the gay male culture of the time suggesting this community used the story as a metaphor for their own struggle, rather than an example of reading queerly en masse.

A queer reading is easiest when the text is ambiguous or 'polysemic' (Fiske 1987, pp.8485). The equation is simple: the greater the polysemy, the less hegemonic or less dominant the meaning of the text, and the freer the audience is to use their interpretative powers to make oppositional readings from any message. Textual polysemy theoretically encourages multiple readings, but there is disagreement about what constitutes a polysemic text should the entire text be polysemic to warrant the label, or is it enough that one or two elements of the text are polysemic? Are polysemic texts actually screened during primetime television? Research indicates that while a television programme may be saturated with potentially ambiguous signs and meanings, many of us will "routinely experience television in much the same way" (Lewis 1991, p.55); the preferred reading will usually bear the dominant ideology (Bourdieu, 1998, p.16; Fiske 1987, p.117); and with the repetitive nature of television's texts, the intended message is difficult to escape (Bourdieu 1998, p.22; Fenton 2001, p.112; Dow 1996, p.14).

Subverting the dominant reading of the message is difficult to do, despite the presence of a polysemic text. Further, while Kielwasser and Wolf warn although reading a text 
queerly is empowering to individuals "who share a sense of collective subversion, of belonging to a legitimate or recognizable social category of others who perform similar acts of oppositional interpretation" (Kielwasser and Wolf 1992, p.364), they also point out that "the ability to subvert heterosexist texts ... must not be confused with an immunity to homophobic social forces" (ibid., p.364). In support, George and Achilles Theodorson, write that:

[while gay and lesbian youth] can certainly recast the televised world of 'boy meets girl' into one of 'boy meets boy' or 'girl meets girl' . . . this personal interpretive move does not alter the situation of pluralistic ignorance, in which individual members of a group believe incorrectly that they are alone or the only deviants in believing or not believing particular values, while in reality many others . . . secretly feel as they do (Theodorson and Theodorson 1969, in Kielwasser and Wolf 1992, p.364).

This argument is given added validity by Kim et al. (2007). While developing a system with which to count and categorise patterns of what is referred to as the Heterosexual Script, the authors found that in programmes that targeted adolescents, the primary message reiterated was that:

accumulating sexual experience with women is an important, desirable, and even necessary component of masculinity, and boys/men should obtain sexual experience by any means possible ... [and that] attracting boys/men's attention is the primary way by which girls/women attain and assert (a form of) power (Kim et al. 2007, p.154).

\section{Reinscribed Narratives}

Another challenge to the notion that audiences read queerly or 'against the grain' of dominant narratives to find social space for themselves is to be found in Australian educationalist Bronwyn Davies' (1989) study on understandings of gendered behaviour in pre-school children. This study highlights how the power of a pre-existing (cultivated) internalised script can allow the audience/viewer to override the intended meaning of a text (Davies 1989, p.66). The Paper Bag Princess (1987) by Robert Munsch and Michael Marchenko, the text that formed the basis of the study, offers a twist on the classic stories of the heroic male. It concerns a heroic princess who rescues her prospective husband from a dragon who kidnapped him and burned down her castle. After out-witting the 
dragon Princess Elizabeth rescues Prince Ronald. Instead of thanking her, Ronald berates Elizabeth, dressed only in a scorched paper bag, for looking dirty and dishevelled. Davies' study found that despite Princess Elizabeth's bravery, the children still read the standard plot into the story, and reported that it was the Prince who rescued the Princess. While none of the girls thought of Ronald as a hero, the expectation that the central male character will be attractive found some girls still positioning Ronald as a "handsome, brave, nice prince who loves Elizabeth", despite clear evidence to the contrary (Davies 1989, p.66). Likewise, some of the boys still managed to position him in a positive light and completely neglected the Princess's bravery. Moreover, despite his negative treatment of the Princess, few of the boys thought Ronald behaved badly, and many agreed with Ronald's rejection of the Princess because her once beautiful clothes had become dirty. In line with the insistence of Fenton (2001, p.112); Fiske (1987, p.84), Lindlof (1988, p.86), and Minh-Ha (1991 p.5) that viewers actively read texts through the lens of their own experiences, values, and interests, Davies concluded the story was read differently by each child, the differences in interpretation relating "in part to the subject position she/he takes up in the story (positioning her/himself as Elizabeth or Ronald or the dragon), and in part on her/his understandings of gender relations" (Davies 1989, p.60). The children actually continued to impose their internalised script of gender roles, already rigidly in place by the time they were five, reading the dominant message in a resistant text. Davies' study also demonstrates that although audience members may interpret in different ways, hegemonic ideas about femininity and masculinity played a significant part in overall interpretation by all of the children. As Davies comments, "The power of the pre-existing structure of the traditional narrative to prevent a new form of narrative from being heard is ever-present" (Davies 1989, p.69).

Internalised scripts can lead viewers away from or foreclose alternate readings (Hoffner and Cantor 1991, pp.78-79), and this has significant implications for how lesbian characters are represented, because there will always be viewers who are unwilling or unable to see homosexuality as something other than a deviance. As Bourdieu writes, "Ultimately television, which claims to record reality, creates it instead. We are getting closer and closer to the point where the social world is primarily described - and in a sense prescribed - by television" (Bourdieu 1998, p.22). While there is always the possibility that audiences will read 'queerly' or against the grain of conventional or hegemonic meanings and narratives, this does not challenge or undermine the wider notion that television's mass dissemination of normative texts is likely to produce normative effects. To have control of the texts and sites of cultural production with "the 
possibility of reaching everyone" (Bourdieu, 1998, p.14), as television has and does, is to have a "formidable instrument for maintaining the symbolic order" (Bourdieu, 1998, p.16). There is no need, from this perspective, to revert to the notion of the masses-asdupes mindlessly consuming media representations; or again, to engage in debates about the extent to which active audiences read subversively.

Quite simply the predominantly heteronormative narratives that dominate television and other important sites of cultural production (newspapers, magazines, film, internet websites) constitute the world that audiences come to recognise and internalise as normal (Gerbner et al. 1986, p.27: Gross 1991, p.23; Holtzman 2000, p.300). This 'reality' takes on the status of what Bourdieu calls the 'doxic' (Bourdieu 2000); that is, it is accepted as the way of the world, and thus it invariably reproduces itself and influences how and what audiences see. This is a world from which lesbians are largely excluded, and when they are included they are likely to be subject to the violence of vilification or heterosexual conversion.

\section{Conclusion}

This chapter has examined the power of television and how it promulgates mainstream norms. It is the position of this thesis that cultivation analysis, media hegemony, and symbolic annihilation offer explanations for the inequitable treatment of sexual minorities in the media, how viewers' perceptions, both lesbian and heterosexual, are informed by what they see on television, and the relationships that can occur between viewers and media personae all serve to maintain this imbalance. 


\section{Chapter 7}

\section{Television, Soaps and Lesbian Representation}

This chapter presents a character analysis of the lesbians available to audiences of New Zealand's prime-time soap, Shortland Street. I note the strategies that stultify lesbian expression that the literature identifies are rife in this fabricated, but carefully constructed, world.

\section{Introduction}

Media and cultural theorists attest that television is one of the privileged sites where the public becomes (apparently) literate with regard to sexual minorities (see Capsuto 2000; Ciasullo 2002; Gerbner et al., 1986; Gross 1991; 1994; 2001; Holtzman 2000; Kielwasser and Wolf 1992; Sapolsky 2003; St Germain 2003; Walters 2001). On soaps, for instance, characters and their situations are used by viewers as currency in everyday conversations (see film and television scholar Charlotte Brunsdon 1987; Dow 1996; Fiske 1987; Jib Fowles 1992; and Henriette Riegel 1996). Film and television studies scholar Christine Geraghty notes the quotidian diet of drama and intrigue offered by soap operas has traditionally been consumed by women, as the serialised narratives often focus on the importance of female friendships (Geraghty 1991, p.158). Fenton finds that before women's genres were given respect by feminist media inquiry, "Genres such as soap operas and romance which focused on women's experiences and were largely consumed by women, had previously been labelled as "trash"” (Fenton 2001, p.108). The relationship that exists between women and these frequently complex narratives have been commented on (see Brown 1994; Brunsdon 1987; Fowles 1992). The incorporation of more disruptive agents within the soap's dramatic universe has attracted a more heterogeneous audience. Grittier storylines broaching social taboos now marble the rejuvenated genre as the more popular soaps morph from their mid-day ghetto into prime-time positions (Fowles 1992, p.171). ${ }^{36}$ American sociologist C. Lee Harrington notes that same-sex desire is one of those taboos (Harrington 2003, p.216).

Soaps are certainly a paradox. As R. L. Pela writes daytime television often "tests the waters" around sensitive social issues before they are addressed in the prime-time environment (Pela 1997, p.46), but sexuality, race, and class are problematic areas as they "threaten the cosier constructions of the soap community" (Geraghty 1991, p.196). Given

\footnotetext{
${ }^{36}$ Eastenders, Dynasty and Dallas are early examples of the mainstreaming of the soap phenomenon.
} 
that soaps "are predicated on the 'dream' of heterosexual romance, marriage and family life" (Harrington 2003, p.220), the introduction of gay characters could be seen as the antithesis of the traditional soap opera narrative. This can cause some New Zealand viewers extreme discomfort:

I notice with alarm the shows pushing or advocating homosexuality. It was not many years ago that the subject was persona non grata. But now we are getting it hook, line and sinker. Are we to believe that gays are now in the majority or possibly have a large representation at TVNZ? I dread the day homosexuality will become compulsory (Alex Morgan, Dunedin, The TV Guide, 5-11 June 2004, p.117).

The obligatory nature of heterosexuality is promoted in almost all of television programming (Gross 1991, p.20; Hantzis and Lehr 1994, p.120; Morgan and Shanahan 1997, p.9). Recent analysis by Kim et al. (2007, p174) found that television characters not only monitored the behaviours of others to ensure heterosexuality is maintained, but they also policed their own.

\section{Soaps and Sexuality}

Discussing the problems inherent in lesbian characters infiltrating what is a predominantly heterosexual world, Geraghty finds the introduction of lesbian characters would imply that "lesbians are not separate from, and indeed have things in common with, other women", and may call into question the "basis of the relationships between the other women, leaving the strength of their heterosexuality open to evaluation" (Geraghty 1991, p.158). Consequently, when same-sex desire is incorporated into a soap storyline, it is nearly always represented by male characters (ibid); lesbian sexuality still remains too controversial for many. Consider prime-time television's longest running soap, Coronation Street. Over the last 10 years, it has gradually incorporated transgressive characters. The roll-call of non-normative regulars includes Hayley Cropper (the transsexual partner of Roy), and Todd Grimshaw (the gay son of Eileen who came out when living with Sarah Platt who was also carrying his child). However, viewers have had to wait for the inclusion of a gay storyline, a delay that seems somewhat strange considering the topics that have been dealt with over the last few years, such as Sarah's previous underage pregnancy or Martin Platt's affair with schoolgirl Katy Harris. Now a gay man, Sean Tully, the first non-normative regular since Hayley Cropper, introduced through Todd's coming out storyline, is allowed a love interest every now and then. 
Reflecting Geraghty's (1991) assertions that lesbians are too controversial to include in soaps, and despite this queer line-up, there is still no sign of a lesbian figure.

As New Zealand's television landscape is dominated by American material, it seems unlikely that a New Zealand production would offer a lesbian character; and yet the New Zealand-produced soap Shortland Street (Seasons 13 and 14) provides not one but two regular lesbian characters for analysis. Shortland Street first screened on 25 May 1992. Screening every week day at 7.00 p.m. on 2 the soap, which is produced in Auckland by South Pacific Pictures, centres not on the patients but on the lives of the medical and administrative staff and their families. A collaborative effort, the soap's storylines are the work of a stable of writers and directors (see Appendix G). Competing for audience approval against the best of American and British imports, Shortland Street is New Zealand's longest-running drama, and has successfully managed to achieve a balance between cultural relevance and reducing prejudice against locally-made content while maintaining the 'exportability' factor that media scholar Trisha Dunleavy insists is critical for a domestic drama to survive (Dunleavy 2004, p.210). That the characters are homegrown constructions is important, both as a representation of lesbianism and as an opportunity for New Zealand audiences to make a connection with 'the lesbian next door'. Shortland Street can even be considered progressive, in this respect.

\section{Soaps and Sociability}

Soaps add to the viewer's personal universe, augmenting their private lives so they often become the "social universe of choice" (Fowles 1992, p.169). According to author and film critic Charles Derry, so well chronicled are soap storylines it is possible to keep abreast of a plot without even owning a television set (Derry 1992, p.462). Secondary texts of "television knowledges" such as specialist fan magazines, journalistic criticism, and gossip are supported by the advertising industry (Fiske 1987, p.85), and have much social utility. As Riegel observes, the word 'gossip' is often defined in negative terms (Riegel 1996, para.1), and connotes triviality and femininity (Fiske 1987, p.77), but gossip works in two ways: it constructs audience-driven meanings, and "constructs audience communities within which those meanings circulate" (Fiske 1987, p.80). This commonality allows the solitary viewer to feel they are actually watching as part of a group, because he/she knows that others are watching at the same time (ibid., p.80). An episode missed spoils the continuity of the world in which viewers vicariously participate. No other genre of television is supported by secondary texts as is the soap opera, because 
"no other audience cares so avidly about what happens" as much as soap fans do (Fowles 1992, p.171).

Like a virtual water cooler around which to congregate, online discussion forums and fan websites have become a popular way for fans to catch up on the missed episodes and discuss their favourite characters. ${ }^{37}$ The social relationships and virtual communities fans form with others is another significant attraction of fandom, especially for marginalised populations, as evinced by St Germain's study of Xena and Buffy fan sites. Here, entries written by fans illustrated "that Xena and Buffy have had profound influences on viewers, in particular, lesbian viewers" (St Germain 2003, p.11). Shortland Street's online forum documents a similar effect.

Like the Xena and Buffy fansites, Shortland Street's official website Streettalk has seen considerable discussion about the fictional world of Ferndale and its inhabitants (www.streettalk.co.nz). The site provides an archive of all episodes, dossiers on the characters, and discussion forums for storylines. Most importantly, the discussion forum enabled me to observe the effect of, and viewer responses to, particular characters. The characters of Maia and Jay are the subjects of considerable activity in this forum, and I use this source of information in my analysis.

\section{Shortland Street's Sapphos}

In order to interrogate lesbian representation on Shortland Street, my analysis will centre on one critical question: how is lesbianism (sexuality and lifestyle) represented? Supporting this investigation are three specific areas of inquiry, namely:

- What degree of homonormativity is displayed by Shortland Street?

- Do the lesbian characters presence, or storylines, reinforce heterosexuality or homosexuality as the preferred state?

- What conditions or qualifications are imposed on the characters of Maia and Jay?

Returning to New Zealand from living in Sydney, Jay Copeland and Maia Jeffreys move back to Auckland to settle down together. From the episode on 25 June 2004, the audience learns from Jay's father's (Victor Kahu) first reaction that Jay has changed quite considerably in her time away in Australia. Jay (known to her family as Jessica) has

${ }^{37}$ The most interesting facility on these forums is a polling of where visitors can vote for their preferred outcome of certain storylines. Quite how this free market research affects the outcome of the writers' storylines is not known. 
changed her name, abandoned her career as a classical musician, and returned to New Zealand with her partner Maia. Unlike Maia, Jay has not come out to her family; an issue that causes considerable stress for her, and creates tension between the couple over the first month of their time on the soap.

Over the next few weeks, the relationship between the two women becomes increasingly fraught because of Jay's reluctance to come out to her father. ${ }^{38}$ Maia grows tired of her public demotion to a friend and a secret Jay is ashamed of. Befriended by fellow nurse Vinnie Cruse, she confides in him about their relationship and the tension growing between her and Jay. The closeted Jay is horrified when she later discovers that Vinnie knows about their relationship and another round of arguing ensues. The situation soon becomes untenable for Maia; she moves out and starts flatting with Vinnie. Tired of the charade, and after the women were spotted kissing by another character, Maia outs herself (and Jay in the process) to Victor, who also works at the hospital. ${ }^{39}$ Both Victor and Jay's aunty, Te Hana Hudson, react positively to the news and they quickly accept Jay as a lesbian, and accept her relationship with Maia. Despite gaining her family's acceptance, Jay is still positioned as a paranoid and insecure figure, and the relationship between the women is just as volatile as before Jay came out. Jay's paranoia reaches new heights when a pregnant lesbian patient called Gail comes into the hospital. ${ }^{40}$

The undermining of lesbian sexuality begins when Gail tells Maia she is a lesbian, but has been cheating on her partner, with a man. When it is discovered that Gail is having an ectopic pregnancy, Maia becomes complicit in deceiving her patient's partner. Maia's professional duplicity is the last straw for the insecure Jay, and after six weeks on screen, she heads back to Sydney, leaving Maia in Auckland. Without Jay, Maia quickly becomes absorbed in the social milieu of the hospital, and Coltrane (the local bar), where there are many who vie for Maia's attention. When Jay returns to Ferndale on Christmas Day, both women realise their romantic spark must be rekindled. While some characters celebrate the women's renewed romance, there are others, particularly Dr Mark Weston, who would prefer that Jay had stayed away.

\footnotetext{
${ }^{38}$ Victor assumes Jay and Maia are heterosexual and, initially, he accounts for their lack of interest in men as the women having high standards. It could be argued Victor arrived at this conclusion because the women conform to the heterosexual ideals of what women should look like.

${ }^{39}$ Episode screened 12/7/2004.

${ }^{40}$ Episode screened 2/8/2004.
} 
Over the subsequent years the scriptwriters have attempted to flesh out and naturalise Maia and Jay's story with the arrival of Maia's parents and sisters, charting their vocational efforts, and consolidating their relationship by having them become engaged. However, there are too many shortfalls in the narrative that indicate a strong level of tokenism with regard to their presence in the storylines.

\section{Confessions and Coming Out Narratives}

The confessional ritual requires an audience. As French philosopher Michel Foucault emphasises:

"one does not confess without the presence (or virtual presence) of a partner who is not simply the interlocutor but the authority who requires the confession, prescribes and appreciates it, and intervenes in order to judge, punish, forgive, console and reconcile" (Foucault 1978, p.61).

More importantly, the authority is always heterosexual; it is likely their coming out storyline cemented Maia and Jay's otherness for much of the audience. Stifling it under the weight of confessions storyline, the writers show lesbian sexuality as problematic; a large amount of the desire between the women is overridden by the fears, pressures and frustrations of coming out.

Although the coming out narrative usually frames same-sex sexual activity with guilt (Hurley 2005, p.54), one positive consequence is its educative potential as the viewer vicariously experiences the reality of living in a society where heterosexuality is required and presumed, as well as underscoring the paralysing effects of internalised homophobia (Walters 2001, p.200). While Jay's coming out anxieties left the audience to appraise correctly that heterosexism was the reason for her distress, the trauma of the closet and the attendant pressures that a heterocentrist society exerts on homosexuals went without any further investigation or comment. This quintessentially gay event, with all its potential to help inform non-heterosexual members of the audience, focussed on how the heterosexual characters would be affected by being outed, rather than on any positive effects for lesbians.

For Foucault, the attraction of confession is linked to a belief that such declarations have a liberatory effect: "in the person who articulates it: it exonerates, redeems, and purifies him; it unburdens him of his wrongs, liberates him, and promises him salvation" (Foucault 
1978, p.62). Confession only partially frees lesbians and gay men, however. While the character of Maia has always been out that has not meant that she has escaped from heterosexual oppression. Living in the world as a lesbian has meant Maia has entered into a different field of power, one that carries its own forms of repression, as her openness about her sexuality causes her to be pressured and harassed by heterosexual men, and becomes a source of embarrassment for her mother, Yvonne, and her sisters, Tania and Libby.

Before the colonisation of New Zealand, and the imposition of Judeo-Christian morality, "the loving of one's own gender was an ancient, even tribal, practice, honourable and revered" (Te Awekotuku 1991c, p.37). Although the character of Jay is a very modern Māori lesbian, she still suffers from the imported legacy of Christianity as she fears her father's rejection at the discovery of her sexuality. In fact, Jay's cultural differences are only ever apparent when she is with other members of her family. No aspect of her ethnicity and her cultural heritage, or how it affects her lesbian sexuality, are ever discussed with Pākehā Maia, suggesting tokenism of a different variety. The manner in which ethnicity is treated here is reminiscent of Toni Morrison's (1992) exposition of American literature and literary criticism. An African-American writer, Morrison charges that the silence on ethnicity results from "the fact that the habit of ignoring race is understood to be a graceful, even generous, liberal gesture. To notice is to recognise an already discredited difference" (ibid., pp.9-10).

\section{Mainstreaming Lesbians}

Ciasullo observes that lesbian visibility in the mainstream media is dependent on her heterosexual appeal. Manicured to fit mainstream sensibilities, the conventionally feminine lesbian is more easily integrated into mainstream culture where heterosexual men can imagine her sexuality away (Ciasullo 2002, p.213). Maia is no exception. Obligingly acquiescent to the heterosexual gaze, she embraces many of the other traditional stereotypes about women; Maia is the owner of a very breathy, little girl-like voice, she is caring, dresses fashionably and is feminine; she is a nurse, and wants to be a mother. In Shortland Street heterosexual men are usually attracted to Maia, and some have pursued her. The most tenacious heterosexual male in pursuit of Nurse Jeffrey's affections is Dr Mark Weston.

Dr Weston is besotted by Maia, and he is tireless in his efforts to gain her affection, despite her rebuffs. Their already intense friendship is amplified by the storylines that 
throw Mark and Maia together in highly dramatic situations. A man of privilege, Mark is used to getting what he wants, and viewers are often led to believe that he will get Maia eventually. Mark also endears himself to Maia's family by diagnosing Maia's father Ian with an obscure disease, about which Mark has expert knowledge. At one point, Maia is so distraught about her father's illness that she apparently forgets her own sexuality and nearly kisses Mark.

Maia is always positioned by the scriptwriters as the damsel in distress, while Dr Weston is shown as the rescuing hero, her knight-in-white coat. His chivalric qualities are often to the fore, especially when Maia is around. In another example, after leaving Coltrane one evening, Maia and Jay are attacked by a stranger. ${ }^{41}$ The man, who had approached Maia earlier in the evening when she was alone at the bar, advised he would rape them in order to "make them straight". While Jay fights the attacker, Maia, who was totally competent at defending herself at a self-defence course a few weeks earlier, freezes. Mark arrived on the scene moments later and subdued the attacker. After the attack, Mark hugs a stillshaken Maia, whispering: "I will always be there for you". 42

Mark again rescues a screaming Maia from being thrown off a cliff top by an increasingly deranged friend of Mark's, Hugo Cardmont. ${ }^{43}$ The drama started as Maia, Mark, and other hospital staff, were taking part in a sports competition involving a number of hospitals. When Shortland Street's team arrives in the countryside for the competition Mark tells Maia, as she inspects the accommodation, "It might be your lucky day Maia, you and I might be sharing a bunk". ${ }^{44}$ Maia giggles: "In your dreams, mate, in your dreams", letting Mark nuzzle her neck and rest his head on her shoulder, as a lover would. In the bush for an orienteering competition, Mark tries to kiss Maia. ${ }^{45}$ Upset with his more serious advance, Maia runs away, only to be grabbed shortly afterwards by the masked Hugo. Maia screams, "Mark! Help me!" and true to form, he obliges. The cliff-top struggle ends

\footnotetext{
${ }^{41}$ Episode screened on 7/7/2005.

${ }^{42}$ Episode screened on $7 / 7 / 2005$.

${ }^{43}$ Also a man of wealth and privilege, Hugo and Mark were best friends who first met at boarding school. It is eventually revealed that Hugo is the Ferndale stalker and that he is in love with Mark. Jealous of any women Mark has been attracted to, once he realises Mark's passion for Maia, he sets out to eliminate her. Hugo survives the cliff-top fall and seeks Mark's help for his injuries.

${ }^{44}$ Episodes screened 19/7/2005 and 20/7/2005.

45 The close-up of Maia and Mark apparently about to kiss was played often in the week leading up to this particular episode.
} 
with a ranting Hugo confessing his hidden love for Mark, before tumbling to an uncertain doom below.

Many of the social stereotypes used to control and limit the threat posed by lesbian sexuality appear in Shortland Street's lesbian storyline, but the key message embedded in the Maia/Mark plot arc is that despite her rejection of him sexually, Maia needs Mark. The writers maintain this even when he begins a relationship with her sister, Tania. All of these highly-charged events strengthen the viewer's association of Maia with Mark, a strategy that provides the perfect air of confusion surrounding Maia's sexuality. The question becomes not one of will she turn straight, but will she choose Mark over Jay?

I'm sick of you going on about Mark Weston. When we get married next year I want to make sure it's just the two of us tying the knot! [Jay to Maia]. ${ }^{46}$

Nothing comes between Maia and Mark, not even Jay. Just as the audience is asked to believe that Maia delights in Mark's constant sexual interest in her, we are also to believe she is comfortable with his rude and dismissive attitude toward Jay. Conversely, Jay is perpetually uncomfortable with Maia and Mark's friendship, and often requests that Maia spends less time with him. While Maia placates Jay in one scene, she is batting off Mark's advances in the next. After reading Maia's diary Jay asks her if Mark has ever pressured her for more than friendship. ${ }^{47}$ Maia lies, saying no. However, Maia's denial leaves one wondering why she protected him. One interpretation is that she is interested in Mark. This inference is that he means more to her than Jay, a notion reinforced a few months later when Maia dances and flirts the night away with Mark at the hospital's fundraising casino night. The flirtation is so obvious between the two it prompts another core character, Robyn, to ask the question that was no doubt on many viewers' minds: was Maia romantically interested in Mark? Would she end up like her patient Gail? ${ }^{48}$ These scenarios also position Jay in the role of the insecure girlfriend.

\footnotetext{
${ }^{46}$ Episode screened 2/9/2005.

${ }^{47}$ Troubled at the intimacy between Maia and Mark, Jay reads Maia's diary. While the content of the diary entry is unclear, Maia says that it was something she wrote it a long time ago when she and Jay had split up. Episode screened 31/1/2005.

${ }^{48}$ Episode screened 11/3/2005.
} 
Regarding soap operas, Derry argues that it is a genre that flourishes on romances that cannot be consummated (Derry 1992, p.456). While the scriptwriters have introduced an ambiguity in Maia's feelings for Mark, they have resisted the temptation to explicitly have Maia's character become attracted to Mark (or any other man). However, positioning Maia as a damsel in distress and Mark as her rescuing hero assuages the heteromasculine ego. It is safe to assume that for those viewers who identify with Mark Weston, the fact his character remains a powerful figure for Maia mitigates the threat posed by her lesbianism. Further, the Maia/Mark relationship helps position Maia so that her sexuality can be reinterpreted as heterosexual.

After the denouement of the Hugo storyline, Mark and Maia briefly become closer than ever, as they both deal with the shock and trauma caused by Hugo's attack on Maia. Mark once again challenges Maia's sexuality, begging her to reveal her "true" feelings for him. Maia tells Mark, in the clearest terms so far, that she does not have romantic feelings for him, and neither will she, "ever". ${ }^{49}$ Mark decides Maia's friendship is not enough. Acrimony creeps in to the friendship. He begins to ignore her, and embarks on a campaign to speak to her only about work matters. A turnaround ensues as Maia then begins to chase Mark, who is intent on punishing Maia for her rejection of him.

With his inamorata out of his reach Mark begins dating Maia's sister Tania, after betting another male character that he could sleep with her first. Aware of the bet, Maia wants to protect her sister and warns her about his motives. However, Maia has had concerns about all of Mark's love interests, and the basis of her concern can be read as jealousy (as indeed Jay and Tania do). At the end of the 2005 season, Maia discovers that Mark has been cheating on Tania with a large number of women, and steps into the role of his personal minder, believing his excuses that his string of one-night stands are the result of a sex addiction. This keeps Maia and Mark in the same emotional loop, sharing a trauma together.

The pairing of a gay man with a straight woman offers the "ultimate twist" (Battles and Hilton-Morrow 2002, p.92) on the delayed consummation trope, and as communications theorist Helene Shugart notes, has become a popular comedy storyline (Shugart 2003, p.67). Following in the footsteps of their gay brothers (as is seemingly always the case), the lesbian/straight man dyad offers a similar tension. The difficulty is that the feminine lesbian character must be sexually capricious to exist in a television environment (Gross

${ }^{49}$ Episode screened 21/7/2005. 
2001, p.74; Hamer 1994, p.71; Walters 2001, p.162). Shortland Street's lesbian characters contribute significantly to this impulse. While the subversive potential of the feminine lesbian is strong, the weaknesses and criticisms made by scholars about the feminine lesbian are palpably evident in the characters of both Maia and Jay. The fickleness displayed by nearly all feminine lesbian characters on New Zealand prime-time television is in keeping with Ellis's hypothesis that feminine lesbians are not "true" inverts (Greenberg 1988, p.382) and will eventually respond to a man's advances (Nestle 1992, pp.143-144), resulting in the restoration of heterosexuality. By using this device, the writers have introduced the stereotype that lesbianism is 'just a phase'.

The writers have also created doubt about Jay's sexuality by placing her in a heterosexual dyad with a cancer victim, Norman Hanson. When Maia's plans to fall pregnant are halted by the genetic risk of Kennedy's disease, Jay decides she will carry the baby. Norman had earlier offered to be the sperm donor, but his offer is declined after he is diagnosed with a brain tumour. Eventually, Jay and Maia acquiesce to Norman's desire to father a child before he dies, and Norman becomes a much more active participant in the conception than he first thought. Jay, who has never had nor wanted sex with a man, decides to copulate with Norman on the pretext that the child should be conceived "with love". 50

The suggestion that insemination should occur via heterosexual intercourse again promotes the primacy of heterosexuality, and implies the self-insemination method is not only necessarily unnatural, but devoid of such emotion. The sexualisation of the arrangement between Jay and Norman is gratuitous and appears to be done for the benefit of the heterosexual gaze.

Support for the patriarchically-subversive notion that lesbian couples are viable parents is undermined by the continual message that children should only really be an option for heterosexual couples, as journalist and author Brenda Cooper argues, the nuclear family is at the heart of heteronormativity (Cooper 2002, p.49). ${ }^{51}$ The weight of the

\footnotetext{
${ }^{50}$ Episode screened 31/5/2005.

${ }^{51}$ This message is conveyed more directly in a later episode when Felicia, a young woman struggling with her nascent lesbianism, joins the cast. Felicia plays for a women's sports team coached by Jay's younger male cousin, Eti. Felicia and Eti begin dating, but Felicia's sexual interest lies in Jay. After a period of confusion, Felicia kisses Jay, who rejects her. Episode screened 26/6/2006. In a subsequent episode, an embarrassed and hurt Eti refuses to discuss the break-up, preferring to blame the break-up on Jay's friendship with Felicia rather than Felicia's attraction to Jay. Although Jay and Maia are Eti's acting guardians, it is suggested by Maia, and repeated several times in one episode, that Eti needs to talk to a man about the situation. Implicit in this statement is that lesbian couples are unable to parent a male child without the help of a man. Episode screened 27/6/2006.
} 
heteronormative bias is never more evident than in the scripting of Maia and Jay's desire for a child.

The artificial conception storyline and its subtext angered some viewers:

I am really annoyed with the Shortland Street writers for the way that you have approached Jay trying to get pregnant ... I was so disappointed when I saw the storyline the other night that Jay was going to sleep with Norman. Jay's character is of a modern, intelligent young woman. Surely you guys know that the majority of partnered lesbians do not sleep with men to get pregnant, they get a guy to donate sperm, then self inseminate using a needleless syringe. I thought this was going to be a great storyline for you to explore the diversity of families, but instead you have just made my life as a lesbian trying to get pregnant more difficult. I get enough bad jokes and incredibly intrusive questions about how I am going to get pregnant, without a popular tv show making people even more ignorant. I really thought that the show was growing up, I mean I know the show has to be sensationalist to some extent, but in NZ just having a gay woman/couple try and get pregnant would have been enough, rather than giving in to the usual dumb old storyline of lesbian has sex with a man! (Wahine, 2 June 2005, http://www.streettalk.co.nz/modules/newbb/viewtopic.php?topic_id=121 \&forum=7, accessed 19 August 2006).

Apparently to reiterate that baby-making is better left to heterosexuals, the writers create an about-face in the storyline. After strongly registering her lack of interest in motherhood, Norman's partner, Li Mei Chen, decides she will have his child - the legitimate (read: heterosexual) and old-fashioned way - precluding the donor arrangement. For the next few months Jay and Norman exchange lingering looks and share a closeness that unsettles both their partners. When her heterosexual partner dies after a car crash, Jay becomes obsessed with having Norman's child, quite apart from the original intentions of having a family with Maia, in terms of the patriarchal concern of continuing “the Hanson line". A feud ensues between Jay and Li Mei in terms of access to 
Norman's remaining sperm, which is being held at a fertility clinic. Maia is left out of this life-changing event. ${ }^{52}$

\section{George, the Butch Lesbian}

Just as feminist inquiry by media theorist Catherine Lumby (1997), has shown the consequences that the distorted representation of women has on a culture (see also Faludi 1992; Wolf 1991), the paucity of a certain type of image can be just as damaging. The invisibility of the butch in the prime-time environment and conversely, her stereotypic depiction, support the tenants of symbolic annihilation. Shortland Street introduced George, a butch lesbian, who obeyed stereotype. George was introduced a few months after Jay's departure for Sydney. ${ }^{53}$ George and her partner Fee are old and distant friends of Maia. It seemed that the writers were beginning to populate Maia's existence with some lesbian friends, but instead the butch was depicted as the 'bad' lesbian to the femme's 'good' lesbian.

George is partnered with the very feminine Fee. The Butch/Femme dyad is a favourite social stereotype of heterosexuals, but in mainstream media it is an unusual sight. As Ciasullo observes:

Virtually none of the mainstream representations of lesbianism in the 1990s pair a femme or feminine lesbian with a butch or masculine lesbian (Ciasullo 2002, pp.206-207).

Predictably then, the diversity offered by George and Fee did not last long. In the few episodes she appeared, George was represented as a hostile, angry character, visiting the Shortland Street plastics unit to find a cosmetic surgeon who would remove her breasts. This modification would, in her words, make her "look more like a man". ${ }^{54}$ This plotline directly invoked the sexological persona of Ellis' lesbian invert, the man in a woman's body. In reality, such body modifications unsettle many lesbians who argue Butch identities 'disintegrate' when women transition into men (Rubin 1992, p.475). Although transgender viewers may have found resonance with the actions and/or attributes of

\footnotetext{
${ }^{52}$ Norman stores his sperm at a clinic before he undergoes treatment for his cancer. Jay and Li Mei are both on the donor list. Jay later fails to become pregnant after self-insemination, apparently supporting the forewarned premise that heterosexual sex is the 'right' method for conceiving. Episode screened on $2 / 11 / 2005$.

${ }^{53}$ Episode screened on 15/11/2004.

${ }^{54}$ Episode screened on 16/11/2004.
} 
George's character, lesbian viewers are less likely to. George's (Butch) lesbian identity is significantly compromised by the suggestion that she seeks to surgically transform her biological female sex. The Butch lesbian expression of her gender does not rely on altering her body. To suggest it does hinders the ability of lesbian viewers to connect with unadulterated lesbian characters.

Because she conforms to male models of femininity, the feminine lesbian character can usually be tolerated precisely because she is both unthreatening and seemingly integrated into existing masculinist power structures and narratives. As Bourdieu writes:

\begin{abstract}
Masculine domination constitutes women as symbolic objects (who) ... exist first through the gaze of others, that is, as welcoming, attractive and available objects. They are expected to be 'feminine', that is to say, smiling, friendly, attentive, submissive, demure, restrained, self-effacing. And what is called 'femininity' is often nothing more than a form of indulgence toward real or supposed male expectations (Bourdieu 2001, p.66).
\end{abstract}

The butch, therefore, remains "too loaded, and too dangerous" a figure for mainstream consumption (Ciasullo 2002, p.223). George's quest for a double mastectomy fractures her relationship with Fee, and George is removed from the programme. Fee then pursues the equally feminine Maia.

In her brief appearance, it was clear George was meant to reinforce stereotypical ideas about the butch lesbian: she is a freakish, aggressive, and an altogether unwomanly creature, who really wants to be a man - the sexologist's 'true' invert (Doan and Waters 1998, p.43; Jeffreys 1997, p.107). It is unclear whether the Butch/Femme pairing was a deliberate device to mirror heterosexuality. Fee is a wholly heteronormative construction, heavily encoded with conventional heterosexual signifiers. Conversely George, a lesbian who does not conform to traditional feminine expectations in either her dress or her manner, is presented as freakish. There are many different ways to be masculine (Rubin 1992, p.469). However, according to the heterosexist mind, “any woman who doesn't look or act like a woman isn't a woman and is therefore deserving of ridicule" (Ciasullo 2002, p.218). Instead of being allowed to reject male-defined femininity and still be a woman, George's masculinity was immediately conflated with the desire to be a man, positioning lesbians who are not feminine as 'other' (ibid., p.218). 
Contrasted with the eminently more transgressive image of George, the three femmes (Fee, Maia, and Jay) emerge as more feminine, more closely aligned with the tropes of heterosexuality, and therefore the more acceptable, 'good' lesbians. At the same time, the audience is clearly invited to value one of the two models of lesbian dyads over the other; the Butch/Femme pairing is clearly valued less than the femme/femme pairing. The feminine dyad of Maia and Jay instructs the audience that despite a woman's sexuality, only an assimilated image is acceptable and that this is the image to which lesbians, like heterosexual women, should conform. In this manner, the lesbian characters of Shortland Street promote the Beauty Myth to lesbian and non-lesbian audience member.

\section{Disconnecting Lesbians}

Removing lesbian and gay characters from their political and social contexts is another necessary impost on transgressive characters if they are to be considered suitable for mainstream visibility (Cragin 2006, p.197, Dow 2001, pp.135-136, Walters, 2001, p.16). Ciasullo emphasises the visible lesbian in the post-Ellen era is "typically a de-politicized lesbian, divorced from her feminist roots, in many ways, she is the descendant from the 1970s 'good' lesbian, good in part because she eschews 'serious' issues like sexual politics" (Ciasullo 2002, p.220). Shortland Street has taken this route.

The disconnection of the lesbian from her political voice is illustrated best with the arrival of a new patient, Cathy Zimmermann, feminist author and lesbian. The author of several books on lesbianism, Cathy is a character of academic accomplishment and standing. Having read some of her work, the as until now apolitical Maia hails Ms Zimmermann as her hero(ine), and is honoured to be assigned to her care. Although it is rare for Maia to speak about political issues, particularly lesbian political issues, a conversation ensues between Maia and Cathy about her books and her politics. However, instead of any meaningful dialogue, Cathy's strong feminist views are quickly neutralised by Maia, who lectures her hero(ine): “things have changed, we don't have to be so staunch or manhaters". ${ }^{55}$ With that line, audience members have just been sent several messages: that only older lesbians are feminist; that feminism (synonymous with lesbians) is redundant; and that the heteronormative status-quo is perfectly acceptable. In a cast with more lesbian characters, espousing such a view could well be explored, but with only three lesbians two of whom have been shown to be significantly heteronormative - these notions go unchallenged.

\footnotetext{
${ }^{55}$ Episode screened on 4/10/2005.
} 
A more positive interaction occurred later when Cathy spots one of the doctors, Sarah Potts, and exclaims "Now she's sexy". When Maia tells Cathy that Sarah is straight Ms Zimmerman replies: "Don't you know? The only difference between a straight girl and a dyke is a bottle of vodka." The homonormative quality of this interaction stands out in sharp contrast to the relentlessly heteronormative perspective of the usual discourse between characters. However, without established support for the lesbian characters, the risk is that what might resonate with the audience is the idea that Cathy is a predatory lesbian.

After a short hiatus, Cathy returns to Ferndale to persuade Maia to be a cover girl for a lesbian magazine, Sapphire. ${ }^{56}$ At the same time, Yvonne had commenced an active search for a friendship with someone her own age and, as only a soap would have it, Yvonne and Cathy meet each other in the hospital café. The women strike up a friendship and both agree to meet for dinner and drinks. Seeing the two together at Coltrane, Jay realises Yvonne is unaware her new friend is a lesbian activist. When Maia arrives they are amused by the irony that the vehemently homophobic Yvonne is not aware that she is dining with a highly political lesbian. When all is revealed, a shocked Yvonne recoils:
You're ... like Maia?
Cathy: If you mean am I gay, then yes.
Yvonne: Why didn't you tell me?
Cathy: It hadn't come up.

When both women realise Maia and Jay had already discovered this before them and were enjoying the situation, Cathy berates them for being "cruel" women. Maia explains she and Jay hoped her friendship with her mother would show Yvonne lesbians were nice people and that lesbianism is not just a phase. Cathy, the supposedly strident lesbian feminist activist, scolds Maia and Jay, hissing, "Ambush and humiliation don't help". 57 Instead of naming Yvonne's embarrassment as the homophobic reaction it was, the camera lingers on Yvonne, positioning her as the hurt and wounded victim. Later, another opportunity in the plot for Cathy to address Yvonne's bigotry is ignored when Yvonne tells Cathy she feels too uncomfortable to pursue the friendship.

\footnotetext{
${ }^{56}$ Episode screened on 17/11/2005.

${ }^{57}$ Episode screened on 18/11/2005.
} 
Besides their meeting with Cathy, none of the lesbian pairings (Jay and Maia or Maia and Fee) attend any women-only spaces, lesbian bars, or gay events. Lesbians clearly exist in Ferndale, but their communities are hidden. The lack of lesbian community connections infers that 'new' lesbians are integrated and assimilated into the heterosexual world. Dislocated from any gay social or political context, the women can be neatly grafted onto the heterosexual community.

The doubt surrounding the women's sexuality in Shortland Street clearly excites some viewers, and annoys others. Many fans of the soap are quite clear in a heterosexual reading of Maia and Jay. For example:

I think Maia likes Mark you notice the way they look at each other I kinda think theres something going on there I wonder (Clairerox, 13 July 2005, http://www.streettalk.co.nz/modules/newbb/viewtopic.php?

topic_id=2226\&forum=13\#forumpost56888, accessed 19 August 2005). ${ }^{58}$

$i$ think jay and maia are confused about their sexuality

if you say - "yes i am gay" you don't go and flirt with other men!!!! $i$ think they are very confused and I would like to see maia off the show and jay with Norman :) (Juju, Hamilton, 8 July 2005, http://www.streettalk.co.nz/modules/newbb/viewtopic.php?topic_id=2453 $\&$ forum=13\#forumpost62439, accessed 19 August 2005).

Regarding Maia and Jay's sexuality, these fans complain:

Why is it always a stage or a phase we are going through? can't it just be that thats how we feel. we would rather be with the same sex other than the opposite. (Lezzie_Dezz, $31^{\text {st }} \quad$ August 2006, http://www.streettalk.co.nz/forum/comments.php?DiscussionID=909\&pag $\mathrm{e}=6$, accessed 22 September 2006). ${ }^{59}$

\footnotetext{
${ }^{58}$ Spelling is as in the original.

${ }^{59}$ Spelling is as in the original.
} 
Its all a bit same old same old with the writers having some bloke try to break them up ... suppose its the male teaser thing about sexy gay girls and men falling for them ... but they would be more under threat from a sexy girl. THEY ARE THE BOMB!!! (Jay_is_hot, 8 August 2005, http://www.streettalk.co.nz/modules/newbb/viewtopic.php?topic_id=2453 $\&$ forum=13\#forumpost62439, accessed 26 October 2006).

I hope they never put Maia and Mark together or Maia and Jay with any guy cause to turn them straight would ring untrue to these characters.... turning them straight would be as untrue as turning Jay Chinese or Maia Samoan (Tommys, 15 April 2005, http://www.streettalk.co.nz/modules/ newbb/viewtopic.php?topic_id=634\&forum=5, accessed 20 April 2005).

If we are saying that mark and maia will get together its like saying homosexuality is just a phase some people go through. Why would maia "choose" this phase for all these years just to waste all that time all those years of standing up to people who see the world differently (‥a.m, 30 August 2005, http://www.streettalk.co.nz/modules/newbb/viewtopic. php?topic_id=2642\&forum=13\#forumpost70928, accessed 1 September 2005). ${ }^{60}$

However, another viewer warns:

Well we all remember Carolyn the lesbian...until Greg came back! No reason why the same story line wont happen again! (Rubicon, 21 July 2005, http://www.streettalk.co.nz/modules/newbb/viewtopic.php? topic_id=2226\&forum $=13 \&$ viewmode $=$ flat\&order $=$ ASC\&start $=30$, accessed 22 August 2005).

There are bona fide issues lesbians face that could be incorporated into the storylines, such as the real pressures of discrimination and sexual harassment. Exploring such topics would help to reinforce lesbian viewers' sexuality - including their sexual difference - as something that was not "unnatural" and "abnormal".

${ }^{60}$ Spelling is as in the original. 


\section{Conclusion}

The television soap is a strange mixture of the conventional, and the disruptive and unstable. On the one hand it necessarily reproduces, endorses and adheres to social conventions, narratives and values, while on the other hand constantly calling into question the certainty of these values and narratives through the repeated introduction of the 'other' - the strange, the threatening and the inexplicable. Lesbians clearly have a place in the contemporary soap because they stand outside conventional and normative subject categories - they make for a convenient and appealing other. At the same time the tendency for soap narratives to return to valorise the known, and expel, demonise or convert the strange, means that the status of lesbian representations is at best provisional and problematical: the soap makes valuable use of, while never accepting, negotiating or attempting to come to terms with, social heterogeneity. Lesbians can be represented as present and acting within the community, but only as a kind of reminder which the community needs to confront and overcome - usually involving the violence of expulsion or conversion. 


\section{Chapter 8}

\section{Shortland Street}

The weaving of snatches of reality into the narrative by scriptwriters is a powerful strategy that encourages a sense of reality between a fictional world and the audience (Fowles 1992, p.168). The Civil Union Act 2004 came into effect on 26 April 2005 and the attendant protests by a disturbingly large number of New Zealanders anxious to keep the right of a legal union away from same-sex couples, their ranks swelled by an extremist Christian sect, was proverbial manna from heaven for scriptwriters who already had a lesbian couple as core cast members. This chapter analyses how romance and desire between Maia and Jay is molested and how this spoils the vicarious pleasures some Shortland Street fans were taking from the depiction of two women in love.

\section{Introduction}

This chapter analyses how the relationship between Maia and Jay, and the romance and desire that characterises it, is represented in the soap Shortland Street. The story of Maia and Jay's Civil Union begins with an engagement. At the women's home Jay is crying on Maia's shoulder after receiving the news that she is not pregnant; distraught, she tells Maia she wants them to be a "real" family. Prompted by Jay's disclosure, Maia gets on one knee and asks her to marry her. While Maia's proposal is spontaneous and clearly heartfelt, a heterosexual proposal a few episodes later was shown in a more traditionally

romantic light. ${ }^{61}$ Andrew Solomon's proposal to Sarah Potts has been meticulously planned with all of the traditional signifiers of romance. It is a night of candles, of soft music, and petals strewn across the floor. It is a night of orchestrated romance versus Maia's proposal to Jay on the couch.

\section{Not a Real Wedding}

Jay and Maia first announce their wedding plans to Jay's colleague Shannon Hudson in the hospital café. Although a little taken aback, Shannon congratulates the couple. Hearing the fuss, Maia's sister Tania approaches the women and asks them what the congratulations are for. When she is told the news, Tania's first response is fear as she

${ }^{61}$ Episode screened on $17 / 6 / 2005$. 
gasps: "Oh my God. Does Mum know?"62 Tania's initial reaction is followed by a warning to her sister: "You know you two are going to send mum to an early grave". Tania's sudden concern for her mother showed a lack of character continuity; she had spent the preceding episodes supporting her sister and rolling her eyes at her mother's inability to accept Maia and Jay's relationship. It suggests Tania's reaction is a device to advise the audience to expect Yvonne to be upset at the news, and be completely against what is usually a happy and significant step for any couple. The negativity is continued in the Emergency Department, when Tania sneers at Maia about which family name the couple will assume, Maia replies:

Maia: Why can't you just be happy for me?

Tania: Happy that my sister is an utter freak?

Maia: How does committing to the one I love make me a freak?

Tania: Why do you have to go through with this stupid Civil Union thing

— you're living together, isn't that enough?

Maia: What the hell has it got to do with you?

Tania I'm thinking of Mum - she's going to be devastated. ${ }^{63}$

Later in the episode, Jay and Maia celebrate together at Coltrane. Seeing the women drinking champagne, Yvonne incorrectly assumes the celebration is about Maia's new job as charge nurse she had recently applied for. Before she reaches the couple, Tania intervenes and tells her mother that the celebration is not about the job, but that they are getting married. Initially upset and bewildered, and then outraged and embarrassed, Yvonne marches over to the women and confronts them about the wedding. Maia tells an increasingly agitated Yvonne:

Mum, you're making a spectacle of yourself.

Yvonne: I'm making a spectacle — this from the girl who is running round town telling everyone she is marrying another woman!

Telling her sister off for upsetting their mother, Tania retorts:

\footnotetext{
${ }^{62}$ Episode screened on $20 / 6 / 2005$.

${ }^{63}$ Determined to marry a doctor, Tania manipulates her way around her male medical colleagues with military precision; her mother vociferously praises these dating tactics in front of Maia. It seems as long as she's heterosexual, Tania can do no wrong.
} 
Tania: I'm not the one breaking mum's heart.

Jay: She's getting married Tania — not joining the circus.

Yvonne: She may as well be joining the circus [sobs] the way that people will talk about you.

Leaving the restaurant, Maia stops in the foyer to comfort Jay and suggests they go home to celebrate. As she goes to kiss Jay, Mark also arrives at Coltrane. Watching the women he says, through a smirk, "Keep going - I'll grab some popcorn". However, his forlorn look as they walk away indicates to the viewer he is also upset at the news. ${ }^{64}$

Yvonne's later reaction to Andrew and Sarah's engagement is in stark contrast to her reaction toward her daughter's news. This response amplified the couples' difference rather than reducing it. Yvonne is given every opportunity to rail against Maia and Jay's engagement, and to celebrate Andrew and Sarah's. For example, when Yvonne notices Sarah's engagement ring she reacts with excitement, and invites everyone at reception to behold Sarah's bejewelled hand. Noticing a ring on Maia's engagement finger she queries Maia about it, saying it looks like an engagement ring. When her daughter informs her that it is, Yvonne snorts with disgust. The storyline clearly privileges the heterosexual couple over the lesbian couple. No character questioned whether Maia and Jay should adopt the model offered because it is historically heterosexual, and may not fit a lesbian relationship. Rather, the narrative followed the usual (heteronormative) protocol of focusing on the reactions of heterosexuals to same-sex desire (Dow 2001, p.129), and focussed on a mother's embarrassment and a thwarted heterosexual man's grief. Whether the scriptwriters intended the audience to empathise with Maia and Jay in response to Yvonne's lack of support is unclear. The fuss made about Andrew and Sarah's engagement, despite the reality of Sarah's feeling, illustrated the strength of the norms associated with such an announcement - but only for heterosexual couples.

It is interesting to note that the only characters shown defending or really celebrating the women's engagement are Jay's father Victor and step-mother Te Hana, who were both off-screen at the time. Their congratulations are never actually heard as Jay speaks to them by telephone. Those who reacted negatively are all onscreen regulars, and their expressions of outrage, offence, or general distress at the women's union are heard loudly

${ }^{64}$ It is revealed in the first few episodes of 2006, after Tania finds out about his lunchtime and late night liaisons with numerous women, that Mark's love for Maia and her rejection of him is the cause of his behaviour. 
and often. In one episode, Yvonne is allowed to embark on a diatribe with no countering, arguing, or mitigation from Maia or anyone else. ${ }^{65}$ When Maia invites Yvonne "as mother of the bride" to go shopping, Yvonne recoils:

Mother of the Bride? What does that make Mrs Copeland [Jay's mother]? Mother of the Bride \#2? I've said all along that this was not a real wedding. I don't know why I was pretending it was.

A crestfallen Maia tells her mother:

When I imagined my wedding day when I was a little girl I imagined you were there, helping me.

To which, Yvonne replies:

And when I imagined your wedding day, there was always a bride and a groom ... I know that's not going to happen and that's fine. And I do want to be involved ... it's just I don't know how. I still can't see this Civil Union as a real wedding as hard as I try... and I am trying, I promise.

Later that day, after unsuccessfully shopping for her wedding dress, Tania asks Maia if the reason she is having trouble is because she has not seen Jay's dress, and is anxious that whatever she buys will complement what Jay is wearing. When Maia confirms she will not know what Jay is wearing until the big day, an open-mouthed Yvonne snipes: "It seems silly to go along with that superstition." And Tania opines:

You should have married that girl that you used to go out with from Nursing School ... Susan. That would have been so much easier. Susan was so butch she looked like a bloke. She could have worn a tie and a jacket.

Yvonne adds:

${ }^{65}$ Episode screened on $27 / 1 / 2006$. 
You see, that has never made sense to me. If you are going to be lesbian it's because you prefer women to men, so why would you go out with a girl who wears a flannel shirt and working men's boots? Seems to be missing the point.

Except for a barely audible sigh of exasperation from Maia, Yvonne's question goes unanswered. This has been the prevailing trend throughout this story, as any audience members who may have been genuinely interested in an answer to the question were left wanting as Maia falls silent. Later, the three are seen discussing the logistics of the day. Yvonne nods with approval when Maia tells her that Cathy Zimmerman is going to be the celebrant. When Maia says there will also be women coming from Sydney, a jaded Tania complains: "Oh God, I hope it's not a platform for lesbian experimental protest songs". Yvonne begins to look uncomfortable when she hears that one of Jay's friends from university has offered to do a drag show. For the third time in the same episode, Yvonne is allowed to articulate her homophobia as she screams at her daughter:

Why do you want some transvestite prancing about at your wedding? I'll tell you why, because it's not a wedding it's a bloody circus ... If you and Jay want to make a spectacle of yourselves fine, but don't expect me to be watching. ${ }^{66}$

Stung by her mother's words, Maia is speechless, and once again Yvonne's homophobic vitriol is given the most airtime as the camera traces the outrage on Yvonne's face, while muting the response of the aggrieved Maia. Yvonne's opposition to her daughter's civil union gains new strength with the arrival of another of Maia's sisters, Libby. The tension between Maia and her sister is evident from the start, and the ceremony provides the scriptwriters with a perfect vehicle for even more family drama. At a get-together meal at Coltrane, Maia asks Libby if she is coming to the 'cupping'. When Libby acts puzzled Maia tells her she had sent her an invitation. Libby sneered, "Oh THAT, I thought it was a joke. I mean marrying a woman just because you can?" Assuming Maia and Jay's relationship is nothing more than an attention-seeking stunt and referencing the chic status of faux lesbianism (discussed earlier in Chapter 2, p.42), Libby goes on to tell the group that her friend in London, "decided to become a dyke" because "being a lesbian is the new

\footnotetext{
${ }^{66}$ Episode screened 27/1/2006.
} 
black", and she will do anything to get attention. ${ }^{67}$ When Libby asks Yvonne how she feels about this "mugging", Yvonne breaks into tears and tells her that as much as she is trying to be supportive of Maia, she is uneasy about it. Yvonne then accepts Libby's invitation to accompany her on an overseas trip, causing great distress to Maia who sees the invitation as a way to spoil the wedding. The trip does not eventuate, however, as Libby leaves New Zealand in disgrace after it is revealed she is seeing a married man.

\section{Lesbian Desire and Intimacy}

Maia and Jay are not Shortland Street's first lesbians. ${ }^{68}$ However, they are the first lesbian couple to enjoy such longevity, a situation that it is proving uncomfortable for some New Zealanders. Distressed by Maia and Jay these viewers voiced their anger and disappointment:

I have been a devout follower of Shortland Street since its inception but unless the scriptwriters aim their pens in a more sensible direction, I shall be channel-hopping in 2005 ... while I do not begrudge the lesbian pair (Maia and Jay) their affair, could they please keep it low key? Along with a lot of other folk I am heartily sick of watching their continual petting. All very off-putting. (TV Guide Fan, Albany, The TV Guide, 15-21 January 2005, p.114).

Wouldn't it be nice to see one soap avoiding political correctness and not ramming homosexual ideology down our throats? They are after all, a minority but you would not think so looking at our TV screens. No wonder young people are so confused (Give Us A Break, Hastings, The TV Guide, 11-17 December 2004, p.116).

While there are hints of erotic desire, the romantic displays of affection between the women can only be classified as distinctly tepid when compared to the intensity given to heterosexual couples. Sitting together on the couch or holding hands over the table, the vast majority of physicality between the women consists of hugs and shoulder pats. Stripped of any romantic emotion or intimacy, the commitment to having a baby,

\footnotetext{
${ }^{67}$ Episode screened 2/2/2006.

${ }^{68}$ The first lesbian character, Dr Meredith Fleming, was introduced to the soap in 1994, after the first gay male character Jonathan McKenna appeared in 1993. Following on from Dr Fleming, other women that have been involved (although not exclusively) in same-sex relationships are nurses Annie Flynn, Carolyn Buxton, and Dr Laura Hall. Only the subsidiary characters, nurses Fee and Lauren, patients Gail and Jonelle, and friend George, have all been involved briefly in the Maia/Jay plot arc.
} 
something that would be surrounded by romance and significance between any heterosexual couple, is instead brokered between the two women during a coffee break over the staffroom table; the lesbian baby plot then concentrated on the details of the insemination and Jay and Norman's one-night stand, instead of the commitment between Maia and Jay.

I counted the displays of affection between lesbian couples and between heterosexual couples for the next nine episodes after TV Guide Fan's letter. This sample period also happened to include the most significant lesbian storyline yet, when the Maia/Fee/Jay love triangle was about to reach its climax. If lesbian intimacy was at its peak, surely it would be at this time with an extra lesbian character.

I counted the number of kisses between couples, and the number of 'other' displays of intimacy, such as petting. For comparison, I made the same counts for a similar nine-day period later in the year. The number of exchanges of intimacy between heterosexual couples in each episode far outweighs those between the lesbian couples (Fig.5). However, because there were far more heterosexual couples than lesbian couples, the disparity that exists in displays of intimacy could simply be a result of the number of couples in each group. For a more meaningful comparison, I controlled for the number of couples, placing the instances of intimacy upon the same metric to enable comparisons between measurement periods as well as by couple type (lesbian vs. heterosexual) (Fig.6).

Fig. 5. Number of displays of intimacy by couple type on Shortland Street (17-27 January 2005 and 8-18 August 2005).

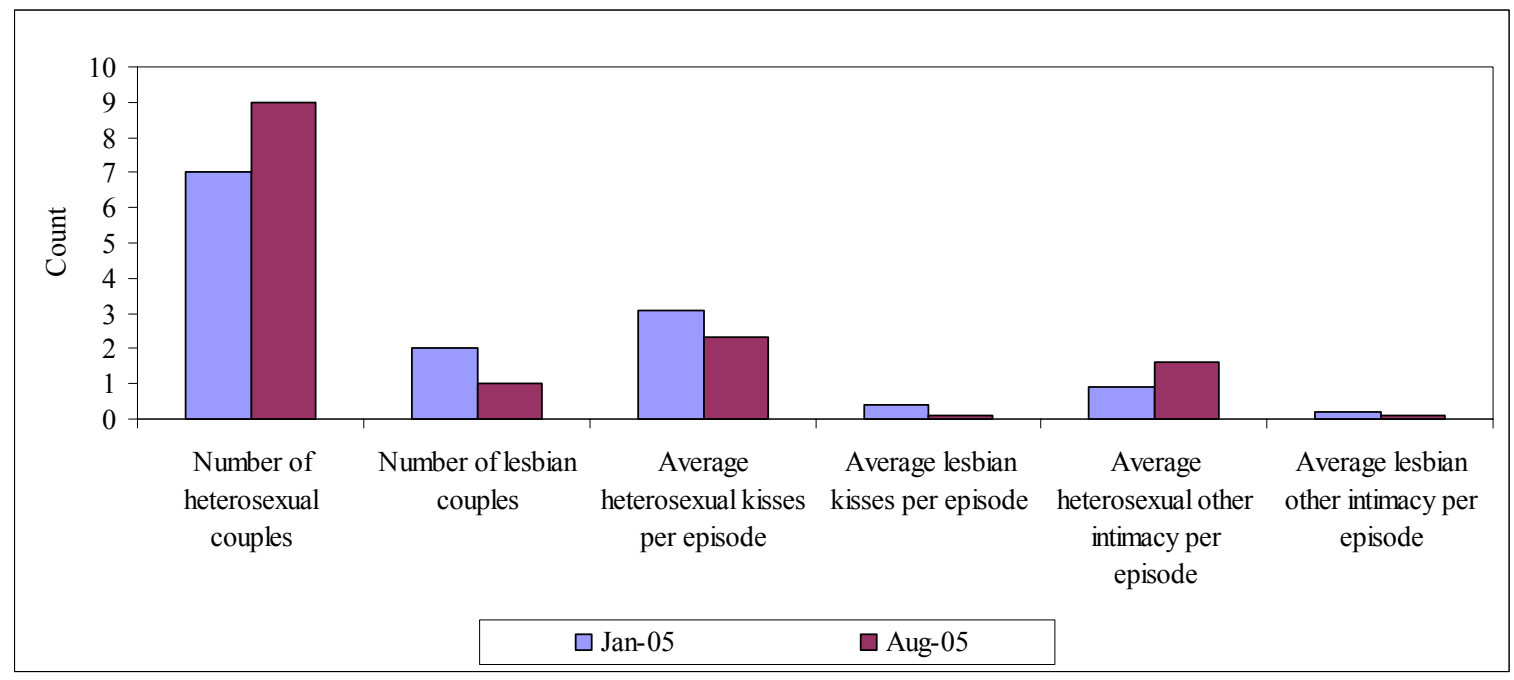


Ciasullo's observation that lesbian characters are defined by their sexuality yet are usually desexualised is evident here (Ciasullo 2002, p.182). As shown in Figs. 5 and 6, even during an intense, romantic, and highly visible storyline, the women shared very little intimacy in comparison to their heterosexual counterparts. Throughout July/August 2005, with their relationship relatively stable, Maia and Jay were involved in making significant life decisions: they decided to formally unite their lives under the Civil Union legislation, and intended to have a baby. Despite this, the women share very little physicality. Even when the number of couples was controlled for, and the count was conducted during a stage of expected considerable intimacy (getting engaged and planning a baby), intimacy displayed by lesbian couples was still insignificant compared to that of their heterosexual counterparts. While they are allowed some intimacy, the characters of Maia and Jay were totally defined (yet 'othered') by their lesbian sexuality.

Fig. 6. Displays of intimacy on Shortland Street with control for number of couples (1727 January 2005 and 8-18 August 2005).

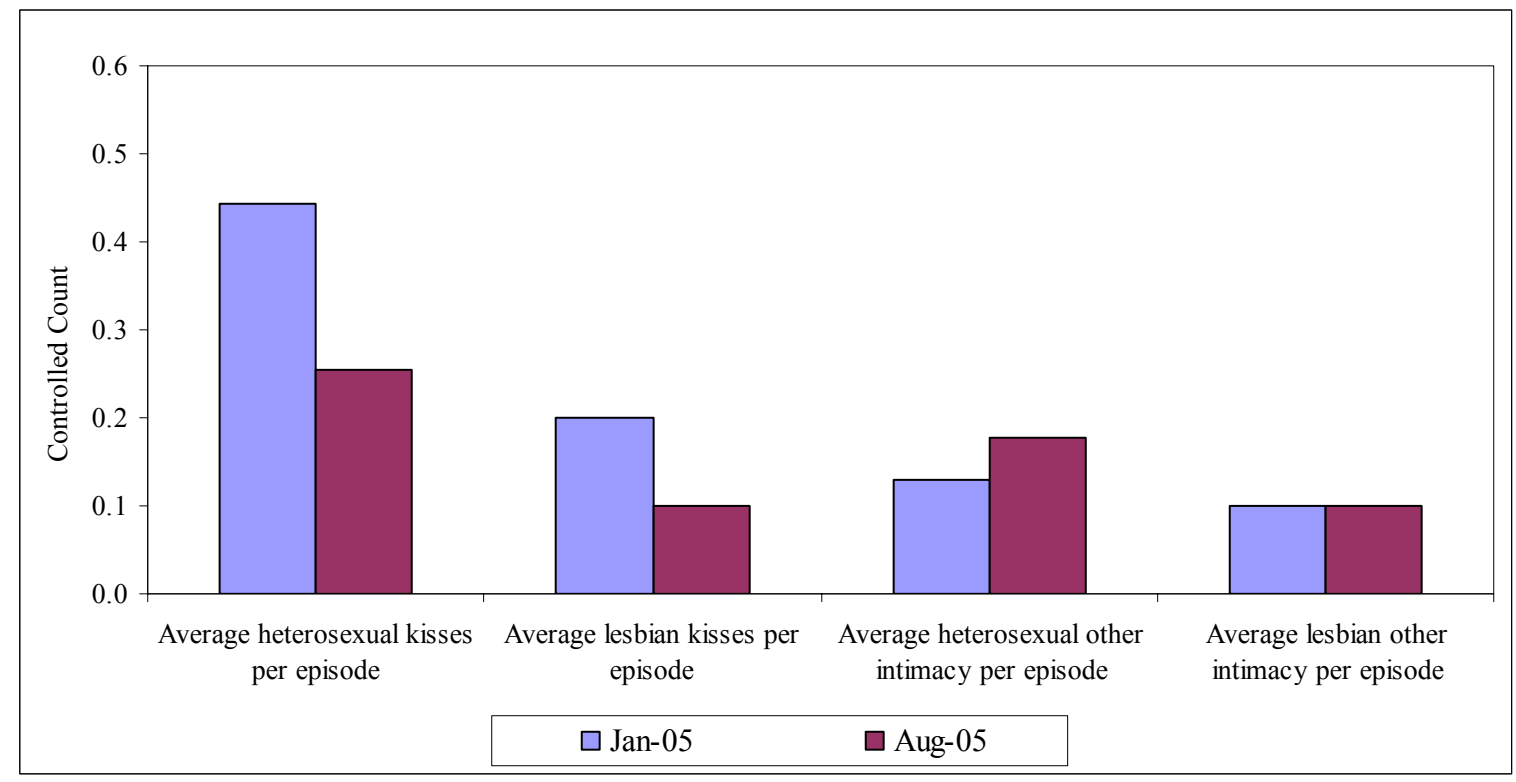

The weeks leading up to the wedding were dedicated almost exclusively to voices opposing the women's union. The usual cacophony of opposition from Yvonne was joined by Libby, and the sudden refusal of Jay's parents to attend the wedding. This was a major continuity issue as only episodes before, Te Hana and Victor had been the first (and notably the only family members) to be supportive of the women's Union. The final homophobic element of the day was when the 20 or so members of the extremist Christian 
group, 'Serenity' Church, who protested at the wedding. ${ }^{69}$ The Serenity Church, an obvious parody of the Destiny Church, a right-wing evangelical movement in New Zealand that was aggressively opposed to the Civil Union Bill becoming legislation, enters Shortland Street viewers' consciousness through new nurse Baxter Cormack. Baxter is a member of Serenity and soon begins to date Claire Solomon, a core cast member. ${ }^{70}$ Despite his fundamentalism and his membership of a religious cult, Baxter is represented as nothing less than a reasonable and balanced person, someone who is even seen as being a positive influence on the wayward Claire. While Claire initially rejects Baxter because of his affiliation to the extremist group, he eventually ingratiates himself, his friends, and their fundamental doctrines into her life (with the support and encouragement of many other characters). This courtship provides the opportunity for the initially scornful Claire to ask questions about Serenity Church, and its extreme fundamentalist doctrine is soon communicated to the audience through Baxter's gentle and measured delivery.

For many bigoted heterosexuals, the idea of same-sex nuptials "can inspire true moral indignation" (Capsuto 2000, p.352). The scriptwriters soon provide the pious Baxter with an opportunity to air his beliefs about same-sex marriage - without being challenged or a dissenting view being offered by any other character - when he refuses to raise his (nonalcoholic) drink in a toast to the women's happiness at a wedding shower thrown by Maia's colleagues. This was the only scene in the build-up to the wedding that supported and celebrated the women's wedding, but even this moment was spoilt. Baxter and his Serenity Church friend Courtney provide companionship and much-needed support for the orphaned and world-weary Claire, but their opposition to same-sex unions unsettles her. When Courtney begins talking about Maia and Jay's Civil Union, Claire questions weakly: "I suppose you don't approve?" to which Courtney replies: "Marriage is for a man and a woman ... If you don't believe in the Bible, believe in human biology". ${ }^{71}$ The

\footnotetext{
${ }^{69}$ The fictitious 'Serenity Church' is a clear reference to the Destiny Church, headed by the self-appointed, 'Bishop' Brian Tamaki. Legal reasons might have been behind renaming Destiny as 'Serenity' but the symbolism would not have been missed by many New Zealand viewers.

${ }^{70}$ One of the main aims of Destiny Church is a return to Christian morals and values. When the Civil Union Bill came before Parliament, Members from throughout New Zealand gathered in Parliament grounds to protest against the Bill and other recent social reforms, such as the legalisation of prostitution that occurred a year earlier in 2003. Members claimed these reforms were signifiers of declining moral standards in New Zealand which were encouraged by a liberal government led by a woman. Discussing the harm caused by legalised prostitution, feminist, activist and author Mary Lucille Sullivan concludes, “... the prostitution industry ... makes invisible the harm experienced by women and girls caught up in systems of commercial sexual exploitation" (Sullivan 2007, p.46).
}

${ }^{71}$ Episode screened 13/2/2006. 
usually confrontational Claire falls silent, and once again a lack of a rebuttal allows a homophobic statement to be voiced without contradiction or challenge. ${ }^{72}$ With that backdrop, the drama progressed to the wedding itself.

The women's special day begins with a shot of them waking in bed together, sharing a closed-lipped kiss (the most passionate kiss is reserved for heterosexual couple Tania and Vinnie at the end of this episode). Maia and Jay's Civil Union is thought to be a first in the world of the soap opera (The TV Guide, 11-17 February 2006, pp.22-23). The day is soon to become a battlefield. Teenager Eti, Jay's cousin who can usually be relied on for a misinformed quip or two, sets the tone as Maia and Jay's guests began to arrive for the ceremony. Commenting about Jay and Maia's (feminine) lesbian friends attending the wedding, he remarks "She is cute enough; she should be able to get a man". ${ }^{73}$ Once again, no character challenges these statements. The only sentiment of true acceptance was spoken by Maia's father, Ian. When his wife again begins to show distress that her daughter's wedding day is not as she had imagined Ian responds, "You imagined her in love, which she is". This sentiment is then drowned out as the wedding party is set upon by the fanatical right wing members of Serenity Church.

Devastated that their day of romance is being used to promote the agenda of religious fanatics, Maia and Jay have second thoughts about going ahead with the ceremony. Departing from their usual unsupportive comments, Yvonne and Tania spring to the defence of the couple. With Yvonne's feelings about the wedding previously presented, this ceasefire in the Jeffreys family's homophobic hostilities could be interpreted as more of a circling of the familial wagons against attacks from outsiders, than any genuine support for the ceremony. The usually outspoken, cynical, and street-wise Claire, who the viewer is used to seeing arguing with anyone about almost anything, looks uncomfortable when she sees that her new friend Courtney is among the protesters. Instead of coming to the defence of Maia and Jay, which is a behaviour that would be consistent with her character, she remains silent, her loyalty to Maia and Jay obviously compromised by her growing relationship with Baxter and Courtney.

\footnotetext{
72 The demeaning of the women's union in such a way is commensurate with Jay and Norman's requirements that the conception of their baby be done "with love", a notion plainly offensive to viewers such as Wahine (see Chapter 7, p.147).

${ }^{73}$ Episode screened 14/2/2006.
} 
Rather than postpone the event, Maia and Jay decide instead to use the protest as a catalyst to continue, and the ceremony goes ahead to "prove a point" against religious intolerance. The idea of making a commitment for love (like heterosexuals do) morphed into a pointscoring exercise; the women continue in what was supposed to be a romantic commitment to each other in order to defy a handful of extremists. Later, when Claire tells Baxter that Courtney was at the protest, Baxter replies: "Courtney went too far" by protesting at the women's wedding. He goes on to say that he considered Courtney's actions had given the ceremony "more meaning than it deserves". ${ }^{74}$ The ugliness of Baxter's comment does prompt Claire to ask him to leave, but on-screen debate to challenge homophobic vitriol is once again missing.

\section{Homophobia as Violence}

In Excitable Speech, Butler asks the question: "When we claim to have been injured by language, what kind of claim do we make?" (Butler 1997, p.1). Morrison writes "That oppressive language ... is violence, not merely a representation of it. Oppressive language is not a substitute for the experience of violence. It enacts its own kind of violence" (Morrison, cited in Butler 1997, p.9). The on-screen inclusion of homophobic sentiment, while omitting the counter-arguments strongly suggests that Baxter's values are being privileged over sectarian tolerance, and that the writers are being selective over what justifies an injury, or when a character may legitimately show outrage. For example, Maia and Jay have to cope with daily instances of bigotry and homophobia, yet when a photo of a drunken Baxter exposing his buttocks appears on the staff notice board with the tag "Mooning for Jesus", Baxter complains to the head nurse that his human rights are being violated and that his religion is being mocked. While Baxter is allowed to convey his indignation about a prank that mocked his religion, Maia and Jay are never allowed to express the hurt, harassment, and injury caused to them by the homophobia they experienced on their wedding day.

\section{Reading Lesbians Normatively}

Some cultural commentators argue there is no privileged meaning of any text, and that the media's power to promulgate dominant ideologies is significantly weakened because our individual perspectives and beliefs allow us to interpret media messages in ways that relate to our own experiences (Bonner et al. 1992a, p.7; Fenton 2001, p.112; Fiske 1987, p.84; Fuss 1989, p.35; Lindlof 1988, p.81 and Minh-Ha 1991, p.5). An individual's viewpoint can be is "influenced by factors such as gender, age, race, class, and sexual

\footnotetext{
${ }^{74}$ Episode screened 14/2/2006.
} 
orientation" (Bonner et al. 1992a, p.7; see also Fenton 2001, p.112; Fuss 1989, p.35; and Minh-Ha 1991, p.5). While it may be true that audience members use their own experiences and views to judge or interpret a character's actions, common conceptions of reality are cultivated by accumulated exposure to the patterns within television (Gerbner et al. 1986, p.19). The primacy of heterosexuality is cultivated in myriad ways on Shortland Street. This fan writes: ${ }^{75}$

Maia and Mark are the most together couple on the show if it would happen. Jay needs to $\mathrm{c}$ that Mark and Maia will always have something between them. (Hello Kitty, July 21 2005, http://www.streettalk.co.nz/ modules/newbb/viewtopic.php?topic_id=2226\&forum=13\&viewmode=fla t\&order=ASC\&start=30, accessed 19 August 2005).

Or, as squeezed4eva suggests:

maia and mark shud get together have an affair so jay can see that maia will always have sumthing with mark ... i think they are cute together. (squeezed4eva, July 21 2005, http://www.streettalk.co.nz/modules/ newbb/viewtopic.php?topic_id=2226\&forum=13\&viewmode=flat\&order= ASC\&start=30, accessed 19 August 2005).

And, in a reference to Jay and Norman and their quest to have a child together. ${ }^{76}$

i think jay lyks norman in a way

(Vinnie's Girl, August 7 2005, http://www.streettalk.co.nz/modules/ newbb/viewtopic.php?topic_id=2226\&forum=13\#forumpost56888, accessed 9 October 2005).

These comments indicate the viewers prefer to read heteronormatively, aided by the ambiguity the scriptwriters intentionally created around Maia and Jay's sexuality. Not only are these contributors reading the text using their own knowledge of social norms, they are reading in terms of the heterosexist narrative that men and women eventually surmount the insurmountable.

\footnotetext{
${ }^{75}$ Spelling is as in the original.

${ }^{76}$ Spelling is as in the original.
} 
One of the ideas cultivated by the script is the notion that heterosexual procreation would have seen Jay and Maia's child conceived "with love", as opposed to self-insemination. The discourse surrounding the conception issue also promotes the notion that lesbian sexuality is recreational and not as meaningful, or productive, as procreational heterosexual intercourse. I turn now to the matriarchal character of the show, Yvonne Jeffreys to examine how she is used to cultivate heterosexuality. The soap opera offers the audience the chance to identify with women normally excluded from drama because of age, appearance, or status (Geraghty 1991, pp.17-18). Yvonne plays a significant part in the discourse surrounding Maia and Jay, and is the major contributor when it comes to uninformed comment about same-sex desire. Her position is sexist as well as heterosexist and homophobic. Reflecting the popular cultural conventions reserved for dealing with same-sex desire, Maia and Jay's sexuality is presented as a "problem" to be solved (Gross 2001, p.83), or considered only in terms of the effect it has on heterosexuals (Dow 2001, p.129). While Yvonne's scripted reaction mirrors many parents' actual reactions when they realise their child is not going to conform to their heterosexual assumption, the constant focus on Yvonne's grief is yet another contribution to the negative discourse about same-sex desire. However, Yvonne is not alone in her distress.

Eltham, who falls in love with Maia, is the first to vent his frustration at her nonheterosexuality. Signalling her alarm at the dogged pursuit of Maia by Eltham, one of this country's lesbians writes:

Please, Shortland Street writers. Stop the path you are walking with Maia and Eltham! You have had Eltham infer that he can 'cure' Maia of her lesbianism by being the right man for her. This is not the way with lesbians. We choose this lifestyle because it is where we are most happy and comfortable. Not because we haven't met the right man or have been put off by our experiences with men. We cannot live peacefully knowing thousands of your viewers are being fed this rubbish ... Please don't brainwash the public on something that is not true. We have enjoyed your attempts to write about gay themes. And although the Jay and Maia scenes were weak as water and rather pathetic, at least it helps us a little more for the public to see us as normal human beings. Having the family accept and embrace these two, and other gays you have put in made us hope it will help with real gays in their coming out to families. Please tread carefully, 
writers! (Karryn, Upper Hutt, The TV Guide, 11-17 September 2004, p.117).

While Yvonne and Mark had the most to say, other characters voice their view that lesbian sexuality is less than acceptable. For example, Whetu is full of admiration after meeting his enterprising cousin Jay and seeing her entrepreneurial abilities as she sets about marketing Kahu Kai, a family food business. Quickly appraising Whetu of her relationship with Maia, Eti tells him, "She's a dyke mate ... and you should see her girlfriend ... it's a real waste". ${ }^{77}$

Although viewers can choose to reject the views predominantly expressed by these characters, the dominant reading is that their view is accurate and valuable commentary on same-sex desire because onscreen they go unchallenged. True lesbian identity is symbolically assaulted by this treatment. Certainly it could be argued the crude prejudice of Yvonne, Libby, Tania and the Serenity Church may be seen as having certain didactic possibilities, illustrating how their bigotry is hurting the women. The time dedicated to the execration of lesbian sexuality is more likely to have a corrosive effect on the self-esteem of lesbian audience, rather than provide an opportunity to educate heterosexual viewers about the damage and pain homophobia causes. Many times the uninformed statements made by Yvonne or Eti, and the religiously-inspired homophobia of the Serenity Church members pass unchallenged, at least not with any efficacy. Consider the ways in which positive representation is undercut. Barely an interaction goes by involving Yvonne and Maia which does not include a very strong message that her lesbian daughter is an embarrassment to her. Rarer still is a scene that involves Yvonne, Maia, and Jay when she conceals her discomfort at their relationship. The time given Yvonne's intolerance, and embarrassment about Maia's desire for her own sex, together with her constant championing of heterosexuality, gives an unequivocal voice to the message that heterosexual relationships are valued over same-sex relationships.

The homogenising effect television has on its audience and on a culture is discussed by Gerbner et al. (1986, p.27), who suggest heavy television viewing leads viewers to believe in a reality consistent with that shown on television, even though television does not often reflect the actual world. Similarly, despite the fact we are aware of the fictitious nature of the media, we can attribute many areas of our 'knowledge' of reality to what we learn from the fictional characters we see on television (Gross 1994, p.144). The reality

\footnotetext{
${ }^{77}$ Episode screened on 24/11/2005.
} 
represented in Shortland Street tends to reinforce myths and misinformation about samesex desire and identities. Reflecting that reality over others not only creates a discourse about lesbianism that is negative (and is thus unempowering to lesbian viewers), but it also helps to create a distorted image among those viewers who have little or no direct contact with lesbians. Such distortions of homo-reality, warping reality by lengthening and widening some parts while minimising and ignoring others, as Gitlin (1980, p.29) has already identified in the skewed media coverage of news events, has the potential to further bigotry and ignorance.

\section{The Vicissitudes of Identification}

Shortland Street fans have developed strong psycho-social relationships with characters they identify with, and the intensity of the relationships is illustrated by the commentary they provide in the on-line forum, www.streettalk.co.nz. Lesbian viewers' ability to forge a para-social relationship (PSR) with Maia and/or Jay on the grounds of homophily would be hampered by the ultimate heteronormative blow when Jay, a staunchly identified lesbian, not only has sex with her male business partner Dylan, but appears to savour and enjoy it. ${ }^{78}$ The dissonance and distress felt by viewers at the disconnection caused by the Jay/Dylan/Maia plot resonated throughout the forum: ${ }^{79}$

I actually hate Shortland Street right now. HOW DARE THEY have a civil union and then ruin the whole meaning of a civil union by making a lesbian become straight. I think this is so so SOOOO stupid...so annoyed cant even explain it in words!!! ( $\underline{\operatorname{Loz}}, 16$ August 2006, http://www.streettalk.co.nz/forum/comments.php?DiscussionID=909\&pag $\mathrm{e}=4$, accessed 19 August 2006).

...there hasn't been a Shorty storyline that has hit me on an emotional level like this one ever before... I had dreams about Jay coming up to me crying about it ( http://www.streettalk.co.nz/forum/discussion/909/6/jay-dylan-maia, accessed 16 September 2006).

\footnotetext{
${ }^{78}$ The character of Dylan Preston was introduced in mid-July 2006. Jay and Dylan first kiss (episode screened 19/7/2006), then begin a sexual relationship (episode screened 16/8/2006).

${ }^{79}$ Spelling is as in the original.
} 
Within the dramatic world of the soap there are two types of realism:

an 'external realism' created by reference to the outside world, through set, modes of dress, and the discussion of contemporary events, and an 'internal realism', whereby characters conform to our knowledge and expectations of them, which is derived from having watched the serial (Brunsdon 1987, p.148).

That Jay, a lesbian-identified woman could be seduced by a man compromised the internal reality many viewers knew of the character Jay. Unable to relate to her experience, viewers felt disconnected from a character they originally identified so strongly with:

I've stopped even watching shorty this week coz I hate the storyline so much! it's dumb that the writers made up this series of events coz it totally goes against what we knew about Jay (streetfighter, 25th August 2006, http://www.streettalk.co.nz/forum/comments.php?DiscussionID= 909\&page $=5$, accessed 19 September 2006). ${ }^{80}$

This is ridiculous. someone that's been gay their whole life suddenly switches?? (clarity_in_daylight, $16 \quad$ August 2006, http://www.streettalk.co.nz/forum/comments.php?DiscussionID=909\&pag $\mathrm{e}=4$, accessed 19 August 2006).

Finding ways to palliate Jay's apparent heterosexual aberration, this viewer put her relationship with Dylan down to a business arrangement:

She is really scared of loosing her job at Coltrane and desperate to be independant and able to support herself and her family (esp since they want a child soon) and so perhaps is scared that revelations along the line of "piss off Dylan Im gay, back off mate you are sooo not my type" may actually hinder the Kahu Kai success (jay_is_hot, 19 July 2006,

\footnotetext{
${ }^{80}$ Spelling is as in the original.
} 
http://www.streettalk.co.nz/forum/discussion/909/jay-dylan-maia/\#Item_0, accessed 19 August 2006). ${ }^{81}$

The storyline contributed to the body of social knowledge about feminine lesbians, particularly regarding the locus of their sexuality, and it irritated this Shortland Street viewer: ${ }^{82}$

After shorty last week when jay kissed dylan... my flatm8 goes to me... 'oh $\mathrm{i}$ think she smiled because she forgot what it felt like to kiss a man and realised it was good'. I was like... what?!... not every girl wants to be with a guy!! (woah_jaxsta, $25 \quad$ July 2006. http://www.streettalk.co.nz/forum/discussion/909/2/jay-dylan-maia/, accessed 28 July 2006).

This comment illustrates the significance representation has: audiences make meaning from media texts with far-reaching consequences. The flatmate understood Jay's behaviour in terms of the pseudo-invert hypothesis, and had that view reinforced. Others saw things differently, and it could be argued that those Shortland Street fans who do not have a strong (or any) para-social relationship with Maia and Jay are the ones who post comments of this tenor: ${ }^{83}$

I don't see anything even remotely far-fetched about Jay falling for a man...Sexuality is much more fluid than a lot of politically-correct types would have us believe - especially with women (muriel, 16 August 2006, http://www.streettalk.co.nz/forum/comments.php?DiscussionID= 909\&page=4, accessed 19 August 2006).

Jay engaging in sex with a man is not the problem; the plots of soaps can require characters to use sex as a method to achieve goals. In this line of reasoning, it does not matter that her sexuality would logically prevent Jay from taking this action (especially as Dylan believes she is heterosexual); what matters is that she openly divulges her motive to the audience to explain her actions. Instead, the scriptwriters give Jay several ambiguous

\footnotetext{
${ }^{81}$ Spelling is as in the original.

${ }^{82}$ Spelling is as in the original.

${ }^{83}$ Spelling is as in the original.
} 
lines to support her 'sexual instability' but none to clarify her actions and to allay other viewers' fears she is "turning straight". Eventually, Jay claimed her attraction was due to his personal characteristics. The message promoted by this plotline is that, given the right circumstances, the most strongly identified lesbian can find passion with a man. The administrator of the website employed by the show's producers to manage feedback about the storylines, wrote: ${ }^{84}$

All I wonder is that can't people experiment, or be attracted to individual people (irrespective of their sex)? Does everyone have to fall on the $100 \%$ gay $100 \%$ straight $100 \%$ bisexual categories? It bugs me when people go on about how Jay can't be attracted to a man ... Isn't it remotely possible that someone could be attracted to anyone... given the right circumstances? (admin, $24 \quad$ July 2006. http://www.streettalk.co.nz/forum/discussion/909/2/jay-dylan-maia/, accessed 28 July 2006).

This message illustrates how the show further uses its authority to encourage doubt amongst and about lesbian characters in its viewers. Not only does this comment convey support for the socially-accepted myth that the 'right' man can rehabilitate a lesbian to heterosexuality, but the expectations of viewers are severely affected by the lack of lesbian signs the women display. They do not carry markers of their community, their political positioning, or their sexuality, in any obvious way such as style of dress, as this viewer commented: ${ }^{85}$

I find Maia and Jay a very unbelievable Homeosexual couple. Their scenes together just look like 2 friends hugging or going out together... when I see them on the show I don't believe that they are true lesbians. $\quad(j u j u$ hamilton, $\quad 3 \quad$ August 2006. http://www.streettalk.co.nz/modules/newbb/viewtopic.php?topic_id=2453 $\&$ forum=13\#forumpost62456 [accessed 22 September 2006]).

\footnotetext{
${ }^{84}$ Spelling is as in the original.

${ }^{85}$ Spelling is as in the original.
} 
Similarly, while the attention Maia gave Mark frayed viewers' tempers to an extent, Jay's attraction to a man was the last straw for some. This Streettalk contributor umbraged: ${ }^{86}$

That is the one thing that pisses me off about Maia/Jay on this show...all the threats to their relationship are men! Can't lesbians have affairs with other lesbians? (Suzycat, $30^{\text {th }} \quad$ August 2006, http://www.streettalk.co.nz/forum/comments.php?DiscussionID=1215\&pa ge=1\#Item_0, accessed 22 September 2006).

The show's writers dealt with Jay's adultery by adding a homonormative element to the plot. In the week leading up to Maia's discovery of the affair, for the first time, Maia and Jay socialise with other lesbians; the women hosted Cathy Zimmerman and her girlfriend, Regina. In true soap tradition, Cathy also knows Dylan. Unaware that Jay has already been seduced by Dylan, Cathy announces that Dylan has a reputation of promiscuity but that for once, "there will be one gorgeous young woman he can't have" ${ }^{87}$ In the same week, Yvonne also says her first words of support for the women's relationship, telling Jay she could see how happy they were together and that if her other daughters had relationships as good, she would be a happy mother. Yvonne's comments, and action showing Jay and Maia within a lesbian social network were largely included to highlight Jay's guilt and the consequences of her betrayal of her lover, family, and previously hidden lesbian friends. Once her affair with Dylan is exposed, a disgraced Jay leaves Maia and the house they shared. ${ }^{88}$

As de Lauretis (1984) argues of woman's image in film, the construction of the televisual image of woman is connected to the viewer not only by the medium and its production but by the male characters:

The woman is framed by the look of the camera as icon, or object of the gaze: an image made to be looked at by the spectator, whose look is relayed by the look of the male character(s). The latter not only controls

\footnotetext{
${ }^{86}$ Spelling is as in the original.

${ }^{87}$ Episode screened 25/8/2006.

${ }^{88}$ Episode screened 31/8/2006. Jay later returns and attempts to resurrect her relationship with Maia. This fails when she admits she cannot guarantee she will never be attracted to men. Jay is subsequently the first victim of Joey, the Shortland Street serial killer, who murders women he deems unchaste.
} 
the events and narrative action but is "the bearer" of the look of the spectator (de Lauretis 1984, p.139).

This relationship is why it is so concerning to see male characters so involved in Maia and Jay's storylines - Mark, Eti, Eltham, and their attacker all act as the viewer, desirous of them; Norman and Dylan manage to consummate that desire. The same principle applies to the homophobia displayed by the characters of Yvonne and Baxter. The viewer's positionality determines whether they read with or against the grain of this perpetually heterosexist message.

By their very nature, characters in soap operas do not stay happy and out of trouble for very long. A few events of note occurred before the submission of this thesis that I felt warranted discussion. Most notably Maia became pregnant to Mark via self-insemination after which Maia had an explicit dream sequence about having sex with Mark in which penetration was strongly implied. ${ }^{89}$ Such erotic detail was never shown between Maia and Jay. A few months later Jay was murdered by serial killer Joey Henderson. ${ }^{90}$ While Jay was not the only woman killed in the serial killer plot arc, the character's murder adds to the tally of lesbian characters who have met untimely and grisly deaths (see Chapter 2, p.24). The continuing presence of Maia on the soap has seen the character displaying many of the 'sad', 'mad' and 'bad' stereotypes often reserved for lesbians, and noted by my focus group participants (see Chapter 5, pp.94-95). Invoking the murderous lesbian cliché, Maia confesses to her friend and fellow nurse Alice Piper that she shot and killed surgeon Ethan Pierce in the cliff-hanger ending of 2008. When Alice colludes with Maia to keep the crime from being discovered, Maia starts to fall in love with Alice. When Alice makes it clear that she does not want a relationship with her, Maia becomes increasingly possessive. Feeling pressured by Maia's attention, Alice decides to take a holiday. Maia tells Alice that she cannot cope without her. Overwhelmed by Maia's possessiveness, Alice tells Maia she needs professional help. ${ }^{91}$ Suffering with the horror of the murder, Maia's mental state becomes increasingly unstable. When Maia's delusional and manic behaviour escalates, Maia's sister Tania commits Maia to a psychiatric institution. ${ }^{92}$ Despite the incredulous and fantastical storylines inherent in

\footnotetext{
${ }^{89}$ Episode screened 31/5/2007.

${ }^{90}$ Episode screened 27/8/2007.

${ }^{91}$ Episode screened 3/4/2009.

${ }^{92}$ Episode screened 22/5/2009.
} 
soap operas, the dramas that beset heterosexual characters are grounded in reality (sickness, or employment issues), while Maia and Jay's storylines revolve solely around their sexuality or mental state and stretch credulity to the point where there is only a very slender trace of positive sentiment.

\section{Conclusion}

To what extent is lesbianism (sexuality and lifestyle) promoted positively on Shortland Street? This analysis finds that nearly all of the usual characteristics already identified in the literature as being reserved for lesbian visibility were present: homosexuality was positioned as a 'problem' to be solved (see Gross 2001, p.83); lesbians were only ever depicted in terms of the effect they had on heterosexuals (see Dow 2001, p.129); women were shown as confused or sexually capricious (see Gross 2001, p.74; Hamer 1994, p.71; Walters 2001, p.162; and Wilton 1995, p.97); they were defined by their sexuality, yet desexualised (Ciasullo 2002, p.182; Kessler 2006, p.131), and they were depoliticised (Cragin 2006, p.197; Dow 2001, pp.132-136). In short, Shortland Street's scriptwriters have offered the audience a profoundly flawed representation of lesbianism. The characters of Jay and Maia function in a tokenistic manner: lesbian characters are included to give a contemporary look and perform political tolerance.

To economise on a fundamental point, a homonormative perspective is crucial to positive lesbian representation. For characters or a script to convey homonormative values or to have elements of homonormativity, the following imperatives need to be addressed:

- same-sex attraction or relationships to be shown as normal, natural, and even incidental;

- the characters should voice political arguments that support their sexuality/sexual difference, with other characters supporting this;

- there is a need for heterosexual characters who voice support for a same-sex relationship or same-sex attraction; and

- there is a need for lesbian characters to belong to communities outside of their heterosexual family and friends.

When assessed by these indicators, the degree of homonormativity displayed by the lesbian characters and the surrounding discourse has been negligible; in fact, the ideological inflections of heterosexuality were so overwhelming in the construction of 
Maia and Jay it is necessary to actively read the lesbian sexuality into the lesbian characters. The heteronormative bias of the script was supported in four strategic ways:

- lesbian visibility is used as a vehicle to naturalise the primacy of heterosexuality;

- lesbian desire is problematised

- hetero-relations are privileged and normalised;

- heterosexuality is constantly promoted as natural, while same-sex desire is devalued, demeaned, and degraded.

Maia and Jay's potential to disrupt the meta-narrative of heteronormativity has been etiolated by the conditions that make lesbian sexuality palatable for mainstream audiences. When the characters are not being paired off with men, attacked in their beds, or dangled from cliff tops, Shortland Street's lesbians are placed in the familiar role reserved for lesbians and gays; that is as catalysts for heterosexuals' understanding (see Dow 2001, Walters 2001). Mark is perplexed at how Maia will choose her own sex over him; Maia's mother Yvonne is grief-stricken by her daughter's choice of partner. Both eventually come to understand that Maia's sexuality is permanent, and begrudgingly come to accept it. 


\section{Chapter 9}

\section{The L Word}

Living amongst the glitz and glamour of Los Angeles, primped and preened to perfection, and adorned with all things Gucci, The L Word's suite of lesbian characters are beautiful, successful, and very sexual. ${ }^{93}$ As with Shortland Street, my analysis of the first-ever lesbian series centres on one critical question: how is lesbianism (as sexuality and lifestyle) represented? Underpinning this chapter, that analyses The L Word's lesbian characters, are three specific areas of inquiry:

- What degree of homonormativity is displayed on The L Word?

- Do the representations reinforce heterosexuality as the preferred state?

- What conditions or qualifications are imposed on the lesbian characters?

\section{Introduction}

Like many Hollywood successes, The L Word has its own back-story filled with failure and difficulty before its triumph. As journalist Veronica Lee reports, homophobic conservatism amongst American network executives stalled initial attempts by co-creator and writer Ilene Chaiken for a decade (Lee 2004). After the success of the American incarnation of the controversial British series Queer As Folk, a series that offered a candid representation of the sex life of gay men, the American industry gave the go-ahead to the all-lesbian television show which was picked up by the American network Showtime Networks Inc., and premiered on American television in January 2004.

\section{The World of The L Word}

Gross emphasises that "The ultimate expression of independence for a minority audience struggling to free itself from the dominant culture's hegemony is to become the creators and not merely the consumers of media images" (Gross 1991, p.41). The L Word lesbians are certainly doing it for themselves. Working alongside industry writer, producer and lesbian, Ilene Chaiken, are lesbian co-writer and director, Rose Troche (director of the lesbian film Go Fish in 1992) and Guinevere Turner (star and co-writer of Go Fish). Lesbian celebrities are also found throughout the cast: a central character is played by

\footnotetext{
${ }^{93}$ The $L$ Word was created by Ilene Chaiken, Kathy Greenberg and Michele Abbott and produced by Rose Lam. Executive producers: Steve Golin, Larry Kennar, and Ilene Chaiken.
} 
Leisha Hailey, a former partner of singer and lesbian icon kd lang, and actor Tammy Lynn Michaels (American singer Melissa Etheridge's partner) also puts in a cameo appearance.

The $L$ Word, a title that plays nicely on the long-established trope of lesbian invisibility, is set in Los Angeles. Each of the 14, hour-long episodes of Season One begins with a vignette involving a sexual act that has a relevance to the episode it precedes. The writers and directors of each episode are listed in Appendix H. Central to the show's narrative is the character of Bette Porter and her partner of seven years, Tina. Bette is The L Word's alpha female. The director of a museum and art gallery, Bette is glamorous, educated, and professionally successful. She has a beautiful home, a successful career in the arts world, and is actively engaged, with Tina, in the pursuit of a man who is willing to donate his sperm so they can realise their shared dream of becoming "moms". Bette and Tina want the transaction done with minimal complications. From attempts at soliciting their friends to an aborted threesome, acquisition of the necessary liquid proves anything but easy.

The other core characters in Bette and Tina's social circle are Alice (a journalist), Shane (hairdresser to Hollywood wives), and Dana (a professional tennis player). Most of the interaction between the women happens at The Planet, a coffee bar owned and operated by the exotic and enigmatic character, Marina. All of the women are identified as lesbians with the exception of Alice, who is adamantly bisexual. Then there is the curious Jenny, the girlfriend of Bette and Tina's neighbour, Tim. In Episode 1, we see Tim (the only regular male character in the show) busying himself in preparation for Jenny's arrival after she decides to move to LA to pursue her relationship with Tim more seriously. However, from day one, Jenny becomes intrigued with her lesbian neighbours; she soon becomes a regular at The Planet and has eyes for many others besides Tim.

A thematic hybrid between Sex in the City and Queer As Folk, the sex lives of the women of The $L$ Word are explicit, and the storylines are emotionally engaging. Unlike other series where femme lesbian characters have existed within a prevailing context of heteronormativity, The L Word conveys a strong homonormative message: that lesbian sexuality is normal and desirable. The inclusion of purely lesbian issues and knowledge further strengthens the homonormative accent, and will likely find a resonance among many lesbian viewers. For example, the claustrophobic nature of many lesbian communities is an accepted phenomenon in most lesbian circles, and this is referred to in The L Word. In the pilot episode, Alice tries to give some perspective to a lonely Dana by pictorially revealing 
just how few of their ex-lovers it takes to link them in a "web of intimacy". It takes only four women to link Alice to Dana.

Critics of lesbian representation on television have noted lesbian visibility is often unidimensional as the characters are shown outside of political contexts and dislocated from any lesbian community (Battles and Hilton-Morrow 2002, p.101; Ciasullo 2002, p.182; Dow 2001, pp.135-136; Walters 2001, p.16). Departing from this tradition, the majority of The L Word storylines focus on the relationships between the women and their intimate lives and their friendships. The women are also implicated in a much larger world. All are shown in their professional capacities, interacting with their colleagues or clients, and Bette, Dana, and Alice are also shown as sisters and as daughters. In a very real sense the women comprise a family; sharing in each other's highs and offering support through the lows. So intimate are the women that they even know the day when Bette and Tina intend to perform the insemination. Anthropologists like Kath Weston (1991) have studied how lesbians and gays, often rejected by their families of origin, form alternate familial configurations that provide all of the personal and emotional support of traditional 'families'. The L Word, unlike the great majority of programmes, certainly supports the model to which Weston refers.

\section{Sexual Expression in The $L$ Word}

Sexual expression between lesbian characters found in mainstream texts is often minimised (Ciasullo 2002, p.182; Hantzis and Lehr 1994, p.108; Kessler 2006, p.131). The libidinous women of The $L$ Word have certainly shaken off that condition as The $L$ Word does not shy away from the physicality of same-sex attraction. The physical intimacy between the women is a significant part of the success of the series, due in part to the absence of realistic and erotic lesbian sex scenes on mainstream television. Noting this, Chambers (2006, pp.96-97) offers criticism of the sexual intimacy within The $L$ Word, arguing opportunities to explore sexual dynamics between women in the first season were lost (2006, pp.96-97). Similarly, Lorna Wheeler and Lara Raven Wheeler argue the sex scenes that were shown were actually sanitised and unadventurous (Wheeler and Wheeler 2006, p.101).

While not explicit enough for some, the fact that the women openly desire and are being desired by other women is one of the key differences in the representation of lesbian characters compared with Shortland Street's Maia and Jay. More significantly, the series sets a new benchmark in the realm of vicarious lesbian pleasure by reducing the 
participation of men. The lack of male characters allows the focus to be on the women, and limits opportunities for them to be judged according to male standards. However, a discordant and gratuitous moment occurred in a central storyline of Season One: Bette and Tina's quest to become mothers. ${ }^{94}$ Bette and Tina are so compelled to have a child they risk unprotected sex with a male stranger to satisfy their dreams of motherhood (Chambers 2006, p.91). Criticisms that the show panders to the male heterosexual gaze (Wolfe and Roripaugh 2006, p.43), find some justification in this scene.

Another jarring heteronormative note occurs in Episode 10 (Luck, Next Time), when the notion that heterosexuality is natural and same-sex desire is inferior is asserted by one of the heterosexual male characters, Andrew. After flirting for a while, Andrew says to Alice: "Now, what was that mandate? Simple boy on girl sex with no complicated stuff?" Implicit in Andrew's comment is that heterosexual sex is straightforward, while same-sex intimacy is necessarily complicated. His statement has the effect of reinstating the dominance of heterosexuality rendering lesbian sexuality as deviant. This idea is reinforced by a conversation between Alice, Shane, and Dana:

Alice: And he's rough, y' know? It's like he fucks me, y' know ... it's hot.

Shane (disinterested): Yeah, that's wicked hot.

Alice: It is. It really is because there's not that bullshit of like, y' know, I'll do you then you'll do me and y' know ...check in ... have we had equal time and all that crap.

While the heteronormative potential of Alice's comments was neutralised somewhat by Shane's disinterest, and Dana's assertion that while the bisexual Alice enjoys sex with men, not all women do, this commentary constitutes a disruption to the homonormative groove of the text. Male (hetero)sexuality is, however, limited to a device for the continuation of lesbian storylines and character development.

\section{The Reality of Homophobia}

A recurring theme throughout the series is the intersection of the women's sexuality with many oppressive elements of a wider hetero-centric society. The material effects of homophobia are highlighted in a number of ways, most notably in storylines that involve tennis pro Dana. While Dana's own homophobia is often treated humorously, it also

${ }^{94}$ Television programmes such as ER and Shortland Street have invested heavily in this device. 
highlights the oppression and fear many lesbians face. Dana is terrified of the consequences coming out may have for her both personally and professionally. As armoury against heterosexual guests who are attending a party thrown by Bette and Tina, she takes along her male tennis partner, Harrison. This proves a flimsy ruse for a number of reasons, the main one being that Harrison, or 'hun' as she insists on calling him loudly, quite clearly prefers men. As well as the ridiculous strategies Dana employs to pass as heterosexual, her fears cause her to lose Laura, a women with whom she is in love.

When her corporate sponsors (Subaru) find out the truth, they launch a successful marketing campaign acknowledging Dana's sexuality with the slogan 'Get Out and Stay Out' ${ }^{95}$ In Episode 9, Dana's delight at her sponsor's acceptance of her sexuality soon turns to dread, as such a public campaign means the discovery of her sexuality by her parents is imminent. On the tailwind of her sponsor's acceptance, Dana decides it is time to tell her wealthy conservative parents, but she chooses a Republican Party luncheon where her mother is being celebrated as "Woman of the Year" as the perfect opportunity. It does not go well. Before she has a chance to tell them, a fan appears and asks Dana to autograph her copy of the advert. ${ }^{96}$ Her parents are delighted about their daughter's fame and ask to see the magazine spread. When her mother sees the slogan she does not understand what it means. Panicked, Dana explains: "It's a marketing campaign for women... like me who are ...out ... doorsy ... like me ... y’ know, tennis players.” After refocusing on why they had attended the event, courtesy of a pep talk in the toilets by Alice, Dana comes out to her parents. We do not see her telling them but the scene then cuts to the blackened faces of her parents, storming out of the luncheon, as Mrs Fairbanks tells her daughter: "We all have feelings for our girlfriends Dana; it doesn't mean you have to act on them."

This retort suggests she resents her daughter's choice, and that such a freedom was unattainable for her. Freedom is a theme repeated several times. When Dana recounts her coming out to Shane, Shane suggests Dana's mother's comments were probably a sign that at some point she fell in love with one of her girlfriends, and got her heart broken. This scenario is actually presented in the opening vignette and is also implicit in Shane's relationship with the married and older Sherry. Despite the liberal society The L Word characters inhabit, when her husband finds out about their affair, Sherry tells Shane the

\footnotetext{
95 The fictional sponsorship of Dana's pro tennis career by Subaru reflects a reality of sexual minorities: corporate interests have started to market gays "as gays" (Walters 2001, p.236).

${ }^{96}$ The implication is that not all attendees at the Republican gathering have issues with Dana's lesbianism.
} 
financial privileges of staying in her marriage make it impossible to choose her, despite their budding love.

Betrayal laced with homophobia is presented in other storylines, most notably in Bette's. Bette's father supports his daughter's relationship until he learns of Tina's pregnancy. Instantly minimising the women's relationship to a "friendship", he advises that he will not accept the child, as it was conceived outside of a heterosexual relationship. Instead he tells Bette and Tina the pregnancy is "a fiction of your own creation". The women are devastated. Bette encounters homophobia in her professional life too. In Episode 13 (Locked Up), Christian fundamentalists gather outside the gallery to protest about a controversial art installation, and the art/pornography dialectic receives an obligatory airing. In keeping with its homonormative perspective, the dominant message these scenes impart is that homophobia is wrong, and the Christian fundamentalists are mob-rule automatons. ${ }^{97}$ Bette advocates that the exhibition go ahead on legal grounds citing, as the real case the episode is based on did, the First Amendment. This episode flexes a little political muscle as Bette also defends the content of the exhibition, affirming nonheterosexual expression.

\section{A Privileged World}

The women of The L Word largely adhere to the white and feminine schema; the series is firmly located in a white, middle-class lesbian orientation rather than one of ethnic and class diversity (Chambers 2006, p.82). All of the central characters in The L Word are white, or pass as white. For example, two non-white characters, Bette and Marina, are missing many of the signs that afford any true classification of their heritage. More concerning is the only unmistakeably African-American character, Kitt, can also be read as reiterating negative characteristics that communications scholars Sut Jhally and Justin Lewis find are used to stereotype African-Americans as "lazy and stupid" (Jhally and Lewis 1992, p.94). For example, Kitt is the least successful of all the women. She is unemployed, a recovering alcoholic, and is also the most unreliable of the all main characters. Similarly, the only Asian is an ancillary character appearing in Episode 6, as an hysterical woman intent on harassing Tina and Bette because their sperm donor was her boyfriend.

\footnotetext{
${ }^{97}$ According to American culture expert Margaret McFadden, Bette's clash with the Religious Right over an art installation was based on a real life event (McFadden 2006, p.125).
} 
It is widely recognised that early feminists largely ignored the experiences of non-white women. The insistence that all women share the same oppression ignores the very real differences that exist among women of colour (this issue is discussed by Lorde 1984; Smith and Smith 1983, and Minh-Ha 1991). An argument that requires consideration, as Bryson notes:

The problem now is not simply one of acknowledging that differences exist, but of challenging the underlying assumption that white women are the norm and that the experiences of black women, women of colour or Third World women are some kind of alien problem or optional extra: this assumption not only denies the validity and primacy of these 'other' experiences, but can often lead to condescending and over-simplistic generalisations or tokenism with regard to all 'non white women' (Bryson 1992, p.254).

The subject of ethnic identity and oppression is addressed only through Bette and Tina's desire for a family. In Episode 9, during a first-time parents' group meeting, Bette discusses her frustration that she and Tina would find it very hard to find a biological mother willing to let a lesbian couple adopt her child. Yolanda, an African-American woman, challenges Bette:

Yolanda: You talk so proud and forthright about being a lesbian. I haven't once heard you talk about being an African-American woman. All I hear from you is that a white chick should have a white baby.

Bette: I said nothing of the kind.

Yolanda: I am a Black woman. That is who I am and how I identify. Now, I get the impression that you don't even think of yourself as AfroAmerican.

Bette: I am. Half African-American and my mother is white. ${ }^{98}$

Yolanda: But legally, you're Black, isn't that a fact?

\footnotetext{
${ }^{98}$ Bette wanted a child of mixed ethnicity to reflect her and Tina's heritage. Tina was clearly surprised when she finally met donor Marcus, who Bette felt "was 'the perfect donor"” and demanded of Bette: "How could you not tell me Marcus Allwood was black?” Bette interprets this as Tina’s rejection of her ethnicity.
} 
Bette: That's the white man's definition of me, yes. The one drop rule. ${ }^{99}$ So basically what you are saying is that you want white America to define me ...What I want to know is how do you justify you pushing me so hard to come out as a black woman when all the while you let us mistake you for a straight woman?

Silence.

Yolanda: You thought I was straight?

Bette: Well why wouldn't I? I mean you're not exactly readable as a lesbian and you didn't come out and declare yourself. It wasn't until I read your poem from Sistahs Stand Up...on being a Black, socialist, feminist lesbian working to overthrow the white male capitalist patriarchy - I notice that lesbian comes last.

Yolanda: But you see, I did not negate it. I did not deny it. I did not leave it out.

Bette: Well neither did I. I mean, I would never define myself exclusively as being white anymore than I would define myself as being exclusively Black. I mean really, why is it so wrong for me to move more freely in the world just because my appearance doesn't announce who I am.

The code we choose also assigns us to an 'insider' or 'outsider' position, dependent on what we share with those with whom we are located. Just like the feminine lesbian who can "pass" in the heterosexual world, it is easier for Bette than Yolanda to negotiate her life as white in a racist world. Many African-American homosexuals argue against the idea of a unitary gay identity, as this assumes a common oppression that is shared among all homosexuals, notes sociologist Steven Seidman (Seidman 1993, p.120). Similarly, Lorde writes:

as a black feminist comfortable with the many different ingredients of my personality ... I am constantly being encouraged to pluck out some one aspect of my identity and present this as a meaningful whole, eclipsing or denying the other parts of self. But this is a destructive and fragmenting way to live (Lorde 1984, p.120).

\footnotetext{
${ }^{99}$ As Julie Greenberg finds, the "one drop rule" can be traced from its racist origins when anyone with one drop of "black blood" was considered to be Black (Greenberg 2002, p.103).
} 
The Bette/Yolanda discourse allows a reasonably open discussion of the realities people with multiple marginalised identities face and reminds the viewer the individual in question is the only person with the right to determine their identity. The conversation between Bette and Yolanda confirms that which 'otherness' we find most oppressive is a matter of choice. For Yolanda, the marginalised identity is race, while for Bette, her sexuality is the site of her oppression. Author Mary Gentile makes the point:

Differences and similarities can be like nested dolls, just when you think you've found a 'match' for yourself, you learn that there's another layer of complexity just inside (Gentile 2002, p.190).

According to queer scholarship, gay identity constructions merely serve to "reinforce the dominant hetero/homosexual code with its homonormativity" (Seidman 1993, p.130). Urging us to do away with the boxes required by the paradigm of categorisation, queer proponents such as Fuss insist the homo/heterosexual binary corresponds to an inside/outside dialectic that privileges and legitimises heterosexuality while rendering same-sex desire as abnormal (Fuss 1991, p.1). The L Word makes several gestures toward the queer movement throughout the series, incorporating a smorgasbord of queer characters into the narrative. Yet the queer identities appear to be problematised each time they arise.

\section{Bisexuality}

Bisexuality is a major theme of the show. Two subsidiary female characters are ostensibly heterosexual, and both have affairs with Shane. However, the plot arcs of core cast members Jenny and Alice give bisexuality its primary visibility. Insults between the characters are a regular part of the conversations and exchanges; Dana attacks Alice's sexual capriciousness, and Alice chides Dana over her fear of coming out. While the tension between Dana and Alice indicates an attraction between them (a storyline that is not explored until Episode 14), it is the character of Jenny who moves between male and female lovers, a characteristic celebrated by Johnson as "a momentary embrace of abundance" (Johnson 2006, p.128). Jenny's interest in women was initially viewed by boyfriend Tim as titillating. He even encouraged her to talk about her attraction to another woman, appropriating lesbian sexuality as part of their sex play.

Dana's need to categorise Alice as either straight or gay (this issue is discussed by feminist authors Loraine Hutchins and Lani Kaahumanu 1991, see also Paula Rust 1992), 
and Alice's resistance to such categorisation, is a site of friction throughout the first season. Although the two women are friends, Dana disrespects and distrusts the either/or quality of Alice's sexuality, and frequently refers to Alice as a "dirty bisexual". In Episode 5 Alice confides to Tina, after being betrayed by a woman again, that she is going to start dating men exclusively.

Tina: Are you sure you want to go back to men?

Alice: Positive. I've had enough drama and mind fuck and women are fucking crazy.

Tina: Yeah and men are boring.

Alice: Yeah, well bring it on because I could do with a little uncomplicated and boring boy/girl sex masquerading as love. It's fine by me.

Implicit in Alice's comments is the emotional involvement she has with women and the lack of intensity in her relationships with men. This nadir in Alice's love life is used as a device to introduce the character of Lisa, one of the queerest lesbians in the series. Lisa is a 'lesbian-identified man'. Lisa displays many of the characteristics usually attributed to women (sensitivity attentiveness, and loyalty), and Alice soon succumbs to Lisa's charms. Lisa is not male-to-female transgendered, he dresses and looks like a man. For the bisexual Alice, this womanly man is perhaps her ideal lover. When she introduces Lisa to the other women, a jealous Dana fires the opening gambit:

Dana: Is the lesbo man dating the fake bisexual?

Alice: I am a bisexual.

Annoyed by the tension, Kitt explodes:

Damn it! What is it with you people and your need to take apart everything and process every detail? ... If the dude wants to give up his white man ways to be a second class citizen then, hey! Welcome to our world.

Desperately seeking acceptance and absolution herself, Kitt's diatribe about forgiveness and acceptance of Lisa is contextualised, and the integrity of her political support for Lisa is weakened by this subtext. 
The L Word explains the logistics of a queer character's reality. Alice's attraction toward Lisa deepens, and the couple finally consummate their relationship in Episode 8. As they become more physically involved, Lisa reaches into his bag and pulls out a dildo. When Alice points out that he has a penis, Lisa replies:

Lisa: But that's not how I want to make love to you.

Alice: That's the way I want you to, OK?

Lisa: But it goes against who I am.

Alice: Listen, you, you're a man, you're a man named Lisa, but you are definitely a man.

There are several readings of Lisa's phallic reticence. One sees lesbian sexuality as being so exotic, so attractive to some heterosexual men that they want to have sex with a woman by overriding their physicality (as Lisa did), in order to experience lesbian sexuality. A queer reading would see Lisa as the embodiment of the instability between sexuality, gender, and desire. Despite how he may have identified, the lesbian characters saw him as a man, and the only woman attracted to him was bisexual, not lesbian. Lisa is an awkward device. His claim of a lesbian identity rests solely on what he sees as the lesbian sex act (sex without a penis), and by assuming gendered mannerisms (e.g., a willingness to talk about his feelings, supportiveness, attentiveness).

Alice quickly tires of the relationship, and new and less complicated horizons are not far away. After Lisa discovers Alice and Andrew (a heterosexual who was introduced to the series as a blind date originally arranged for Dana by her homophobic mother) on the couch together, the following discourse takes place:

You know what Lisa? When I first started seeing you I wanted something simple and easy and instead I end up with the most complicated interpretation of sexual identity I've ever encountered. Y'know, you 'do' lesbians better than any other lesbian I know. OK I don't want a lesbian boyfriend OK? I'm sorry. I want a boyfriend who's straight or I want a lesbian who's a girl.

Sexual and gender identity categories are broadened and 'new' identities generally tolerated in The L Word but even within the relaxed embrace of Alice, Lisa's queerness 
proves untenable. Shane, in contrast, picks and chooses from feminine and masculine attributes, but is still able to be located within a lesbian continuum.

As gender theorist Toni Lester emphasises, “Men don't own masculinity any more than women own femininity" (Lester 2002, p.4), and each can be performed by either sex (Butler 1990, p.137, Halberstam 1998, p.144). Amongst the core characters, Shane transgresses the male-defined ideal of what a woman should most look like. The libidinously hyperactive tomboy shuns intimacy, uses drugs, and goes clubbing in between cutting the hair of (and bedding) her clientele. Shane's lothario-like qualities, and her apparent lack of emotional attachment, contrast with the feminine qualities of the other women. While Shane, with her Jagger-esque strut, does reject some of the traditional ideals of what it means to be a woman, she appears to fall short of realistically representing the butch lesbian. Yet so supposedly convincing is Shane's androgyny that the viewer is asked to believe she passed as a man and was a sex worker, servicing Hollywood homosexuals (this back story is revealed in Episode 5, when Shane runs into an old associate). With copious applications of eyeliner and eye-shadow, the waif-like Shane appears to be the epitome of another cultural phenomenon, heroin chic.

A very queer lesbian is Ivan, a subsidiary character introduced in Episode 13. Ivan is a drag king who becomes smitten with Kitt when they meet at a drag king contest held at Kitt's club. Drag kings (women who mobilise, parody, and appropriate masculinity) are less visible in mainstream society than drag queens (men who parody femininity). Authors Colleen Auyoup and Julie Podmore posit this is because "the 'actual' gender of the drag king" is the reason for drag kings' relative invisibility" (Auyoup and Podmore 2002, p.63). ${ }^{100}$ While the art of 'kinging' reinforces the notion that masculinity is a masquerade commensurate with Butler's argument that gender is a performance (Butler 1990, p.137), the drag king, with all her parody, is not without criticism (see Jeffreys 2003, p.127). As media theorist Vicky Crowley argues, criticism of the drag king phenomenon often comes from those who are "butch sympathetic and butch-identified lesbians and is not necessarily part of 'butch-phobia'” (Crowley 2002, p.288).

\section{The Good/Bad Gay Dichotomy}

The L Word's lesbian characters seem to straddle the heterosexually-dictated 'good gay'/bad gay' divide. For example, all of the women conform to the male-defined model of attractiveness, and are therefore 'good' lesbians; while the show's butches, Ivan and

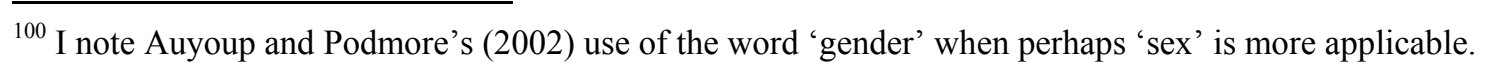


Shane, are softened, highly stylised, and both wear as much make-up as the feminine lesbians. In another configuration, Shane, Alice, and Jenny's promiscuity, coupled with the failure of Bette and Tina's relationship, can be seen as devaluing the monogamy that the 'good' lesbian must uphold. Cragin (2006, p.197) argues feminine lesbians verge on the 'good' lesbian category, but the series clearly contests and works against the heteronormativity of the televisual landscape. The characters inhabit a lesbian world and secondly, their sexuality is not exhibited for the amusement of a heterosexual audience. These elements are important components of the series' construction and success.

Realistic lesbian representation recognises and shows the heterogeneity of lesbian communities, a population that Stein comments is "a seeming multiplication of diverse subcultural pockets and cliques - corporate dykes, arty dykes, dykes of colour, clean and sober dykes - of which political lesbians are but one among many" (Stein 1992, p.436), The $L$ Word functions along the lines of this description. The characters are generated from a wide range of sources: we have the 'nice' characters; the recovering alcoholic; the sporty dyke; and the driven work-a-holic. However, within this varied representation, the white, middle-class femme takes centre stage. Ciasullo finds the hegemonic lesbian aesthetic problematic, first because screening femmes leaves little room for non-feminine lesbians in the cast, and second, because the non-feminine character is far better placed to "challenge cultural fantasies about lesbianism than a feminine lesbian might" (Ciasullo 2002, p.223). Despite this, she concedes that the femme lesbian possesses some subversive power, such as the ability to challenge heterosexual assumptions about stereotypes (perhaps the chief educative virtue of The $L$ Word).

\section{The Myth of the Affluent Gay}

Privileging a marginalised minority group like lesbians is not without consequence. Taken to the extreme, the 'good' lesbian can become deified as a kind of goddess, a chic chimera that all other lesbians must live up to. Similar to communication scholars Robert Brookey and Robert Westerfelhaus's (2001) study, the deleterious effect of deification of subordinated groups is illustrated in Jhally and Lewis' (1992) analysis of The Cosby Show. An African-American family living in New York, The Huxtables were elite. Both parents were professionals (the father a doctor, the mother a lawyer) and the children, primarily privileged because of their parents' professions, were also expected to mirror their parents' professional and academic success. These middle-class images are a reversal of the usual roles reserved for African-American characters, and they created a new "enlightened" form of racism, cultivating new expectations among white viewers: "the 
Huxtables proved that Black people can succeed: yet in doing so they also prove the inferiority of Black people generally" (Jhally and Lewis 1992, p.95). Similarly, the women in The L Word occupy privileged positions in a city where only the most successful survive in comfort. Bette is The L Word's Huxtable. Her apotheosis masks and minimises the effects of homophobic and racial oppression she would most likely encounter in real life.

Historically, lesbians have not been targeted as a separate consumer group (Clark 1993, p.186), but with increased visibility and ostensibly larger amounts of discretionary income, the lesbian too has become a target for capitalist image-makers. ${ }^{101}$ The L Word seriously disrupts the obstinate stereotype of lesbians being dowdy, home-loving, sensible shoe-wearing women draped in flannel (Walters 2001, p.161). ${ }^{102}$

While femininity has traditionally been read as indicating passivity and subordination, many women are keen to promulgate the idea that they can be "both feminine and strong" (Ussher 1997, p.58). The L Word lesbians are more likely to represent these women. Although designer clothes, wealth, and a party-going lifestyle were more likely to be associated with gay men, an emergent representational trend has seen the obdurately frumpy lesbian stereotype morph into a well-heeled, sexy one (Clark 1993, p.189). Many voices can be heard that challenge the accuracy of affluent lesbians and gays, however. As feminist economist Prue Hyman advises, the "pink dollar picture is a myth when used as a generalisation about most lesbians/gay men" (Hyman 2001, p.119). Lesbian and gay couples without children do have higher incomes on average than their heterosexual counterparts, but lesbian and gay male couples with children support their children on lower average incomes than do heterosexual couples with children (Hyman 2001, p.122). ${ }^{103}$

\footnotetext{
${ }^{101}$ For an excellent discussion about homosexuality's relationship with capitalism, see John D’Emilio (1993).

${ }^{102}$ As Stein explains, "the flannel-and-denim look was not so much a style as it was an anti-style - an attempt to replace the artifice of fashion with a supposed naturalness, free of gender roles and commercialized pretence" (Stein 1992, p.432). The anti-fashion stance also provided a valid way for lesbians to separate themselves "from heterosexual culture politically" and to signal their lesbianism to other women (Clark 1993, p.188).

${ }^{103}$ In the 1996 New Zealand census, couples in same-sex relationships were asked to identify themselves for statistical purposes. While the data found that gay/lesbian couples without children did have a higher income levels than heterosexual counterparts, of those same-sex couples with children, Hyman notes that the pink dollar myth is selective because overall, heterosexual couples with children are better off than those without, but for same sex couples, the opposite applies (Hyman 2001, p.122).
} 
When the myth of gay wealth enters the political arena, the stereotype of the affluent homosexual becomes an effective tool used by anti-gay campaigners to argue that they are already a privileged group, and not in need of further civil rights protection (Hyman 2001, p.119, Walters 2001, p.241). Lounging around swimming pools and driving expensive cars, the characters of The $L$ Word contribute to the myth of lesbian affluence. The logic that wealth means you do not need basic human rights is fundamentally flawed, but it is this component that is often omitted from lesbian representation. As feminist theorist Rosemary Hennessy writes:

money, not liberation, is the bottom line ... the increasing circulation of gay and lesbian images in consumer culture has the effect of consolidating an imaginary, class-specific, gay subjectivity for both gay and straight audiences (Hennessy 2000, p.112).

In this respect, the fiscally-privileged characters of The L Word cannot be credited with challenging the myth of gay affluence; moreover, to the same extent they will define what kind of lesbian will be welcomed into the mainstream, and which will remain on the periphery.

The $L$ Word indirectly prizes another patriarchal notion: the valorisation of monogamy, developed through Bette and Tina. The stability of the women's relationship is something that is admired, and even provides a foundation for some of the other characters, especially Shane. Monogamy is ascribed a positive value and this is something that critics like Johnson (2006) and Chambers (2006) dislike because of its heteronormative connotations. In Episode 2, Bette lectures her libidinous friends about the virtues of monogamy which is a principle she argues, "Isn't just hypothetical; it's something that people actually practice." At the end of the first season, however, Bette comes to resent, and ultimately transgress, the monogamy that she and Tina once prized.

\section{Conclusion}

Assessing Season One of The L Word for its homonormative qualities, I observed homonormativity was upheld in two fundamental ways: same-sex desire was shown as normal, and the lesbian characters shown as part of wider lesbian communities. While the characters (with the exception of Shane) are the very models of heterosexually-defined femininity, their sexuality is not displayed exclusively for the scrutiny or pleasure of a straight audience. However, heterosexual couplings, Alice's insistence that lesbian sex 
acts are complicated, and heterosexual coupling is unproblematic, do undermine the homonormative strength of the programme. In addition, the show does not represent or give voice to butch lesbians, lesbians of colour, lesbians of age, and lesbians of lower economic status. A truly progressive twist would have been if core characters Bette and Tina were at least androgynous, while the inclusion of more alternative relationships such as lesbian polyamory would have given the series the more radical edge that critics like Chambers (2006) and Johnson (2006) crave. The series' shortcomings need to be balanced against its homonormative perspective, however, as seldom has there been a text that offers such a strong, affirming voice to lesbian desire on New Zealand television.

The ' $\mathrm{L}$ ' in the show's title also describes the scheduling: 'late night'. The programme's ability to influence the cultural conversation about lesbian sexuality has been substantially reduced due to the scheduling decision of $T V N Z$, that buried it in the depths of late night programming. Scheduling The $L$ Word in prime-time would have seen TVNZ fulfil the Broadcasting Act's diversity requirements, with a series that also has majority audience appeal. The policy strategies that protect minorities include "mainstreaming" specialist representation to ensure that it airs within prime-time, to receive maximum exposure (Horrocks 2004a, p.24). Instead, TVNZ scheduled the series to show in an inhospitable timeslot. This scheduling decision, along with low to no advertising, helped to symbolically annihilate positive lesbian visibility for the majority of viewers, particularly young lesbians, which was a point also noted by Labett's participants (Labett 2006, pp.2223). One of my focus group participants recognised the mind-set and double standards that accompany the inclusion of lesbian characters in a heterosexual space:

Because they're a gay couple, it kind of means there's something a bit, sort of, adult about that, or a bit sexy or dirty or something (heterosexual man).

When rival network Prime screened the series a year later in an earlier timeslot, the decision may have been based on a desire to exploit this impression. While TVNZ's communications spokesperson (incorrectly) insisted that the series held no mainstream appeal, Prime predicted otherwise. Perhaps because Prime receives the least audience share of the free-toair-channels (TVNZ Annual Report 2007, p.8), it adopted a salacious advertising strategy, which capitalised on the titillatory value lesbian sex scenes hold for heterosexual men. Billboard and print advertising were employed to promote a pixelated image of two people kissing. The same image also appeared on the inside cover of The TV Guide, October 21-27, 
2006 (see Appendix I). Prime's advertising strategy appears to reflect Dyer's observation that how a grouped is treated is directly linked with how they are represented in the media (Dyer 1993, p.1). It appears TVNZ's scheduling decision, and Prime's advertising campaigns are manifestations of how lesbian sexuality is treated in this supposed era of visibility: seen but hidden, titillating but placating the heterosexual audience.

The unfriendly scheduling of The L Word was also the subject of comment by New Zealand columnist Diana Wichtel:

The $L$ Word, at a punishing time of $11.30 \mathrm{pm}$, is really quite good ... This is adult viewing. But what's a bit of nudity when you consider what Eating Media Lunch gets away with (pretty much everything you can think of and then some) much earlier in the evening (Wichtel 2005, p.71).

When I invited TVNZ to comment about the scheduling choice, their communications spokesperson replied:

The $L$ Word is a fantastic show but will appeal to only a select audience.

(Christine Wilton [nee Gilchrist]. E-mail message to author, 31 August 2005) (for full reply see Appendix J).

TVNZ's assumption about the niche appeal of the show was wrong, as heterosexual reviewers and viewers alike endorsed the show and lamented its timeslot:

The gender politics are satisfyingly complex and mostly you forget about gender altogether as the usual relationship disasters and dysfunctions unfurl (Wichtel 2005, p.71). ${ }^{104}$

What happened to The L Word (formerly TV2, Mondays)? It's a fantastic show, not all melodramatic and fake like some other programmes. And you don't have to be gay or a lesbian to watch it.

(Sam Molony, Buller, The TV Guide, 29 April - 5 May 2006, p.113).

\footnotetext{
${ }^{104}$ While this comment illustrates support for the show, it plays into Johnson's (2006) complaint that true queer representation should not import heterosexual models of relationships because they inevitably force the characters into traditional heterosexual positions, such as the betrayed and the betrayer, to advance the drama. I believe that showing monogamous lesbian dyads in all their stages is not about assimilation, it is about reflecting a relatively common reality. It reflects mine.
} 
This show rox!!! I am straight and this is probably one of my favourite shows ever. (*Sam* 25 October 2006. http://www.throng.co.nz/the-1word/the-1-word-seasons-1-4-in-a-row, accessed 12 November 2006).

Participants of Labett's study of New Zealand sexual minority audiences reported that late scheduling of programmes with gay-specific content reinforces their social marginalisation and invisibility, and exposed the tokenism of this apparent inclusion (Labett 2006, pp.22-23). The initial conservative scheduling slot for The L Word by TVNZ (Mondays at 11.25 p.m. on 2), and the subsequent lack of advertising, meant that many viewers, especially young lesbians, would have missed an eminently more homonormative representation of lesbian sexuality than that offered by Shortland Street's flawed femmes. ${ }^{105}$

Despite its shortcomings, The L Word provides a significant shift in the discourse that usually accompanies the televisual script for lesbian femmes. In a very real sense it can be argued the characters of The L Word decentre the privileged position of heteronormativity while centring homonormativity, a quality redemptive enough to make it a significant text of empowerment for lesbians. From an operational perspective, The L Word is a slick, big budget American series with high production values that could be purchased by TVNZ at a fraction of local production costs. The $L$ Word cannot be everything to everyone. The characters largely conform to a white feminine middle-class schema, limiting the opportunity to represent and value other schemas, but the show also offers one of the most homonormative accounts of lesbian sexuality and life available to viewers. For that reason alone, Bette, Tina, and co hold a broader appeal and the series warranted a more hospitable time-slot.

\footnotetext{
${ }^{105}$ The L Word did not screen on New Zealand television during the focus group component of this study. It is possible that had it been screening, some of my participants would have been able to refer to it during the focus groups. It was first broadcast by TVNZ outside of prime-time, and then later broadcast inside primetime at 9.30 p.m. on Tuesdays, by Prime.
} 


\section{Chapter 10}

\section{Discussion}

Leading this investigation were a series of research questions designed to gauge the frequency, breadth, and homonormativity of lesbian characters on prime-time television in New Zealand. This chapter brings together the various findings of my multiple method exploration of lesbian visibility in New Zealand's prime-time television landscape, in order to evaluate them against the research questions and the established literature, and media effects theories. The limitations of the study and ideas for future research are also presented.

\section{Introduction}

This thesis examined how frequent lesbian depictions were in the New Zealand television landscape during 2004 - 2006. The sample of prime-time programming on the four most watched free-to-air channels revealed lesbian characters comprised only $1.2 \%$ of the 1192 characters available. Two lesbian core cast characters comprised 10 of the 14 instances, as they appeared each weeknight of the measurement period. New Zealand prime-time television, therefore, offered just six individual lesbian characters a week; and four were incidental characters. Lesbian characters in the most significant source of prime-time lesbian representation during the research period were outnumbered by their heterosexual counterparts 8:1; and when homonormative representations of lesbians were available to audiences, they were confined to time slots outside of prime-time.

These findings illustrate how sparse the representation of lesbians is in New Zealand's prime-time televisual environment. Remarkably, this small measure of visibility represents an improvement on visibility from previous periods (see Capsuto 2000, p.43; Gross 2001, p.82; and Holtzman 2000, p.303). This observation was supported by focus group participants, and the low visibility trend on New Zealand screens is aligned with Herman's (2003) and St Germain's (2003) studies of lesbian representation. The overwhelming proportion of characters that were heterosexual speaks to the symbolic annihilation of a minority group and the continuing hegemony of New Zealand's television programming, representing, as McQuail (1994, p.256) and Dickey (1987a, p.82) observe, the interests of those already in power. 


\section{Focus Groups: Comparisons and Contrasts}

I used focus groups to investigate how viewers respond to the lesbian representation available on New Zealand television in the post-Ellen era. Many participants provided statements that illustrated they had knowledge of social scripts about lesbians, supporting the theory that media cultivates perceptions and expectations of sexual minorities, and suggested a relationship between social norms and television representation. This suggests the focus group participants have similar expectations of lesbian representation reminiscent of Davies' (1989) findings that prior social knowledge affected interpretations and meaning, similar to the phenomena of subjectivity (see also de Lauretis, 1984). The views of the heterosexual focus group participants never replicated the animus of correspondents found in secondary sources like The TV Guide, and some were as knowledgeable as the lesbian participants. This was not surprising given the participants had to opt in to the research, and had some degree of interest in the topic. However, the two lesbian groups were able to recall a much larger quantum of lesbian characters than any other group, and this is an index of their awareness regarding lesbian representation.

Small differences between the Australian and New Zealand lesbian samples were found. The average age of the New Zealand lesbian group (44 years) was higher than the Australian lesbian group (35 years). As a group, the average number of hours per day participants spent watching television was two hours. The mean of the Australian lesbian sample was higher than this (2.6 hours), while the mean of the New Zealand lesbian sample was slightly lower (1.9 hours). The Australian sample also reported a slightly higher number of televisions (2.3 televisions) in their homes than the New Zealand lesbians (1.7 televisions).

In total, the New Zealand lesbian sample recalled lesbian characters from 40 different programmes (an average of 4 per participant), just exceeding that recalled by the Australian sample (37 programmes, an average of 6.2 per participant). This result suggests that if the Australian group had been larger, the number recalled would have been higher. Alternatively, owing to the paucity of sources of lesbian representation, if The L Word had been screening before, or during, the time the New Zealand focus groups were conducted, the New Zealand tally may have been higher.

Lesbian characters from programmes originating in a variety of different countries were nominated by focus group participants, and the majority of lesbian participants reported their enjoyment of these characters. This suggests that culturally specific identifiers are 
not necessary for audiences to develop para-social relationships with the characters. Rather, the realism of the characters as lesbians is paramount. It is to the more important question, the diversity and quality of these characters, that I now turn.

\section{Reading Shortland Street and The L Word}

New Zealand television's lesbian couple, Shortland Street's Maia and Jay, correspond to the notion that to make a lesbian core character palatable to as wide an audience as possible is to construct an assimilated lesbian, one that does not challenge the heterosexual audience (Kessler 2006, p.134). Assimilated lesbians are "stripped of visual references to lesbian culture, politics, history, aesthetics, and sexuality: These feminine 'lesbians' that are left, hardly seem different from the coupling of two heterosexual women" (Cragin 2006, p.196), symbolically annihilating their differences to suit heterosexuality. Dow (2001) draws the parallel between The Cosby Show and Ellen, in that these shows are about minority characters that were meant to appeal to a wide audience. My analysis has found that the assimilation of Shortland Street's Maia and Jay has resulted in them taking on the behaviours of the dominant order, which supports Kitzinger's observations of televisual media (Kitzinger 1984, p.48). The New Zealand lesbian focus group participants were acutely aware of how lesbian sexuality is subjugated within Shortland Street. They noted the characters' assimilated (de-lesbianised) appearance and forms of behaviour, and the evanescent nature of their sexuality within the storylines.

As a group, $88 \%$ of the participants recalled lesbian characters in sexual relationships. Despite this, the quality of those relationships and the depictions of them were assessed as low. Participants noted the relationships often dissolved under pressure, and that displays of intimacy between lesbian couples were surrounded by trepidation (scenes where couples were discovered to be secretly kissing were nominated as examples), or not given as much air time as heterosexual couples in similar scenarios. This latter observation was supported by the quantitative analysis of the displays of intimacy between lesbian and heterosexual couples on Shortland Street. The intimacy afforded lesbian couples was minimal in contrast with their heterosexual counterparts, despite being part of a significant romantic storyline during both periods of measurement. These findings illustrate that the

symbolic annihilation of lesbian characters can occur even when they are the subject of a central storyline. 
Sitcoms and soaps are not designed to be political, but my analysis of Shortland Street revealed the serial did present distinct political stances. Maia and Jay were not allowed to claim a political voice, but a chorus of other characters were afforded opportunities to articulate their homophobia (a vehicle to transmit heterosexist values). Depicting the dayto-day difficulties that lesbians face from a homonormative perspective on a sitcom, in particular, would shatter that genre's protective boundaries, and therefore, its appeal as a commercial product. The history of homophobic depictions, outlined in the literature, indicates presenting stereotypes of lesbians as figures of amusement has much more commercial appeal than homonormative representations which are relegated to late night, low-earning slots. This dovetails neatly with the argument that patriarchy exerts social control through the media by promulgating the project of heterosexuality via gendered and heteronormative television scripts of television scripts (in particular, see Kim et al. 2007; see also The American Psychological Association 2007; Bourdieu 2001; Gross 2001; Lamb and Brown 2006; Holtzman 2000; Morgan and Shanahan 1997; St Germain 2003; van Zoonen 2004).

Unlike Shortland Street, The L Word - a programme constructed primarily by lesbians, for lesbians - is a series heavy in homonormative values. Lesbian sexuality is depicted as normal; the desire between the women is centred, while heterosexuality is sidelined; the women are part of a larger lesbian community, are supported by their family and friends and are supportive of them in return; and bigotry is not only explored but represented as morally wrong. These observations were supported by the comments of the Australian lesbian focus group participants, and turn, support McFadden's (2006, p127) study of The $L$ Word. In this light, The $L$ Word provides an oppositional voice to the heterosexual hegemony of television, representing what Littlejohn (1999, p.355) refers to as "a diversity of values" that "speak out in opposition to the ideology of the powerful". TVNZ's decisions to schedule the programme so late at night can be seen as being aligned to the idea that opinions that contest the dominant ideology are treated as "fringe" (ibid., p.236) as the theory of media hegemony suggests.

Lesbians are not an homogeneous population (Baird 2005, p.78; Dobkin 1990, p.4; Stein 1992, p.431). Yet despite the focus group participants confirming society stereotypes lesbians by associating them with masculinity, the literature, my own interrogation of the New Zealand television landscape, and comments from a strong majority of my focus group participants confirm that the modern palette of prime-time lesbians is largely confined to an assimilated, (white), feminine aesthetic (see Chapter 5, pp.96-97). 
Television appears to promote a countertype (Nachbar and Lause 1992, p.239) of sociallyregarded lesbianism, but closer scrutiny finds a fabricated and deified image: heterosexual with a twist. We are not seeing a new realistic lesbian figure; we are seeing the heterosexualisation of the lesbian image. This heterosexualisation originates from Ellis's premise that positions feminine lesbians as pseudo-inverts, only in same-sex relationships because of circumstance rather than inclination (Jeffreys 1989, p.10). The theoretical perspective and the results of this thesis suggest that the media hegemonically promotes the pseudo-invert, eroding the disequilibrium that exists between a conventionally feminine lesbian character and a conventionally feminine heterosexual character, so that the lesbian fiction is assimilated to the dominant model. For example, faux lesbians, Jay and Maia, reiterate the societal norm typically transmitted in the mass media that 'women love men' (see Abbot and Love 1972, p.37), and erode the transgressive nature of the feminine lesbian. By its heterosexualisation of the feminine lesbian, television prescribes heterosexuality for lesbians.

Sexual fluidity receives considerable television exposure when non-heterosexual characters feature in the storyline, an occurrence that Atmore notes results in disappointment for lesbian audiences (Atmore 1992, p.2). Typically this involves dalliances with lesbianism before returning to heterosexuality. Penelope and Wolf argue that bisexual expression can be used to maintain the primacy of heterosexuality because scenarios can be presented that show women are powerless to resist men who desire them (Penelope and Wolf 1993, p.6). It supports the underlying component of Ellis' hypothesis, also echoed by queer theory, that coupling between women is a sex act, not an expression of a sexual identity. The content analyses of the two significant sources of lesbian representation within New Zealand's television landscape revealed that Shortland Street employed this strategy, while The L Word took a different approach. Here, sexual fluidity was used to help a character to come out and to signal the organic bisexuality of another character. Within Shortland Street, however, the queer argument that sexuality is more elastic than the sexual categories of 'lesbian', 'bisexual', and 'gay' was used to introduce doubt about the sexuality of feminine lesbians. This was actively encouraged by plotlines and scripting, the Shortland Street fansite administrator and interpreted as such by many Shortland Street viewers (see Chapter 8, pp.171-172). Shortland Street's femme lesbians are, therefore, kept in an evolutionary cul-de-sac as the dominant message suggested by the show is that: lesbians do not know they can be heterosexual (queer), and lesbians will become heterosexual eventually (heterosexism). 
The feminine lesbian is valued within the mainstream media because she can be sexually confined within these boundaries once her legitimacy is compromised; the butch is a more anarchic figure. She is the ultimate transgressor. Typically, television eschews the butch image, as many of my focus group participants noted (see Chapter 5, p.97). On those rare occasions when she is visible, she is represented as an anomaly, "an aberration whose sexual/gender indeterminacy evokes a curiosity, confusion, and even derisive laughter" (Ciasullo 2002, p.217). It is possible the egregious representation of the butch lesbian character George, in Shortland Street, would have evoked all three states in many viewers, directly contravening the protection supposedly afforded sexual minorities under $6(\mathrm{~g})$ of The-Free-to-Air Television Code of Broadcasting Practice but adhering to the theory of media hegemony.

George had the potential to introduce some much needed texture into the prime-time lesbian representation within the research frame. This was evinced in the responses of many lesbian focus group participants, who reported the dominant femme aesthetic bored them, complaining that even those characters they had expected to be coded butch, such as lesbian criminals, possessed a patina of femininity (see Chapter 5, p.102). George also provided an opportunity, rare in mainstream television texts, to explore the rigidity of the binary categories of 'woman' and 'man', the anxiety that exists around gendered behaviours, and individuals whose bodies and desires are at odds with heteronormative cultural expectations. Instead, the writers encouraged the scorn that heterosexism reserves for the butch by reducing George to a spectacle; the characterisation clearly echoed Ellis' true invert hypothesis in George's desire "to look more like a man". ${ }^{106}$

A variation of the favoured strategy of symbolically annihilating butch lesbian characters by omitting them altogether is to feminise them. This strategy is a new way for soaps, dramas, and sitcoms to show homosexual characters and was frequently reflected in the descriptions of butch characters focus group participants gave. The character Shane from The L Word exemplifies this protocol. Many of Shane's qualities, such as her lack of emotional attachment, her low, husky voice, and her swagger, contrast with the feminine qualities of the other women. Even so, the boy-chic qualities Shane possesses are short of realistically representing the butch lesbian. Observing a similar phenomenon in film, Halberstam laments, "The butch character is played as a shadow of her former self" (Halberstam 1998, p.217).

\footnotetext{
${ }^{106}$ Episode screened on $16 / 11 / 2004$.
} 
The 'glam' butch and drag king Ivan contribute to the symbolic annihilation of masculine women, even within lesbian dramas. However, it could be argued that by not fitting into the binary of Butch or Femme, these two characters speak more realistically about the heterogeneity of lesbians than all other lesbian representation I observed during the research period. The inability to pinion The L Word lesbians into the traditional Butch/Femme binary contributes to its merit and goes some way to address what Walters calls the "tiresome litany of liberal sameness" (Walters 2001, p.16). Nevertheless, the opportunity for realistic butch representation was limited, and this kind of representation was nominated by several lesbian focus group participants as what they desired most.

The realism of any lesbian character will be compromised if the programme's script is cemented in heteronormativity. The norms I identified Shortland Street perpetuating relate to the primacy of heterosexuality. Maia and Jay are used as devices to support this project in various ways: their sexuality is a revelationary talking point for heterosexual characters; their unavailability to would-be suitors is gradually eroded through comments, conflicts, and plot arcs; intimacy between them is desexualised; and their visible disconnection from lesbian signs allows viewers to ignore the women's sexuality. With the constant reiteration of the normality of heterosexuality, coupled with a lesbian character finding a heterosexual passion, a less homonormative depiction of lesbian sexuality would be difficult to imagine.

The convergent view of my content analysis, the opinions of focus group participants, and comments from secondary texts such as contributors to the streettalk forum and The TV Guide, is that Shortland Street gives an underwhelming at best, homophobic at worst, representation of lesbian sexuality. Maia and Jay's most significant contribution to the literacy that exists around the lesbian lifestyle is that they are regular core characters, appearing on a popular programme that plays in the New Zealand prime-time environment. Also, given that New Zealand television has a strong bias toward white Anglo-centricism (Kothari et al. 2004, p.135), and this is also true of lesbian television characters (Ciasullo 2002, p.201; Chambers 2006, p.82), Jay’s Māori ethnicity offers some diversity.

In contrast, the lesbian characters in The L Word have made an important shift away from many of these patterns. Offering a rare perspective of desire between women, The $L$ Word's homonormativity is cultivated in a number of ways. Most significant is the absolute normalisation and desirability of lesbian sexuality; the women's desires centre 
exclusively on other women, and same-sex love between women is shown as a desirable and achievable state. While heterosexuality is not devalued or demeaned, it is decentred from the narrative. The problems a heterosexist society can cause in women's professional and personal lives are examined but not focussed on, while bigotry and intolerance are shown as offensive. In addition, the most important personal relationships the lesbian characters have are with other lesbian characters.

Viewers were also able to detect the differences between the two programmes. The homonormative accent of The L Word found resonance with focus group participants who had seen it and comments from Shortland Street viewers (from participants and those posted online), are testament to the frustration and disappointment many felt when watching the soap's version of same-sex love. During the research period it was perceived as a prime-time product that pandered to the heterosexual gaze, and will likely continue to do so.

\section{Looking at Identification}

Studies by Labett (2006) and St Germain (2003) show that the motivation of many lesbians to search for lesbian images is affirmation and a salve for their own self-esteem. Similarly, most lesbian participants in my focus groups also explained how lesbian characters have validated their sense of self and their lesbian identity. Homophily, identification, and para-social interaction (PSI) explain the vicarious relationships viewers develop with television characters (Cohen 1997, 2006; Eyal and Rubin 2003; Hoffner 1996; Rubin et al. 1985). Despite the overwhelming weaknesses in Maia and Jay, lesbian viewers identified with the characters because they explicitly identified as lesbians.

Compromising the sexual identity of lesbian characters, either directly or indirectly, can be distressing for many viewers (St Germain 2003). Focus group participants and fans alike were alternately thrilled to add Maia and Jay to the cluster of characters they adored, and devastated when their realism was compromised. After the initial excitement, the lack of homonormativity of the lesbian characters eroded these psycho-social interactions. In her study of lesbian viewers' attitudes toward post-Ellen lesbian icons such as Buffy The Vampire Slayer and Xena: Warrior Princess, St Germain (2003) found lesbian viewers are often willing to settle for "inadequate, possibly damaging images of lesbian identity and experience" which "indicates a lack of entitlement for more adequate representation" (St Germain 2003, p.178). This same tension, between being grateful for any visibility while being aware of the many weaknesses inherent in the representation available, was evident 
in the comments of many of my lesbian focus group participants (see Chapter 5, pp.120121). For example, many of the lesbian focus group participants complained about the lesbian stereotypes, representation, and plot arcs that reinforced heterosexuality, particularly within Shortland Street. Despite this, participants and fans acknowledged they continued watching the characters.

The lack of chances to identify with a lesbian character as someone you may want to be, or to be attracted to, or to know, can encourage lesbian viewers to subvert the text to their own needs. One participant from the New Zealand lesbian group reported she preferred to watch male-oriented programmes, although her reading of male characters is different to her heterosexual sisters. This participant's attraction to, and identification with, a scubadiving character played by Lloyd Bridges and his interactions with female characters, helped her to develop her knowledge of her sexuality (see Chapter 5, p.117). This welldocumented 'insider' strategy has two implications. The first is that identification has psycho-social significance for viewers (Cohen 1997, p.519), particularly for the mental health of sexual minorities (Dow 2001, p.135; Labett 2006, p.iv; St Germain 2003, p.168) and is supported by this study. The second is the suggestion this strategy is so flexible that the sex/gender of characters does not have to be the viewer's own (probably a choice compelled by the importance of having a para-social relationship). Why then, should there be any concern about unrealistic lesbian representation? Aside from only one focus group participant who acknowledged this strategy, the immediate question is whether, if this individual had the opportunity to use a female character in the way she had used the male, she would still have chosen the male on which to fashion her identity? By choice or ability, but almost certainly out of necessity, she read the male character in a way that suited her; other individuals may not have the inclination or the ability to do so, particularly adolescents (Kielwasser and Wolf 1992, p.364).

This thesis has argued that the way sexual minority characters are positioned is to the detriment of the groups they represent. A corollary of this is that realistic lesbian representation is a litmus test for the health of gender and sexuality roles in society at large. As Gross emphasises, to be visible on television is to have social power (Gross 1994, p.143), and when television reflects that power, that social power becomes stronger.

Patterns are prevalent in television and they are heavily implicated in the cultivation process (Gerbner et al. 1986, p.18). These patterns seduce us until they become what we expect to see; what we understand as normal, regardless of genre. These patterns are also 
stubbornly resistant to change. One of the principle patterns on television is the love story, the heterosexual love story. This sequence of boy-meets-girl, boy-gets-girl, is so prevalent that when a lesbian love story is shown, it is soon overwhelmed by the powerfully familiar heterosexual love story sequence and dissolves into a heterosexual romance. This is especially true for lesbian characters in prime-time programmes shown on television in New Zealand. Just as Ciasullo found lesbians are "heterosexualised" in most popular texts in America (Ciasullo 2002, p.219), the findings of this study show that the lesbian characters who occupy prime-time positions are similarly produced - both aesthetically and behaviourally - for the safe enjoyment of heterosexual viewers.

\section{Limitations}

The limitations of this study relate to the landscape analysis and the composition and the generalisability of the focus groups to the New Zealand television viewing population. To provide context for the Shortland Street and The L Word content analyses and the history of images available to the focus group participants, I twice sampled the New Zealand television landscape. Once to determine the composition of the programming by sampling a week's programming in each season, and once to determine the composition of the character base in which lesbian characters feature by sampling a week of fictional primetime programming. I could have contrasted this latter measure with a subsequent sample or samples to afford comparison with the first, and arguably, afford additional depth to the character analysis. However, the initial landscape analysis revealed the kind of programming did not vary over the four seasons, and indicated a reduced likelihood of finding another period where lesbian characters would comprise more than $1.2 \%$ of all characters within prime-time programming. Consequently, the Shortland Street and The L Word content analyses and the focus groups were the primary tools chosen to investigate lesbian visibility on New Zealand television.

The five slices of the sexual demographics my focus groups comprise are too small to be generalisable, and necessitate hesitancy in extrapolating the results of this component of my research in any meaningful way to the New Zealand television viewer population. All the participants lived in a metropolitan capital city (Wellington and Sydney); were employed in white collar work (with the exception of the youth, who were students); and, in the case of the homosexual men and women, attended gay events. Empirically, this may constrain the sample, but it fits with my focus group methodology. To conduct successful focus groups, I required only a fraction of the number of participants that Rankine's (1997) study sought, so the concern about response rate did not plague my study as it did 
hers. The focus group participants, whether part of the sexual minority or majority, cannot be considered representative, however. Rather, their responses can be considered a representative example of the attitudes of urban, educated, predominantly white, viewers of lesbian television images.

I acknowledge the ability to contrast heterosexual and homosexual youth would have extended my analysis, however, given the difficulty in gaining access to this population, I felt it was important to access the homosexual adolescents as an extension of the New Zealand lesbian and gay men groups. Given the insight displayed by many of the adult heterosexual focus group participants, extending the sample to include adolescent heterosexuals might have generated similar results. Still, adolescent homosexuals are an under-researched population (see Kielwasser and Wolf 1992; Le Brun et al., 2004) and I consider giving them a voice through this research of critical importance.

\section{Future Directions}

This thesis represents a much-needed inquiry into the quality of the lesbian fictions that have begun to slide into the mainstream television environment and their effect, and will hopefully stimulate further research into the script of lesbian desire in prime-time television and lesbians' responses to them. Some lines of further inquiry are outlined below.

Feminist analyses of media images of women have identified the prescriptive way in which femininity is represented (van Zoonen 2004, p.30). Wolf's polemic The Beauty Myth (1991) exposes the harm the male-controlled media has had on women through these prescriptions. More recent explorations by Kim et al. (2007), Lamb and Brown (2006), and the American Psychological Association (2007), shows little has changed. The results of this thesis indicate the same 'beauty' dictates Wolf (1991) highlights have been extended to lesbian characters. The script of lesbian desire dominating mainstream television texts in the post-Ellen era depicts lesbian characters as beautiful, chic women who are really no different than their heterosexual sisters in looks and behaviour. While there are lesbians who fit this aesthetic hegemony, it appears that because they are the most represented, feminine lesbians are the only ones valued in television texts. More concerning, the femininity of lesbian characters is capitalised on and doubt is introduced over femmes' sexuality, a strategy which is analogous with Ellis's pseudo-invert principle. 
Similar to the unrealistic expectations that were generated from deified representations of ethnic minorities outlined by Jhally and Lewis (1992) (see Chapter 9, p.189), I argue the current dominant schema of lesbian images creates new expectations of, and places new pressures on, lesbians. While some of my participants were pleased with the feminine aesthetic for lesbian characters (see Chapter 5, p.100), others lamented the feminisation/decline of butch characters (see Chapter 5, p.97). Considering the significantly detrimental effect of media images on women's mental and physical wellbeing, high on the research agenda should be research that explores the effect deified, heteronormative lesbian images have on lesbian viewers' mental and physical well-being. New forms of discrimination may also result against lesbians who do not fit into the 'good', assimilated, pretty, white, successful mould. This kind of research could also document a shift in the way lesbian view themselves, any pressure they may feel to conform to the feminine code, or that their sexuality is a phase.

It may be perceived addressing the aspects of lesbian representation specifically privileges lesbianism at the expense of bisexuality or other minority sexualities. This is an interesting question, and future research could study the portrayal of fictional bisexual and transgender women and the responses of specific groups to these representations.

The nature of para-social interactions can differ according to the viewer (Cohen 1997, p.519). For example, sex is one of the mediating factors as studies show women develop stronger para-social relationships than men (Bailey et al. 1987, in Cohen 1997, p.525). What effect the added layer of same-sex desire has in these relationships is as yet unknown. Further research could be dedicated to lesbian television characters and the effect the three relationship variables of homophily, identification, and para-social interaction have among a marginalised population such as lesbians.

Realistic and positive lesbian representation has been shown to be essential for lesbians' self-esteem and self-validation (Labett 2006, p.iv; St Germain 2003, p.168) and reassurance against a homophobic culture (Dow 2001, p.135). Even the acknowledgement of same-sex desire between men was quite literally a life-line for one New Zealand lesbian (see Chapter 3, p.62). Although lesbian participants found lesbian representation important, the constant manipulation of the integrity of the feminine lesbian was harmful to many viewers, as my focus groups participants and contributors to other forums articulate (see Chapter 5, p.98 and Chapter 8, pp.169-170). In interviews and in secondary texts such as magazines, the reassertion of the heterosexuality of the actors, who play gay 
characters, is another way that heterosexuality is affirmed (see Chapter 2, pp.45-46). The effects these revelations may have on lesbian viewers, who may have formed intense psycho-social relationships with those characters, is another area that warrants further investigation.

Strong relationships between television characters and viewers create programme and channel loyalty (Cohen 1997, p.518). If lesbian viewers perceive lesbian characters to be homonormative, this should weaken the potential para-social relationship and compromise their viewer loyalty. Future research could investigate the link between viewer loyalty and para-social interaction, identification, and homophily. Producing programmes if not characters with more acceptable levels of homonormativity could increase audience share (and channel revenue). In this scenario, lesbians are not a niche market as TVNZ assert, but rather, are an untapped market.

Future research on conditions of lesbian representation on New Zealand television could also take into account the channel preferences of the audience. This thesis illustrates the different composition of the most watched free-to-air channels, particularly in their fiction to non-fiction ratios, and how frequently they provide lesbian characters. Television channels have different target audiences, and the relationship between non-heterosexual characters and a channel's target audience should be explored. For example, could lesbians' need for mirroring in a world that prefers to ignore them (Gair 1985, cited in St Germain 2003, p.27), assist them to develop a channel loyalty that caters to their need for representation?

\section{Conclusion}

This study has shown that contemporary lesbian visibility on New Zealand television is less than satisfactory. The question that emerges then is how can television produce robust fictions? A homonormative perspective is crucial to positive lesbian representation which includes showing same-sex desire as natural and normal and incidental; showing lesbian characters as part of a larger lesbian community; characters voicing political arguments that support their sexuality/sexual difference; and having other characters supporting this. Including these homonormative elements will disrupt the heterosexual hegemony of the television narrative sufficiently to afford realistic and positive representation of lesbians and lesbian sexuality. As Bourdieu writes: "To accomplish a durable change in representations (we) must perform and impose a durable transformation of the internalized 
categories (schemes of thought) which ... confer the status of the self-evident necessary ... 'natural reality"' (Bourdieu 2001, p.121).

\section{A Final Word}

In my professional capacity with The Office of Film and Literature Classification, an awareness of harm is fundamental to many of the discussions in which I am involved. The notion of harm also underlies this thesis; specifically, the harm I believe is caused by the deliberately heterosexist versions of lesbian sexuality now found on the most influential of all mediums, television.

The idea that viewers can be harmed or injured by images they consume, or words they hear or read, is an area of considerable debate (see Chapter 6, pp.127-128). However, such is the power and influence of the mass media that "all governments ... have developed some rules to regulate" visual mediums such as television (Horrocks 2004c, p.14). Although freedom of expression is guaranteed to every individual in New Zealand under section 14 of the Bill of Human Rights Act 1990, The Office of Film and Literature Classification exists to restrict or ban material that contain depictions likely to be injurious to the public good. While television in New Zealand is not subject to state censorship, The Broadcasting Act 1989, establishes the broadcasting standards to which broadcasters must adhere. Despite the argument that texts are available for alternate readings, (see Abel 2004, p.123; de Lauretis 1984. pp. 38-39; Fenton 2001, p.112; Fiske 1987, p.84; Fuss 1989, p.35; Minh-Ha 1991, p.5), the existence of key legislation such as The Films, Videos, and Publications Classification Act 1993, The Broadcasting Act 1989, and the Free-To-Air Television Code of Broadcasting Practice, are a direct acknowledgement by the New Zealand government of the power of the media, and the potential harm certain content can have on the public good.

Dobkin counsels: "The main reason we need to find Lesbians is because it feels so good when we do and so bad when we don't" (Dobkin 1990, p.5). Despite the initial pleasure gained from having our sexuality acknowledged in mainstream texts, my own observations, comments from participants, and the many contributors to online forums confirm that, too often, the lesbian fictions offered provide little satisfaction. Far from being ideologically neutral, this thesis finds that the lesbian fictions on New Zealand television are constructions that promulgate a hegemonic view that fits the economy of heterosexual desire. While my criticism may bring charges of ideological overcoding from other viewers, celebrating increased representation without critical discernment will 
cultivate a new set of unrealistic beliefs and expectations among all that consume them. Only a critical analysis of the lesbian image, not a sense of indebtedness, will encourage that quality. After all, as this thesis shows, there has been enough straight talking about lesbians. 


\section{References}

Abbott, Sidney and Barbara Love. 1972. Sappho was a Right-On Woman. New York: Scarborough House.

Abel, Sue. 2004. Mrs Lee's Knowing Wink: Reading Race in New Zealand Advertising. In Roger Horrocks and Nick Perry, eds. Television in New Zealand. Programming the Nation. Oxford and New York: Oxford University Press, 116-134.

American Psychological Association: Task Force on the Sexualization of Girls. 2007. Report of the APA Task Force on the Sexualization of Girls. Washington, DC; American Psychological Association. www.apa.org/pi/wpo/sexualization.html. [accessed 26 February 2007].

Andsager, Julie. 2006. Seduction, Shock, and Sales: Research and Functions of Sex in Music Video. In Tom Reichert and Jacqueline Lambiase eds. Sex in Consumer Culture. The Erotic Content of Media and Marketing. Mahwah New Jersey: Lawrence Erlbaum Associates. 31-50.

Atmore, Christine L (1992). Other Halves. Lesbian-feminist post-structuralist readings of some recent New Zealand print media representations of lesbians. Doctoral thesis in Sociology. Victoria University of Wellington.

Auyoup, Colleen and Julie Podmore. 2002. Making Kings. In Donna Troka, Kathleen Lebesco and Jean Noble, eds. The Drag King Anthology. New York and London, Oxford: Harrington Park Press, 51-74.

Baird, Barbara. 2005. The L Word; Histories, Theories, and Contemporary Stories of Lesbianism. In Gail Hawkes and John Scott, eds. Perspectives in Human Sexuality, Part 2, Chapter 4. Melbourne, Australia: Oxford University Press, 6184.

Barthes, Roland. 1977. Image, music, text. Essays selected and translated [from the French] by Stephen Heath. London: Fontana.

Battles, Kathleen and Wendy Hilton-Morrow. 2002. Gay Characters in Conventional Spaces: Will and Grace and the Situation Comedy Genre. Critical Studies in Media Communication 19(1): 87-105.

Bell, Claudia. 1996. Inventing New Zealand. Everyday Myths of Pakeha Identity. Auckland, New Zealand: Penguin Books NZ Ltd.

Benshoff, Harry M. and Sean Griffin. 2004. America on Film. Representing Race, Class, Gender, and Sexuality at the Movies. Massachusetts, US, Oxford UK and Carlton Victoria, Australia: Blackwell Publishing.

Binnie, Jin. 2007. Sexuality, the Erotic and Geography: Epistemology, Methodology and Pedagogy. In Kath Browne, Jason Lim and Gavin Brown eds, Geographies of Sexualities. Theory, Practices and Politics.UK and USA: Ashgate, 
Biocca, Frank. A. 1988. Opposing Conception of the Audience: The Active and Passive Hemispheres of Mass Communication Theory. In J. A. Anderson, ed. Communication Yearbook 11: Newbury Park, CA: Sage, 51-80.

Bonner, Frances, Lizbeth Goodman, Richard Allen, Linda Janes, and Catherine King, eds. 1992a. Introduction: On Imagining Women. United Kingdom: Polity Press and The Open University, 1-12.

Bonner, Frances, Lizbeth Goodman, Richard Allen, Linda Janes, and Catherine King, eds. 1992b. Negotiating meanings from popular Television and Film. United Kingdom: Polity Press and The Open University, 190 -192.

Bourdieu, Pierre. 1998. On Television and Journalism. London: Pluto Press.

Bourdieu Pierre. 2000. Pascalian Meditations. Cambridge: Polity Press.

Bourdieu, Pierre. 2001. Masculine Domination. Cambridge: Polity Press.

Briggs, Susan. 1998. Television in the home and family. In, Anthony Smith and Richard Paterson eds, Television: An International History. New York: Oxford University Press, 109-121.

Brookey, Robert A. and Robert Westerfelhaus. 2001. Pistols and Petticoats, Piety and Purity: To Wong Foo, the Queering of the U.S. Monomyth, and the Marginalizing Discourse of Deification. Critical Studies in Mass Communication 18(2): 141156.

Brown, Gavin, Browne Kath and Jason Lim. 2007. Introduction, or why have a book on geographies of Sexualities. In Kath Browne, Jason Lim and Gavin Brown eds, Geographies of Sexualities. Theory, Practices and Politics.UK and USA: Ashgate, 1-18.

Brunsdon, Charlotte. 1987. Feminism and Soap Opera. In Kath Davies, Julienne Dickey, and Teresa Stratford, eds. Out of Focus. Writings on Women and the Media. Chapter 8, London: The Women's Press, 147-149.

Bryson, Valerie. 1992. Feminist Political Theory. An Introduction. New York: Paragon House.

Bryson, Valerie. 1999. Feminist Debates. Issues of Theory and Political Practice. London: MacMillan Press Ltd.

Butler, Judith. 1990. Gender Trouble: Feminism and the Subversion of Identity. New York: Routledge.

Butler, Judith. 1997. Excitable Speech. London: Routledge.

Butler, Judith. 2004. Undoing Gender. London: Routledge.

Capsuto, Steven. 2000. Alternate Channels. The Uncensored Story of Gay and Lesbian Images on Radio and Television. New York: Ballantine Books. 
Carragee, Kevin. M. 1993. A Critical Evaluation of Debates Examining the Media Hegemony Thesis. Western Journal of Communication 57 Summer: 330-345.

Carstarphen Meta G. and Susan C. Zavoina, eds. 1999. Sexual Rhetoric. Media Perspectives on Sexuality, Gender, and Identity. Westport, Connecticut and London: Greenwood Press.

Castle, Terry. 1993. The Apparitional Lesbian. Female Homosexuality and Modern Culture. New York: Columbia University Press.

Chambers, Samuel. A. 2006. Heteronormativity and The L Word: From a Politics of Representation to a Politics of Norms. K. In Kim Akass and Janet McCabe, eds. Reading The L Word. Outing Contemporary Television. New York and London: I. B. Tauris and Co Ltd., 81-98.

Christoffel, Paul. 1989. Censored: A Short History of Censorship in New Zealand. Monograph Series 12. Government Print.

Ciasullo, Ann M. 2002. Desirable Deviance: Representations of Lesbianism for the Straight Mind. Dissertation for PhD, Lexington: University of Kentucky.

Clark, Danae. 1993. (Originally published in 1991). Commodity Lesbianism. In Henry Abelove, Michele Ana Barale, and David M. Halperin, eds. The Lesbian and Gay Studies Reader Chapter 2. New York and London: Routledge, 186-210.

Cohen, Jonathan. 1997. Para-Social Relations and Romantic Attraction: Gender and Dating Status Differences. Journal of Broadcasting and Electronic Media. Vol. 41(4): 516-529.

Cohen, Jonathan. 2006. Audience Identification with Media Characters. In Jennings Bryant and Peter Vorderer eds. Psychology of Entertainment. Mahwah, New Jersey: Lawrence Erlbaum \& Associates, 183-197.

Conway, Richard J. 2006. A Trip to the Queer Circus: Reimagined Masculinities in Will and Grace. In James R. Keller and Leslie Stratyner, eds. Essays on Recent Programming. The New Queer Aesthetic on Television. Jefferson, North Carolina and London: McFarland and Company Inc., 75-84.

Cooper, Brenda. 2002. Boys Don't Cry and Female Masculinity: Reclaiming a Life and Dismantling the Politics of Normative Heterosexuality. Critical Studies in Media Communication 19(1): 44-63.

Cragin, Becca. 2006. Lesbians and Serial TV: Ellen Finds Her Inner Adult. In James R. Keller and Leslie Stratyner, eds. Essays on Recent Programming. The New Queer Aesthetic on Television. Jefferson, North Carolina and London: McFarland and Company Inc., 193-208.

Crowley, Vicki. 2002. Drag Kings "Down Under": An Archive and Introspective of a few Aussie Blokes. In Donna Troka, Kathleen Lebesco and Jean Noble, eds. The Drag King Anthology. New York and London, Oxford: Harrington Park Press, 285-308.

Davies, Bronwyn. 1989. Frogs and Snails and Feminist Tales. Preschool Children and Gender. Sydney, Wellington, London and Boston: Allen and Unwin. 
Davies, Kath, Julienne Dickey, and Teresa Stratford. 1987. Introduction. In Kath Davies, Julienne Dickey, and Teresa Stratford eds. Out of Focus. Writings on Women and the Media. London: The Women's Press, 1-13.

D’Emilio, John. 1993. (Originally published in 1983). Capitalism and Gay Identity. In Henry Abelove, Michele Ana Barale, and David M. Halperin, eds. 1993. Chapter 5. The Lesbian and Gay Studies Reader. New York and London: Routledge, 467476.

de Lauretis, T. 1984. Alice Doesn't: Feminism, Semiotics, Cinema. London and Basingstoke: The MacMillan Press Limited.

Derry, Charles. 1992. Television Soap Opera: "Incest, Bigamy, and Fatal Disease". In Jack Nachbar and Kevin Lause, eds. Popular Culture: An Introductory Text. Bowling Green, OH: Bowling Green State University Popular Press, 445-462.

Dickey, Julienne 1987a. Heterosexism and the Lesbian Image in Press. In Kath Davies, Julienne Dickey, and Teresa Stratford, eds. Out of Focus. Writings on Women and the Media. Chapter 5. London: The Women's Press, 81-89.

Dickey, Julienne. 1987b. Women for Sale - The Construction of Advertising Images. In Kath Davies, Julienne Dickey, and Teresa Stratford, eds. Out of Focus. Writings on Women and the Media. Chapter 5. London: The Women's Press, 74-77.

Doan, Laura and Chris Waters. 1998. Introduction. Part II, Homosexualities. In Lucy Bland and Laura Doan, eds. Sexology Uncensored. The Documents of Sexual Science. Cambridge: Polity Press, 41-45.

Dobkin, Alix. 1990. Introduction. In Julia Penelope and Sarah Valentine, eds. Finding the Lesbians. Personal Accounts from Around the World. Freedom CA: The Crossing Press, 1-5.

Dollimore, Jonathan. 2001. Sex, Literature and Censorship. Polity Press: Oxford, UK.

Dow, Bonnie J. 1996. Prime-Time Feminism. Television, Media Culture, and the Women's Movement Since 1970. Philadelphia: University of Pennsylvania Press.

Dow, Bonnie J. 2001. Ellen, Television, and the Politics of Gay and Lesbian Visibility. Critical Studies in Media Communication 18(2): 123-140.

Duggan, Lisa. 2002. The New Homonormativity: The Sexual Politics of Neoliberalism. In Russ Castronovo and Dana Nelson eds, Materializing Democracy: Toward a Revitalized Cultural Politics, Durham: Duke University Press, 175-194.

Duncker, Patricia. 1995. 'Bonne Excitation, Orgasme Assuré'. The Representation of Lesbianism in Contemporary French Photography. Journal of Gender Studies, 4(1): 5-15.

Dunleavy, Trish. 2004. Made in New Zealand: The Genre of Television Drama. In Roger Horrocks and Nick Perry, eds. Television in New Zealand. Programming the Nation. Oxford and New York: Oxford University Press, 203-221. 
Dyer, Richard. ed. 1980. Gays and Film. Introduction. London: BFI Publishing, 1-4.

Dyer, Richard. 1993. The Role of Stereotypes. The Matter of Images. Essays on Representation. London and New York: Routledge.

Dyer, Richard. 1999. Stereotyping. In Larry Gross and James Woods, eds. The Columbia Reader: On Lesbians and Gay Men in Media, Society, and Politics. New York: Columbia University Press, 297-301.

Elliott, Deni. 2003. Moral Responsibilities and the Power of the Media. In Paul Martin. Lester and Susan Dente Ross, eds. Images That Injure. Pictorial Stereotypes in the Media $2^{\text {nd }}$ Ed. Westport Connecticut: Praeger, 7-14.

Erai, Michelle. 2004. Exile, Maori and Lesbian. In Lynne Alice and Lynne Star, eds. Queer in Aotearoa New Zealand. Palmerston North, New Zealand: Dunmore Press Ltd., 35-46.

Eyal, Keren and Alan M. Rubin. 2003. Viewer Aggression and Homophily, Identification, and Para-Social Relationships with Television Characters. Journal of Broadcasting and Electronic Media, March 2003, Vol. 47(1): 77-98.

Faderman, Lillian. 1992. Odd Girls and Twilight Lovers. A History of Lesbian Life in Twentieth Century America. New York: Penguin.

Faludi, Susan. 1992. Backlash. The Undeclared War Against U.S. Women. London: Vintage.

Fejes, Fred and Kevin Petrich. 1993. Invisibility, Homophobia and Heterosexism: Lesbian, Gays and the Media. Critical Studies in Mass Communication 10, 396422 .

Fenaughty, John. 2004. The End of Queer: Heteronormativity and Suicide. In Lynne Alice and Lynne Star eds. Queer in Aotearoa New Zealand, Palmerston North, New Zealand: Dunmore Press Ltd., 71-85.

Fenton, Natalie.2001. Feminism and Popular Culture. In Sarah Gamble, ed. The Routledge Companion To Feminism and Postfeminism. London and New York: Routledge, 104-116.

Ferguson, Ann. 1990. Is there a lesbian culture? In Jeffner Allen, ed. Lesbian Philosophies and Cultures. New York: State University of New York Press, 6388.

Fiske John. 1987. Television Culture: Popular Pleasure and Politics. New York: Methuen.

Fiske, John. 1989. Understanding Popular Culture. London: Unwin Press.

Foster, Guy Mark. 2006. Desire and the "Big Black Sex Cop": Race and the Politics of Sexual Intimacy in HBO's Six Feet Under. In James R. Keller and Leslie Stratyner, eds. Essays on Recent Programming: The New Queer Aesthetic on Television. Jefferson, North Carolina and London: McFarland and Company Inc., 99-112. 
Foucault, Michel. 1978. The History of Sexuality: Volume 1. An Introduction. New York: Random House.

Fowles, Jib. 1992. Why Viewers Watch. A Reappraisal of Television's Effects. Newbury Park, London, New Delhi: Sage.

Freiberg, Freda.1987. The Bizarre in the Banal: Notes on the Films of Jane Campion. In Annette Blonski, Barbara Creed and Freda Freiberg. eds. 1987. Don't Shoot Darling. Women's Independent Filmmaking in Australia. Richmond, Australia: Greenhouse Publications Pty Ltd, 328-333.

Frye, Marilyn. 1983. The Politics of Reality: Essays in Feminist Theory. Freedom California: The Crossing Press.

Fuss, Diana. 1989. Essentially Speaking: Feminism, Nature and Difference. New York and London: Routledge.

Fuss, Diana. ed. 1991. Inside/Out Lesbian Theories, Gay Theories. New York: Routledge, $1-11$.

Fuss, Diana. 1993. Freud's Fallen Women: Identification, Desire, and “A Case of Homosexuality in a 'Woman". In Michael Warner, ed. Fear of a Queer Planet. Queer Politics and Social Theory. Minneapolis and London: University of Minnesota Press, 42-68.

Gauntlett, David. 2002. Media, Gender and Identity. An Introduction. London and New York: Routledge.

Geertz, Clifford. 1983. Local Knowledge: Further Essays in Interpretative Anthropology. New York: Basic.

Gentile, Mary C. 2002. How We Learn Who We Are. In Toni. Lester, ed. Gender Nonconformity, Race, and Sexuality. Charting the Connections. Madison Wisconsin: The University of Wisconsin Press, 180-201.

Geraghty, Christine. 1991. Women and Soap Operas: A Study of Prime-Time Soaps. Cambridge: Polity Press.

Gerbner, George and Larry Gross. 1976. Living with Television. The Violence Profile. Journal of Communication 26(2): 172-199.

Gerbner, George, Larry Gross, Michael Morgan and Nancy Signorielli. 1986. "Living with Television: The Dynamics of the Cultivation Process." In Jennings Bryant and Dolf Zillmann, eds. Perspectives on Media Effects, Chapter 2, Hillsdale, NJ: Lawrence Erlbaum \& Associates Inc., 17-40.

Gill, Rosalind. 2007. Gender and the Media. Cambridge, UK: Polity.

Gitlin, Todd. 1980. The Whole World is Watching: Mass Media and the Making and the Unmaking of the New Left. Berkeley: University of California Press. 
Glamuzina, Julie and Alison J. Laurie. 1995. Parker and Hulme. A Lesbian View. Ithaca, New York: Firebrand Books.

Greenberg, David F. 1988. The Construction of Homosexuality. Chicago: The University of Chicago Press.

Greenberg, David F. 1997. Transformations of Homosexuality - Based Classification. In Roger N. Lancaster and Micaela di Leonardo, eds. The Gender Sexuality Reader. Culture. History. Political Economy. Routledge: New York and London, 179-193.

Greenberg, Julie. A. 2002. Definitional Dilemmas: Male or Female? Black or White? The Law's Failure to Recognize Intersexuals and Multiracials. In Toni Lester, ed. Gender Nonconformity, Race, and Sexuality. Charting the Connections. Madison Wisconsin: The University of Wisconsin Press, 102-124.

Gross, Larry. 1991. Out of the Mainstream: Sexual Minorities and the Mass Media. Journal of Homosexuality 21, 19-46.

Gross, Larry. 1994. What is Wrong with this Picture? Lesbian Women and Gay Men on Television. In R. Jeffrey Ringer, ed. Queer Words, Queer Images. Communication and the Construction of Homosexuality. New York and London: New York University Press, 143-156.

Gross, Larry. 2001. Up From Invisibility: Lesbians, Gay Men, and the Media in America. New York: Columbia University Press.

Halberstam, Judith. 1998. Female Masculinity. Durham, North Carolina: Duke University Press.

Hall, Radclyffe. 1928. Reprinted in 1973. The Well of Loneliness. London: Barry and Jenkins.

Hamer, Emily. 1996. Britannia's Glory. A History of Twentieth Century Lesbians. London and New York: Cassell.

Hantzis, Darlene. M. and Valerie Lehr. 1994. Whose Desire? Lesbian (Non) Sexuality and Television's Perpetuation of Hetero/sexism. In R. Jeffrey Ringer, ed. Queer Words, Queer Images. Communication and the Construction of Homosexuality. New York and London: New York University Press, 107-121.

Hamer, Diane. Netting the Press: Playing with Martina. In Diane Hamer and Belinda Budge, eds. 1994. The Good, the Bad and the Gorgeous. Popular Culture's Romance with Lesbianism. London: Pandora, 57-77.

Harrington, C. Lee. 2003. Homosexuality on All My Children: Transforming the Daytime Landscape. Journal of Broadcasting and Electronic Media, 47(2): 216-233.

Hawkes, Gail. 2004. Sex and Pleasure in Western Culture. Cambridge, UK: Polity Press.

Hawkes, Gail and John Scott. 2005. Sexuality and Social Theory. In Gail Hawkes and John Scott, eds. Perspectives in Human Sexuality, Part 1, Chapter 2. Melbourne, Australia: Oxford University Press, 21-38. 
Hawthorne, Susan. 2002. Wild Politics. Melbourne: Spinifex Press.

Hennessy, Rosemary. 2000. Profit and Pleasure: Sexual Identities in Late Capitalism. New York and London: Routledge.

Herman, Didi. 2003. "Bad Girls Changed My Life": Homonormativity in a Women's Prison Drama. Critical Studies in Media Communication. 20(2): 141-159.

Hoagland, Sarah, Lucia. 1990. Lesbian Ethics and Female Agency. In Jeffner Allen, ed. Lesbian Philosophies and Cultures. New York: State University of New York Press.

Hoffner, Cynthia and Joanne Cantor. 1991. Perceiving and Responding to Mass Media Characters. In Jennings Bryant and Dolf Zillmann, eds. Responding to the Screen: Reception and Reaction Processes. Hillsdale, NJ: Lawrence Erlbaum \& Associates Inc., 63-101.

Hoffner, Cynthia. 1996. Children's Wishful Identification and Para-social Interaction with Favourite Television Characters. Journal of Broadcasting and Electronic Media, 40(3): 389-402.

Holtzman, Linda. 2000. Media Messages. What Film, Television, and Popular Music Teach Us About Race, Class, Gender and Sexual Orientation. Armonk, New York and London: M. E. Sharpe.

Horrocks, Roger and Nick Perry, eds. 2004. Television in New Zealand. Programming the Nation. Oxford and New York: Oxford University Press.

Horrocks, Roger. 2004a. The History of New Zealand Television. "An Expensive Medium for a Small Country'. In Roger Horrocks and Nick Perry, eds. Television in New Zealand. Programming the Nation. Oxford and New York: Oxford University Press, 20-43.

Horrocks, Roger. 2004b. Construction Site: Local Content on Television. In Roger Horrocks and Nick Perry, eds. Television in New Zealand. Programming the Nation. Oxford and New York: Oxford University Press, 273-285.

Horrocks, Roger. 2004c. Studying New Zealand Television: Themes, Methods, and Perspectives. In Roger Horrocks and Nick Perry eds. Television in New Zealand. Programming the Nation. Oxford and New York: Oxford University Press, 5-19.

Horton, Donald and R. Richard Wohl. 1956. Mass Communication and Para-Social Interaction. Observations on Intimacy at a Distance. Psychiatry, 19: 215-229.

Howes, Keith. 1993. Broadcasting It: An Encyclopaedia of Homosexuality in Film, Radio and $T V$ in the U.K. London and New York: Cassell.

Hurley, Michael. 2005. Contemporary Gay Cultures in Australia. In Gail Hawkes and John Scott, eds. Perspectives in Human Sexuality, Part 2, Chapter 3. Melbourne, Australia: Oxford University Press, 41-60.

Hutchins, Loraine and Lani Kaahumanu. 1991. eds. Bi Any Other Name: Bisexual People Speak Out. Boston: Alyson Publications, Inc. 
Hyman, Prue. 2001. Lesbians and Economic/Social Change: Impacts of Globalisation on Our Community(ies) and Politics. In A. Laurie, ed. Lesbian Studies in Aotearoa/New Zealand. New York: Harrington Park Press, 115-132.

Jeffreys, Sheila. 1989. 'Does it Matter if They Did It?' In The Lesbian History Group, eds. Not a Passing Phase: Reclaiming Lesbians in History 1840-1985. London: The Women's Press, 19-28.

Jeffreys, Sheila. 1994. The Queer Disappearance of Lesbians. Sexuality in the Academy. Women's Studies International Forum, 17(5): 459-472.

Jeffreys, Sheila. 1997. The Spinster and Her Enemies: Feminism and Sexuality 18801930. Australia: Spinifex Press.

Jeffreys, Sheila. 2003. Unpacking Queer Politics. Malden Massachusetts, USA: Polity Press.

Jhally, Sut and Justin Lewis. 1992. Enlightened Racism: The Cosby Show, Audiences and the Myth of the U.S. Dream. Boulder, Col: Westview Press.

Johnson, Merri Lisa. 2006. 'L' is for Long-Term: Compulsory Monogamy on The $L$ Word. In Kim Akass and Janet McCabe, eds. Reading The L Word. Outing Contemporary Television. London and New York: I. B. Tauris and Co Ltd., 115137.

Jones, Alison. 1992. Writing Feminist Educational Research: Am 'I' in the Text? In Sue Middleton and Alison Jones, eds. Women and Education in Aotearoa 2. Auckland University Press: Bridget Williams Books, 18-32.

Keller, James R. and Leslie Stratyner. 2006. Introduction. In James R. Keller and Leslie Stratyner, eds. Essays on Recent Programming. The New Queer Aesthetic on Television. Jefferson, North Carolina and London: McFarland and Company Inc., $1-8$.

Kelly, Liz, Sheila Burton and Linda Regan. 1994. Researching Women's Lives: or Studying Women's Oppression? In Mary Maynard and June Purvis, eds. Researching Women's Lives from a Feminist Perspective. UK and US: Taylor and Francis, 27-47.

Kessler, Kelly. 2006. Politics of the Sitcom Formula: Friends, Mad About You, and the Sapphic Second Banana. In James R. Keller and Leslie Stratyner, eds. Essays on Recent Programming. The New Queer Aesthetic on Television. Jefferson, North Carolina and London: McFarland and Company Inc., 130-146.

Kielwasser, Alfred P. and Michelle Wolf. 1992. Mainstream Television, Adolescent Homosexuality, and Significant Silence. Critical Studies in Mass Communication, 9(4): 350-373.

Kim, Janna L., C. Lynn Sorsoli, Katherine Collins, Bonnie A. Zylbergold, Deborah Schooler and Deborah, L. Tolman. 2007. From Sex to Sexuality: Exposing the Heterosexual Script on Prime-Time Network Television. Journal of Sex Research, 44(2): 145-157. 
Kinsey, Alfred. C. Wardell, B. Pomeroy, Clyde E. Martin and Paul H. Gebhard. 1965. (Originally published in 1953). Sexual Behavior in the Human Female. New York: Pocket Book Inc.

Kitzinger, Celia.1987. The Social Construction of Lesbianism. London: Sage.

Klapper, Joseph. 1960. The Effects of the Mass Communication. Glencoe, II: Free Press.

Kothari, Shuchi, Sarina Pearson and Nabeel Zuberi. 2004. Television and Multiculturalism in New Zealand. In Roger Horrocks and Nick Perry, eds. Television in New Zealand. Programming the Nation. Oxford and New York: Oxford University Press, 135-151.

Kramarae, Cheris and Paula A. Treichler (with assistance from Ann Russo). 1985. A Feminist Dictionary. Boston, London and Henley: Pandora Press.

Krueger, Richard A., and Mary-Anne Casey. 2005. Focus Groups: A Practical Guide for Applied Research $3^{\text {rd }}$ ed. Thousand Oaks California: Sage Publications.

Labett, Tess. 2006. Gay and Lesbian Television Audiences for NZ On Air. http://www.nzonair.govt.nz/files/about/Gay06_web.pdf. [accessed 13 March 2007].

Lamb, Sharon and Lyn Mikel Brown. 2006. Packaging Girlhood. Rescuing our Daughters from Marketers' Schemes. New York: St Martin's Press.

Lather, Patti A. 1991. Feminist Perspectives on Empowering Research Methodologies. In Patti Lather. ed., Getting Smart: Feminist Research and Pedagogy with/in the Postmodern. New York: Routledge, 70-85.

Laurie, Alison. J. 1987. Lesbian Feminism: A Re-view of Oppression. Sites, No 15, Spring 1987. Massey University Press, 59-67.

Le Brun, Christel, Elizabeth Robinson, Helen Warren and Peter Watson. 2004. NonHeterosexual Youth - A Profile of their Health and Wellbeing: Data from Youth 2000. Auckland: The University of Auckland. Youth2000.

Lee, Veronica. 2004. Let's Hear it for the Girls. The Observer, January 42004. http://observer.guardian.co.uk/review/story/0,6903,1115523,00.html. [accessed 1 June 2005].

Lesbian and Gay Psychology Review. 2005. Lesbian and Gay Psychology Review Special Issue: Critiquing Psychology: A Reappraisal of The Social Construction of Lesbianism 6(2).

Lester, Toni. 2002. Introduction. In Toni Lester, ed. Gender Nonconformity, Race, and Sexuality. Charting the Connections. Madison, Wisconsin: The University of Wisconsin Press, 3-17.

Lester, Paul Martin and Susan Dente Ross. 2003. Images That Injure. An Introduction. In Paul Martin Lester and Susan Dente Ross, eds. Images That Injure. Pictorial Stereotypes in the Media. Westport, Connecticut, London: Praeger, 1-4. 
Lewis, Justin. 1991. The Ideological Octopus: An Exploration of Television and Its Audience. New York and London: Routledge.

Lindlof, Thomas. R. 1988. "Media Audiences as Interpretive Communities". In James A. Anderson, ed. Communication Yearbook 11. Newbury Park, CA: Sage, 81-107.

Lippmann, Walter. 1961. Public Opinion. New York: The MacMillan Company

Lips, Hilary M. 1991. Women, Men, and Power. Mountain View, California: Mayfield Publishing Company.

Littlejohn, Stephen. W. 1999. Theories of Human Communication, $6^{\text {th }}$ edition. New Mexico: Wadsworth.

Lorde, Audre. 1984. Sister Outsider. Essays and Speeches by Audre Lorde. Freedom CA: The Crossing Press Feminist Series.

Lumby, Catherine. 1997. Bad Girls. The Media, Sex and Feminism in the '90s. St Leonard's, Australia: Allen and Unwin.

MacKinnon, Catharine. 1993. Only Words. Cambridge: Havard University Press.

Maynard, Mary and June Purvis. 1994. Introduction. Doing Feminist Research. In Mary Maynard and June Purvis, eds. Researching Women's Lives from a Feminist Perspective. UK and US: Taylor and Francis, 1-9.

Mayne, Judith. 2000. "Caged and Framed: The Women-in-Prison Film.” Framed: Lesbians, Feminists and Media Culture. Minneapolis: University of Minnesota Press, 115-145.

McFadden, Margaret. 2006. 'We cannot afford to keep being so high-minded': Fighting the Religious Right on The L Word. In James R. Keller and Leslie Stratyner, eds. Essays on Recent Programming. The New Queer Aesthetic on Television. Jefferson, North Carolina and London: McFarland and Company Inc., 113-129.

McLaren, Angus. 1999. Twentieth Century Sexuality. A History. Oxford, UK and Massachusetts US: Blackwell Publishers.

McLelland, Mark. 2005. Out on the World Stage. The Limits of Queer. In Gail Hawkes and John Scott, eds. Perspectives in Human Sexuality. Part 2, Chapter 8. Melbourne, Australia: Oxford University Press 142-152.

McLuhan, Marshall. 1964. Understanding Media: The Extensions of Man. New York: McGraw-Hill.

McQuail, Denis. 1994. Mass Communication Theory. An Introduction. $3^{\text {rd }}$ ed. London: Sage.

Minimum Energy Performance Standards: A study for the Energy Efficiency and Conservation Authority April 2005. http://www.eeca.govt.nz http://www.eeca.govt.nz/eeca-library/products/home-appliances/report/energyefficiency-strategies-televisions-05.pdf p.4 [accessed 12 October 2006]. 
Minh-Ha, Trinh.T. 1991. When the Moon Waxes Red: Representation, Gender and Cultural Politics. New York: Routledge.

Minkoff, Wendy. 2003. Mad Girls, Bad Girls: the Figure of the Murderous Lesbian in 1990s Film. University of California, Santa Cruz.

Morgan, Michael and James Shanahan. 1997. Two Decades of Cultivation Research: An Appraisal and Meta-Analysis. In Brant R. Burelson, ed. Communications Yearbook 20. Thousand Oaks, CA: Sage Publications Ltd., 1-45.

Moritz, Marguerite J. 1994. Old Strategies for New Texts: How U.S. Television is Creating and Treating Lesbian Characters. In R. Jeffrey Ringer, ed. Queer Words, Queer Images. Communication and the Construction of Homosexuality. New York and London: New York University Press, 122-156.

Moritz, Marguerite J. 2003. Recapturing the Archetype: An Inclusive Vision of Sexuality and Gender. In Paul Martin. Lester and Susan Dente Ross, eds. Images That Injure. Pictorial Stereotypes in the Media $2^{\text {nd }}$ Ed. Westport Connecticut: Praeger, 197-206.

Morley, David. 1992. Television, Audiences, and Cultural Studies. London: Routledge.

Morrison, Toni.1992. Playing in the Dark. Whiteness and the Literary Imagination. New York: Vintage.

Mulvey, Laura. 1975. Visual Pleasure and Narrative Cinema. Screen 16.3: 6-18. Online version

https://wiki.brown.edu/confluence/display/MarkTribe/Visual+Pleasure+and+Narr ative+Cinema [accessed 5 August 2008].

Munsch, Robert and Michael Martchenko. 1987. The Paper Bag Princess. London: Ashton Scholastic.

Nachbar, Jack and Kevin Lause. 1992. Breaking the Mold: The Meaning and Significance of Stereotypes in Popular Culture. In Jack Nachbar and Kevin Lause, eds. Popular Culture: An Introductory Text. Bowling Green, OH: Bowling Green State University Popular Press, 235-245.

Nestle, Joan. 1992. The Femme Question. In Joan Nestle, ed. The Persistent Desire. A Butch-Femme Reader. Boston: Alyson Publications Inc., 138-146

Netzhammer, Emile C. and Scott A. Shamp. 1994. Guilt by Association: Homosexuality and AIDS on Prime-Time Television. In R. Jeffrey Ringer, ed. Queer Words, Queer Images. Communication and the Construction of Homosexuality. New York and London: New York University Press, 91-106.

Oakley, Ann. 2000. Experiments in Knowing: Gender and Method in the Social Sciences. Cambridge: Polity Press.

Pela, R.L. 1997. The Days of Whose Lives? Genre. 48 (95): 46-49. 
Penelope, Julia. 1990. The Lesbian Perspective. In Jeffner Allen, ed. Lesbian Philosophies and Cultures. New York: State University of New York Press, 89108.

Penelope, Julia and Susan J. Wolf. 1993. Introduction. Lesbian Identity/Lesbian Communities/Lesbian Culture: Creating our Survival. In Julia Penelope and Susan J. Wolf, eds. Lesbian Culture. An Anthology. The Lives, Work, Ideas, Art and Visions of Lesbians Past and Present. Freedom California: The Crossing Press, 122.

Phoca, Sophia. 2001. Feminism and Gender. In Sarah Gamble, ed. The Routledge Companion To Feminism and Postfeminism. London and New York: Routledge, 55-65.

Phoenix, Ann. 1994. Practising Feminist Research: The Intersection of Gender and 'Race' in the Research Process. In Mary Maynard and June Purvis, eds. Researching Women's Lives from a Feminist Perspective. UK and US: Taylor and Francis, 49-71.

Prasad Rajen, Max Abbott, Trisha Dunleavy, Robert Boyd-Bell, Hone Edwards, Ian Fraser, Rick Friesen, Jane Parker, John Terris and Jane Wrightson. 2004. Towards Precautionary Risk Management of TV Violence in New Zealand. The Report to the Minister of Broadcasting of the Working Group: TV Violence Project April 2004. http://www.tv-violence.org.nz/work-group-report.html [accessed 10 September 2006].

Ramazanoglu, Caroline with Janet Holland. 2002. Feminist Methodologies: Challenges and Choices. London: Thousand Oaks, New Delhi: Sage Publications Ltd.

Rankine, Jenny. 1997. The Great Late Lesbian and Bisexual Women's Discrimination Survey. Auckland [N.Z.]: Discrimination Survey 1997.

Read, C. Stanford. 1998. (Originally published in 1921). Homosexuality. Part II. In Lucy Bland and Laura Doan, eds. Sexology Uncensored. The Documents of Sexual Science. Cambridge: Polity Press, 59-61.

Reichert, Tom, Kevin R. Maly and Susan C. Zavoina. 1999. Designed for Male Pleasure: The Myth of Lesbian Chic in Mainstream Advertising. In Meta G. Carstarphen and Susan C. Zavoina, eds. Sexual Rhetoric. Media Perspectives on Sexuality, Gender, and Identity, Part IV. Westport, Connecticut and London: Greenwood Press, 123-133.

Reinharz, Shulamit. 1992. Feminist Methods in Social Research. New York and Oxford: Oxford University Press.

Rich, Adrienne. 1993. (Originally published in 1986). Compulsory Heterosexuality and Lesbian Existence. In Henry Abelove, Michele Ana Barale, and David M. Halperin, eds. The Lesbian and Gay Studies Reader 1993, Chapter 3. New York and London: Routledge, 227-254.

Rich, B. Ruby. 1995. Introduction. In Julie Glamuzina, and Alison J. Laurie. Parker and Hulme. A Lesbian View. Ithaca, New York: Firebrand Books, i-xi. 
Riegel, Henriette. 1996. Soap Operas and Gossip. Journal of Popular Culture. 29(4): 201-209.

http://proquest.umi.com.helicon.vuw.ac.nz/pqdweb?index $=50 \& i d=3 \&$ srchmode $=$ $1 \&$ vinst $=$ PROD \& fmt $=3 \&$ startpage $=1 \&$ clientid $=7511 \&$ vname $=$ PQD \&did $=10506$ $465 \&$ scaling $=$ FULL \&ts $=1177881778 \& v$ type $=$ PQD\&qt $=309 \& T S=1177881798 \&$ clientId=7511 [accessed 30 March 2007 from the ProQuest database].

Roof, Judith. 1991. "Polymorphous Diversity". A Lure of Knowledge: Lesbian Sexuality and Theory. Chapter 6, New York: Columbia University Press.

Rubin, Alan. M. Elizabeth M. Perse and Robert A. Powell. 1985. Loneliness, Para-Social Interaction, and Local Television News Viewing. Human Communication Research 12: 155-180.

Rubin, Gayle. S. 1992. Of Catamites and Kings: Reflections on Butch, Gender, and Boundaries. In Joan Nestle, ed. The Persistent Desire. A Butch-Femme Reader. Boston: Alyson Publications Inc., 466-482.

Rubin, Gayle. S. 1993. (Originally published in 1982). Thinking Sex: Notes for a Radical Theory of the Politics of Sexuality. In Henry Abelove, Michele Ana Barale, and David M. Halperin, eds. The Lesbian and Gay Studies Reader, Chapter 1. London and NewYork: Routledge, 3-44.

Rubin, Rebecca. B. and Michael P. McHugh. 1987. Development of Para-Social Interaction Relationships. Journal of Broadcasting and Electronic Media, Vol. 31(3): 279-292.

Rust, Paula. C. 1992. The Politics of Sexual Identity: Sexual Attraction and Behaviour Among Lesbian and Bisexual Women. Social Problems, 39(4): 366-386.

Russo, Vito. 1981. The Celluloid Closet: Homosexuality and the Movies. New York: Harper and Row.

Ryan, P.M. 1995. The Reed Dictionary of Modern Maori. Birkenhead, Auckland: Reed Books.

Sanderson, Terry. 1995. Mediawatch. The Treatment of Male and Female Homosexuality in the British Media. London and New York: Cassell.

Sapolsky, Barry S. 2003. The Attraction and Repulsion of Media Sex. Journal of Broadcasting and Electronic Media. 47(2): 296-302.

Sedgwick, Eve Kosofsky. 1990. The Epistemology of the Closet. Berkeley: University of California Press.

Seidman, Steven. 1993. Identity and Politics in a "Postmodern" Gay Culture: Some Historical and Conceptual Notes. In Michael Warner, ed. Fear of a Queer Planet. Queer Politics and Social Theory. Minneapolis: University of Minnesota, 105142.

Shugart, Helene A. 2003. Reinventing Privilege: The New Gay Man in Contemporary Popular Media. Critical Studies in Media Communication, 20(1): 67-91. 
Smith, Barbara and Beverly Smith 1983. (Originally published in 1990). Across the Kitchen Table: A Sister to Sister Dialogue. In Cherrie Moraga and Gloria Anzaldúa, eds. This Bridge Called My Back. Writings by Radical Women of Color. $2^{\text {nd }}$ ed. New York: Kitchen Table: Women of Color Press, 113-127.

Souhami, Diana. 1996. Mrs Keppel and her daughter. London: HarperCollins.

Stein, Arlene. 1992. 'All Dressed Up, But No Place To Go? Style Wars and the New Lesbianism'. In Joan Nestle, ed. The Persistent Desire. A Femme-Butch Reader. Boston: Alyson Publications, 431-439.

Stein, Arlene. 1997. Sisters and Queers: the Decentering of Lesbian Feminism. In Roger N. Lancaster and Micaela di Leonardo, eds. The Gender/Sexuality Reader. Culture, History, Political Economy. Routledge: New York and London, 378-391.

St Germain, Noelle. R. 2003. The Impact of Media on Lesbian Experience and Perception of Self. A Doctoral Dissertation. St. Mary's University San Antonio, Texas.

Sullivan, Mary Lucille. 2007. Making Sex`Work. A Failed Experiment with Legalised Prostitution. Melbourne: Spinifex.

Svetkey, Benjamin. 2000, Is Your TV Set Gay? Entertainment Weekly, October 6, 24-28.

Tallen, Bette S. 1990. How Inclusive is Feminist Political Theory? In Jeffner Allen, ed. Lesbian Philosophies and Cultures New York: New York Press, 241-257.

Te Awekotuku, Ngahuia. 1991a. Maori and Feminist: My View. In Mana Wahine Maori: Selected Writings in Maori Women's Art, Culture and Politics, Auckland: New Women's Press, 17-21.

Te Awekotuku, Ngahuia. 1991b. Mana Wahine Maori: Selected Writings in Maori Women's Art, Culture and Politics. Auckland: New Women's Press, 9-14.

Te Awekotuku, Ngahuia. 1991c. Dykes and Queers: Facts, Fairytales and Fictions. In Mana Wahine Maori: Selected Writings in Maori Women's Art, Culture and Politics, Auckland: New Women's Press, 37-41.

The 2002 Cultural Experience Survey. (2002). Statistics New Zealand. http://www.stats.govt.nz/NR/exeres/39B6A2C6-4358-4806-AA6021A9E2B70401.htm [accessed 10 October 2006].

The Lesbian History Group, eds. 1989. Introduction. Not a Passing Phase. Reclaiming Lesbians in History 1840-1985, London: The Women's Press, 1-18.

Thornley, Jeni. 1987. Past, Present and Future: The Women's Film Fund. In Annette Blonski, Barbara Creed and Freda Freiberg, eds. 1987. Don't Shoot Darling. Women's Independent Filmmaking in Australia. Richmond, Australia: Greenhouse Publications Pty Ltd, 61-68.

Tropiano, Stephen. 2002. The Prime-Time Closet. A History of Gays and Lesbians on TV. New York: Applause. 
Tuchman, Gayle. 1978. Symbolic Annihilation of Women by the Mass Media. In Gayle Tuchman, Arlene Kaplan Daniels, and James Benit, eds. Hearth and Home:

Images of Women in the Mass Media, New York: Oxford University Press, 3-38.

Tuhiwai Smith, Linda. 1999. Decolonising Methodologies. Research and Indigenous Peoples. Dunedin: University of Otago Press.

TVNZ Annual Report. Inspiring New Zealand Viewers on Every Screen. FY2007. 2007. Television New Zealand.

http://images.tvnz.co.nz/tvnz_images/tvnz/About\%20TVNZ/tvnz_annual_report_2 007.pdf (accessed 1 October 2007 ).

Ussher, Jane M. 1997. Fantasies of Femininity. Reframing the Boundaries of Sex. London: Penguin Books.

Valdivia, Angharad N. 1995. Feminism, Multiculturalism and the Media: Global Diversities, London: Sage Publications.

van Zoonen, Lisbet. 2004. Feminist Media Studies. London: Sage Publications.

Walters, Suzanna, Danuta. 2001. All The Rage. The Story of Gay Visibility in America. Chicago and London: The University of Chicago Press.

Warner, Michael. 1993. Introduction. In Michael Warner, ed. Fear of a Queer Planet. Queer Politics and Social Theory. Minneapolis: University of Minnesota, viixxxi.

Weston, Kath. 1991. Families We Choose: Lesbians, Gays, Kinship. New York: Columbia University Press.

Whatling, Clare. 1997. Screen Dreams: Fantasising Lesbians in Film. Manchester and New York: Manchester University Press.

Wheeler, Lorna and Lara Raven Wheeler. 2006. Straight-Up Sex in The L Word. In Kim Akass and Janet McCabe, eds. Reading The L Word. Outing Contemporary Television. London and New York: I.B. Tauris and Co Ltd, 99-110.

White, Patricia. 1999. Uninvited. Classical Hollywood Cinema and Lesbian Representability. Bloomington and Indianapolis: Indiana University Press.

Wilton, Tamsin. 1995. Immortal, Invisible: Lesbians and the Moving Image. London and New York: Routledge.

Wittig, Monique. 1992. One is Not Born a Woman. The Straight Mind and Other Essays. Boston: Beacon Press, 9-20.

Wolf, Naomi. 1991. The Beauty Myth: How Images of Beauty are used Against Women. London: Vintage.

Wolfe, Susan J. and Lee Ann Roripaugh. 2006. The (in)visible lesbian. In Kim Akass and Janet McCabe, eds. Reading The L Word. Outing Contemporary Television. London and New York: I.B. Tauris and Co Ltd, 43-54. 
Women's Monitoring Network. 1987. Women as Sex Objects. In Kath Davies, Julienne Dickey, and Teresa Stratford, eds. Out Of Focus. Writings on Women and the Media. Chapter 5. London: The Women's Press, 70-72.

Zita, Jacquelyn. N. 1990. Lesbian Body Journeys: Desire Making Difference. In Jeffner Allen, ed. Lesbian Philosophies and Cultures. New York: State University of New York Press, 327-345.

\section{Newspaper articles}

Anon. 1965. Social problem films supported. The Taranaki Herald, 14 October 1965.

Anon. 2004. There's Something Queer in the Air. The Dominion Post The TV Week, 6 January 2004, 10.

Barry, Rebecca. 2004. Out on the Street, e.g. Magazine, The New Zealand Herald, 16-22 September 2004, 4-5.

\section{Magazines and online articles}

Alex Morgan. 2004. Dunedin. The TV Guide, 5-11 June. New Zealand: Fairfax Magazines, 117.

Anon. 1970. Censorship and the censors. Thursday. The Magazine for Modern Women, 11 June 1970, 25.

Anon. 2007. 'It's not just two birds snogging'. Telegraph.co.uk. http://www.telegraph.co.uk/arts/main.jhtml?xml=/arts/2002/10/08/bfstir08.xml. [accessed 19 August 2007].

Give Us A Break. 2004. Hastings. The TV Guide, 11-17 December. New Zealand: Fairfax Magazines, 116.

Hall, Oliver. 2005. Learning to be a Lesbian. Express 19 October - 2 November, 10-11.

Karryn. 2004. Upper Hutt. The TV Guide, 11-17 September. New Zealand: Fairfax Magazines, 117.

Linda. 2005. Tauranga. The TV Guide, 12-18 February. New Zealand: Fairfax Magazines, 116.

Molony, Sam. 2006. Buller. The TV Guide, 29 April - 5 May. New Zealand: Fairfax Magazines, 113.

The L Word poster image. The TV Guide, 21-27 October 2006, inside front cover. New Zealand: Fairfax Magazines.

The New Zealand Listener, 3-9 September 2005, 200(3408), p.78.

The New Zealand Listener, 28 October-3 November 2006, 206(3468), p.82. 
TV Guide Fan. 2005. The TV Guide, Albany. 15-21 January. New Zealand: Fairfax Magazines, 114.

Wedding to Make History. The TV Guide, 2006. 11-17 February. New Zealand: Fairfax Magazines, 22-23.

Wichtel, Diana. 2005. Good for a Laugh. The New Zealand Listener, 17-23 December 2005, 201(3423), 70-71.

\section{The TV Guides used for the programme listing analysis}

The TV Guide, 15-21 May 2004. New Zealand: Fairfax Magazines.

The TV Guide, 31 July-6 August 2004. New Zealand: Fairfax Magazines.

The TV Guide, 13-19 November 2004. New Zealand: Fairfax Magazines.

The TV Guide, 15-21 January 2005. New Zealand: Fairfax Magazines.

\section{Websites}

http://www.bsa.co.nz

http://www.imdb.com

http://www.maoritelevision.com

http://www.streettalk.co.nz

http://www.throng.co.nz 
Appendix A

Consent Form

VICTORIA UNIVERSITY OF WELLINGTON

Te Whare Wanargia is Upoka o te lka a Maui

\section{CONSENT FORM FOR PARTICIPANTS INVOLVED IN A STUDY OF LESBIAN REPRESENTATION ON TELEVISION}

You are invited to give your consent to take part in focus groups assembled to investigate the attitudes of New Zealanders/Australians to lesbian representation on television.

Your attendance at the group meeting will involve:

- Completing an anonymous questionnaire

- Viewing a selection of photographs of women

- Being prepared to participate in follow-up discussions

Please sign this consent form below.

I have read the information sheet, I understand its terms and I am willing to take part in a focus group. I understand that my participation is voluntary and strictly confidential.

If you would like to receive a copy of the summary of findings once this study is completed, please provide address details below.

Yes, I would like to receive a copy of the summary of findings of this study once it is completed. Please email me a copy to

or post to: 
Appendix B

Information sheet for New Zealand participants

VICTORIA UNIVERSITY OF WELLINGTON

Te Mhare Warargia is lipoka o te lka a Maui

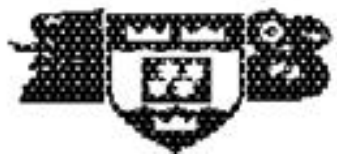

\section{INFORMATION SHEET FOR PARTICIPANTS INVOLVED IN A STUDY OF LESBIAN REPRESENTATION ON TELEVISION}

\section{Who is conducting the research?}

My name is Alison Hopkins and I am PhD student in Gender and Women's Studies, at the School of Education at Victoria University, Wellington.

\section{What is the purpose of this research?}

Television is a powerful medium that is a central component to many people's lives. Because art and life have a reciprocal relationship, does television portray real people accurately? What happens when the only characters on television are heterosexual? How do non-heterosexuals perceive this? As people living in the $21^{\text {st }}$ century, television is still the cornerstone of our entertainment mediums: it informs us not only of current events, but how to live our lives, what is acceptable and what is not.

- I am particularly interested in how the portrayal of lesbian characters has changed over time and how lesbian characters are perceived by a general audience.

- This research will allow me to study the changes in representations of lesbian characters on television in New Zealand over the last forty years and your perceptions, as New Zealanders, of lesbianism as informed by the medium of television.

In order to conduct my investigation I intend to assemble six separate focus groups. The first four of the six groups will be for adult-only participants. The adult groups will be organized by gender and sexuality and will comprise:

1. Women who identify themselves as lesbians

2. Women who identify themselves as heterosexual

3. Men who identify themselves as homosexual

4. Men who identify themselves as heterosexual 
The last two groups will comprise adolescent New Zealanders and will be organized by sexuality only and will comprise:

5. Adolescent girls and boys who identify as lesbian and gay

6. Adolescent girls and boys who identify as heterosexual

The focus groups will convene on separate evenings and participation is both voluntary and confidential.

Please Note: In order to participate successfully, participants must have daily access to a television set

What is involved if you agree to participate?

Participants are invited to attend a meeting, tomorrow, Saturday $28^{\text {th }}$ at $2.30 \mathrm{pm}$, to be held at my workplace:

\section{Level 4}

BP House,

Crn Waring Taylor Street and Customhouse Quay.

Security to the building is ensured by card access only. To make sure all participants find their way, please meet me outside beforehand across the road at :

Leuven Belgian Beer Café, 135-137 Featherston Street in the city from 2.00 p.m. Contact me on my mobile 0276969484 if you need directions.

Participants of each group will be invited to complete a questionnaire, view a selection of photographs of women and then take part in discussions afterwards. I anticipate that the research process will take about 1-1/2 to 2 hours.

As previously mentioned, participation is confidential and no identifying information will be sought from participants. However, discussions from each group will be taped, and comments from particular speakers may be used in my thesis. The anonymity of participants who engage in discussions will be ensured as those people who do contribute to discussions will not be asked for their names and will be referred to in my thesis only by their gender and by what group they are from.

\section{What happens to the information that you provide?}

- After the information has been collected from the discussion group(s), I will use the results to write up my doctoral thesis that will be submitted to my supervisor and other university staff for assessment.

- The questionnaire and other raw data that you have provided will be destroyed after the successful submission of my thesis.

- The overall findings may also be submitted for publication in a peer reviewed journals or presented at conferences.

All material collected will remain strictly confidential. The only people who will have access to any material from my study will be me and my two supervisors, Dr Alison 
Laurie and Dr Lesley Hall. If you have any questions or would like to receive further information about this research, please contact me at hopkinalis@student.vuw.ac.nz or my principal supervisor Dr Alison Laurie, Gender and Women's Studies, School of Education, at Victoria University, P.O Box 600, Wellington. 


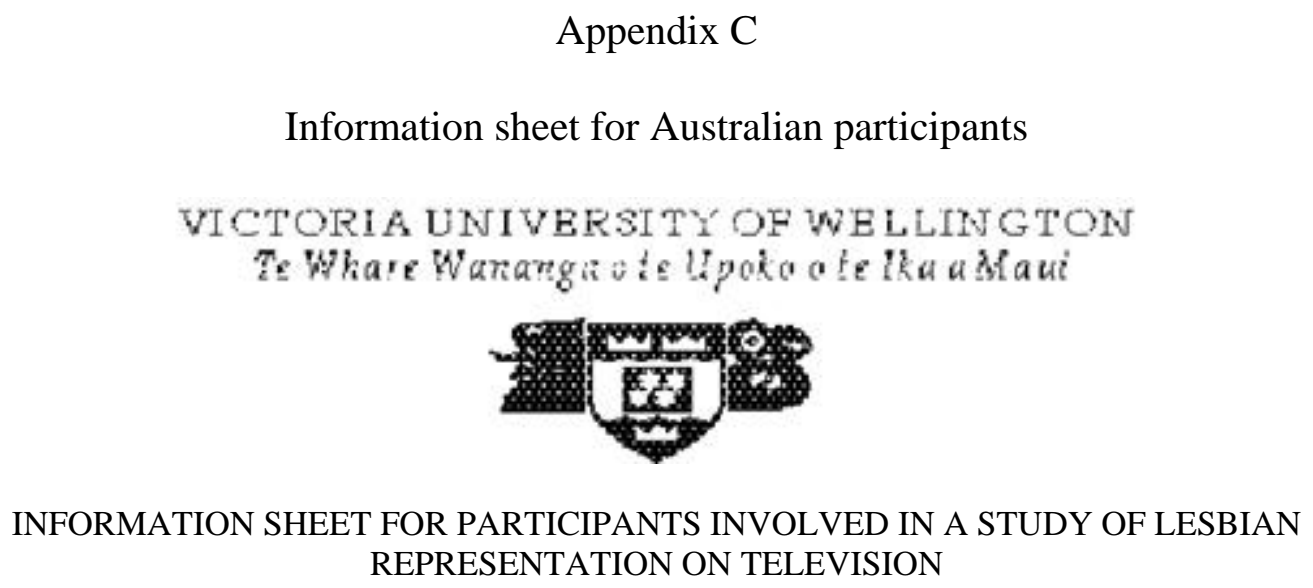

\section{Who is conducting the research?}

My name is Alison Hopkins and I am PhD student in Gender and Women's Studies, at the School of Education at Victoria University, Wellington, New Zealand

\section{What is the purpose of this research?}

Television is a powerful medium that is a central component to many people's lives. Because art and life have a reciprocal relationship, does television portray real people accurately? What happens when the only characters on television are heterosexual? How do non-heterosexuals perceive this? As people living in the $21^{\text {st }}$ century, television is still the cornerstone of our entertainment mediums: it informs us not only of current events, but how to live our lives, what is acceptable and what is not.

I am particularly interested in how the portrayal of lesbian characters has changed over time and how lesbian characters are perceived by a general audience. My research will allow me to study the changes in representations of lesbian characters on television in New Zealand over the last forty years and the perceptions of New Zealanders toward lesbianism, as informed by the medium of television.

I would like to take the opportunity to compare the attitudes of New Zealanders about lesbian representation on their free-to-air television channels with those held by Australians.

\section{What is involved if you agree to participate?}

Participation is both voluntary and confidential.

\section{If you are interested in participating in this study please meet me at Café Cinque, Newtown at 2.30pm on Saturday, 31 July 2004.}

Please Note: In order to participate successfully, participants must have daily access to a television set 
Participants will be invited to complete a questionnaire, view a selection of photographs of women and then take part in discussions afterwards. I anticipate that the research process will take about 1-1/2 to 2 hours.

As previously mentioned, participation is confidential and no identifying information will be sought from participants. However, discussions from each group will be taped, and comments from particular speakers may be used in my thesis. The anonymity of participants who engage in discussions will be ensured as those people who do contribute to discussions will not be asked for their names and will be referred to in my thesis only by their gender and by what group they are from.

\section{What happens to the information that you provide?}

- After the information has been collected from the discussion group(s), I will use the results to write up my doctoral thesis that will be submitted to my supervisor and other university staff for assessment.

- The questionnaire and other raw data that you have provided will be destroyed after the successful submission of my thesis.

- The overall findings may also be submitted for publication in a peer reviewed journals or presented at conferences.

All material collected will remain strictly confidential. The only people who will have access to any material from my study will be me and my two supervisors, Dr Alison Laurie and Dr Lesley Hall. If you have any questions or would like to receive further information about this research, please contact me at hopkinalis@student.vuw.ac.nz or my principal supervisor Dr Alison Laurie, Gender and Women's Studies, School of Education, at Victoria University, P.O Box 600, Wellington. 
Appendix D

Questionnaire

LESBIAN CHARACTERS ON (NEW ZEALAND/AUSTRALIAN)

TELEVISION

QUESTIONNAIRE

\section{SECTION ONE - DEMOGRAPHIC INFORMATION}

Please tick the box that indicates your gender:

Woman

Man

Girl

Boy

Other e.g. Intersexed, Transgendered etc

Please tick the box that you believe best describes your sexuality at the present time:

Homosexual
Lesbian
Gay
Heterosexual
Bi-sexual
Queer
Other
Unsure


Please tick the box that indicates which age range you are in:

Under 20 years

20 - 30 years

30 - 40 years

40 - 50 years

50 - 60 years

60 years and over

\section{SECTION TWO - VIEWING HABITS}

Please tick the boxes to answer the following questions:

Q1 How many televisions are there in your home?

One

Two

Three or more

Q2 Please indicate approximately the hours each day that you would watch television:

Eight hours or more daily

Between 3 and 7 hours daily

Two to three hours daily

Less that 2 hours daily

5 to 10 hours weekly

Less than 10 hours monthly

Irregular viewing 
Many people believe that women and men should possess certain traits and behave in gender-specific ways. The next set of questions requires you to think about the characteristics that many people attribute to women and lesbians.

Q3 Please list the main characteristics or behaviours that you think society regards as desirable for women.

Q4 Can you explain why these behaviours and characteristics are attributed to women?

Q5 When many people think about lesbians they also attribute particular characteristics to them. Now list the characteristics and behaviours that you believe society thinks are applicable to lesbians. 
Q6 Can you explain why these types of behaviours and characteristics are attributed to lesbians?

\section{SECTION FOUR - REPRESENTATION}

The next set of questions focuses on your recollection of lesbian characters that have been shown on television in (New Zealand/Australia).

Q7 Please list any lesbian characters (fictional) on television that you can recall from any drama, comedy, horror, serial, film etc that has been shown on television in (insert name of country). Please give as much information as you can. Try to remember the name of the character or the name of the programme and if possible, approximately when you saw the programme.

Q8 What words could be used to describe the lesbian characters you remember? 
Q9 Were any of the lesbians in romantic or sexual relationships? Again, try and give details such as the characters' names and the names of the programmes they appeared in etc.

Q10 Was any physical intimacy shown between the women? If so, what type of intimacy was used to indicate that the women were in a sexual relationship? For example, were the women shown kissing?

Q11 How did you respond to those portrayals of lesbian sexuality? Please tick any of the boxes below.

I was disgusted

I had no significant reaction

I was turned on

I was offended

I was pleased

I was embarrassed

I didn’t care

Please include any other response you felt, here 
Please give reasons why:

Q12 Would you describe any of the lesbian characters you remember as masculine? If so, try to remember the names of the characters and why you thought they were masculine.

Q13 Would you describe any of the lesbian characters you remember as feminine? Again, if you do remember lesbian characters as feminine please try to remember the names of those characters and why you thought they were feminine.

Q14 If lesbian couples were shown, how were they paired?

Masculine/masculine

Feminine/feminine

Masculine/feminine

Q15 Can you remember the occupations of any of the lesbian characters? If you can please list the characters' occupations below: 


\section{SECTION FIVE - OPINIONS}

Today we have discussed many issues surrounding lesbian representation on (New Zealand/Australian) television. The next set of questions is about your opinions regarding the portrayal of lesbian characters on television.

Q16 Do you think that the portrayal of lesbian characters that you have seen on (insert name of country) television is realistic?

Yes

No

Unsure - as I have not knowingly met any self-identified lesbians

Please give reasons why:

Q17 Do you believe that there should be changes to the way lesbians are represented on television? Please indicate your choice by ticking one of the boxes below.

No

Yes

Unsure

If you ticked 'Yes', what kind of changes would you like to see made: 
Q18 Do you think that lesbian representation on (New Zealand/Australian) television has changed over the period that you have been watching it?

No

Yes

Unsure

If so, how has it changed?

Q19 How important do you think it is to have lesbian characters on television? Please indicate your choice by ticking one of the boxes below.

Not important

Of some importance

Very important

Unsure

Please give reasons why

Q20 In your opinion, do you believe that more intimacy in lesbian relationships should be shown on television? Please indicate your choice by ticking one of the boxes below.

Yes

No

Unsure 
Don’t care

Please give reasons why:

Q21 Please indicate your choice by ticking one of the boxes below to answer the statement. Overall, I would say that television has . . .

Reinforced my view of lesbians

Challenged my view of lesbians

Not changed my views of lesbians

Q22 Do you know any self-identified lesbians? Please indicate your choice by ticking one of the boxes below

Yes

No

Unsure (I know some may be but they haven’t said)

Q23 In your opinion do gay men appear on television more than lesbians?

Yes

No

Unsure 
If you do think that gay men appear on television more than lesbians, can you think of any reasons why this happens?

Q24 Do you think the increased visibility of lesbians and gay men on television means that society is now more tolerant of minority sexualities?

$\square \quad$ Yes

$\square \quad$ No

$\square \quad$ Unsure

Please give reasons why:

Q25 Other than television, have you seen lesbian images in any other sources?

Yes

No

If yes, please list where you saw these images. Please include as much information as you can. 


\section{SECTION SIX - IMAGES}

\section{LESBIAN IMAGES}

This part of the research involves looking at a set of images. The people in the photographs are all women. Do you think that they are all heterosexual? In your opinion, do any of these women look like lesbians?

Q 26 Please circle the letter that corresponds with the photograph of anyone who, in your opinion, looks like a lesbian.

$\begin{array}{lllllllll}\text { A } & \text { B } & \text { C } & \text { D } & \text { E } & \text { F } & \text { G } & \text { H } & \text { I }\end{array}$

Please give reasons for your choice(s) 
This section has been included to give you an opportunity to comment about the research process that you have participated in this evening.

Q27 What part of the research process did you enjoy most? Please indicate your choice by ticking one of the boxes below

$\square \quad$ Questionnaire

Discussion

Photographs

All of it

None of it

Q 28 Did you feel inhibited during the discussions?

$$
\text { Yes }
$$

No

If you did feel inhibited please give reasons why: 
Q 29 Please use this space to write anything that you feel is important for me, as the researcher, to know about your experience as a participant in this evening's research. 
Appendix E

Photographs used in Questionnaire

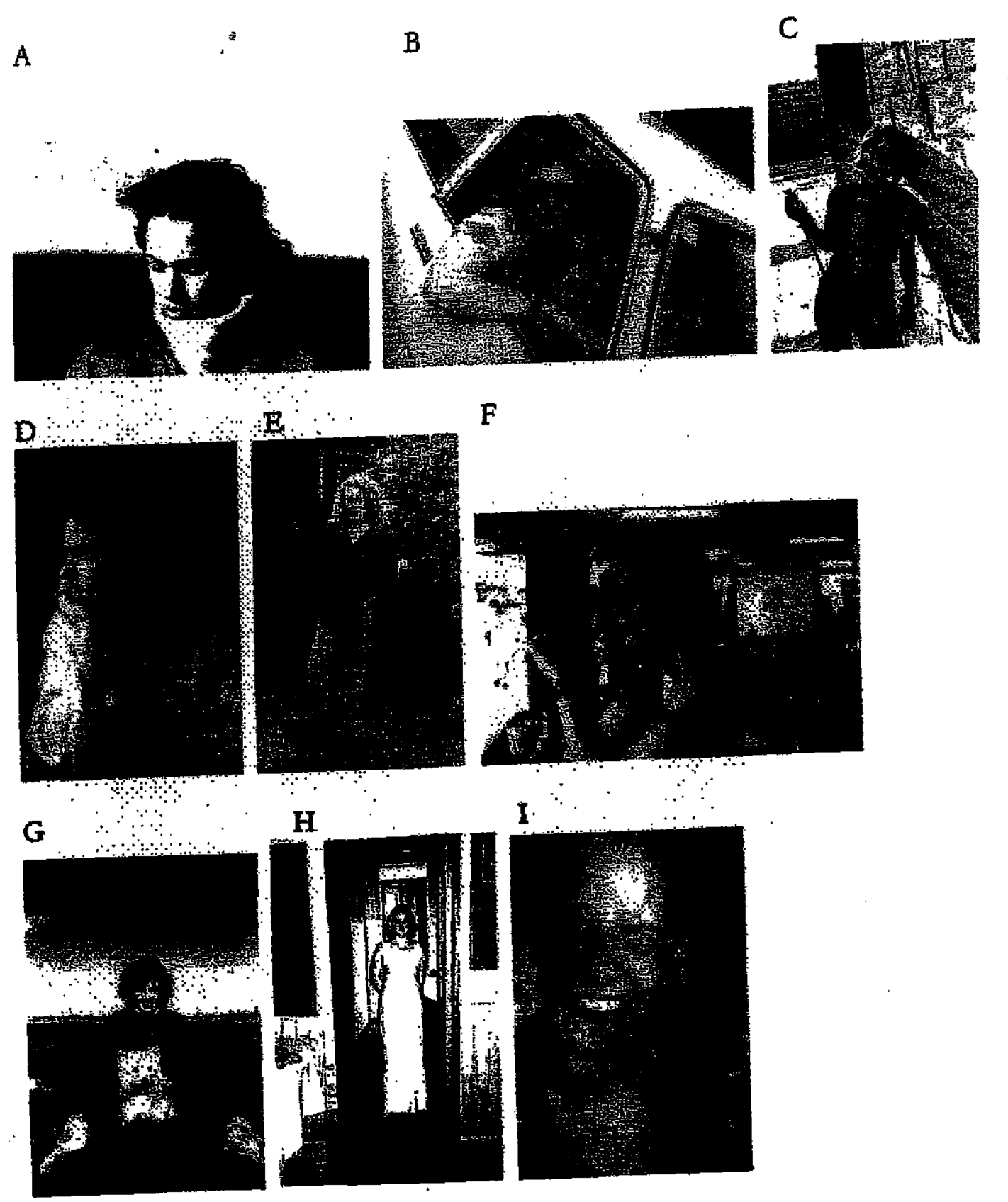


Appendix F

E-mail from Kate Ward, Communications and Research Advisor for the Broadcasting Standards Authority

Date Tue, 15 Jun 2004 15:40:49 +1200

From Info <Info@bsa.govt.nz> 8

To "alison.hopkins@paradise.net.nz" <alison.hopkins@paradise.net.nz> Subject RE: Further to my inquiry about the Códes ...

Parts 駺 1 [no description] text/plain $1.69 \mathrm{~KB}$

筑唯 Message Source

Hi Alison

Well, it has been interesting to research all this for you!

Minor amendmients were: made to the codes of broadcasting practice from time to time during the early 1990s. In the minutes of the Authority's meeting of 15 \& 16 october 1991, it is recorded that the Ainthority "agreed that sexpal orientation should be one of the criteria about which programmes should not encourage denigration or discrimination." This was-in. "Standard 26 " of the code at the time. According to the 24525 February 1992 minutes, a code update had been offered/distributed to interested parties - I think that sufficiently confirms your net findings.

Ail the best

Kate Ward

Communications and Research Advisor

Broadcasting Steandards Authority

PO BOX 9213 .

Wellington, New zealand

$+6443829508$

Web: www.bsa.govt.nz 
Appendix G

Writers and directors of cited Shortland Street episodes cited.

2004

Writers: Jan Prettejohns and Ben Marshall. Directors: Katie Wolfe and Murray Keane. Episode screened 12/7/2004.

Writers: Rachael McMahon. Director: Caroline Bell-Booth. Episode screened 2/8/2004.

Writer: Paul Sonne. Director: Duncan Smith. Episode screened 15/11/2004.

Writer: Quinton Hita. Director: Duncan Smith. Episode screened 16/11/2004.

\section{5}

Writer: Paul Sonne. Directors: Duncan Scott and Popo Lilo. Episode screened 31/1/2005.

Writer: Kate McDermott. Director: Sam Scott. Episode screened 11/3/2005.

Writer: Kate McDermott. Directors: Popo Lilo and Murray Keane. Episode screened 31/5/2005.

Writer: Lois Booton. Director: Wayne Tourell. Episode screened 17/6/2005.

Writers: Jonathan Cullinane and Kate McDermott. Director: Sam Scott. Episode screened 20/6/2005.

Writer: Quinton Hita. Director: Sam Scott. Episode screened 21/6/2005.

Writer: Kirsty McKenzie. Director: Duncan Scott. Episode screened 7/7/2005.

Writer: Victor Rodger. Directors: Sam Scott and Caroline Bell-Booth. Episode screened 18/7/2005.

Writer: Quinton Hita. Directors: Sam Scott and Caroline Bell-Booth. Episode screened 19/7/2005.

Writer: Ben Marshall. Directors: Sam Scott and Caroline Bell-Booth. Episode screened 20/7/2005.

Writer: Jonathan Cullinane. Directors: Sam Scott and Caroline Bell-Booth. Episode screened 21/7/2005.

Writer: Kate McDermott. Directors: Sam Scott and Caroline Bell-Booth. Episode screened 22/7/2005. 
Writers: Megan Brownhill and Karen Curtis. Director: Wayne Tourell. Episode screened 9/8/2005.

Writers: Jonathan Cullinane. Directors: Sam Scott and Caroline Bell-Booth. Episode screened 12/8/2005.

Writer: Kirsty McKenzie. Directors: Caroline Bell-Booth and Sam Scott. Episode screened 2/9/2005.

Writers: Matthew Saville and Kate McDermott. Director: Anna Marbrook. Episode screened 4/10/2005.

Writer: Victor Rodger. Director: Anna Marbrook. Episode screened 5/10/2005.

Writer: Libby McGee. Director: Anna Marbrook. Episode screened 6/10/2005.

Writers: Kirsty McKenzie and Kate McDermott. Director: Angela Bloomfield.

Episode screened 2/11/2005.

Writer: Paul Sonne. Directors: Sam Scott and Britta Johnstone. Episode screened $17 / 11 / 2005$.

Writer: Karen Curtis. Directors: Sam Scott and Britta Johnstone. Episode screened $18 / 11 / 2005$.

Writer: Rachael McMahon. Director: Caroline Bell-Booth. Episode screened 24/11/2005.

\section{Figs 1 and 2}

\section{7-28 January 2005}

Writer: Ben Marshall. Director: Caroline Bell-Booth. Episode screened 17/2/2005.

Writer: Lynette Crawford-Williams. Director: Caroline Bell-Booth. Episode screened 18/2/2005.

Writer: Lynette Crawford-Williams. Director: Caroline Bell-Booth. Episode screened 19/2/2005.

Writer: Kate McDermott. Director: Caroline Bell-Booth. Episode screened 20/2/2005.

Writer: Lois Booton. Director: Anna Marbrook. Episode screened 23/2/2005.

Writer: Jan Prettejohns. Director: Anna Marbrook: producer. Episode screened 24/2/2005.

Writer: Jan Prettejohn. Director: Anna Marbrook. Episode screened 25/2/2005.

Writer: Kirsty McKenzie. Director: Anna Marbrook. Episode screened 26/2/2005. 


\section{8-18 August 2005}

Writers: Ben Marshall, Kate McDermott and Maria Bolger. Director: Wayne Tourell. Episode screened 8/8/2005.

Writers: Megan Brownhill and Karen Curtis. Director: Wayne Tourell. Episode screened 9/8/2005.

Writer: Kate McDermott. Directors: Sam Scott and Caroline Bell-Booth. Episode screened 10/8/2005.

Writer: Natalie Perese. Director: Caroline Bell-Booth. Episode screened 11/8/2005.

Writer: Jonathan Cullinane. Director: Caroline Bell-Booth. Episode screened 12/8/2005.

Writers: Victor Rodger and Libby Magee. Directors: Sam Scott and Caroline BellBooth. Episode screened 15/8/2005.

Writers: Joss King and Sarah Nathan. Director: Anna Marbrook. Episode screened $16 / 8 / 2005$.

Writer: Lois Booton. Director: Anna Marbrook. Episode screened 17/8/2005.

Writer: Paul Sonne. Director: Anna Marbrook. Episode screened 18/8/2005.

Writer: Paul Sonne. Director: Anna Marbrook. Episode screened 19/8/2005.

\section{6}

Writer: Kate McDermott. Director: Anna Marbrook. Episode screened 27/1/2006. Writer: Libby Magee. Director: Duncan Smith. Episode screened 2/2/2006.

Writer: Jane Hurley. Director: Caroline Bell-Booth. Episode screened 13/2/2006.

Writer: Libby Magee. Director: Caroline Bell-Booth. Episode screened 14/2/2006.

Writer: Kirsty McKenzie. Directors: Murray Keane and Anna Marbrook. Episode screened 17/5/06.

Writer: Karen Curtis. Directors: Caroline Bell-Booth and Sam Scott. Episode screened 26/6/2006.

Writer: John Davies. Director: Jason Daniel. Episode screened 27/6/2006.

Writer: Kirsty McKenzie. Director: Jason Daniel. Episode screened 19/7/2006.

Writer: Megan Brownhill. Director: Caroline Bell-Booth. Episode screened $16 / 8 / 2006$.

Writers: Kelly Kilgour and Lynette Crawford-Williams. Director: Britta Johnstone. Episode screened 25/8/2006. 
Writer: Joss King. Directors: Wayne Tourell and Caroline Bell-Booth. Episode screened 31/8/2006.

2007

Writers: Anthony Ellison and Lynette Crawford-Williams. Director: Wayne Tourell. Episode screened 31/5/2007.

Writers: Kirsty McKenzie, Carl Smith and Kim Harrop. Directors: Angela

Bloomfield and Anna Marbrook. Episode screened 27/8/2007.

Writer: Victor Rodger. Director: Jonathan Alver. Episode screened 18/10/2007.

2009

Writer: Karen Curtis. Director: Geoff Cawthorn. Episode screened 3/4/2009.

Writer: Kate McDermott. Directors: Wayne Tourell and Renato Bartolomei. Episode screened 22/5/2009. 
Appendix $\mathrm{H}$

Writers and directors of The L Word DVD Series (Season One)

Writer: Ilene Chaiken: writer. Director: Rose Troche. Episodes 1 and 2. 'Pilot Episodes.' Showtime Entertainment.

Writer: Susan Miller. Director: Rose Troche. Episode 3. 'Let's Do It.' Showtime Entertainment.

Writer: Angela Robinson. Director: Lynne Stopkewich. Episode 4. 'Longing.' Showtime Entertainment

Writer: Ilene Chaiken. Director: Tony Goldwyn. Episode 5. 'Lies, Lies, Lies.' Showtime Entertainment.

Writer: Rose Troche. Director: Daniel Minahan. Episode 6. 'Lawfully'. Showtime Entertainment.

Writer: Guinevere Turner. Director: Clement Virgo. Episode 7. 'Losing It.' Showtime Entertainment.

Writer: Ilene Chaiken. Director: Tony Goldwyn. Episode 8. 'L'ennui.' Showtime Entertainment.

Writer: Mark Zakarin. Director: Kari Skoglund. Episode 9. 'Listen Up.' Showtime Entertainment.

Writer: Rose Troche. Director: Rose Troche. Episode 10. 'Luck, Next Time.' Showtime Entertainment.

Writer: Ilene Chaiken. Director: Mary Harron. Episode 11. 'Liberally.' Showtime Entertainment.

Writer: Guinevere Turner. Director: Rose Troche. Episode 12. 'Looking Back.' Showtime Entertainment.

Writer: Ilene Chaiken. Director: Lynne Stopkewich. Episode 13. 'Locked Up.' Showtime Entertainment.

Writer: Ilene Chaiken. Director: Tony Goldwyn. Episode 14. 'Limb From Limb.' Showtime Entertainment. 


\section{Appendix I}

Advertisement for The L Word, in The TV Guide, October 21-27 2006

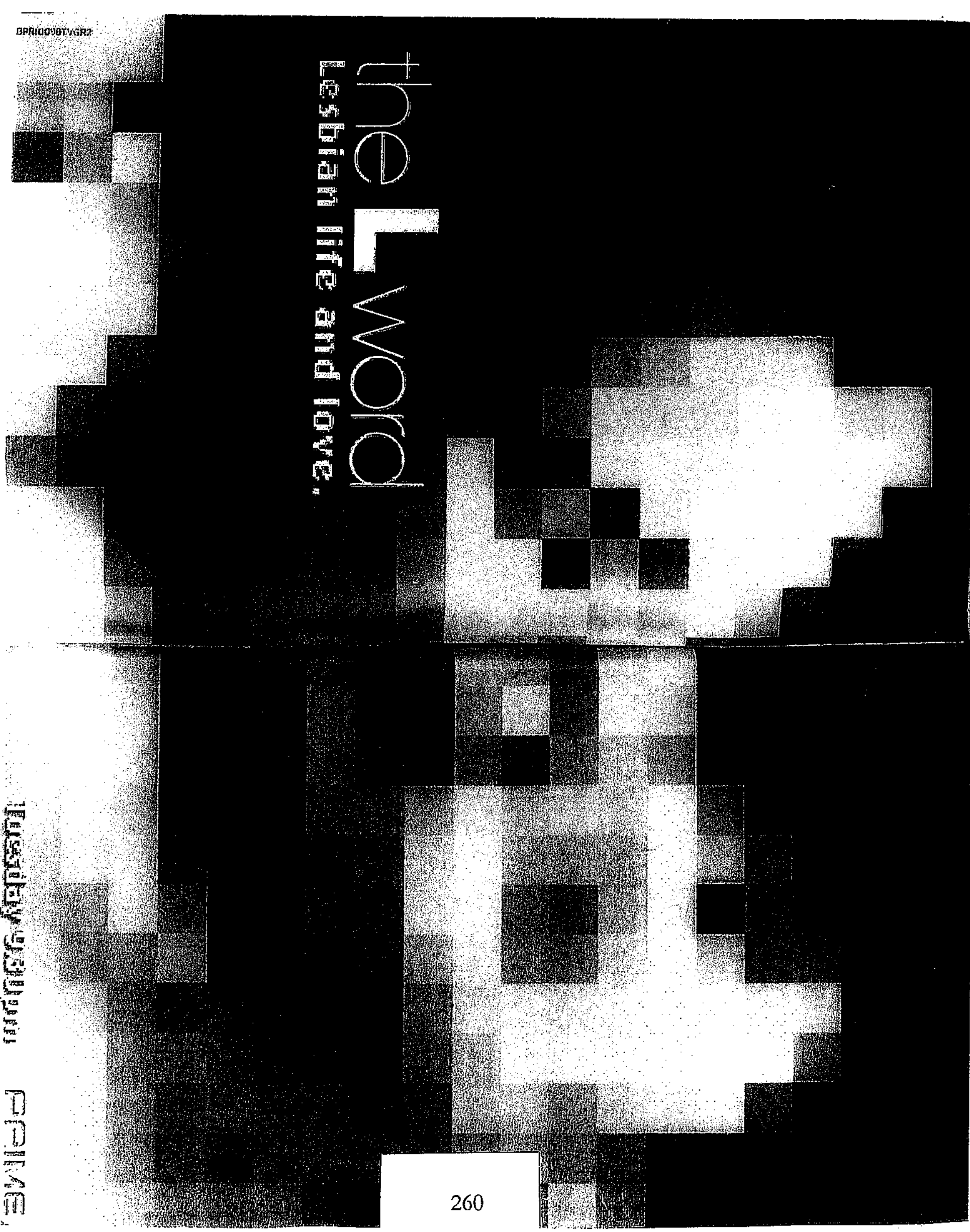


Appendix J

E-mail from Christine Wilton, Television New Zealand

Date Wed, 31 Aug 2005 08:43:42 +1200

From VlewerCorrespondence <ViewerCorrespondence@tvnz.co.nz>

To Alison Hopkins <alison.hopkins@päradise.net.nz>

Subject RE: Query - A Programme - The L Wọrd

$\div$

Parts 彗 1 [no description] text/plain $3.18 \mathrm{~KB}$

琵 Message Source

\section{Hi: there}

We are all excited about The $L$ Word finalily arriving.

Thè is a vast differene between prinetime shows like peaperte Housewives and The word which is an offpeak ? niche' show.

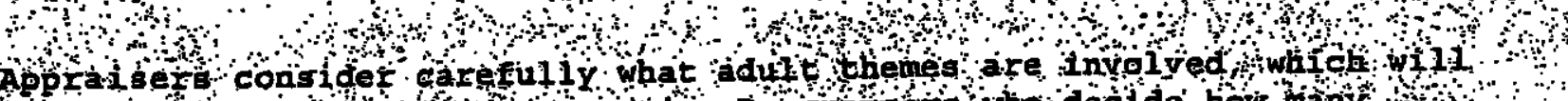

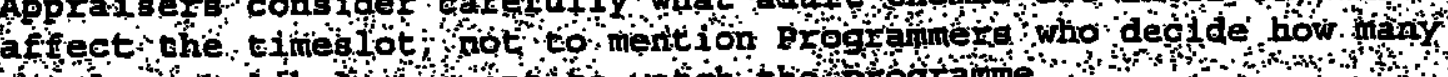
people are ilkely to want to wath theprograme.

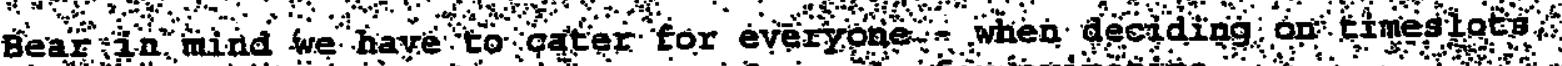

and appea to the biggest anount of people for primetime

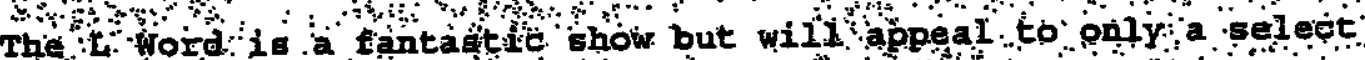

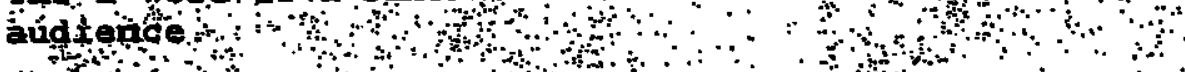

Regärâng promotion TVNa tends to put its anergies into primetime

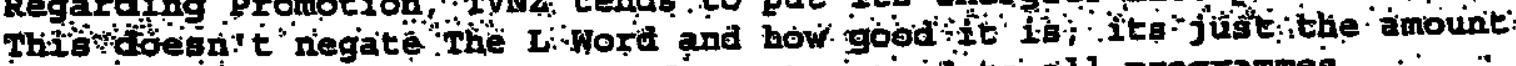

of money and resource we have doesn't exteria to all programmes

Always keep an eye on youx guide for gems like the I wora that cel'ebrate our diversity arid ilfestyle:

We are interested in all feedback and the programers will be gi ven your emall.

Thanks for your email. $\therefore$

Rind regarag

Christine, intod the Gilchrist Coninuinicathos

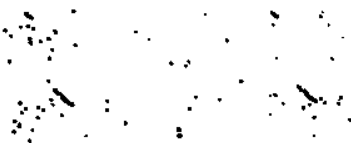

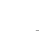

